Florida International University FIU Digital Commons

$11-13-2015$

\title{
Use of Fiber Reinforced Polymer Composite Cable for Post-tensioning Application
}

Xiong Yang

Florida International University, xyang010@fiu.edu

DOI: $10.25148 /$ etd.FIDC000150

Follow this and additional works at: https://digitalcommons.fiu.edu/etd

Part of the Civil Engineering Commons, and the Structural Engineering Commons

\section{Recommended Citation}

Yang, Xiong, "Use of Fiber Reinforced Polymer Composite Cable for Post-tensioning Application" (2015). FIU Electronic Theses and Dissertations. 2259.

https://digitalcommons.fiu.edu/etd/2259

This work is brought to you for free and open access by the University Graduate School at FIU Digital Commons. It has been accepted for inclusion in FIU Electronic Theses and Dissertations by an authorized administrator of FIU Digital Commons. For more information, please contact dcc@fiu.edu. 


\section{FLORIDA INTERNATIONAL UNIVERSITY}

Miami, Florida

USE OF FIBER REINFORCED POLYMER COMPOSITE CABLE

FOR POST-TENSIONING APPLICATION

A dissertation submitted in partial fulfillment of

the requirements for the degree of

DOCTOR OF PHILOSOPHY

in

CIVIL ENGINEERING

by

Xiong Yang

2015 
To: Interim Dean Ranu Jung

College of Engineering and Computing

This dissertation, written by Xiong Yang, and entitled Use of Fiber Reinforced Polymer Composite Cable for Post-Tensioning Application, having been approved in respect to style and intellectual content, is referred to you for judgment.

We have read this dissertation and recommend that it be approved.

$\begin{array}{r}\hline \text { Madasamy Arockiasamy } \\ \hline \text { Arindam Gan Chowdhury U. Ahamd } \\ \hline \text { Ton-Lo Wang } \\ \hline \text { Amir Mirmiran, Major Professor }\end{array}$

Date of Defense: November 13, 2015

The dissertation of Xiong Yang is approved.

Interim Dean Ranu Jung College of Engineering and Computing

Dean Lakshmi N. Reddi University Graduate School

Florida International University, 2015 
(C) Copyright 2015 by Xiong Yang

All rights reserved. 


\section{DEDICATION}

I dedicate this dissertation to my parents and my wife. Without their patience, understanding, support, and most of all love, the completion of this work would not have been possible. 


\section{ACKNOWLEDGMENTS}

I would like to express my sincere gratitude to my advisor, Dr. Amir Mirmiran, for the continuous support of my Ph.D. studies, for his patience, motivation, and immense knowledge. I could not have imagined have a better advisor and mentor for my Ph.D. studies.

I am also grateful to Dr. Ton-Lo Wang, Dr. Arindam Gan Chowdhury, Dr. Irtishad U. Ahmad, and Dr. Madasamy Arockiasamy for serving on my advisory committee.

I would like to acknowledge Dr. Pedram Zohrevand, Edgar Polo, and all personnel and students at the Titan American Structures and Construction Testing Laboratory of the Florida International University for their assistance during the experimental study of this research.

The support of Florida Department of Transportation for providing funding and Florida International University Graduate School for providing me with a dissertation year fellowship are acknowledged.

Last but not the least, I would like to thank my dear friend for their endless support and encouragement. 
ABSTRACT OF THE DISSERTATION

USE OF FIBER REINFROCED POLYMER COMPOSITE CABLE

FOR POST-TENSIONING APPLICATION

\author{
by \\ Xiong Yang \\ Florida International University, 2015 \\ Miami, Florida

\section{Professor Amir Mirmiran, Major Professor}

Corrosion of steel tendons is a major problem for post-tensioned concrete, especially because corrosion of the steel strands is often hard to detect inside grouted ducts. Non-metallic tendons can serve as an alternative material to steel for posttensioning applications. Carbon fiber reinforced polymer (CFRP), given its higher strength and elastic modulus, as well as excellent durability and fatigue strength, is the most practical option for post-tensioning applications.

The primary objective of this research project was to assess the feasibility of the use of innovative carbon fiber reinforced polymer (CFRP) tendons and to develop guidelines for CFRP in post-tensioned bridge applications, including segmental bridges and pier caps.

An experimental investigation and a numerical simulation were conducted to compare the performance of a scaled segmental bridge model, post-tensioned with two types of carbon fiber strands and steel strands. The model was tested at different prestress levels and at different loading configurations. While the study confirms feasibility of both types of carbon fiber strands for segmental bridge applications, and their similar 
serviceability behavior, strands with higher elastic modulus could improve structural performance and minimize displacements beyond service loads.

As the second component of the project, a side-by-side comparison of two types of carbon fiber strands against steel strands was conducted in a scaled pier cap model. Two different strand arrangements were used for post-tensioning, with eight and six strands, respectively representing an over-design and a slight under-design relative to the factored demand. The model was tested under service and factored loads. The investigation confirmed the feasibility of using carbon fiber strands in unbonded posttensioning of pier caps. Considering both serviceability and overload conditions, the general performance of the pier cap model was deemed acceptable using either type of carbon fiber strands and quite comparable to that of steel strands.

In another component of this research, creep stress tests were conducted with carbon fiber composite cable (CFCC). The anchorages for all the specimens were prepared using a commercially available expansive grout. Specimens withstood 95\% of the guaranteed capacity provided by the manufacturer for a period of five months, without any sign of rupture. 


\section{TABLE OF CONTENTS}

CHAPTER

PAGE

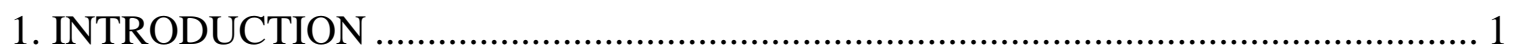

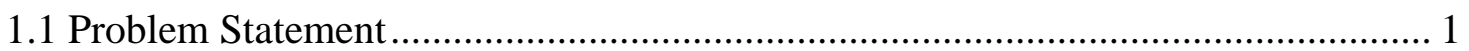

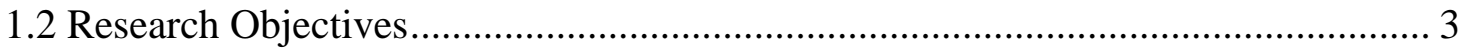

1.3 Research Approach and Methodology............................................................... 4

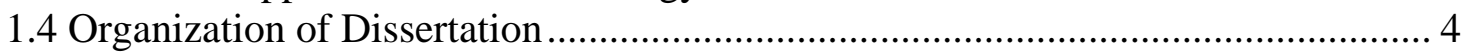

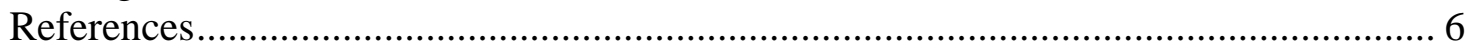

2. POSTTENSIONING OF SEGMENTAL BRIDGES USING CARBON-FIBER-

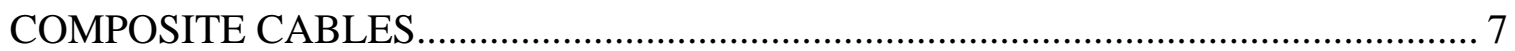

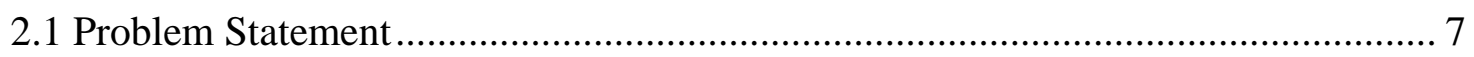

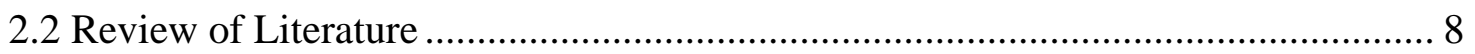

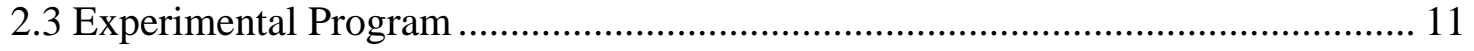

2.3.1 Specimen Preparation and Erection Process................................................ 11

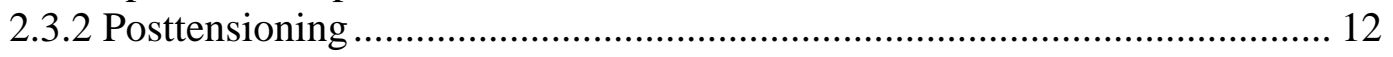

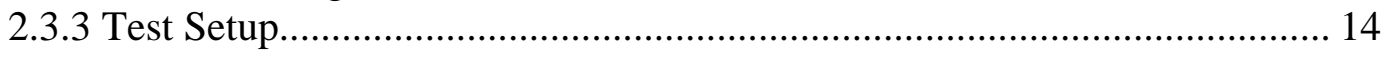

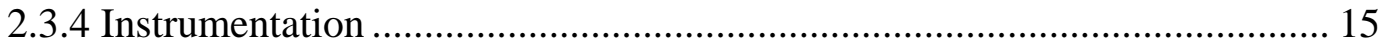

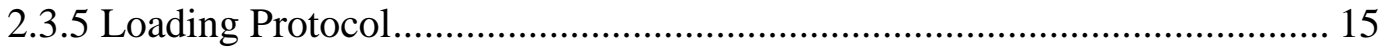

2.4 Test Results and Discussions.......................................................................... 17

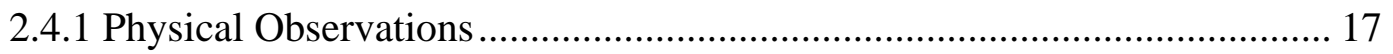

2.4.2 Relaxation Losses of CFCC Tendons ....................................................... 17

2.4.3 Performance under Service Loads ............................................................. 17

2.4.4 Performance under Factored Loads .......................................................... 18

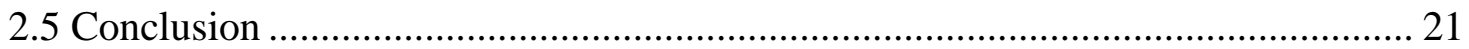

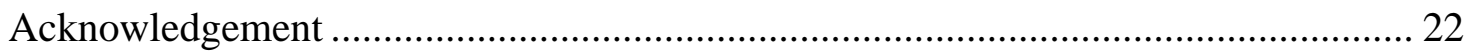

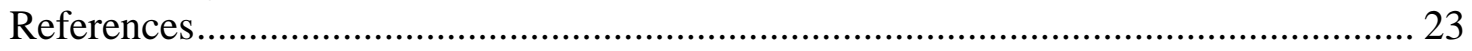

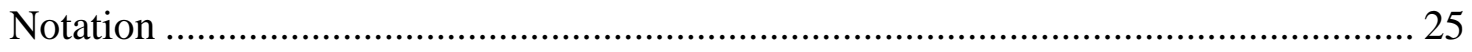

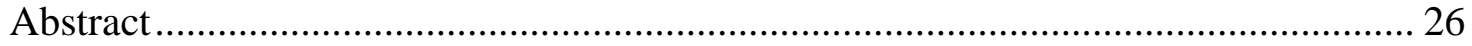

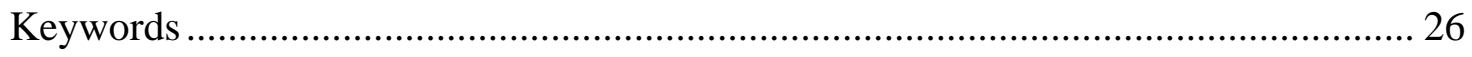

3. EFFECT OF ELASTIC MODULUS OF CARBON FIBER REINFORCED POLYMER STRANDS ON THE BEHAVIOR OF POST-TENSIONED

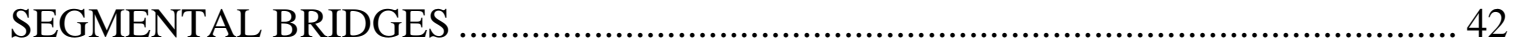

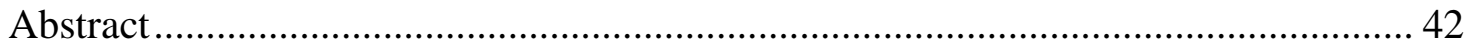

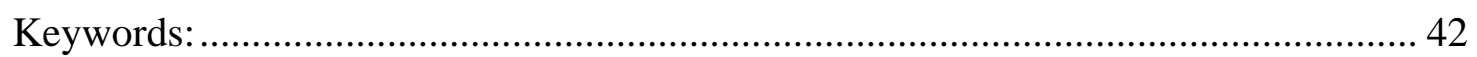

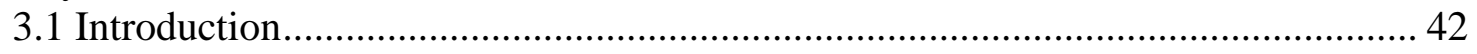

3.2 Experimental Work ......................................................................................... 45

3.2.1 Bridge Mode and Test Procedure …………………...................................... 45

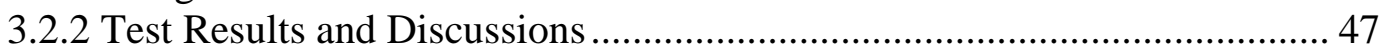

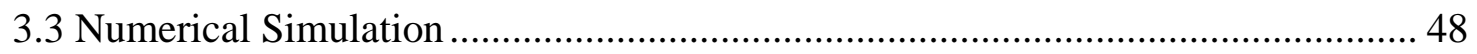

3.3.1 Finite Element Modeling ......................................................................... 48

3.3.2 Parametric Study and Discussions ............................................................ 51 


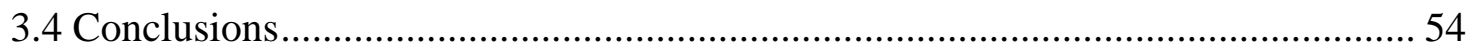

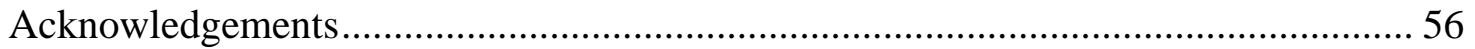

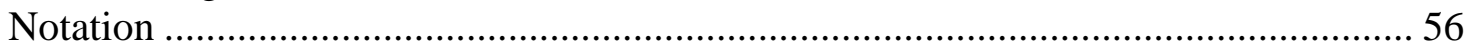

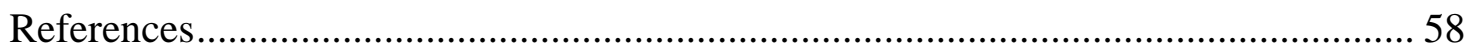

4. A COMPARATIVE STUDY OF UN-BONDED CARBON FIBER AND STEEL STRANDS IN POST-TENSIONED PIER CAPS ......................................................... 73

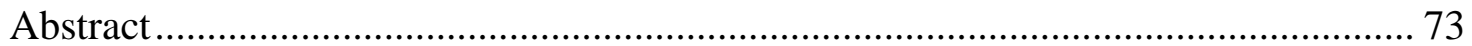

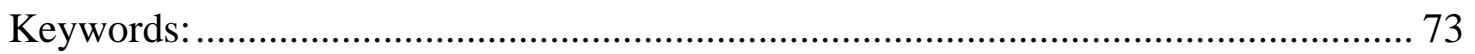

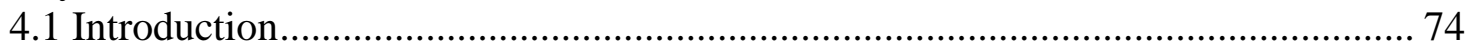

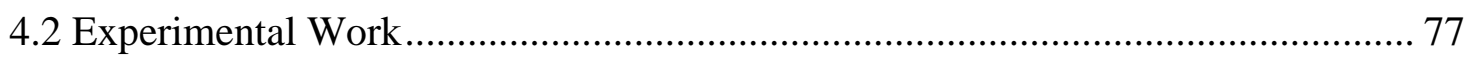

4.2.1 Specimen Preparation ........................................................................... 77

4.2.2 Posttensioning Application ...................................................................... 78

4.2.3 Test Setup and Instrumentation .................................................................... 80

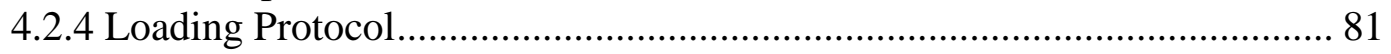

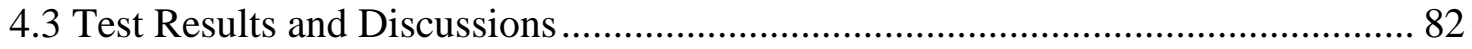

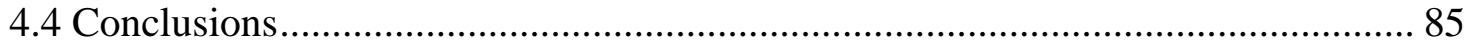

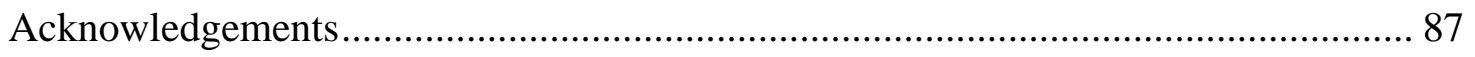

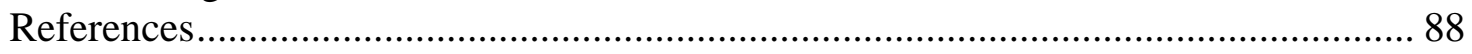

5. CREEP STRESS TEST OF CARBON FIBER COMPOSITE CABLE (CFCC) WITH FIELD-MADE ANCHORAGES AT HIGH STRESS LEVEL ……………........ 108

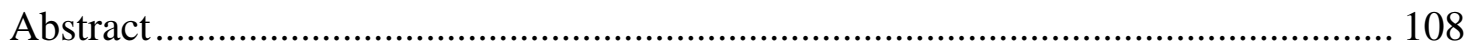

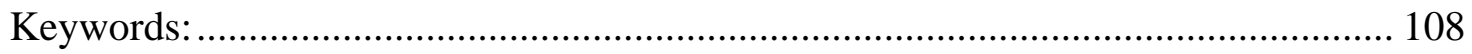

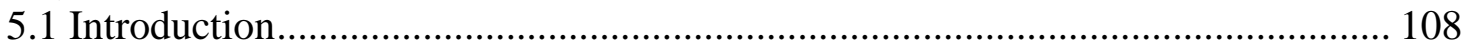

5.2 Experimental Work ........................................................................................ 110

5.2.1 Specimen Preparation ......................................................................... 110

5.2.2 CFCC Rupture Test..................................................................................... 113

5.2.3 Creep Stress Test Setup and Instrumentation .............................................. 113

5.2.4 Creep Stress Test Results and Discussions ................................................ 116

5.2.5 Residual Strength of CFCC Tendons....................................................... 116

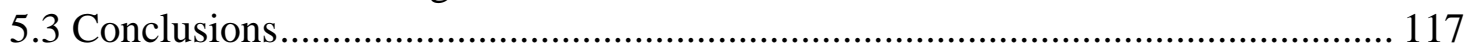

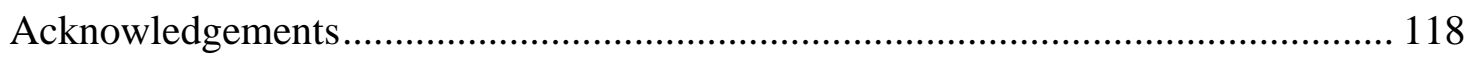

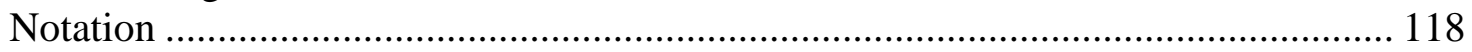

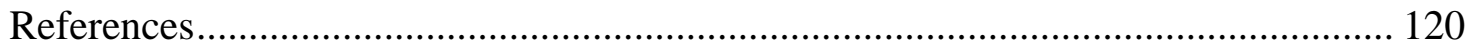

6. RECOMMENDATIONS FOR DESIGN, CONSTRUCTION, INSPECTION, AND REPAIR SPECIFICATIONS ............................................................................. 130

6.1 Review of Currently Available Specifications on CFRP Post-Tensioning System

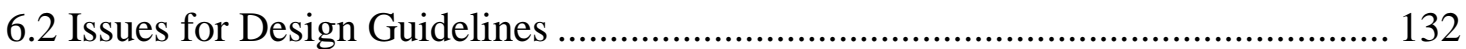

6.3 Issues for Construction Specifications.................................................................... 133

6.4 Issues for Inspection and Repair Specifications .................................................. 133

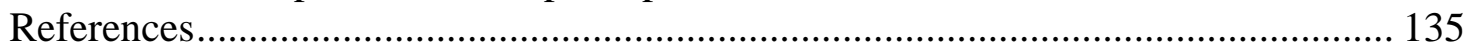




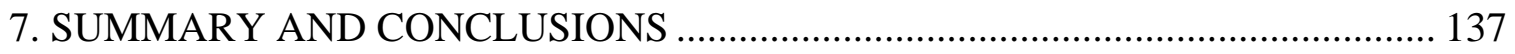

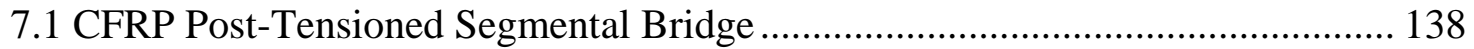

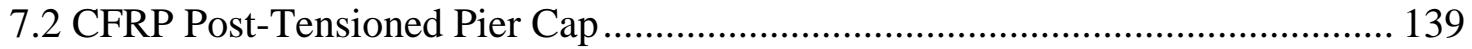

7.3 CFCC Creep Rupture Test .............................................................................. 140

7.4 Recommendations for Design, Construction, Inspection, and Repair

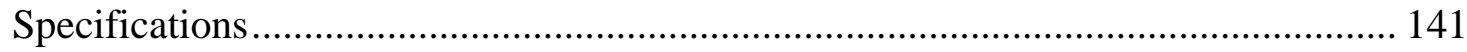

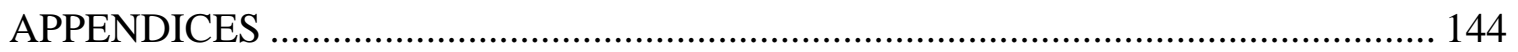

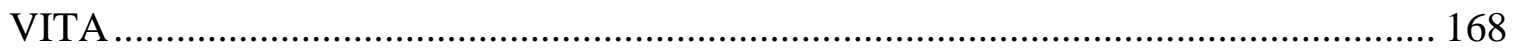




\section{LIST OF TABLES}

TABLE

PAGE

Table 2.1 Geometric and material properties CFCC and steel strands

Table 2.2 Summary of test results at service loads ...................................................28

Table 2.3 Summary of test results at factored loads ..................................................29

Table 3.1 Comparison of Material Properties and Anchorage of EC6, CFCC, and Steel

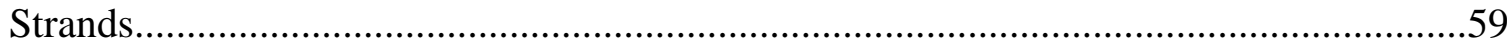

Table 3.2 Summary of Test Results at Service Loads ...............................................60

Table 4.1 Comparison of Material Properties and Anchorage of CFCC, EC6, and Steel

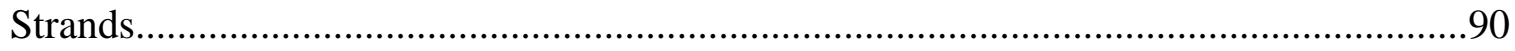

Table 4.2 AASHTO LRFD Design Loads ...............................................................91

Table 4.3 Tip Deflection Summary .......................................................................92

Table 4.4 Average Prestressing Force in Strands .....................................................93

Table 4. 5 Maximum Crack Width Summary for the Major Crack.................................94

Table 5.11 Test Results Summary for the Creep Stress Test......................................121

Table 5.2 Breaking Load Summary and Comparison...............................................121 


\section{LIST OF FIGURES}

FIGURE

PAGE

Figure 1.1 Post-Tensioning in Hammerhead Piers .........................................................

Figure 1.2 Post-Tensioning in Cantilever Piers .........................................................

Figure 1.3 Post-Tensioning in the Top Slab of Box Girders .........................................1

Figure 1.4 External/Internal Tendons in Segmental Bridges........................................2

Figure 2.1 1: 31/2 Scale Model of Long Key Bridge....................................................30

Figure 2.2 Formwork for Segmental Bridge Model .................................................31

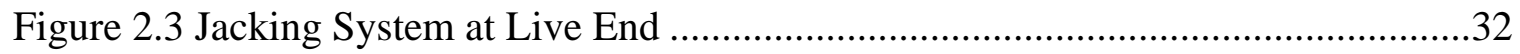

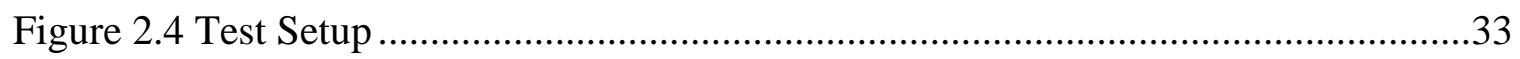

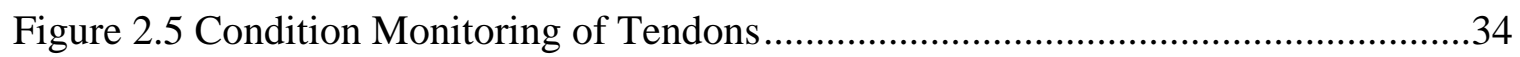

Figure 2.6 Instrumentation Plan for Different Loading Positions .................................35

Figure 2.7 Prestress Relaxation Losses at Different Stresses for Carbon-fiber-composite

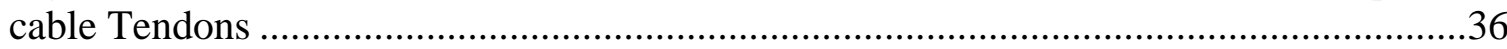

Figure 2.8 Load Displacements of Bridge Model with Carbon-fiber-composite Cable

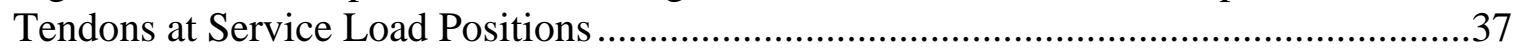

Figure 2.9 Load-joint Openings of Bridge Model with Carbon-fiber-composite Cable

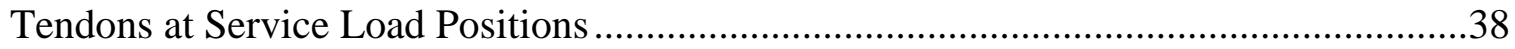

Figure 2.10 Load Displacements of Bridge Model with CFCC and Steel Strands at

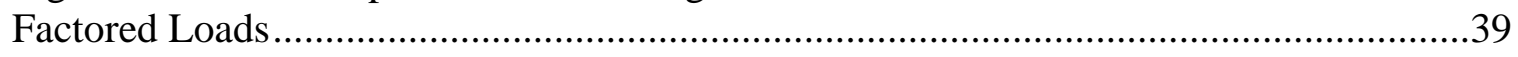

Figure 2.11 Load-joint Openings of Bridge Model with CFCC and Steel Strands at Factored Loads.

Figure 2.12 Detailed Performance Comparison of CFCC and Steel Strands at 29.2 kip

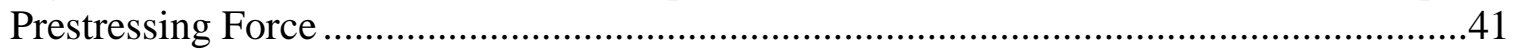

Figure 3.1 Anchorage for Three Types of Strands: (a) EC6, (b) CFCC, and (c) Steel......61

Figure 3.2 Segmental Bridge Test Model .............................................................62 
Figure 3.3 Details of Shear Keys: (a) Shear Keys on the Test Specimen, and (b)

Dimension of the Shear Key

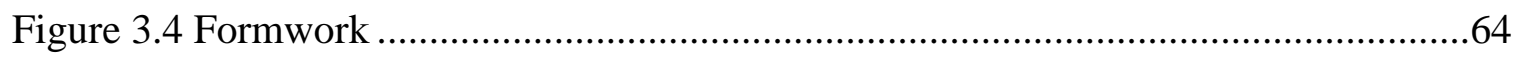

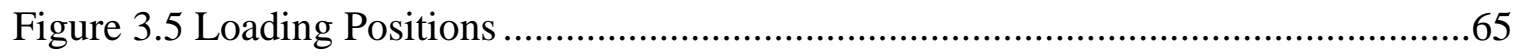

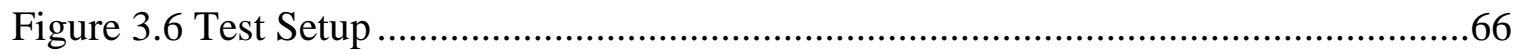

Figure 3.7 Performance Comparisons between Three Types of Strands at $129.9 \mathrm{kN}$ (29.2 kip): (a) Load - Displacement, (b) Load - Joint Opening, and

(c) Load - Prestress Force Increase $67-68$

Figure 3.8 Deformed Shape with Joint Opening of the Finite Element Model

Figure 3.9 Load - Displacement Comparisons between Finite Element Model and

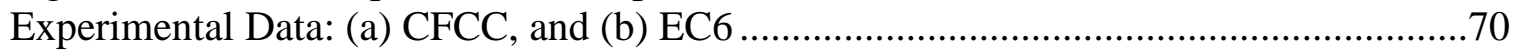

Figure 3.10 Displacement at Factored Load/Span Length - Elastic Modulus for Three Stress Levels .71

Figure 3.11 Stiffness after Joint Opening - Elastic Modulus for Three Stress Levels......72

Figure 4.1 Carbon Fiber Composite Cable: (a) CFCC Strand, and (b) CFCC Anchorage

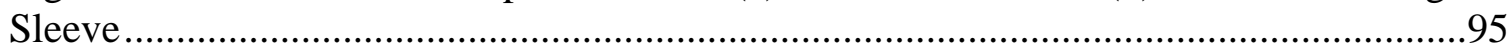

Figure 4.2 EC6 Composite Cable: (a) EC6 Strand, and (b) EC6 Anchorage ....................96

Figure 4.3 Pier Cap Test Model and Loading Pattern

Figure 4.4 Layout for Reinforcement and Post-Tensioning Strands: (a) Reinforcement

Layout, and (b) Strands Layout 98-99

Figure 4.5 Pier Cap Formwork .100

Figure 4.6 Post-tensioning System: (a) Live End for CFCC, (b) Dead End for CFCC, (c) Live End for EC6, (d) Dead End for EC6, (e) Live End for Steel, and (f) Dead End for Steel Strands .101

Figure 4.7 Test Setup and Instrumentation: (a) Sketch for Test Setup, and (b) Experimental Test Setup. 102-103

Figure 4.8 Moment-Tip Deflection Comparison of Pier Cap Model: (a) CFCC Tendons, (b) EC6 Tendons, and (c) Steel strands. 104-105 
Figure 4.9 Moment-Tip Deflection Comparison of Pier Cap Model: (a) 8 Tendons, and (b) 6 Tendons ………………….........................................................................106

Figure 4.10 Crack Pattern: (a) North Side, and (b) South Side ........................................107

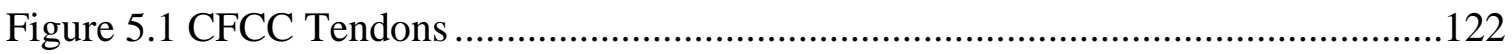

Figure 5.2 Wooden Frame for Casting …………………………..............................122

Figure 5.3 CFCC Tendon Anchorage: (a) Anchorage Sleeve Details for Bustar Expansive Cement Grout, (b) Threaded Rod for Tensioning, and (c) Screws used for Anchorage Casting.

Figure 5.4 CFCC Rupture Test: (a) Test Setup, (b) Ruptured CFCC Tendon..................124

Figure 5.5 Test Frame for Creep Stress Test ……………………………...................125

Figure 5.6 Creep Stress Test with Belleville Washers......................................................126

Figure 5.7 Creep Stress Test with Coil Springs ..........................................................126

Figure 5.8 Load Ratio vs. Time (hour) ...........................................................................127

Figure 5.9 Load Ratio vs. Log Time (hour).....................................................................127

Figure 5.10 Residual Strength Test Results Comparison .................................................128

Figure 5.11 Specimen Failures after Residual Strength Test: (a) Ruptured CFCC

Tendons, (b) Bustar Expansive Cement Grout Losses ....................................................129

Figure A1. Formwork Framing...................................................................................145

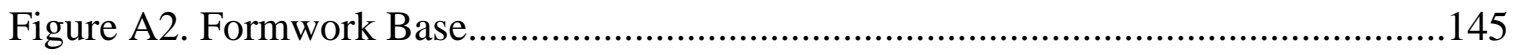

Figure A3. Formwork for End Blocks ..........................................................................146

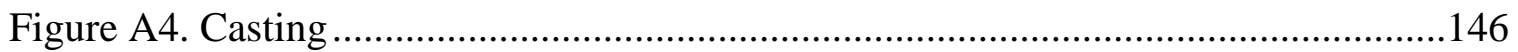

Figure A5. Specimen after Casting ..............................................................................147

Figure A6. Specimen Demolding ……………………................................................147

Figure A7. Specimen Erection (1) ...........................................................................148

Figure A8. Specimen Erection (2) .........................................................................148 
Figure A9. Post-Tensioning Cables through the Segments .149

Figure A10. Protecting the Post-Tensioning Cables at Deviator Block .149

Figure B1. Test Setup for Service Load Position 1 and Ultimate Load Test...... .150

Figure B2. Test Setup for Service Load Position 2 .150

Figure B3. Test Setup for Service Load Position 3 .151

Figure C1. CFCC Load - Displacement for Service Load Position1 and Ultimate Load Test.

Figure C2. CFCC Load - Joint Opening for Service Load Position1 and Ultimate Load Test. 152

Figure C3. CFCC Load - Displacement Opening for Service Load Position 2. .153

Figure C4. CFCC Load - Joint Opening for Service Load Position 2. .153

Figure C5. CFCC Load - Displacement Opening for Service Load Position 3. .154

Figure C6. CFCC Load - Joint Opening for Service Load Position 3. .154

Figure C7. EC6 Load - Displacement for Service Load Position1 and Ultimate Load Test. .155

Figure C8. EC6 Load - Joint Opening for Service Load Position1 and Ultimate Load Test. .155

Figure C9. EC6 Load - Displacement for Service Load Position 2...............................156

Figure C10. EC6 Load - Joint Opening for Service Load Position 2............................156

Figure C11. EC6 Load - Displacement for Service Load Position 3..............................157

Figure C12. EC6 Load - Joint Opening for Service Load Position 3............................157

Figure C13. Steel Load - Displacement for Service Load Position1 and Ultimate Load Test. 158

Figure C14. Steel Load - Joint Opening for Service Load Position1 and Ultimate Load Test. 158

Figure C15. Steel Load - Displacement for Service Load Position 2 .159 
Figure C16. Steel Load - Joint Opening for Service Load Position 2...........................159

Figure C17. Steel Load - Displacement for Service Load Position 3 ............................160

Figure C18. Steel Load - Joint Opening for Service Load Position 3...........................160

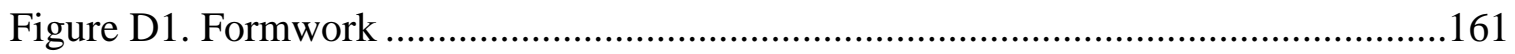

Figure D2. Ducts for Post-tensioning ...................................................................161

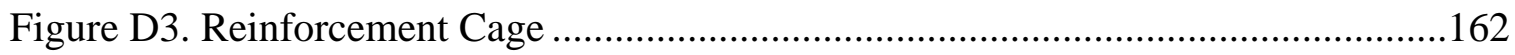

Figure D4. PVC Tube Connection for Post-Tensioning Ducts......................................162

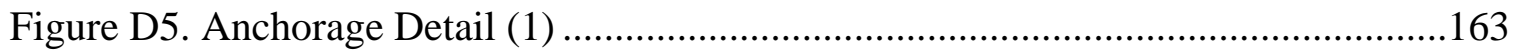

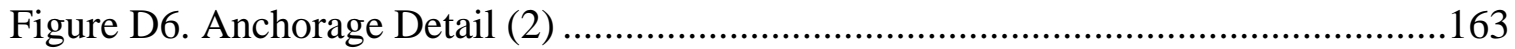

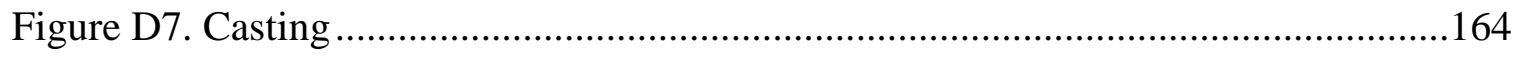

Figure D8. Specimen after Casting ..................................................................164

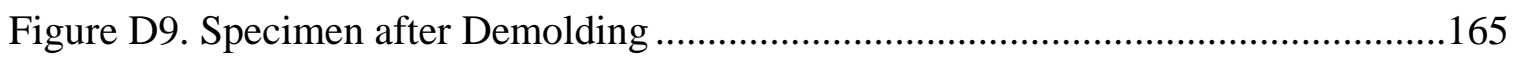

Figure D10. Anchorage Zone Recasting Using Sikadur 32 Hi-Mod Epoxy ....................165 


\section{INTRODUCTION}

\subsection{Problem Statement}

Post-tensioning is often used in continuous beams, floor slabs, hammerhead piers, and segmental bridge construction. Typical examples of post-tensioning tendon applications are shown in Figures 1.1 - 1.4 (Corven and Moreton 2004).

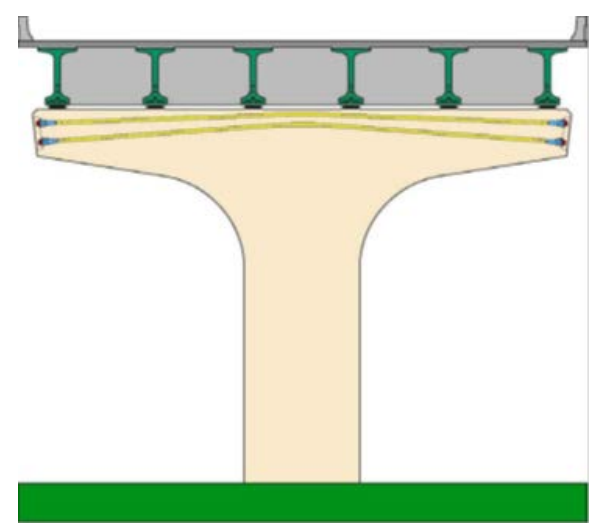

Figure 1.1 Post-Tensioning in Hammerhead Piers

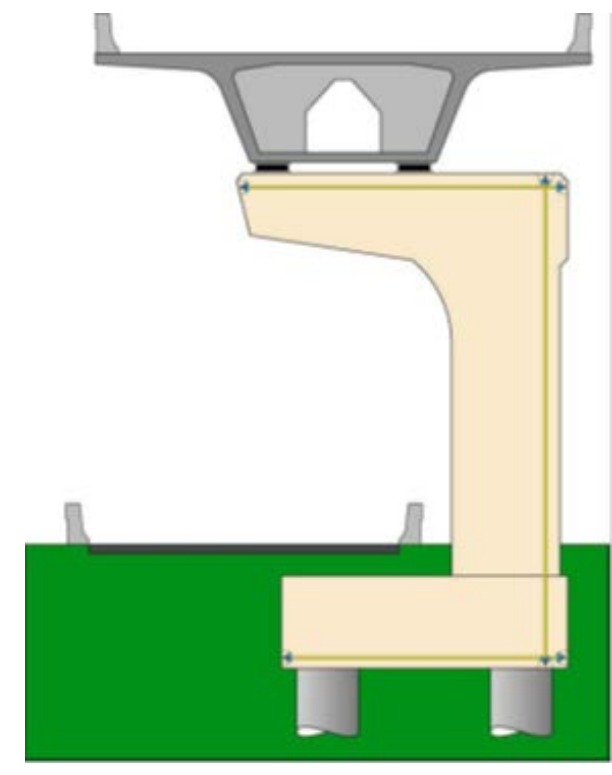

Figure 1.2 Post-Tensioning in Cantilever Piers

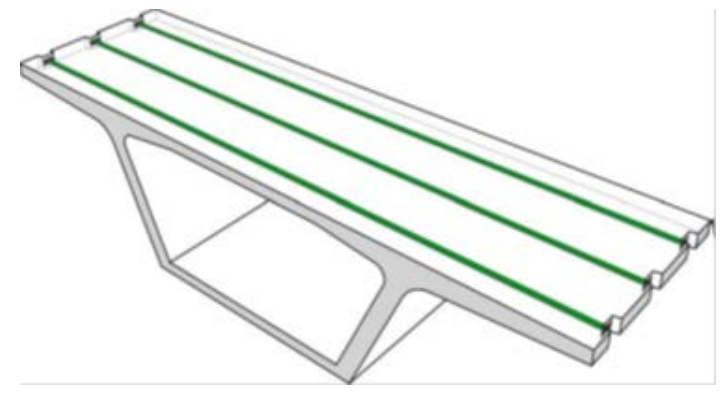

Figure 1.3 Post-Tensioning in the Top Slab of Box Girders 


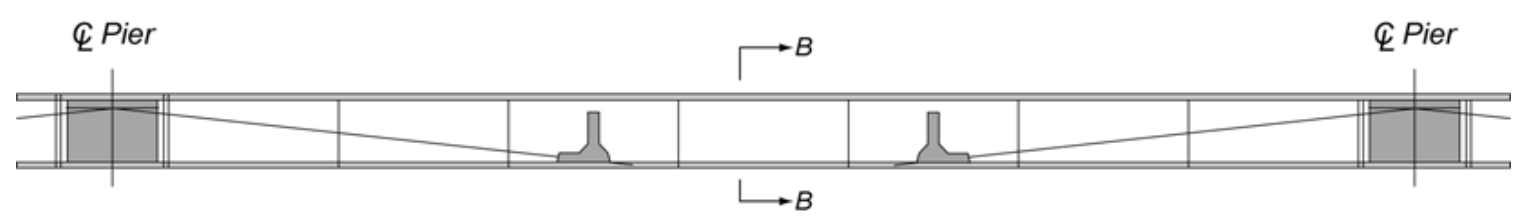

Typical Interior Span

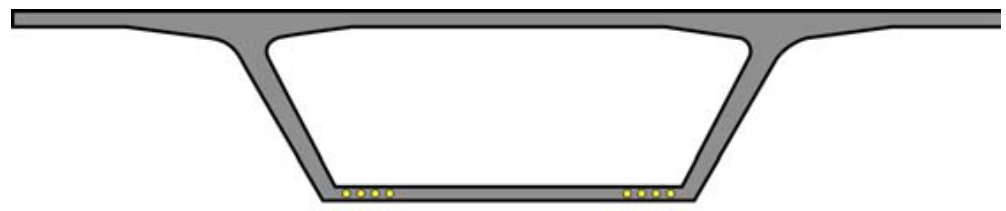

Section $B-B$

Figure 1.4 External/Internal Tendons in Segmental Bridges

Post-tensioning has also been used as a strengthening method in bridge structures.

The advantages of post-tensioning are multiplied when combined with prefabrication so as to reduce on-site construction time. The nature of these applications makes it critically important that the condition of the tendons be maintained to ensure structural integrity. Typically, to ensure that tendons remain in good condition and are free from deterioration due to corrosion, they are placed in ducts made of plastic or galvanized steel. Subsequent to the installation of components and tensioning of tendons, these ducts are filled with a cementitious grout. In recent years there has been a rise in durability issues related to post-tensioning tendons as a results of poor grouting practices or grout inconsistencies.

Corrosion of steel tendons is a major problem for post-tensioned concrete, especially because corrosion is often hard to detect inside grouted ducts. While research continues to develop better means to protect steel tendons against corrosion, considerable effort is devoted to finding suitable non-metallic tendons for post-tensioning applications. Fiber-reinforced polymer (FRP) composite offers a viable alternative to steel tendons. In addition to their superior durability, FRP tendons may result in lower relaxation losses as 
compared with steel (Dolan et al. 2001). FRP tendons may be made with different types of fibers, for example, carbon, glass, aramid, or basalt. Due to their higher strength, elastic modulus, and excellent durability, carbon FRP (CFRP) tendons are the most practical option.

To date, several studies have been carried out on the application of CFRP prestressing in bridge structures. Of all studies on CFRP prestressed concrete structures, only a few have considered CFRP for post-tensioning. An unbonded CFRP posttensioned system has great potential for use in segmental bridges, bridge girders, decks, and pier caps. However, there are still many gaps in our knowledge of CFRP posttensioned systems. For example, to date, a structure in which post-tensioned CFRP tendons are the only prestressing system has not been investigated.

\subsection{Research Objectives}

The primary objective of this research was to investigate the feasibility of the novel unbonded CFRP post-tensioning system and to provide the following guidelines for using CFRP tendons as a viable alternative to steel strands in post-tensioned bridges in Florida:

1. Design Guidelines: Establish design guides for CFRP post-tensioned systems considering material properties, post-tensioning devices, and structural behavior based on the experimental program and analytical simulation.

2. Construction Specifications: Assess the constructability of CFRP posttensioned systems based on the experimental program to lead to construction specifications for CFRP post-tensioned systems. 
3. Inspection Method: Evaluate the methods of inspection of CFRP posttensioned systems, based on the experimental program.

4. Maintenance and Repair Standards: Develop methodologies and guides for maintenance and repair of tendons in CFRP post-tensioned systems, based on the experimental program.

\subsection{Research Approach and Methodology}

To achieve the above objectives, the following experimental work and analytical simulation has been conducted in this study:

1. Scaled CFRP post-tensioned segmental box-girder bridge model

2. Finite element analysis of segmental bridges post-tensioned with CFRP tendons

3. Scaled CFRP post-tensioned pier cap model

4. CFCC post-tensioning anchorage and creep stress test

\subsection{Organization of Dissertation}

This dissertation is comprised of seven chapters. This first chapter serves as an introduction, mainly describing the problem statement, research objectives, and research approach. Chapter 2 to Chapter 5 represent papers from this study published, in press, or in review. Chapter 2 presents the experimental work of post-tensioned segmental box girder bridge model using Carbon Fiber Composite Cable (CFCC) and regular steel strands respectively. Chapter 3 covers the experimental segmental bridge model test results comparison between three types of post-tensioning tendons, CFCC, EC6, and steel strands, and analytical work related to CFRP post-tensioned segmental bridge model. Chapter 4 focuses on the experimental program of the CFRP post-tensioned pier cap model. Chapter 5 describes the creep stress and residual strength test of CFCC. The 
guidelines and specifications for the un-bonded CFRP post-tensioned system are provided in Chapter 6, followed by summary and conclusions for the project, as well as recommendations for future research in Chapter 7. Additional information is provided in the appendices. 


\section{References}

Corven, J., \& Moreton, A. (2004). Post-Tensioning Tendon Installation and Grouting Manual. Federal Highway Administration, Washington, DC

Dolan, C.W., Bakis, C.E., and Nanni, A. (2001). Design Recommendations for Concrete Structures Prestressed with FRP Tendons (Report No. DTFH61-96-C-00019). Federal Highway Association, Washington, D.C. 


\section{POSTTENSIONING OF SEGMENTAL BRIDGES USING CARBON-FIBER- COMPOSITE CABLES}

\subsection{Problem Statement}

Posttensioning is a prevalent and cost-effective construction method for cast-inplace or precast concrete. Together with prefabricated elements, posttensioning is an ideal technique for accelerated bridge construction, reducing on-site construction time and labor. Given the importance of tendons to the structural integrity of posttensioned concrete, they are typically protected in plastic or galvanized steel ducts, which are then filled with grout to prevent corrosion. The ducts, however, may not be completely filled during construction, and if they crack or corrode while in service, moisture and air may reach the tendons and initiate their corrosion.

Corrosion of steel tendons is a major problem for posttensioned concrete, especially because corrosion is often hard to detect inside grouted ducts. While research continues to develop better means to protect steel tendons against corrosion, considerable effort is devoted to finding suitable nonmetallic tendons for posttensioning applications. Fiber-reinforced-polymer (FRP) composite offers a viable alternative to steel tendons. In addition to their superior durability, FRP tendons may result in lower relaxation losses compared with steel.1 FRP tendons may be made with different types of fibers, such as carbon, glass, aramid, or basalt. Due to their higher strength, elastic modulus, and excellent durability, carbon FRP (CFRP) tendons are the most practical option. There are a number of commercially available CFRP tendons, including carbon-fiber-composite cable (CFCC) and CFRP tendons. 
CFCC has been used in a number of applications, ranging from reinforcement in concrete structures to the stay or main cable in bridges and ground anchors. It has also been used in three bridges in Michigan2 and in prestressed piles in Florida and Virginia. To date, however, no study has focused on posttensioning of CFCC in segmental bridges. The objective of this study was to develop a realistic test bed for assessing constructability, design, and inspection of CFCC for posttensioning in segmental bridges.

\subsection{Review of Literature}

A number of studies have focused on posttensioning applications of CFCC. Two half-scale precast, prestressed concrete box-beam bridge superstructure specimens, one with CFCC tendons and the other with conventional steel strands, were tested by Grace et al. ${ }^{3}$ to assess their performance in flexure. Both models exhibited similar behavior irrespective of the type of strand used. Grace et al. ${ }^{4}$ studied the flexural behavior of a fullscale, double-tee beam prestressed using bonded pretensioned CFRP tendons and unbonded posttensioned CFCC tendons. Strain distributionalong the beam section, deflection, cracking load, tensioning, ultimate load-carrying capacity, and failure mode were investigated. The specimens showed considerable strength beyond service load. The results of this study were applied to the design of the double-tee beams used in the construction of the Bridge Street Bridge ${ }^{2}$ in Southfield, Mich.

Grace et al. ${ }^{5}$ tested three bridge models in flexure up to failure. The three models included unbonded, posttensioned CFCC tendons; unbonded CFCC tendons with zero posttensioning force; and no unbonded CFCC tendons. The same number of bonded pretensioned and bonded nonprestressed CFCC tendons was used for each model. Test results showed that the specimen with the higher prestressing force would fail in a sudden 
and brittle mode, whereas specimens with lower prestressing force would fail gradually. The additional unbonded CFCC posttensioning force delayed the development of cracks and reduced the number and size of cracks, as well as the residual deflections.

Fatigue behavior of concrete structures prestressed with CFRP has also been studied. Dolan et al. ${ }^{1}$ reported that cracked CFRP prestressed concrete beams did not show any sign of fatigue failure after 3 million cycles of flexural loading, though cracking was observed after the first million cycles. The beams did not lose any strength due to fatigue even though a gradual softening was observed. Grace et al. ${ }^{6}$ investigated the performance of a continuous CFRP prestressed concrete bridge under 15 million cycles of repeated loads. In this study, there was no significant effect on the prestressing force of externally draped posttensioning tendons. Similarly, no sign of damage in CFRP tendons was observed at the deviators.

Long-term performance assessment of FRP tendons in bridges is necessary. A comprehensive structural-health monitoring of highway bridges consists of four steps: ${ }^{7}$

- sensor placement and measurement

- structural identification and modeling

- damage detection and degradation assessment

- decision-making on rehabilitation and maintenance

Limited data are available on the implementation of an integrated monitoring system for FRP tendons. ${ }^{2,8}$ Available nondestructive methods with potentials for inspection of FRP prestressed concrete structures include visual, reflective, imaging, and load testing. 
Visual inspection of CFCC tendons could be easily implemented using a borescope but may only offer limited insight as to their performance. Reflective methods rely on transmitting various forms of sonic waves and investigating their return response. Most reflective methods are suited for investigating local and small areas and are generally time-consuming if conducted on a point-by-point basis. The acoustic-emission technique, which effectively listens for wire breaks, has been used for monitoring posttensioned and prestressed concrete bridges. Nondestructive techniques in the imaging category allow for a more detailed visual inspection. They include radiographic imaging or tomographic systems. In general, these techniques are difficult and expensive to implement in field conditions and are often applicable to small areas. Finally, structuralelement characteristics can be determined via global load testing. Installation of fiber-optic sensors (at the time of construction) or load cells to monitor stress along CFCC tendons is perhaps the most reliable technique for inspection and monitoring of CFCC.

Even though segmental bridge construction is popular in practice, only a few experiments have been carried out on these types of bridges, and none with CFCC tendons. A comprehensive study ${ }^{9}$ investigated the behavior of a three-span external posttensioned concrete box-girder bridge model with different types of joint connections, including dry joints and epoxy joints. The bridge model was tested under service loads, factored loads, and ultimate loads for different loading configurations, all of which could result in maximum flexure and maximum shear. Test results demonstrated that the epoxy joints could help prevent joint opening and limit bridge deflections. Also, the performance of a scaled single-cell precast concrete posttensioned segmental box-girder 
bridge model with dry joints subjected to cyclic loading and temperature changes was investigated. ${ }^{10}$ Joint opening and cracking were found negligible up to 2 million load cycles. Temperatures did not seem to make much difference across the section either.

\subsection{Experimental Program}

\subsubsection{Specimen Preparation and Erection Process}

A simple-span 1:31/2-scale superstructure model of the Long Key segmental boxgirder bridge in the Florida Keys was constructed as a test bed for a series of experiments to compare posttensioning with CFCC and steel strands. Consistent with the prototype bridge, the model was designed based on the American Association of State Highway and Transportation Officials' (AASHTO's) Standard Specifications for Highway Bridges. ${ }^{11}$ In the 1990s, Arockiasamy et al.10 had used a similarly scaled model of the same prototype, as described earlier. Figure 2.1 shows the bridge model consisting of seven trapezoidal box-girder segments and two solid end blocks with a rectangular section. The tendons were harped at a $5^{\circ}$ angle with contacts limited to the end blocks, and the two deviators in the two segments were placed adjacent to the center segment. Each deviator was designed as a beam to resist uplift at the harping point. The solid end blocks were designed to resist the prestressing force. The segments were connected as dry joints with multiple shear keys along both flanges and webs. Each segment was reinforced using $1 / 4$ in. $(6 \mathrm{~mm})$ diameter steel bars with a yield strength of $60 \mathrm{ksi}(410 \mathrm{MPa})$ spaced at 31/2 in. (89 mm) on center in both longitudinal and transverse directions.

Figure 2.2 shows the fabrication process for the bridge model. Wooden formwork was assembled for the entire bridge model to match cast the segments. Styrofoam was used to create hollow-cores of box-girder sections and the joint shear keys on both 
flanges and webs of each segment. Foam blocks of each pair of segments were matched with the divider foam, interlocking the tongue and grooves that were precut on their surfaces. The pieces of foam were bonded using foam glue. Spacers were made using a circular plate tack welded at one end of a screw to support the foam and to control the thickness of the bottom flange and the webs (Fig. 2). Formwork and the template were designed and built for each anchorage zone to accurately and firmly support the posttensioning ducts and steel plates at the exact $5^{\circ}$ harping angle. The posttensioning ducts within the end blocks were made using a cardboard tube that is supported between the anchorage block and the first foam divider (Fig. 2 upper right). A boom pump facilitated casting of the entire bridge model and its supports using a self-consolidating concrete with a compressive strength of $8630 \mathrm{psi}(59.5 \mathrm{MPa})$ as measured at the time of testing from at least three companion cylinders. The segments were de-molded a week after casting. The foams were carefully removed from within each segment using acetone. The segments were then erected side by side with temporary wooden stands before tensioning.

\subsubsection{Posttensioning}

Table 2.1 lists the geometric and material properties of the two types of strands used for posttensioning the bridge model, as reported by their manufacturers. CFCC tendons are made as seven-wire twisted cables similar to typical steel strands and are available in diameters up to $1.57 \mathrm{in}$. (40 mm). They are guaranteed in strengths up to 241 kip $(1070 \mathrm{kN})$. For the bridge model, 0.49 in. $(12.5 \mathrm{~mm})$ diameter CFCC tendons were used to closely match the $1 / 2$ in. $(13 \mathrm{~mm}$ ) diameter, seven-wire low-relaxation steel stands. 
CFCC tendons are shipped as coiled strands with prefabricated special end anchorages. Although regular chuck anchoring devices for steel tendons are widely available, cost-effective, and reliable, they cannot be applied directly to CFCC tendons because of the brittleness of the cables under transverse-gripping pressure. The anchorage system for CFCC tendons is a factory-made steel sleeve filled with a proprietary resin. The sleeve has internal threads to facilitate posttensioning using a threaded-steel rod and external threads using a circular nut to help lock the prestressing force. This system does not easily accommodate deviations from the preordered lengths, whether due to construction tolerances or miscalculation in the elongation of the cable. Any such deviation may require abandoning the cable entirely or having to develop a build-up at the jacking end to make up for the difference.

Cables in the bridge model were protected at both ends and at the two deviators by using flexible reinforced braided-PVC tubes as jackets. A $1 / 2 \mathrm{in}$. (13 mm) thick neoprene pad was placed atop the cables at each harping point in the deviators to avoid potential damage at sharp corners. The four cables on each side of the model were passed through the segments before placing the end block on the south side of the model, which effectively closed off the system.

From the constructability perspective, the most feasible option for simultaneous posttensioning of multiple cables is to develop a super coupler that transfers the forces from the sleeves of multiple CFCC tendons on one side to regular steel strands on the other side that are pulled by a hydraulic jack. This option allows the contractor to use its current jacking tools to stress CFCC tendons. For the bridge model, however, a second option was developed (Fig. 2.3). It included two $14^{7} / 8 \times 12$ in. (378 $\left.\times 305 \mathrm{~mm}\right), 2$ in. (50 
$\mathrm{mm}$ ) thick steel plates with four $1 \frac{1}{2}$ in. $(38 \mathrm{~mm})$ diameter holes at 3 in. $(75 \mathrm{~mm})$ on center to allow passing the end sleeves through the holes and turning the locknuts or placing the load cells. A pair of hydraulic jacks was sandwiched between the two steel plates at each anchorage. A similar approach was applied to steel strands, except for the use of chucks instead of sleeves and locknuts (Fig. 2.3). Both CFCC and steel strands were posttensioned alternatively between the east and west sides of the model in increments of 20 kip ( $89 \mathrm{kN})$, with an average force of $5 \mathrm{kip}(22 \mathrm{kN})$ in each cable, to reach the target prestressing force, while the load in each cable was continuously monitored using a load cell.

The cables were stressed up to $63 \%, 65 \%$, and $70 \%$ of their guaranteed capacity. The 63\% prestress was designed to match the prestress force that was tested by Arockiasamy et al. ${ }^{10}$ Sixty-five percent is the maximum stress permitted for carbon cables per ACI 440.4R-04. ${ }^{12}$ Seventy percent was chosen to evaluate the performance of the bridge model under an overdesigned prestress force. The relaxation loss of CFCC was recorded at $63 \%$ and $70 \%$ prestress for different durations before load testing the model. After monitoring of stresses in CFCC for almost two months, the 63\% prestress had dropped to $62 \%$ before load testing and is noted as such in the following sections.

\subsubsection{Test Setup}

Figure 2.4 shows the test setup. The test frame included 16 high-strength threaded rods tied down to the strong floor, two W sections supported by the threaded rods on the two sides of the model in the longitudinal direction, one long $\mathrm{W}$ section in the lateral direction, and two hollow structural sections as spreader beams. Under each hollow structural section, there were two loading points, together simulating a single 
truck. At each loading point, a steel hinge was placed under the hollow structural section and on top of a 2 in. $(50 \mathrm{~mm})$ thick steel plate and a 1 in. $(25 \mathrm{~mm})$ thick $12 \times 6$ in. $(300 \times$ $150 \mathrm{~mm}$ ) neoprene pad, the size of which was scaled down to simulate the tire of a standard AASHTO HS truck on the top flange of the bridge segments.

\subsubsection{Instrumentation}

Eight doughnut load cells were used at the dead end of the model to continuously monitor prestress force in each cable. A total of 13 string pots were attached to the segments to measure joint deflections. Six linear potentiometers were mounted on the bottom flange to monitor the opening at critical joints in each load test. Six strain gauges were attached on the top and bottom flanges to record concrete strains near critical joints. Two calibrated pressure transducers were connected to the two hydraulic jacks to monitor the applied loads. A high-speed data acquisition system was used to record the data at a high frequency. Last, four web cameras and floodlights were placed inside the two segments with deviators. The cameras were mounted right on top of the deviators to visually monitor the conditions of the tendons during the tensioning process and the load testing. Figure 2.5 shows the images for the cameras.

\subsubsection{Loading Protocol}

Because the prototype bridge was designed for two lanes of traffic, two standard HS20 trucks were considered as the design live load on the model. ${ }^{11}$ Each truck was simulated with two patch loads in the longitudinal direction of the bridge (Fig. 2.6). Each patch was scaled down from the tire of a standard truck, as described earlier. Figure 6 also shows the three critical positions of the two trucks based on a detailed analysis to develop maximum shear or flexure in the model. Position 1 simulated the most critical 
flexural and shear stresses at the joint closest to the midspan of the bridge model, while position 2 represented maximum flexural stresses in the center segment. Last, position 3 simulated maximum shear at the support joint. The model was tested up to service loads at each of the three load positions, but it was tested up to factored loads only at position 1 . Tests were repeated for each strand type and level of prestressing.

The load in each case was calculated so as to create a stress resultant in the bridge model that was similar to the stress experienced in the prototype bridge. An impact factor of $20.6 \%$ was calculated based on the $118 \mathrm{ft}(36.0 \mathrm{~m}$ ) span length of the prototype bridge. Therefore, the sum of live load and impact was calculated as 9.66 kip $(43.0 \mathrm{kN})$ for the front axle and 38.7 kip $(172 \mathrm{kN})$ for each of the two rear axles of each HS20 truck on the prototype bridge. The three axles for an HS20 truck were simulated as two equivalent axles on the bridge model at a scale factor of $3 \frac{1}{1} 2: 1$, leading to $7.1 \mathrm{kip}(32 \mathrm{kN}$ ) for each axle. Also, a uniform dead-load compensation of 2.5 times the self-weight of the bridge model was considered to account for the scale factor of 3.5:1. The dead-load compensation was replaced with point loads to result in the same maximum moments at critical points. The magnitude of the dead-load compensation was 20.7, 20.3, and 19.1 kip (92.1, 90.3, and $85.0 \mathrm{kN}$ ), for positions 1, 2, and 3, respectively. Therefore, the total service load on the model was 34.9, 34.5, and 33.3 kip (155, 153, and $148 \mathrm{kN})$ for positions 1, 2, and 3, respectively. The factored load was 51.4 kip (229 kN) using appropriate load factors. ${ }^{11}$

Because the purpose of the experiments was to assess the behavior of posttensioning strands and because the expected mode of failure was the crushing of 
concrete (Arockiasamy et al. $^{10}$ ), tests were stopped at the target factored loads due to safety concerns and to allow for repeated loading of the model as a test bed.

\subsection{Test Results and Discussions}

\subsubsection{Physical Observations}

No major crack or failure was observed in the concrete segments during any of the experiments. The images from the interior cameras did not reveal any damage in the strands. However, when CFCC tendons were removed from the bridge model at the conclusion of the experiments, both the cables and the neoprene pads used at the deviators showed minor friction damage (Fig. 2.5). Although no stiffness or strength degradation was observed throughout the experiments, the observed damage implied that CFCC tendons may require a more rigid jacket to protect them from abrasion.

\subsubsection{Relaxation Losses of CFCC Tendons}

Figure 2.7 shows the prestress relaxation losses for CFCC tendons recorded at 63\% and $70 \%$ of the guaranteed cable strength for different durations. The stress loss for the $63 \%$ prestress after 57 days was about $0.7 \mathrm{kip}(3 \mathrm{kN})$, or $2.7 \%$ of the initial stress, which made the effective prestress at the time of testing $62 \%$ of the guaranteed strength. The stress loss after 15 days was $0.2 \%$ for the $70 \%$ stress. The relaxation loss for CFCC tendons was found to be comparable to that of low-relaxation steel tendons.

\subsubsection{Performance under Service Loads}

Figures 2.8 and 2.9 show the load displacements and joint openings, respectively, for the bridge model posttensioned with CFCC tendons under service loads at three different load positions and at different prestress. Prestress was measured at the time of testing. The deflections and openings for position 1 were measured at the joint between 
the two axles. For position 2, the deflections were measured at the midspan of the bridge model and the data for the joint opening was the average reading of four potentiometers attached at the two adjacent joints. For position 3, the displacements and openings are displayed for the joint between the first segment and the end block. The bridge model deflected linearly for the most part at positions 1 and 2, with some stiffness degradation at about service load level. Joint openings, on the other hand, were more curvilinear. Both the displacements and joint openings at position 3 were found to be linear and yet insignificant.

Table 2.2 summarizes test results at service loads for both CFCC and steel strands. The deflection limit of $L / 800$ (where $L=$ span length), which translates to 0.51 in. (13 $\mathrm{mm}$ ) for the bridge model, is found acceptable for both steel and CFCC at the minimum stress of $65 \%$. As noted, displacements and joint openings at position 3 were found to be insignificant.

\subsubsection{Performance under Factored Loads}

Table 2.3 summarizes test results at factored loads for the two types of tendons at different prestress values. These tests were conducted only at position 1 . Figures 2.10 and 2.11 show the complete load displacement and joint opening responses, respectively. Due to the limited stroke of the hydraulic jacks used for testing and safety concerns, the maximum factored load was not achieved at $62 \%$ and $65 \%$ of strength for CFCC tendons, given the higher deformation of the bridge model when posttensioned with CFCC.

The bridge model showed a clear bilinear response for both types of strands and at all prestress values. Before joint opening, the initial stiffness of the bridge model depended on the moment of inertia of the entire section, including concrete and the 
tendons. As such, the different elastic moduli of the two types of strands did not significantly affect the initial stiffness or the first slope of the response because the tendons contributed only a small portion (3\% for steel and $2 \%$ for CFCC) to the entire stiffness of the section. Therefore, the initial stiffness of the bridge model posttensioned with CFCC tendons was only $1.3 \%$ lower than that with steel strands, even though the elastic modulus of CFCC is about 23\% lower than that of steel.

On the other hand, the second slope of the response corresponded to the fully opened joints, in which the tendons played a much more important role by contributing to about $99 \%$ of the stiffness of the section. Therefore, the secondary stiffness of the bridge model correlated directly with the stiffness of the tendons, which explains the much higher stiffness of the bridge model when posttensioned with steel strands.

The transition zone that connects the two linear portions of the response correlates to the decompression of the bottom portion of the section and the corresponding joint openings between the segments. For each type of strand, the higher prestress force helps extend the initial slope of the response and delays the decompression and joint opening. The higher prestress force also slightly increases the initial stiffness of the bridge model, in other words, the first slope of the bilinear response.

Figure 2.12 presents a detailed comparison of the performance of CFCC and steel strands at the $70 \%$ prestress level (that is, 29.2 kip [129 kN]). The top of Fig. 12 shows the load displacements and joint openings, whereas the bottom of Fig. 12 depicts the applied loads versus average force and average strain increase in the strands. The bridge model has a slightly higher initial stiffness with steel strands compared with CFCC. On 
the other hand, it takes a greater load to develop the same force and strain increase in CFCC strands compared with steel strands.

As described earlier, the bridge model was posttensioned with CFCC to develop the same prestressing force as that of steel strands (Eq. [1]).

$A_{p s} f_{p s}=A_{p f} f_{p f}$

$A_{p f}=$ area of prestressing carbon fiber tendons

$A_{p s}=$ area of prestressing steel strands

$f_{p f}=$ stress in prestressed carbon fiber tendons

$f_{p s}=$ stress in prestressed steel strands

This approach, however, leads to much higher deformations and joint openings for segmental bridges with CFCC tendons, as observed in the experiments. Therefore, one may consider a stiffness-based approach to make the responses of the two types of tendons more comparable (Eq. [2]).

$A_{p s} E_{p s}=A_{p f} E_{p f}$

$E_{p f}=$ modulus of elasticity of carbon fiber

$E_{p s}=$ modulus of elasticity of steel

Such a stiffness-based approach could, however, reduce the stress in CFCC to compensate for its lower elastic modulus (Eq. [3]).

$$
f_{p f}=\frac{E_{p f}}{E_{p s}} f_{p s}
$$

For instance, the maximum allowable jacking stress for steel is typically $80 \%$ of its ultimate strength, compared with the $65 \%$ limit recommended for CFCC by ACI 440.4R-04. ${ }^{12}$ Although CFCC could physically be stressed as high as 65\% of its 
guaranteed strength without any concern for stress rupture, using this stiffness-based equivalency approach could potentially reduce the stress to $47 \%$ of its guaranteed strength to provide a similar response to steel tendons.

\subsection{Conclusion}

A 31/2:1 scale model of the Long Key segmental box girder bridge was built as a test bed to compare the performance of CFCC and steel strands at different prestress and at different loading configurations. The following conclusions may be drawn from this experimental study:

- It is feasible to use CFCC for posttensioning segmental bridges from the perspectives of both constructability and design, though some of the construction details for the CFCC posttensioning system are quite different from those used for the steel posttensioning system.

- The main constructability concern for CFCC tendons is that their end anchorages are factory-made together with the strands, and therefore, strands must be ordered at predetermined lengths, considering the increased elongation of the stressed tendons. The system does not easily accommodate deviations from the preordered length and may require abandoning the entire cable or potentially developing a buildup at the jacking end to make up for the difference.

- The segmental bridge model behaved in a bilinear pattern with both types of tendons. Whereas the initial stiffness seemed to be approximately the same for both types of tendons, CFCC tendons led to a much softer response after decompression and joint opening. 
- Higher prestress in both CFCC and steel tendons can delay joint openings and reduce deflections in the segmental bridge model.

- Due to the higher flexibility of the segmental bridge model posttensioned with CFCC, a stiffness-based equivalency approach may provide a more comparable performance with the same bridge model posttensioned with steel. Such an approach, however, may lower the stress in CFCC commensurate with its lower elastic modulus.

Further research is needed on constructability, inspection, and maintenance of CFCC. It may also be of great benefit to replace factory-made anchorages for CFCC tendons with an on-site assemblage.

\section{Acknowledgement}

This study was sponsored by the Florida Department of Transportation under the supervision of William Potter as project manager. The support of Titan America for providing the concrete, $\mathrm{C} \& \mathrm{C}$ Concrete Pumping for providing the concrete pumping, Mo Steel Fabricator \& Erector for the steel frame fabrication, and Emilio R. Vega, the president and CEO of Structural Prestressed Industries Inc. for providing steel strands and steel chucks, are gratefully acknowledged. All experiments were conducted at the Titan America Structures and Construction Testing Laboratory of Florida International University. The views and findings reported here are those of the writers alone and not necessarily the views of sponsoring agency. 


\section{References}

1. Dolan, C. W., C. E. Bakis, and A. Nanni. 2001. "Design Recommendations for Concrete Structures Prestressed with FRP Tendons.” Report DTFH61-96-C00019. Washington, DC: Federal Highway Association.

2. Grace, N. F., F. C. Navarre, R. B. Nacey, W. Bonus, and L. Collavino. 2002. "Design-Construction of Bridge Street Bridge-First CFRP Bridge in the United States.” PCI Journal 47 (5): 20-35.

3. Grace, N., K. Patki, E. Soliman, and J. Hanson. 2011. "Flexural Behavior of Sideby-Side Box-Beam Bridges: A Comparative Study.” PCI Journal 56 (3): 94-112.

4. Grace, N. F., and S. B. Singh. 2003. "Design Approach for CFRP Prestressed Concrete Bridge Beams.” ACI Structural Journal 100 (3): 365-376.

5. Grace, N., T. Enomoto, T., A. Abel-Mohti, Y. Tokal, and S. Puravankara. 2008. "Flexural Behavior of Concrete Box Beams Posttensioned with Unbonded Carbon-Fiber-Composite Cables.” PCI Journal 53 (4): 62-82.

6. Grace, N. F. 2000. "Response of Continuous CFRP Prestressed Concrete Bridges under Static and Repeated Loadings.” PCI Journal 45 (6): 84-102.

7. Alampalli, S., and M. Ettouney. 2003. "Summary of the Workshop on Engineering Structural Health.” In 4th International Workshop on Structural Health Monitoring, pp. 278-284, DEStech Publications: Lancaster, PA.

8. Rohleder, W. J., B. Tang, T. A. Doe, N. F. Grace, and C. J. Burgess. 2008. "Carbon Fiber-Reinforced Polymer Strand Application on Cable-Stayed Bridge, Penobscot Narrows, Maine.” Journal of the Transportation Research Board 2050: pp. 169-176. doi: 10.3141/2050-17.

9. MacGregor, R. J. G., M. E. Kreger, and J. E. Breen. 1989. “Strength and Ductility of a Three-Span Externally Posttensioned Segmental Box-Girder Bridge Model.” Research report 365-3F. Center for Transportation Research, University of Texas at Austin, Austin, Tex.

10. Arockiasamy, M., D. V. Reddy, M. Sivakumar, and M. Shahawy. 2008. "Fatigue Loading and Temperature Distribution in Single-Cell Segmental Box Bridges." Practice Periodical on Structural Design and Construction 13 (3): 118-127.

11. AASHTO (American Association of State Highway and Transportation Officials). 1973. Standard Specifications for Highway Bridges. 13th ed. Washington, DC: AASHTO. 
12. ACI (American Concrete Institute) Committee 440. 2004. Prestressing Concrete Structures with FRP Tendons. ACI 440.4R-04. Farmington Hills, MI: ACI. 


\section{Notation}

$A_{p f}=$ area of prestressing carbon fiber tendons

$A_{p s}=$ area of prestressing steel strands

$E_{p f}=$ modulus of elasticity of carbon fiber

$E_{p s}=$ modulus of elasticity of steel

$f_{p f}=$ stress in prestressed carbon fiber tendons

$f_{p s}=$ stress in prestressed steel strands

$L=$ span length 


\begin{abstract}
Carbon-fiber-composite cables (CFCC) offer a corrosion-free alternative to steel strands. This paper describes the construction and testing of a 31/2:1 scale model of the Long Key segmental box girder bridge model posttensioned with CFCC or steel strands at different prestress and for different loading configurations. The study shows the feasibility of CFCC for segmental bridges. The main concern, however, is that end anchorages are factory-made together with the strands, and therefore, strands must be ordered at predetermined lengths, considering the elongation of stressed tendons. The model behaved bilinearly with both types of strands. Whereas initial stiffness was about the same for both types of strands, CFCC tendons led to a much softer response after decompression and joint opening. Given the higher flexibility of the segmental bridge model posttensioned with CFCC, a stiffness-based equivalency approach may provide a more comparable performance with the same bridge model posttensioned with steel. Such an approach, however, may lower the stress in CFCC commensurate with its lower elastic modulus.
\end{abstract}

\title{
Keywords
}

Bridge, carbon-fiber-composite cable, carbon-fiberreinforced polymers, CFCC, CFRP, posttensioning, segmental. 
Table 2.1 Geometric and material properties CFCC and steel strands

\begin{tabular}{|l|c|c|}
\hline Strand type & CFCC & Steel \\
\hline Nominal diameter, in. & 0.492 & $1 / 2$ \\
\hline Effective area, in. ${ }^{2}$ & 0.118 & 0.153 \\
\hline Guaranteed strength, ksi & 351 & 270 \\
\hline Guaranteed capacity, kip & 41.4 & 41.3 \\
\hline Elastic modulus, ksi & 22,300 & 29,000 \\
\hline Mass density, lb/ft & 0.10 & 0.53 \\
\hline
\end{tabular}

Note: Steel strands were of seven-wire, low-relaxation type. CFCC $=$ carbon fiber composite cable. 1 in. $=25.4 \mathrm{~mm} ; 1 \mathrm{lb}=4.448 \mathrm{~N}$; $1 \mathrm{kip}=4.448 \mathrm{kN}$.;1 ksi =6.895 MPa. 
Table 2.2 Summary of test results at service loads

\begin{tabular}{|c|c|c|c|c|c|c|c|}
\hline \multicolumn{2}{|c|}{ Strand type } & \multicolumn{3}{|c|}{ CFCC } & \multicolumn{3}{|c|}{ Steel } \\
\hline \multicolumn{2}{|c|}{ Effective prestress rorce, kip } & 25.6 & 27.1 & 29.2 & 26.1 & 27.2 & 29.2 \\
\hline \multicolumn{2}{|c|}{$\begin{array}{c}\text { Effective prestress, \% of guaranteed strength or } \\
\text { ultimate strength }\end{array}$} & 62 & 65 & 70 & 63 & 66 & 71 \\
\hline \multirow{2}{*}{ Loading position 1} & Displacement, in. & 0.484 & 0.408 & 0.441 & 0.694 & 0.509 & 0.421 \\
\hline & Joint opening, in. & 0.015 & 0.015 & 0.008 & 0.047 & 0.026 & 0.014 \\
\hline \multirow{2}{*}{ Loading position 2} & Displacement, in. & 0.575 & $\mathrm{n} / \mathrm{a}$ & 0.480 & 0.565 & $\mathrm{n} / \mathrm{a}$ & 0.483 \\
\hline & Joint opening, in. & 0.019 & $\mathrm{n} / \mathrm{a}$ & 0.008 & 0.019 & $\mathrm{n} / \mathrm{a}$ & 0.009 \\
\hline \multirow{2}{*}{ Loading position 3} & Displacement, in. & 0.065 & $\mathrm{n} / \mathrm{a}$ & 0.017 & 0.018 & $\mathrm{n} / \mathrm{a}$ & 0.030 \\
\hline & Joint opening, in. & 0.003 & $\mathrm{n} / \mathrm{a}$ & 0.002 & 0.002 & $\mathrm{n} / \mathrm{a}$ & 0.002 \\
\hline
\end{tabular}

Note: CFCC = carbon fiber composite cable; $\mathrm{n} / \mathrm{a}=$ not applicable. $1 \mathrm{in} .=25.4 \mathrm{~mm} ; 1 \mathrm{kip}=4.448 \mathrm{kN}$ 
Table 2.3 Summary of test results at factored loads

\begin{tabular}{|l|c|c|c|c|c|c|}
\hline \multicolumn{1}{|c|}{ Strand type } & \multicolumn{3}{c|}{ CFCC } & \multicolumn{3}{c|}{ Steel } \\
\hline Effective prestress force,kip & 25.6 & 27.1 & 29.2 & 26.1 & 27.2 & 29.2 \\
\hline Effective prestress, \% of guaranteed strength or ultimate strength & 62 & 65 & 70 & 63 & 66 & 71 \\
\hline Initial stiffness, kip/in. & 65.3 & 66.1 & 67.2 & 57.3 & 64.7 & 68.4 \\
\hline Secondary stiffness, kip/in. & 2.40 & 3.02 & 3.12 & 4.75 & 5.71 & 7.96 \\
\hline Deflection at factored load, in. & n/a & n/a & 2.622 & 3.784 & 2.948 & 1.851 \\
\hline Joint opening at factored load, in. & n/a & n/a & 0.484 & 0.757 & 0.568 & 0.313 \\
\hline
\end{tabular}

Note: $\mathrm{CFCC}=$ carbon fiber composite cable; n/a = not applicable. 1 in. $=25.4 \mathrm{~mm}$; 1 kip = $4.448 \mathrm{kN}$. 


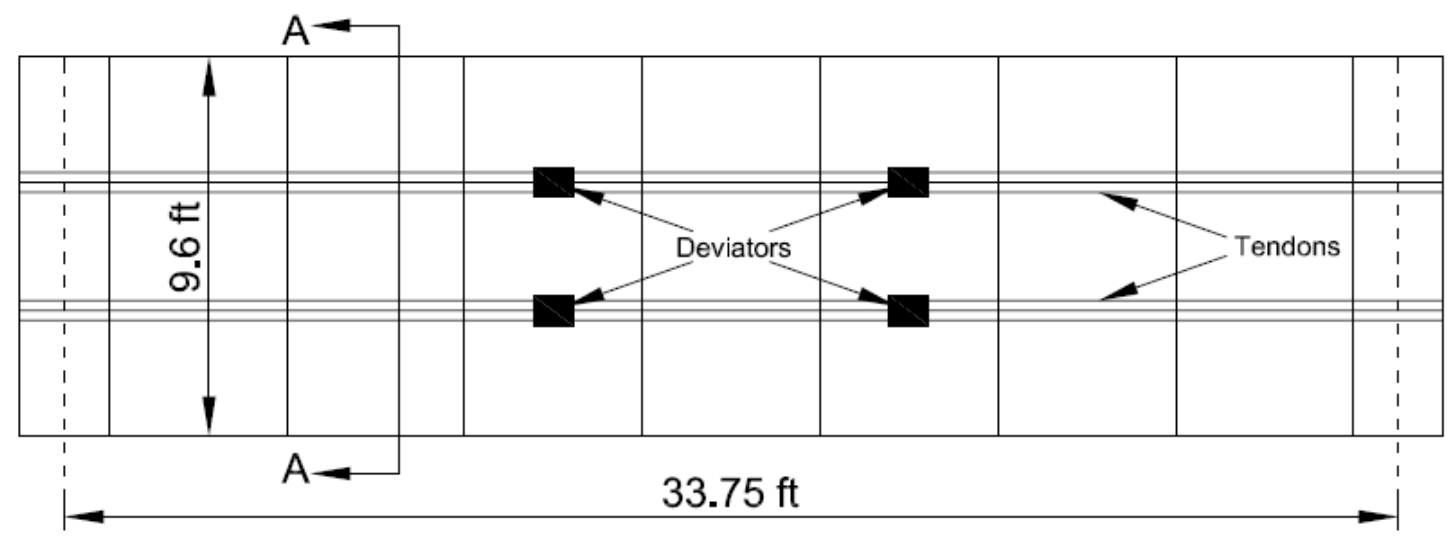

Plan view

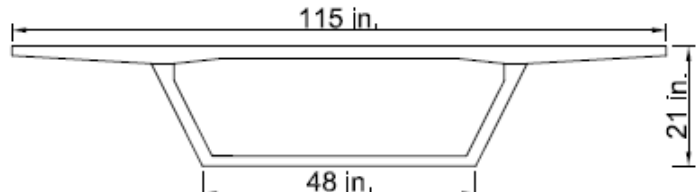

Section A-A

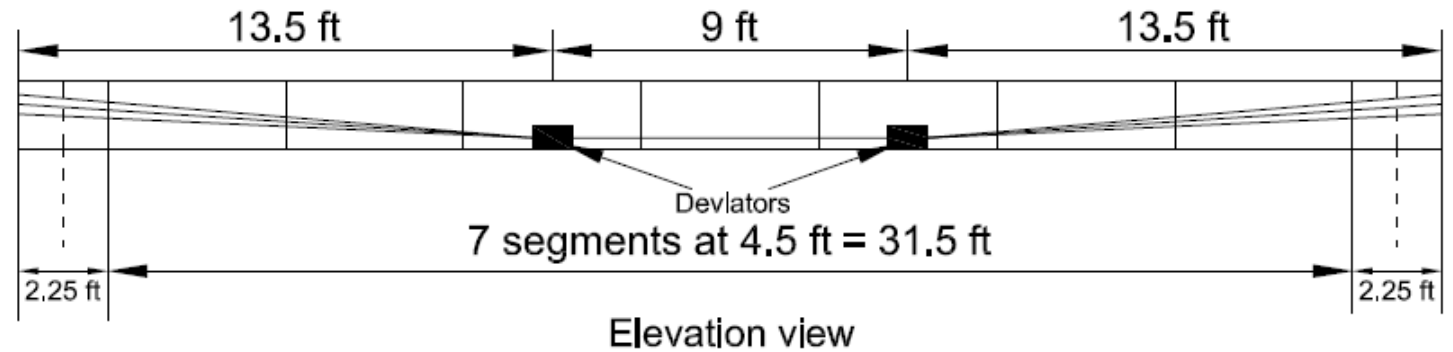

Figure 2.1 1: 31/2 Scale Model of Long Key Bridge. Note: 1 in. $=25.4$ mm; $1 \mathrm{ft}=0.305 \mathrm{~m}$. 

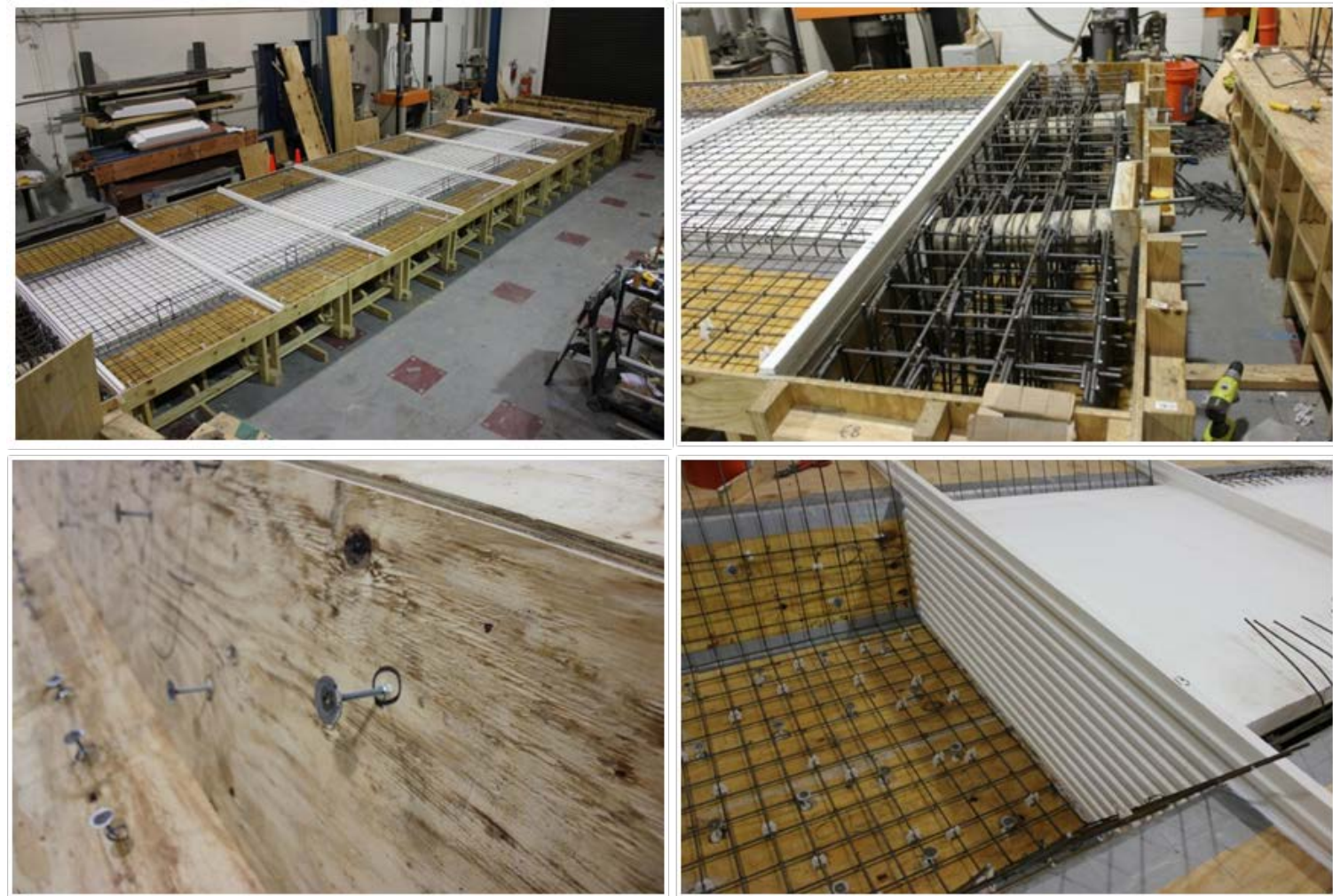

Figure 2.2 Formwork for Segmental Bridge Model. 

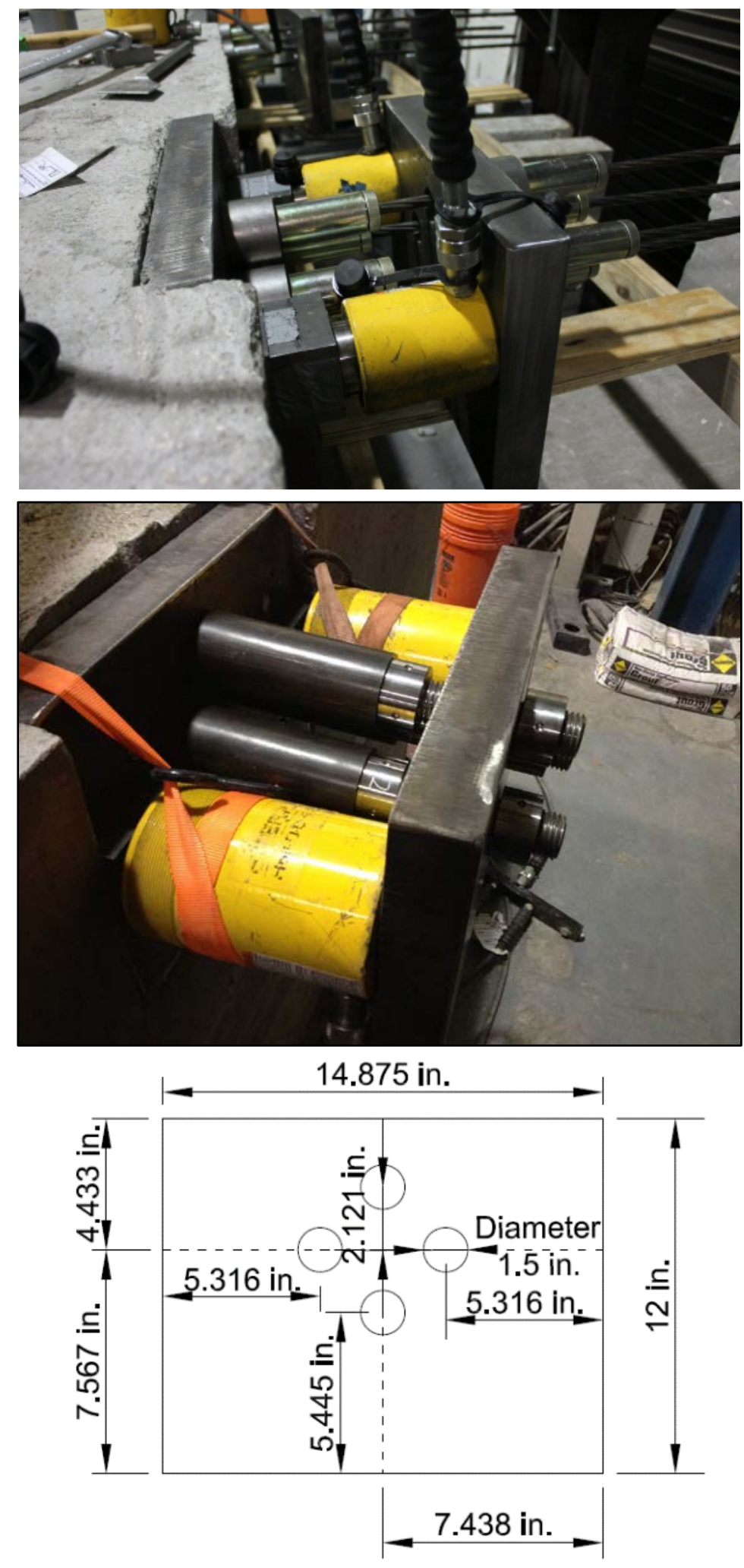

Figure 2.3 Jacking System at Live End. Note: 1 in. $=25.4 \mathrm{~mm}$. 

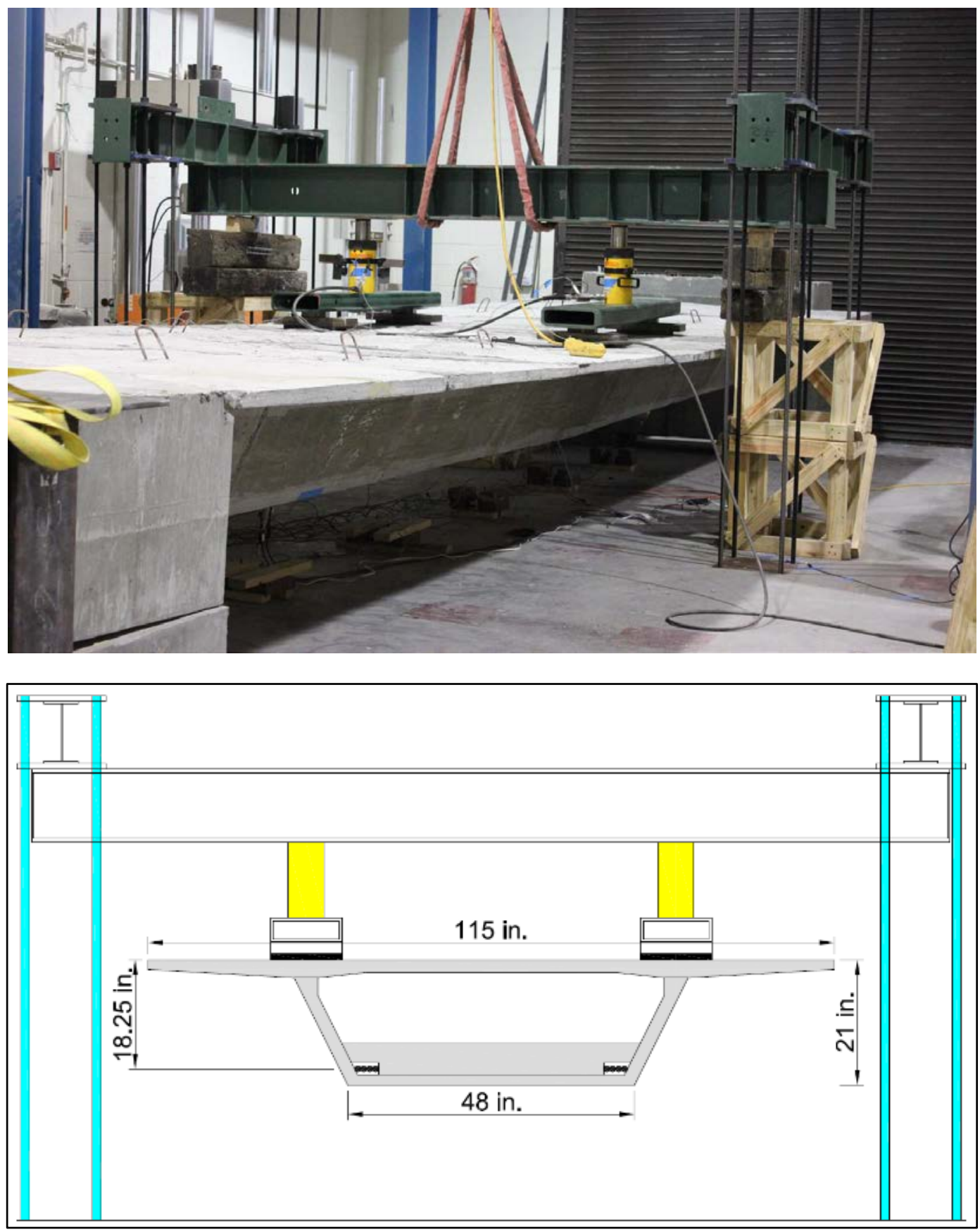

Figure 2.4 Test Setup. Note: 1 in. $=25.4 \mathrm{~mm}$. 

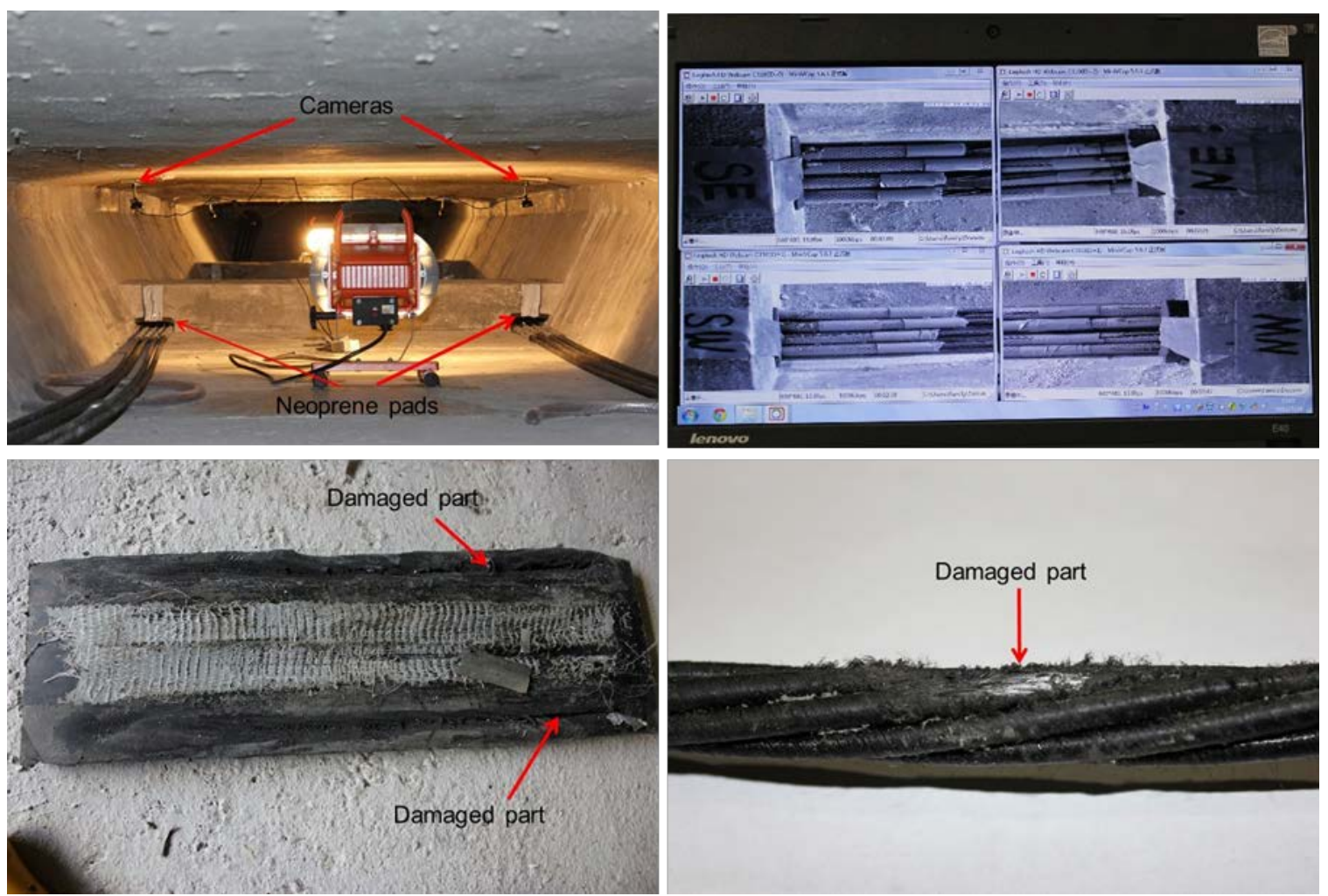

Figure 2.5 Condition Monitoring of Tendons. 


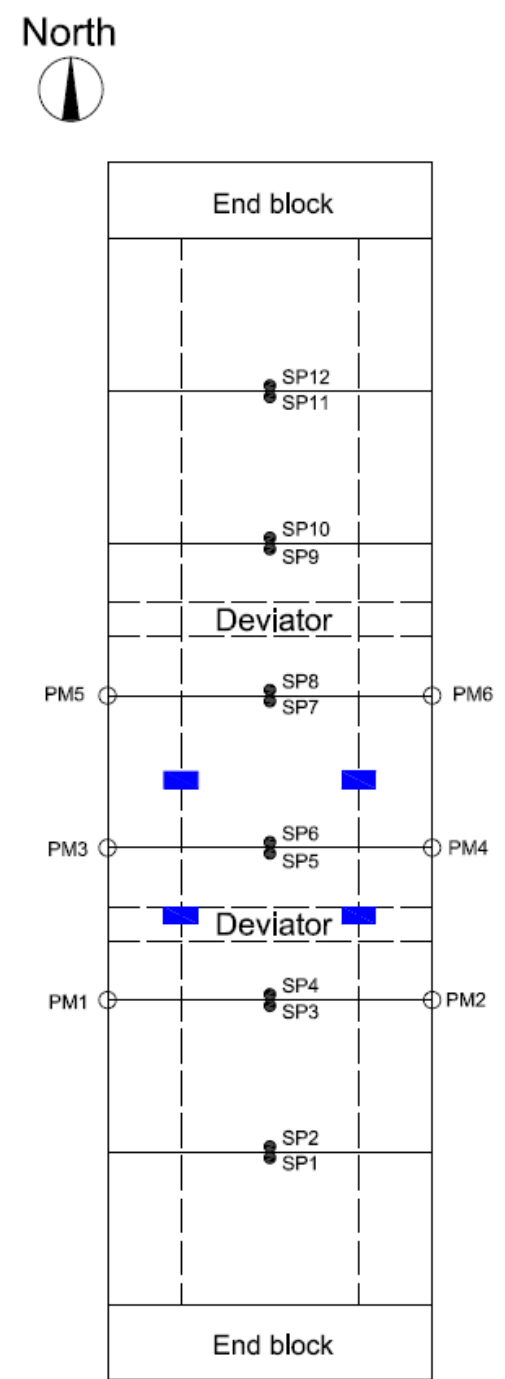

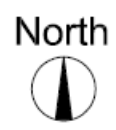

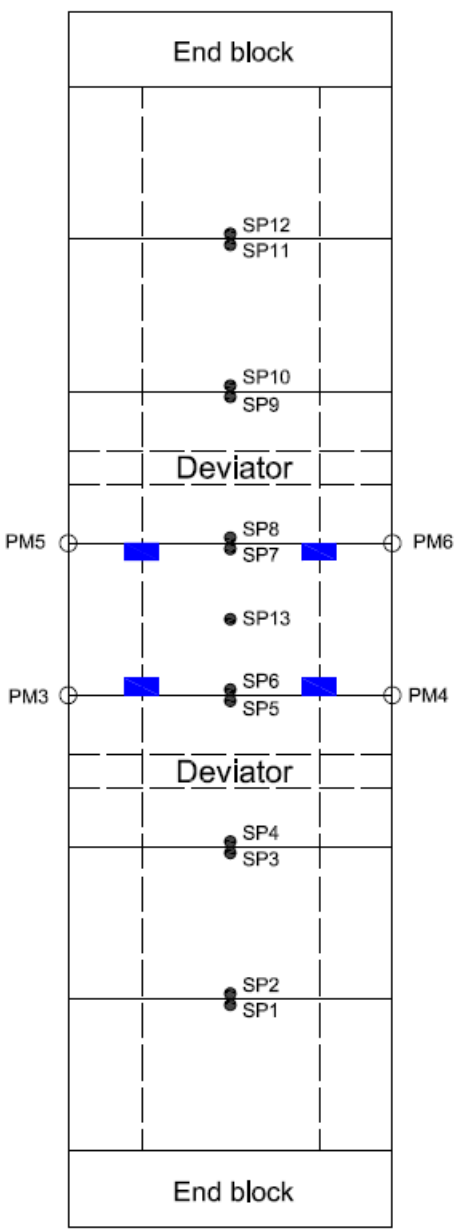

Service Load Position 2
North

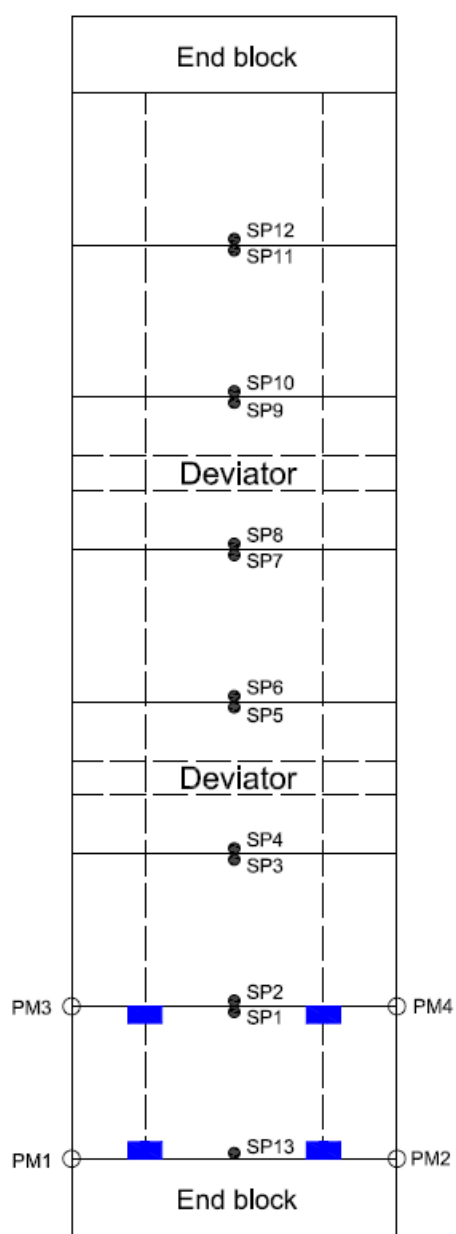

Service Load Position 3
North

(1)

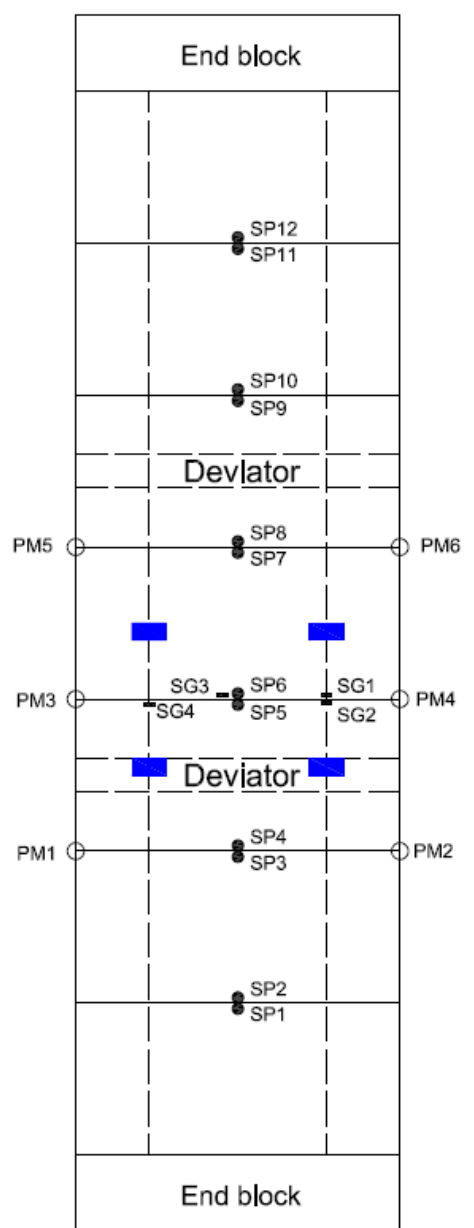

Ultimate Load Position

Figure 2.6 Instrumentation Plan for Different Loading Positions. Note: PM = potentiometer; SG = strain gauge; SP = string pot. 


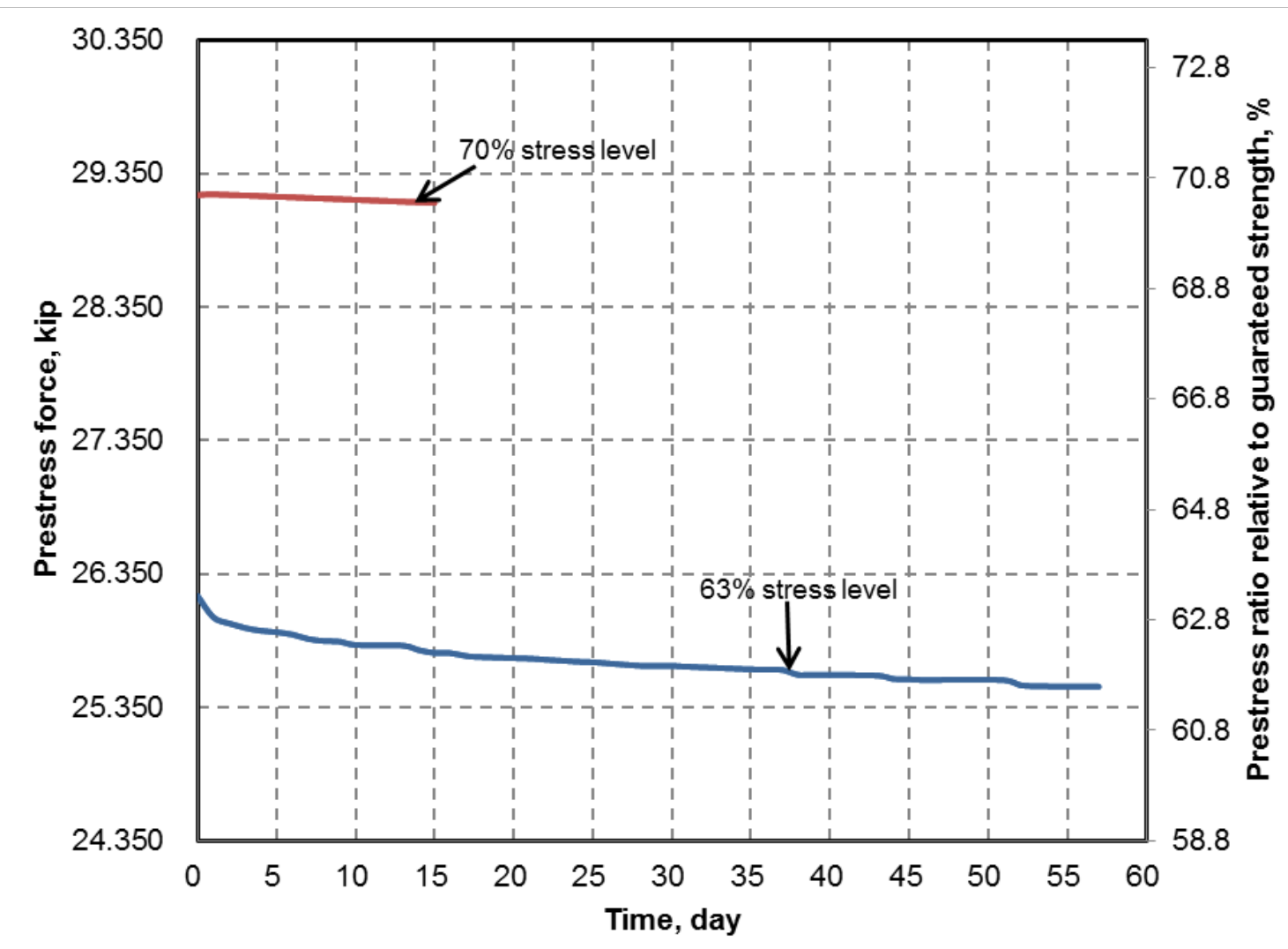

Figure 2.7 Prestress Relaxation Losses at Different Stresses for Carbon-fiber-composite cable Tendons. Note: $1 \mathrm{kip}=4.448 \mathrm{kN}$. 


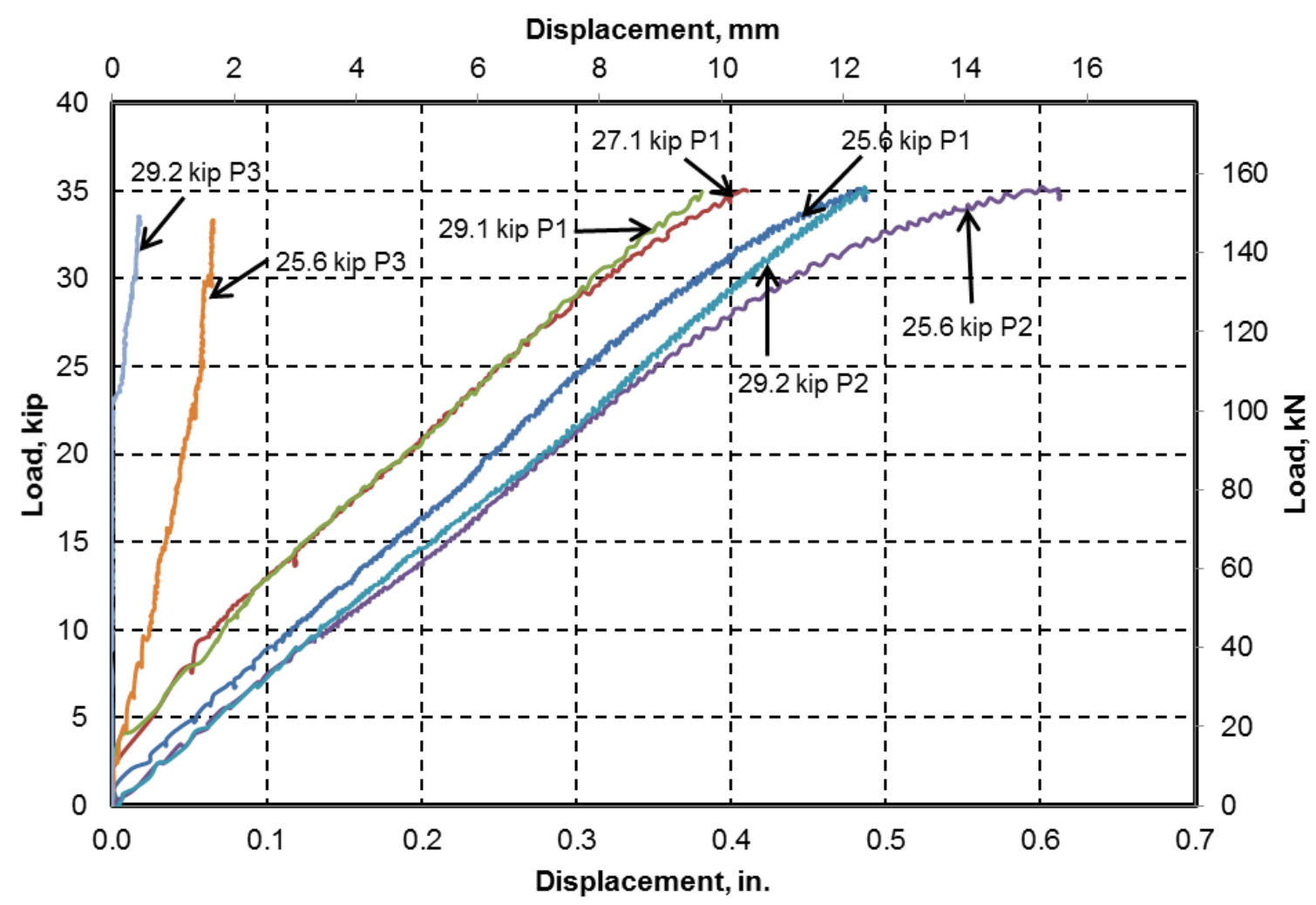

Figure 2.8 Load Displacements of Bridge Model with Carbon-fiber-composite Cable Tendons at Service Load Positions. Note: $1 \mathrm{kip}=4.448 \mathrm{kN}$. 


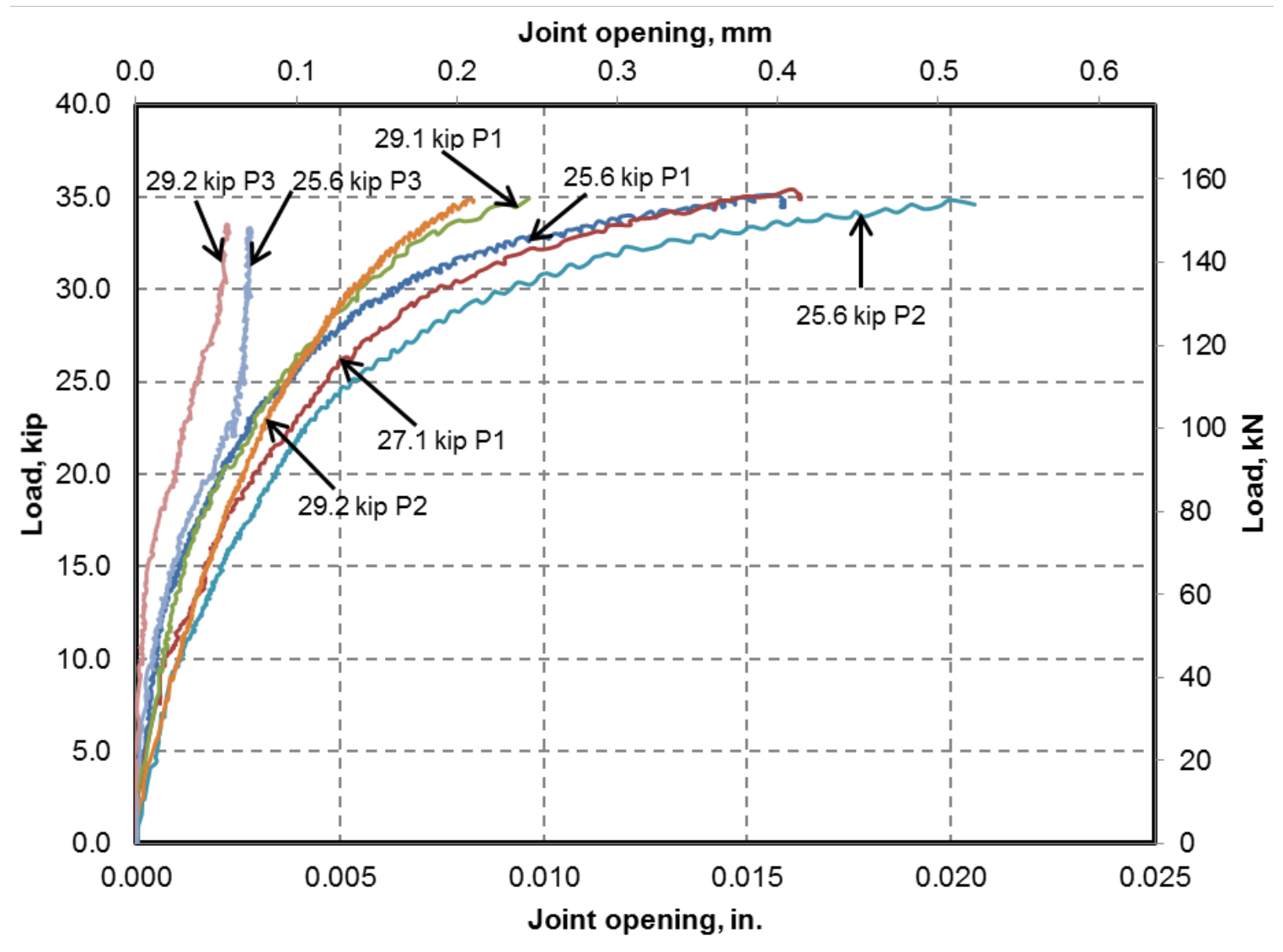

Figure 2.9 Load-joint Openings of Bridge Model with Carbon-fiber-composite Cable Tendons at Service Load Positions. Note: $1 \mathrm{kip}=4.448 \mathrm{kN}$. 


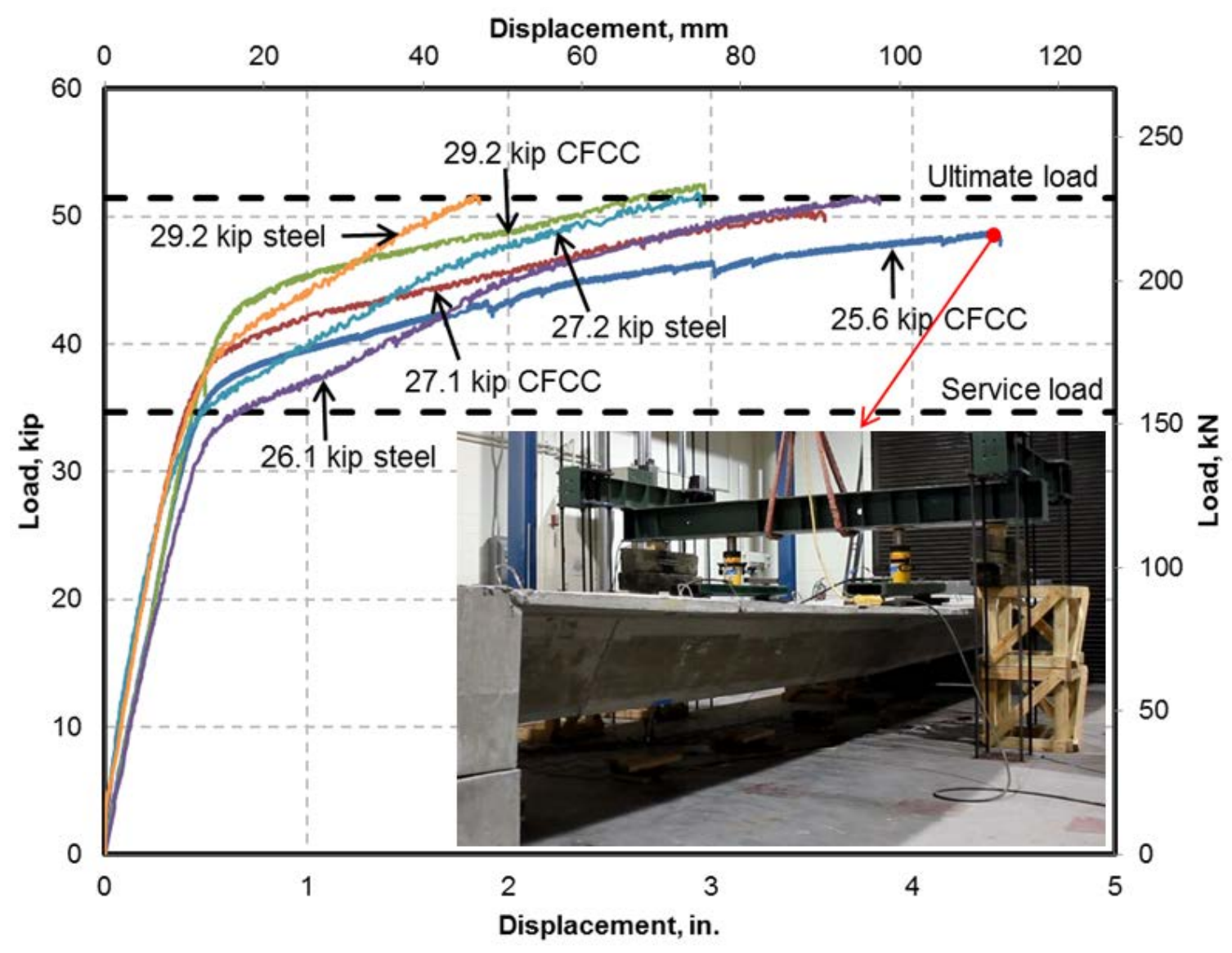

Figure 2.10 Load Displacements of Bridge Model with CFCC and Steel Strands at Factored Loads. Note: CFCC = carbon-fiber-composite cable. 1 kip $=4.448 \mathrm{kN}$. 


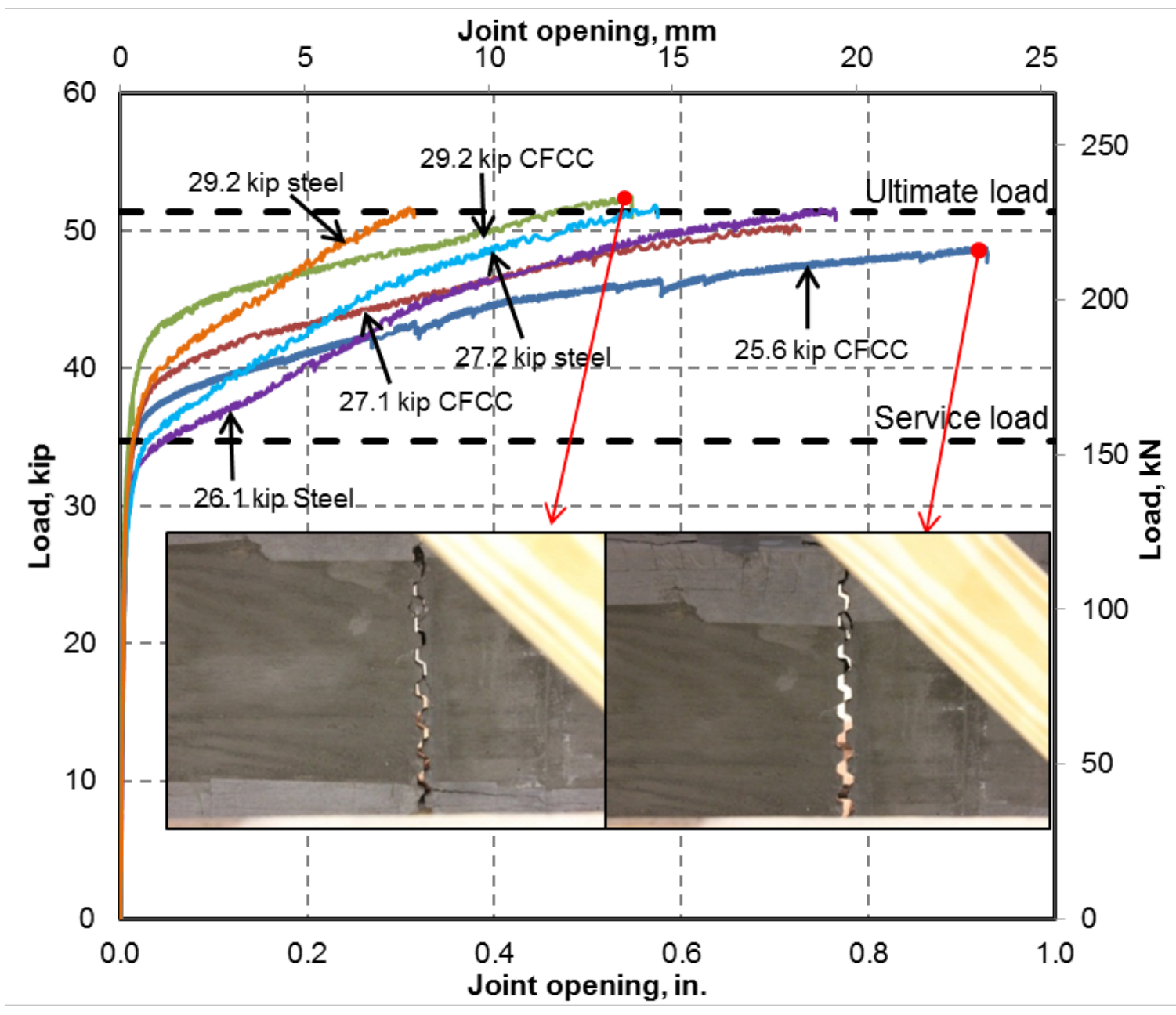

Figure 2.11 Load-joint Openings of Bridge Model with CFCC and Steel Strands at Factored Loads. Note: CFCC = carbon-fiber-composite cable. 1 kip $=4.448 \mathrm{kN}$. 


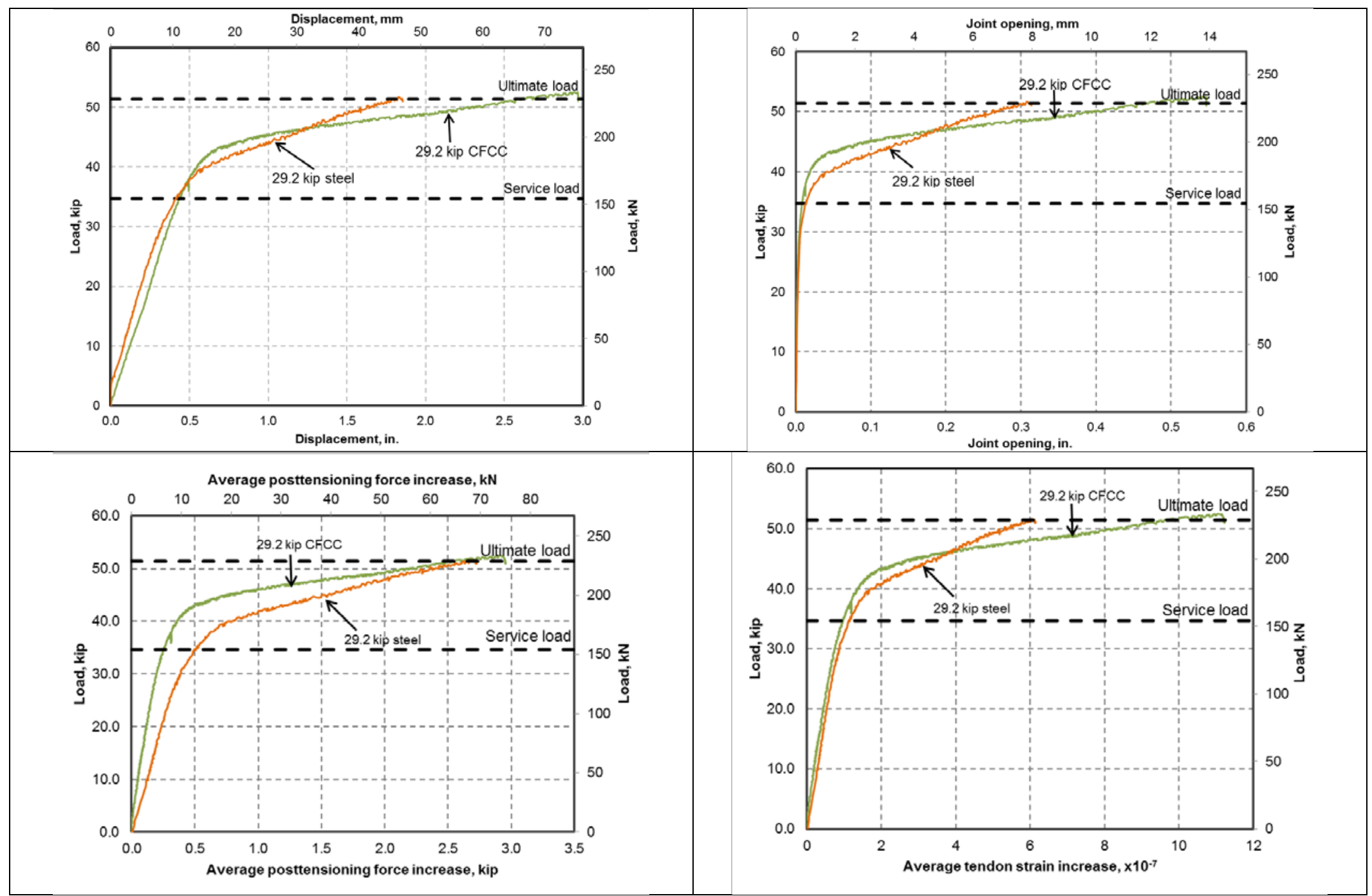

Figure 2.12 Detailed Performance Comparison of CFCC and Steel Strands at 29.2 kip Prestressing Force. Note: CFCC = carbon-fiber-composite cable. 1 kip $=4.448 \mathrm{kN}$ 


\title{
3. EFFECT OF ELASTIC MODULUS OF CARBON FIBER REINFORCED POLYMER STRANDS ON THE BEHAVIOR OF POST-TENSIONED SEGMENTAL BRIDGES
}

\begin{abstract}
Segmental bridges are widely used for accelerated construction, and lower costs and environmental impact. The major concern with such bridges is in the corrosion protection of post-tensioning steel strands. Non-corrosive carbon fiber strands can serve as viable alternatives to help reduce maintenance costs. A novel carbon fiber strand was tested for post-tensioning of a 31/2:1 scaled model of the Long Key segmental box girder bridge, and its performance was compared with prior test data for steel strands and another type of carbon fiber. The most important distinction between the two types of carbon fibers is their elastic moduli, which are $77 \%$ and $93 \%$ of that of steel strands. Numerical simulation was also conducted and the effect of different elastic moduli of the tendons on the structural performance was investigated with a parametric study. While the study confirms feasibility of both types of carbon fiber strands for segmental bridge applications, and their similar serviceability behavior, strands with higher elastic modulus are shown to improve structural performance and minimize displacements after joint opening.
\end{abstract}

Keywords:

Carbon fibers; Prestressed concrete; Post-tensioning; and Segmental bridges.

\subsection{Introduction}

Segmental bridges have grown in popularity in the last few decades, due to their accelerated construction, better means of quality control, and lower maintenance of 
traffic, construction cost and environmental impact, especially in areas with limited access or with environmental concerns. Segmental bridges typically include repetitive concrete box sections that are progressively connected together to form a completed structure in a span-by-span, balanced cantilever or unidirectional cantilever erection process. Structural integrity and long-term durability of segmental bridges depend heavily on corrosion protection of post-tensioning strands, which has been a major concern and the subject of numerous research investigations.

A parallel effort has in recent years has focused on potential use of fiber reinforced polymer (FRP) strands as a non-corrosive alternative to steel. FRP may be made with different types of fibers, e.g., carbon, glass, aramid, or basalt (ACI Committee 440, 2004); of which carbon offers the most practical option, given its higher strength and elastic modulus as well as excellent durability and fatigue strength. Among the various available commercial CFRP strands, carbon fiber composite cable (CFCC) made by Tokyo Rope, Japan, is one of the more popular in post-tensioning applications. Unbonded CFCC system has already been successfully applied in the field (Grace et al. 2002, Grace et al. 2014, and Rohleder et al. 2008), although not for segmental vehicular bridge construction. EC6 is another type of CFRP strands made by Composite Rigging Southern Spars of North Kingstown, RI., primarily used in rigging system of yachts, and has recently been made available for bridge construction. The first study on bridge applications of EC6 was reported by Yang et al. (2015b) who evaluated construction feasibility and structural behavior of a scaled model of a hammerhead pier cap with unbonded post-tensioning using EC6, CFCC or low-relaxation steel strands as the sole and primary flexural reinforcement. Given the strength-based design of pier caps, the study 
showed no major difference among the three types of strands, and found the application of both types of carbon fiber strands for post-tensioned pier caps equally feasible.

As the first and only study on un-bonded post-tensioned segmental bridge application with CFRP cables, Yang et al. (2015a) compared the performance of a scaled model of the segmental Long Key bridge prototype post-tensioned with either CFCC cables or low relaxation steel strands. The study showed the feasibility of CFCC, but suggested the need for a stiffness-based equivalency approach given its lower elastic modulus relative to steel.

EC6 and CFCC are similar in that both can be coiled for shipping and are available in a large range of diameters. There are also some differences between the two types of carbon fiber strands. Table 3.1 summarizes the material properties of the CFCC and steel strands used in the test of Yang et al. (2015b) with a comparable size $12.3 \mathrm{~mm}$ (0.484 in.) diameter EC6 strand. The properties of EC6 strand are very close to those of steel strand. On the other hand, the strength of CFCC strand is 30\% higher than that of steel, while its elastic modulus is $23 \%$ lower as compared to steel. Since CFRP strands are very brittle in the transverse direction, both EC6 and CFCC need pre-fabricated end anchor which is usually a metallic sleeve filled with either resin or expansive grout. The anchorage sleeve needs to be connected to a thread rod for tensioning purpose. Figure 3.1 shows the anchorage for the three types of strands. The size of the anchorage sleeve for EC6 is very close to the size of multi-use chucks for steel strands and about one third of that of CFCC.

Based on the success for the application of EC6 tendons in the scaled posttensioned pier cap model, the present study was formulated to use these tendons for the 
post-tensioning of the same segmental bridge specimen that was tested with CFCC and steel strands in the previous study (Yang et al. 2015 a). The purpose of this study is to assess the feasibility and performance of the post-tensioned segmental bridge with a higher-modulus carbon fiber strands, and to assess the need for a stiffness-based equivalency approach.

\subsection{Experimental Work}

\subsubsection{Bridge Mode and Test Procedure}

The segmental bridge model tested with post-tensioned EC6 strands was the simple-span 1:31/2 scaled model used in Yang et al. (2015a), shown in Figure 3.2, which was constructed as a test bed for the different types of strands under different loading conditions. The model was designed based on AASHTO (1973), consistent with its prototype, the Long Key segmental box-girder bridge in the Florida Keys. The model was composed of seven trapezoidal box-girder segments, two solid end blocks, and two solid concrete supports. The deviators were located in the two segments adjacent to the center segment to accommodate the harped strands at a $5^{\circ}$ angle. All segments were connected with dry joints using multiple shear keys along both flanges and webs. The dimensions and the distribution of the shear keys at the joint are shown in Figure 3.3. The segments were reinforced with $6.4 \mathrm{~mm}(1 / 4 \mathrm{in}$.) diameter steel bars with a yield strength of $414 \mathrm{MPa}$ (60 ksi), spaced at $89 \mathrm{~mm}\left(3^{1 / 2} \mathrm{in}\right.$.) on center in both directions.

Figure 3.4 shows the formwork of the segmental bridge model. Wooden formwork was prepared for the entire model to be match-casted. Styrofoam blocks were used to create the hollow section inside the box girder and the divider foam with precut tongue and grooves between each foam block was used to create the shear keys at the 
joints. The thickness of the bottom flange and the webs were controlled using speciallymade steel spacers to support the foam block. A special formwork was also designed and fabricated at each anchorage zone to help ensure the accuracy of harping angle for the strands. The entire bridge model was made in a single casting with a boom pump, using a self-consolidating concrete with a measured compressive strength of $59.5 \mathrm{MPa}(8,625$ psi).

Three loading positions, which were considered as the critical positions for service load, along with the instrumentation plan are shown in Figure 3.5. Position 1 represents the most critical flexural and shear stresses at the joint of center segment. The maximum flexural stress in the middle of the center segment can be simulated in Position 2. Lastly, Position 3 simulates maximum shear at the support joint. Position 1 was also used for the factored load test. The magnitude of the load in each position was calculated to achieve the same stress resultant experienced in the prototype bridge. Two standard HS20 trucks were used as the design live load and an impact factor of $20.6 \%$ was calculated based on the $36.0 \mathrm{~m}$ (118 ft) span length of the prototype. The three axles for one standard truck were simulated as two equivalent axles on the bridge model, which is $32 \mathrm{kN}$ (7.1 kip) for each axle considering the scale factor of 3.5. Uniform dead load compensation was calculated as 2.5 times the self-weight of the bridge model account for the scale effect and then replaced with point load to results in the same maximum moment at critical points. The total service loads on the test specimen were 155,153 , and $148 \mathrm{kN}$ (34.9, 34.5, and $33.3 \mathrm{kip}$ ) for position 1, 2, and 3, respectively. The factored load was 229 kN (51.4 kip) using appropriate load factors. In total, 27 tests were conducted 
(10 for EC6, 10 for steel, and 7 for CFCC), including factored load tests and service load tests at different prestress levels.

Figure 3.6 shows the test setup, consisting of two $\mathrm{W}$-sections parallel to the bridge model supported by 16 high-strength steel threaded rods tied down to the strong floor, one W-section in the transvers direction and two HSS sections as spreader beams along the model. The standard HS truck tire was scaled down and simulated with $25 \mathrm{~mm}$ (1 in.) thick $305 \times 152 \mathrm{~mm}$ (12 x 6 in.) neoprene pads. Instrumentation included string pots, linear potentiometers, load cells, and pressure transducers for the loading jacks; to respectively monitor vertical displacements, joint openings, prestress load on each strand, and applied loads.

\subsubsection{Test Results and Discussions}

Table 3.2 lists displacements and joint openings for each of the three service load positions. The prestress levels listed represent stress in the strands at the time of testing, i.e., after losses. The displacements and joint openings for Position 1 were measured at the loaded joint. For Position 2, the displacements were measured at mid-span and the data for the joint opening represent the average reading of four potentiometers attached to the two joints of the center segment. For Position 3, the displacements and joint openings were measured between the first segment and the end block. There is not a significant difference between displacements or joint openings at service loads among the three types of strands. Moreover, an increase in prestress force clearly reduces displacements and joint openings.

Figures 3.7 shows the performance comparison between three types of strands at the highest stress level tested in this study $129.9 \mathrm{kN}$ (29.2 kip). The bridge model showed 
a clear bilinear behavior for all three types of strands. The initial stiffness of the model depends on the section properties and to a much lesser extent on the elastic moduli of the strands. Therefore, the initial stiffness does not seem to vary significantly between the three prestress levels and among the three types of strands. The transition zone connecting the two slopes represents the decompression of the bottom flange in the segmental bridge model, which leads to the joint opening. The decompression load is clearly a function of the prestress level - the higher the prestress force, the higher the decompression load for joint opening.

Subsequent to the joint opening, the top flange acts as a hinge, accommodating the rotation of the two adjacent segments. At this stage, the response is signified with a considerably lower stiffness, corresponding mainly to the stiffness of the strands. Elastic modulus of the strand has a profound impact on the secondary stiffness, which is defined as the stiffness of the bridge model after joint opening. As such, displacements and joint openings for EC6 and steel stands are quite close to each other, and considerably lower than those for CFCC strands. This finding has a significant implication in a stiffnessbased equivalency approach, as will be described later.

Figure 3.7 (c) shows the loads versus the increase in prestress force for the three types of strands. The prestress force in the strands increases much more rapidly after joint opening, while maintaining a linear relationship with the applied loads.

\subsection{Numerical Simulation}

\subsubsection{Finite Element Modeling}

A three-dimensional finite element (FE) model of the bridge model was created using the general-purpose FE software (ANSYS 2013), with seven superstructure 
segments and two end blocks. Concrete was modeled using eight-node Solid65 concrete elements which has three degrees of freedom at each node (Megally et al. 2002, 2003a, and 2003b). Post-tensioning tendons were simulated using Link8 3-D Spar elements. The materials for concrete, steel, and the two types of CFRP cables were all presumed to be linear-elastic for the range under consideration, as previously verified by the experiments. The dry joints in the segmental bridge were modeled using surface to surface contact elements CONTA173 and target elements TARGE170 to carry compressive stresses but no tensile stresses. The key options of TARGE 170 element were used as the default options. For the CONTA 173 element, the Lagrange method was used and the initial geometrical penetration was ignored. The behavior of contact surface was set as rough. During all experiments, the shear keys at each joint remained intact and no relative movement was observed between adjacent segments in the vertical direction. Therefore, to simplify the FE model, instead of modeling the shear keys at dry joints, the shear resistance of all contact pairs at the joint was set at its maximum (by setting the contact surface as rough), which can prevent any relative movement in the vertical direction, to simulate the intended function of the shear keys. Supports were modeled with pins and rollers at the bottom nodes of the two end blocks.

Mesh sensitivity study was conducted at the beginning of the finite element modeling process. The method to assess the mesh quality in this study was to evaluate the value of stress discontinuity between adjacent elements at critical locations. The stress variations at shared nodes of two adjacent elements at the critical joint were compared and the percentage differences were maintained below $1 \%$. 
Loads were applied in two steps, similar to the experiments; first, post-tensioning force and self-weight of the model, and subsequently the applied loads. Post-tensioning force was modeled as an initial strain in the link elements, after accounting for all prestress losses. The strands were unbonded throughout the length of the model, and held only at the two deviators and the two end blocks. In order to keep the eccentricity between the two deviators constant, the harping points on the strands were coupled together with the nodes on the corresponding concrete segments in the vertical direction. The self-weight of the model was simulated by defining the gravitational acceleration in the vertical direction. In the second step, the four-point loading was applied on the model at the intersection of the top flange and the web to avoid any unintended punching shear in the flange.

In all experiments, the two end blocks were seated directly on top of the solid concrete blocks. The constraints were not the perfect pin-roller supports as those used in the finite element model, and as such, the friction between the end block and the concrete support needed to be accounted for. Two parallel linear spring elements were placed at the roller supports in the direction of the bridge model to simulate the friction. The spring constant $\mathrm{K}$ was calibrated from one test for each type of strand and applied to all other tests for that same type of strand. The friction force between the end block and the concrete support at the factored load was assumed as the total applied load multiplied by the friction coefficient 0.6 (ACI Committee 318, 2014) between two concrete surfaces. A perfect pin-roller support FE model was first analyzed, and the joint opening at the critical joint of the FE model was compared with the joint opening data of from the experimental tests. The calculated friction force was divided by the difference of the joint 
opening between the FE model and the experimental results, and then divided by 2, since two parallel springs were used, to get the spring constant K. During the first set of experimental loading tests, limited concrete spalling and local damage was noted at the inner edge of the end blocks. The local damage effectively moved the pivot point of the end block towards the center of the support. This was accurately modeled by appropriately moving the placement of the constraints at the end block subsequent to the first experiment.

Figure 3.8 shows the deformed specimen and the joint opening between the segments for one of the tests, as predicted by the finite element model. Figure 3.9 shows a comparison of the load-displacements from the experiments and the FE model posttensioned with CFCC and EC6 strands at three different prestress levels. A close match is observed between the FE results and the experimental data, with a slight discrepancy in the initial stiffness and the curvature of the transition zone. Since only one bridge experimental model was constructed, and EC6 was the last type of tendon, after CFCC and steel strands, used for post-tensioning on the same bridge model, it is possible that some parts of the concrete were shipped off after several factored load tests, which may have affected the stiffness and general behavior of the experimental model slightly. This may explain why there was a better agreement for the FE model with the CFCC strands than for the EC6 strands.

\subsubsection{Parametric Study and Discussions}

To study the effect of elastic modulus and prestress level of post-tensioning strands on the performance of a segmental bridge, the above referenced FE model was used in a prefect pin-roller supports condition and a span length $10.2 \mathrm{~m}$ (33.4 ft). Five 
different elastic moduli were chosen as; $137 \mathrm{GPa}$ (19.8 Msi) based on the value recommended by ACI Committee 440 (2004) for CFCC, 154 GPa (22.3 Msi) as the value provided by the CFCC manufacturer, $170 \mathrm{GPa}$ (24.6 Msi) as an average value between the moduli of CFCC and EC6, 185 GPa (26.8 Msi) as the value provided by the EC6 manufacturer, and $200 \mathrm{GPa}$ (29 Msi) as the high end of elastic modulus for steel. Three initial prestress levels were chosen based on the maximum stress limits as; $1,427 \mathrm{MPa}$ (207 ksi), which is $90 \%$ of the yield strength of prestressing steel; and 1,200 and 1,572 MPa (174 and $228 \mathrm{ksi}$ ) which correspond to 65\% of the guaranteed strengths of EC6 and CFCC strands, respectively, as recommended by ACI Committee 440 (2004). The cross sectional area for the strands was kept constant for all parametric studies.

Figure 3.10 shows the effect of elastic moduli of strands on the displacement at the loaded joint, normalized with respect to the span length. Each of the three curves represents one level of prestress force kept the same for all different elastic moduli. It should be noted that prior to joint opening, the initial stiffness of the model remains essentially the same, irrespective of the prestress level or the elastic modulus of the strands. However, after the joint opening, the higher elastic modulus can significantly reduce the displacements. It is important to note that even though the prestress level does not directly affect the secondary stiffness, it does delay the decompression at the joint, hence effectively reduces the overall displacements of the bridge subsequent to the joint opening. This implies that a higher prestress level can compensate to some extent the lower elastic modulus of the strands, as long as the stress level does not exceed the maximum allowed by the code. 
Figure 3.11 shows a more direct representation of the effects of prestress level and elastic moduli of strands on the secondary stiffness of the bridge. A regression analysis was conducted to find the best fit linear load-displacement relationship after joint opening. The figure shows that in addition to the direct and apparent effect of elastic moduli of strands of the secondary stiffness, the prestress level is also a critical factor. This may be attributed to the fact that the moment of inertia of the section continues to decrease with the opening of the joint, which may be delayed or slowed with the higher prestress force.

The FE model has demonstrated the general implications of the stiffness-based design philosophy. As described by Yang et al. (2015a), the bridge model in the experimental phase of this study was post-tensioned with carbon fiber strands to develop the same nominal failure force as that of steel strands; as

$$
A_{p f} f_{p f}=A_{p s} f_{p s}
$$

where $A_{p f}$ and $A_{p s}=$ area of carbon fiber and steel strands, respectively, and $f_{p f}$ and $f_{p s}=$ nominal stress in carbon fiber and steel strands, respectively. This strengthbased design approach, however, leads to higher deformations and joint openings for segmental bridges with carbon fiber strands, as observed in the experiments of Yang et al. (2015a) and to some extent in this study. Therefore, it may be necessary to resort to a stiffness-based equivalency approach to make the two types of strands more comparable with each other, as

$$
A_{p f} E_{p f}=A_{p s} E_{p s}
$$


where $E_{p f}$ and $E_{p s}=$ elastic modulus of carbon fiber and steel strands, respectively. This stiffness-based design philosophy could, however, limit the stress level in carbon fiber strands to compensate for its lower elastic moduli, as

$$
f_{p f}=\frac{E_{p f}}{E_{p s}} f_{p s}
$$

For instance, the maximum allowable jacking stress level for steel is typically $80 \%$ of its ultimate strength. On the other hand, using the stiffness-based equivalency approach, a similar jacking stress level would translate to only $47 \%$ of the ultimate strength of CFCC, as compared with the 65\% limit imposed by the ACI Committee 440 (2004). It is important to note that the lower stress level does not imply lower capacity nor any safety concern. It is simply an equivalency-based approach to arrive at similar load-deflection performance as that of steel strands. The same approach for EC6 strands yields a jacking stress level of $74 \%$, which is more optimal but higher than that prescribed by the ACI Committee 440 (2004).

It should be noted that the ultimate strain of CFRP tendons at the time of crushing of concrete should be calculated as outlined by ACI Committee 440 (2004) for unbonded and external tendon systems. Furthermore, a strain reduction factor should be applied to evaluate the ultimate strain in the CFRP strands when concrete fails.

\subsection{Conclusions}

A 31/2:1 scaled model of the Long Key segmental box girder bridge was posttensioned using two types of CFRP strands and regular low-relaxation steel strands. The bridge model was tested at three different prestress levels and at different loading configurations. The most important distinction between the two types of carbon fiber strands is their elastic moduli, which for EC6 is about 93\% of that of steel, while for 
CFCC is only $77 \%$ of that of steel. A finite element model of the same scaled segmental bridge model was developed and calibrated against the experimental data. A parametric study was also carried out to investigate the effect of the elastic modulus of carbon fiber strands on the performance of post-tensioned segmental bridge. The following conclusions may be drawn from this comparative study:

- From the perspectives of constructability and short-term performance, both types of carbon fibers may be used in post-tensioned segmental bridge applications. Some construction details for carbon fiber strands, especially their prefabricated anchorage, are quite different from the steel post-tensioning system.

- The segmental bridge model shows a bilinear response irrespective of the type of strand, whether carbon or steel. While the initial stiffness is generally the same for all three types of strands, the secondary stiffness after decompression and joint opening is considerably higher for EC6 and steel strands, in comparison with CFCC strands.

- Whether steel or carbon fiber strands, higher prestress levels can delay joint openings and reduce overall deflections in the segmental bridge model after joint opening.

- Given the higher flexibility of segmental bridges post-tensioned with carbon fibers, the designer may opt for a stiffness-based equivalency approach. Such an approach, however, may limit the stress level in CFCC to approximately $47 \%$ of its ultimate strength, as compared with the $65 \%$ limit imposed by the strengthbased design in the ACI Committee 440 (2004). This may require more CFCC strands with lower prestress levels to achieve the same behavior as that of steel 
strands. The maximum allowable jacking stress level for steel is typically $80 \%$ of its ultimate strength, while using the same approach for EC6 strands yields a jacking stress level of 74\%, much more optimal and closer to that of steel.

Although not studied in this paper, it is understood that the costs of carbon fiber strands and their anchorage systems are much higher than prestressing system using steel strands. On the other hand, non-corrosive nature of carbon fiber strands can significantly reduce long-term costs of repair and maintenance. Further research is needed for the long-term performance, durability and creep stress rupture behavior of carbon fiber strands for future field applications.

\section{Acknowledgements}

This study was sponsored by the Florida Department of Transportation under the supervision of Mr. William Potter as Project Manager. The support of Titan America for providing the concrete, C\&C Concrete Pumping for providing the concrete pumping, Mo Steel Fabricator \& Erector for the steel frame fabrication, Mr. Emilio R. Vega, the President and CEO of Structural Prestressed Industries, Inc. for providing steel strands and steel chucks, and Composite Rigging Southern Spars for providing the EC6 strands are gratefully acknowledged. All experiments were conducted at the Titan America Structures and Construction Testing Laboratory of the Florida International University. The views and findings reported here are those of the writers alone, and not necessarily the views of sponsoring agencies.

\section{Notation}

The following symbols are used in this paper:

$A_{p f}=$ area of carbon fiber tendons; 
$A_{p s}=$ area of steel strands

$E_{p f}=$ elastic modulus of carbon fiber

$E_{p s}=$ elastic modulus of steel

$f_{p f}=$ nominal stress in carbon fiber tendons

$f_{p s}=$ nominal stress in steel strands 
References

AASHTO (1973). Standard Specifications for Highway Bridge. $13^{\text {th }}$ Edition, American Association of State Highway and Transportation Officials, Washington, DC.

ACI Committee 318. (2014). Building Code Requirement for Structural Concrete and Commentary. ACI 318-14, American Concrete Institute, Farmington Hills, MI.

ACI Committee 440. (2004). Prestressing Concrete Structures with FRP Tendons. ACI 440.4R-04, American Concrete Institute, Farmington Hills, MI.

ANSYS. (2013). Release 15.0 User Manual, ANSYS, Canonsburg, PA.

Grace, N.F., Bebawy, M., and Ushijima, K. (2014). "Field Application of Composite Post-Tensioning System.” Concrete International, ACI, 36(11), 39-42.

Grace, N.F., Navarre, F.C, Nacey, R.B., Bonus, W., and Collavino, L. (2002). "DesignConstruction of Bridge Street Bridge-First CFRP Bridge in the United States." PCI Journal, 47(5), 20-35.

Megally, S., Seible, F., and Dowell, R.K. (2003a). "Seismic Performance of Precast Segmental Bridges: Segment-to-segment Joints Subjected to High Flexural Moments and Low Shears.” PCI Journal, 48(2), 80-96.

Megally, S., Seible, F., and Dowell, R.K. (2003b). "Seismic Performance of Precast Segmental Bridges: Segment-to-segment Joints Subjected to High Flexural Moments and High Shears.” PCI Journal, 48(3), 72-90.

Megally, S., Seible, F., Garg, M., and Dowell, R.K. (2002). "Seismic Performance of Precast Segmental Bridge Superstructures with Internally Bonded Prestressing Tendons.” PCI Journal, 47(2), 40-56.

Rohleder, W.J., Tang, B., Doe, T.A., Grace, N.F., and Burgess, C.J. (2008). “Carbon Fiber-Reinforced Polymer Strand Application on Cable-Stayed Bridge, Penobscot Narrows, Maine.” Journal of Transportation Research Board, 2050, 169-176.

Yang, X., Zohrevand, P., Mirmiran, A., Arockiasamy, M., and William, P. (2015a). "Post Tensioning of Segmental Bridges using Carbon Fiber Composite Cables.” PCI Journal, 60(3), 50-62.

Yang, X., Zohrevand, P., Mirmiran, A., Arockiasamy, M., and William, P. (2015b). “A Comparative Study of Unbonded Carbon Fiber and Steel Strands in Posttensioned Pier Caps.” Journal of Composites for Construction, hard copy in press. DOI: 10.1061/ (ASCE) CC.1943-5614.0000596. 
Table 3.1 Comparison of Material Properties and Anchorage of EC6, CFCC, and Steel Strands

\begin{tabular}{lccc}
\hline Tendon Type & EC6 & CFCC & Steel $^{*}$ \\
\hline Nominal Diameter, mm (in.) & $12.3(0.484)$ & $12.5(0.492)$ & $12.7(0.5)$ \\
\hline Effective Area**, mm² (in $\left.{ }^{2}\right)$ & $96(0.1488)$ & $76(0.118)$ & $99(0.153)$ \\
\hline Guaranteed Strength, MPa (ksi) & $1,848(268)$ & $2,421(351)$ & $1,862(270)$ \\
\hline Guaranteed Capacity, kN (kip) & $177(39.7)$ & $184(41.4)$ & $184(41.3)$ \\
\hline Elastic Modulus, GPa (msi) & $185(26.8)$ & $154(22.3)$ & $200(29.0)$ \\
\hline Mass Density, g/m (lb/ft) & $553(0.37)$ & $145(0.10)$ & $781(0.53)$ \\
\hline Anchorage Device Length, mm (in.) & $108(4.3)$ & $330(13)$ & $92(3.6)$
\end{tabular}

* Steel strands were seven-wire low-relaxation.

** The effective areas for EC6 and CFCC are determined by the volume of carbon fiber and resin. 
Table 3.2 Summary of Test Results at Service Loads

\begin{tabular}{|c|c|c|c|c|c|c|c|c|}
\hline \multirow[b]{2}{*}{ Material } & \multirow{2}{*}{$\begin{array}{c}\text { Effective } \\
\text { Prestress Force } \\
\text { on Each Tendon, } \\
\text { kN (kip) }\end{array}$} & \multirow{2}{*}{$\begin{array}{l}\text { Effective } \\
\text { Prestress } \\
\text { Level }\end{array}$} & \multicolumn{2}{|c|}{ Service Load Position 1} & \multicolumn{2}{|c|}{ Service Load Position 2} & \multicolumn{2}{|c|}{ Service Load Position 3} \\
\hline & & & $\begin{array}{l}\text { Displaceme } \\
\text { nt, mm (in.) }\end{array}$ & $\begin{array}{c}\text { Joint } \\
\text { Opening, } \\
\text { mm (in.) } \\
\end{array}$ & $\begin{array}{l}\text { Displaceme } \\
\text { nt, mm (in.) }\end{array}$ & $\begin{array}{c}\text { Joint } \\
\text { Opening, } \\
\text { mm (in.) } \\
\end{array}$ & $\begin{array}{l}\text { Displaceme } \\
\text { nt, mm (in.) }\end{array}$ & $\begin{array}{c}\text { Joint } \\
\text { Opening, } \\
\text { mm (in.) } \\
\end{array}$ \\
\hline \multirow{4}{*}{ EC6 } & $116.1(26.1)$ & $65 \%$ & $13.4(0.528)$ & $0.6(0.024)$ & $12.2(0.480)$ & $0.3(0.013)$ & $1.8(0.071)$ & $0.1(0.002)$ \\
\hline & $120.5(27.1)$ & $68 \%$ & $13.1(0.514)$ & $0.6(0.023)$ & - & - & - & - \\
\hline & 123.7 (27.8) & $70 \%$ & $13.9(0.547)$ & $0.5(0.019)$ & $11.7(0.459)$ & $0.2(0.009)$ & $0.4(0.018)$ & $0.0(0.001)$ \\
\hline & $129.9(29.2)$ & $74 \%$ & $12.1(0.476)$ & $0.3(0.011)$ & $12.8(0.503)$ & $0.2(0.007)$ & $0.3(0.012)$ & $0.0(0.001)$ \\
\hline \multirow{3}{*}{ CFCC } & 113.9 (25.6) & $62 \%$ & $12.3(0.484)$ & $0.4(0.015)$ & $14.6(0.575)$ & $0.5(0.019)$ & 1.7 (0.065) & $0.1(0.003)$ \\
\hline & $120.5(27.1)$ & $65 \%$ & $10.4(0.408)$ & $0.4(0.015)$ & - & - & - & - \\
\hline & $129.9(29.2)$ & $70 \%$ & $11.2(0.441)$ & $0.2(0.008)$ & $12.2(0.480)$ & $0.2(0.008)$ & $0.4(0.017)$ & $0.1(0.002)$ \\
\hline \multirow{4}{*}{ Steel } & $116.1(26.1)$ & $63 \%$ & $17.6(0.694)$ & $1.2(0.047)$ & $14.4(0.565)$ & $0.5(0.019)$ & $0.5(0.018)$ & $0.1(0.002)$ \\
\hline & $121.0(27.2)$ & $66 \%$ & $12.9(0.509)$ & $0.7(0.026)$ & - & - & - & - \\
\hline & $124.1(27.9)$ & $68 \%$ & $11.6(0.457)$ & $0.5(0.020)$ & $10.0(0.392)$ & $0.2(0.009)$ & $1.4(0.057)$ & $0.1(0.002)$ \\
\hline & $129.9(29.2)$ & $71 \%$ & $10.7(0.421)$ & $0.4(0.014)$ & $12.3(0.483)$ & $0.2(0.009)$ & $0.8(0.030)$ & $0.1(0.002)$ \\
\hline
\end{tabular}




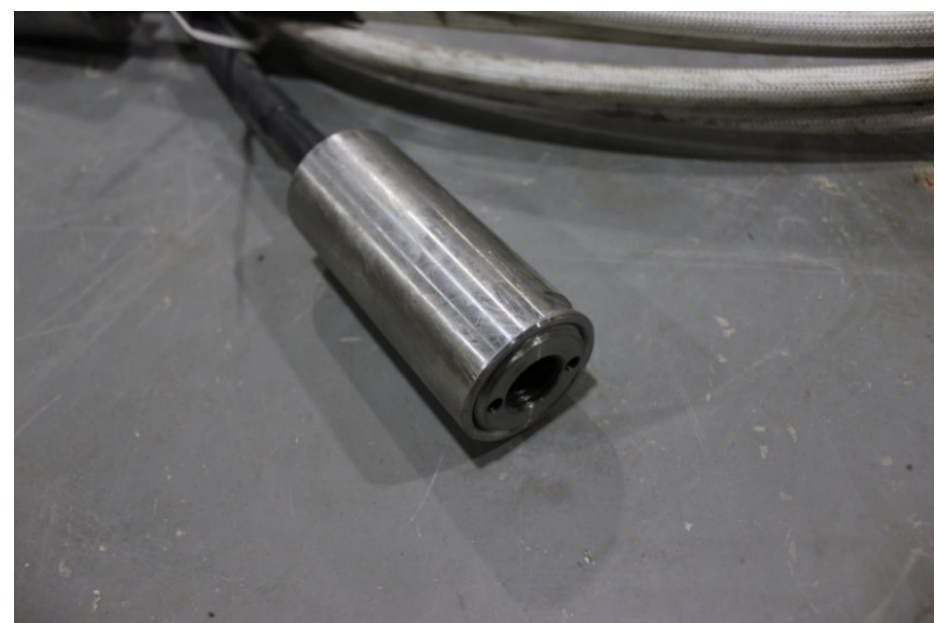

(a)

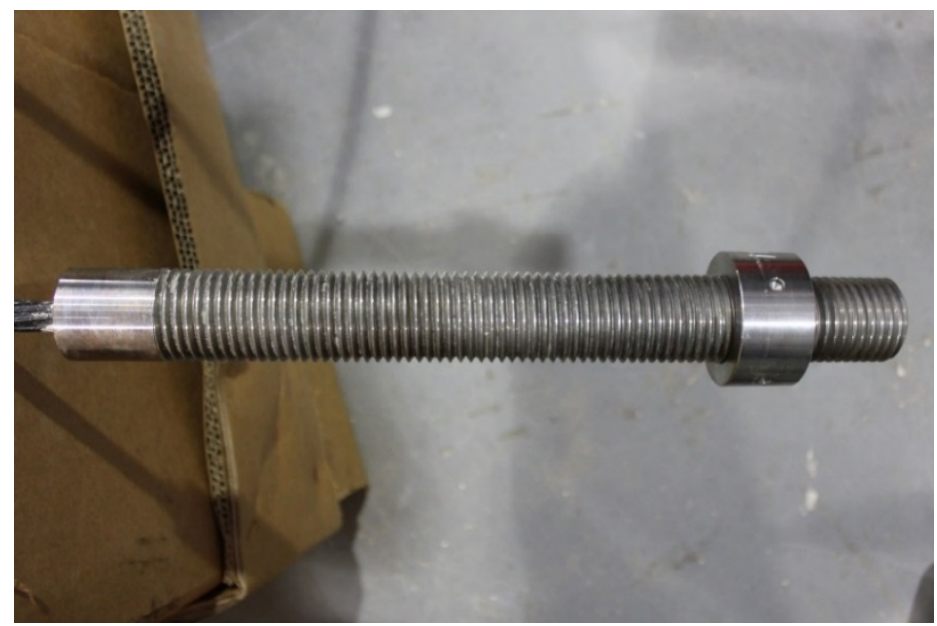

(b)

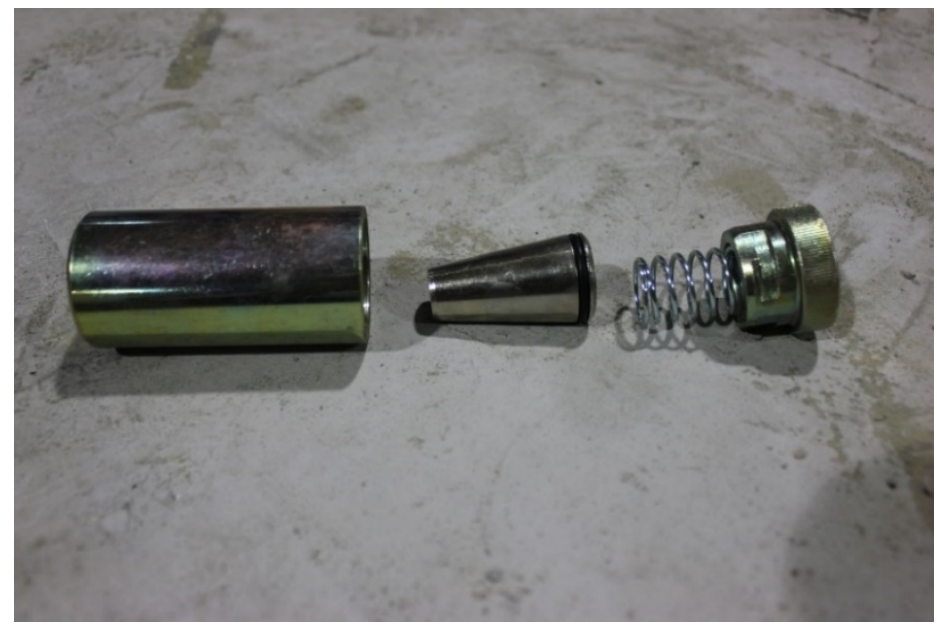

(c)

Figure 3.1 Anchorage for Three Types of Strands: (a) EC6, (b) CFCC, and (c) Steel 

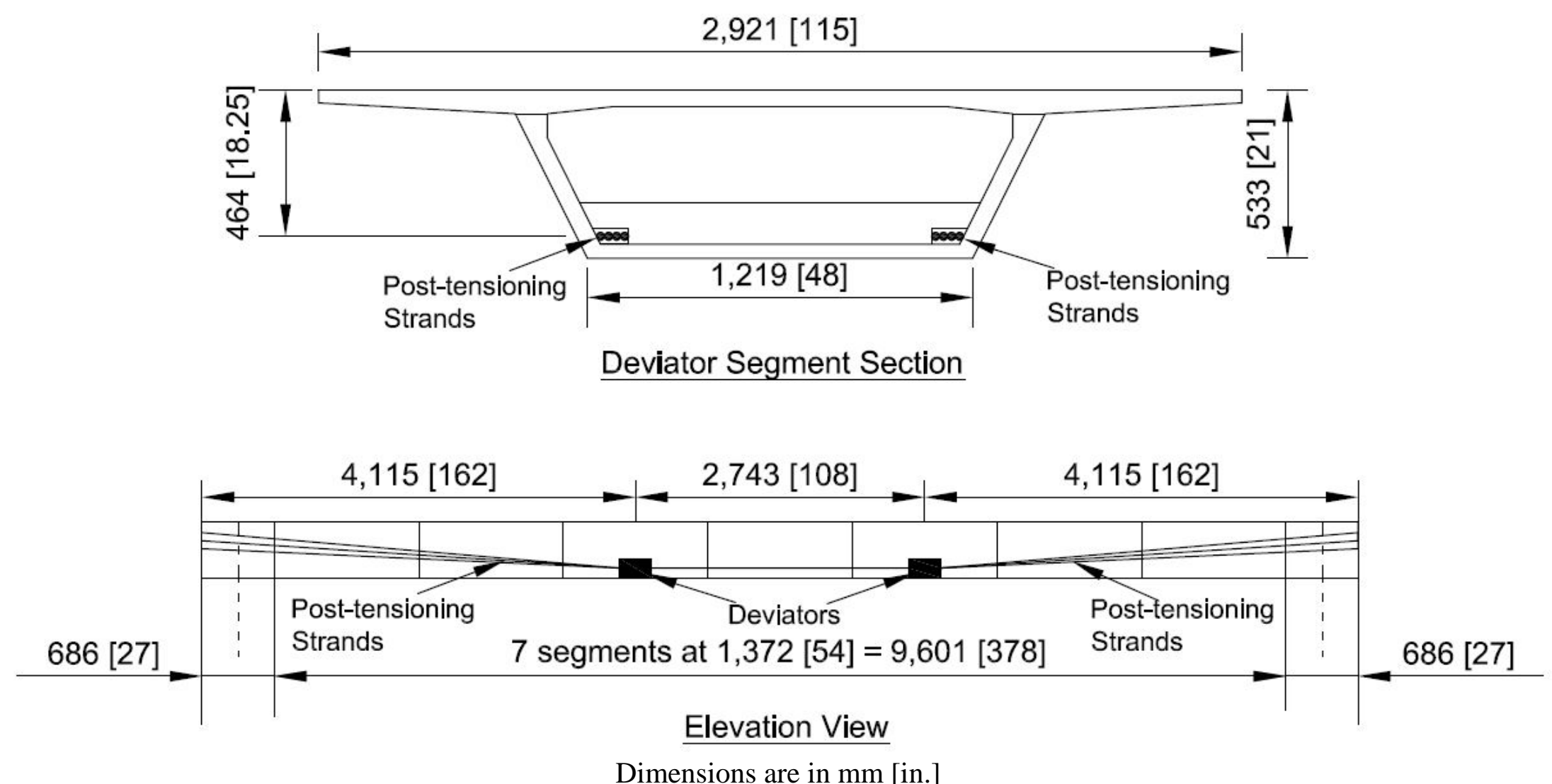

Figure 3.2 Segmental Bridge Test Model 


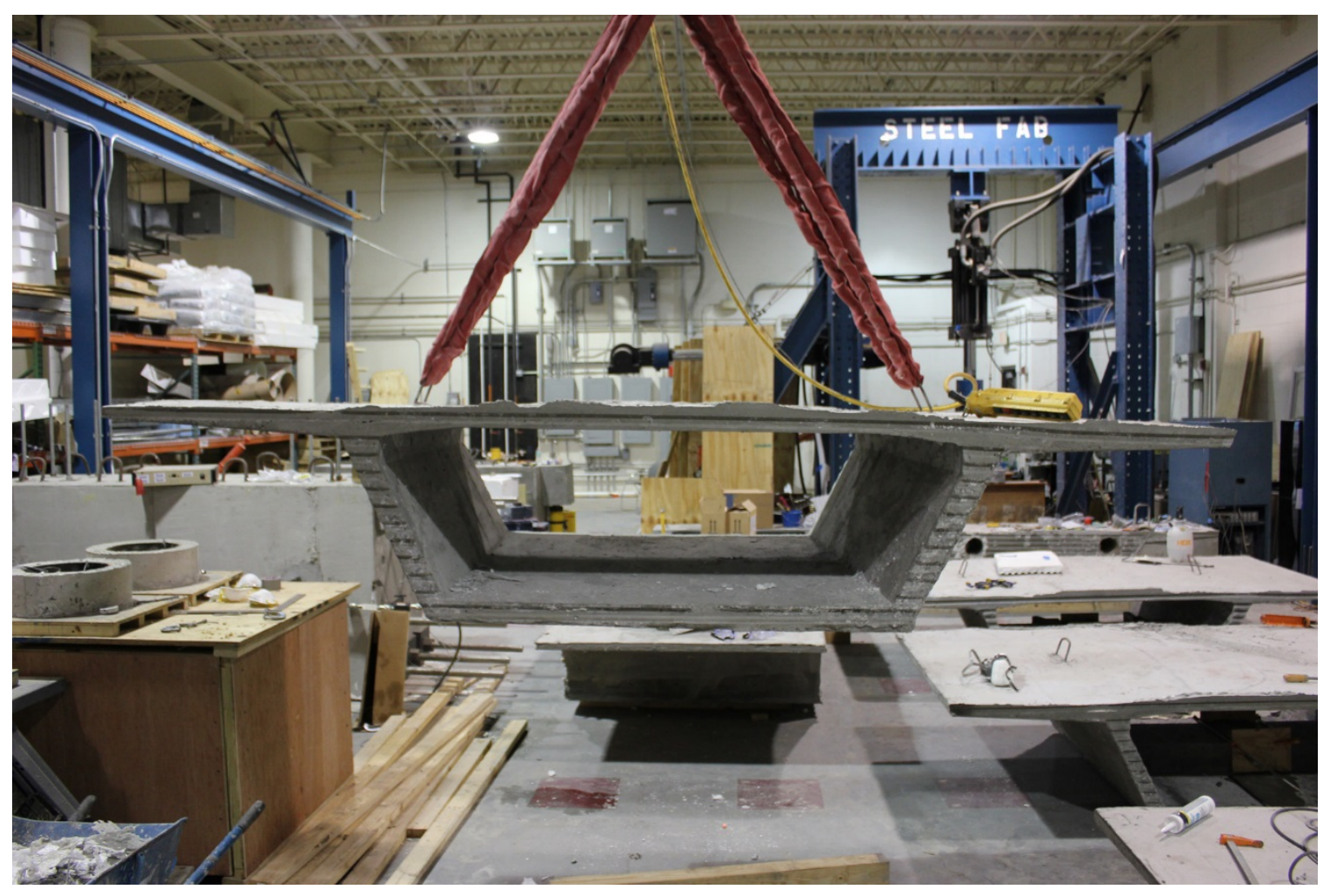

(a)

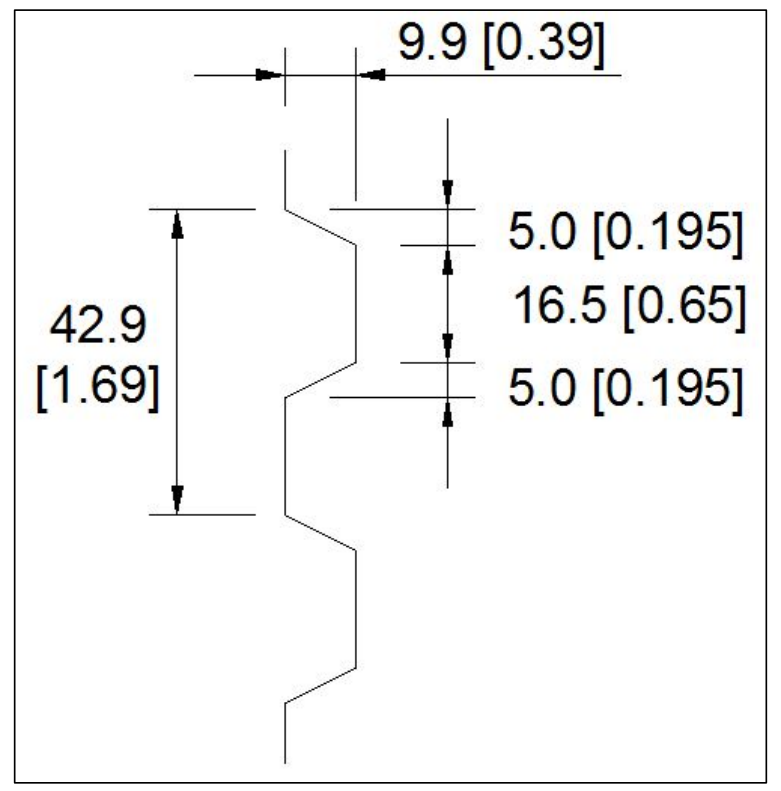

(b)

Dimensions are in mm [in.]

Figure 3.3. Details of Shear Keys: (a) Shear Keys on the Test Specimen, and (b) Dimension of the Shear Key 


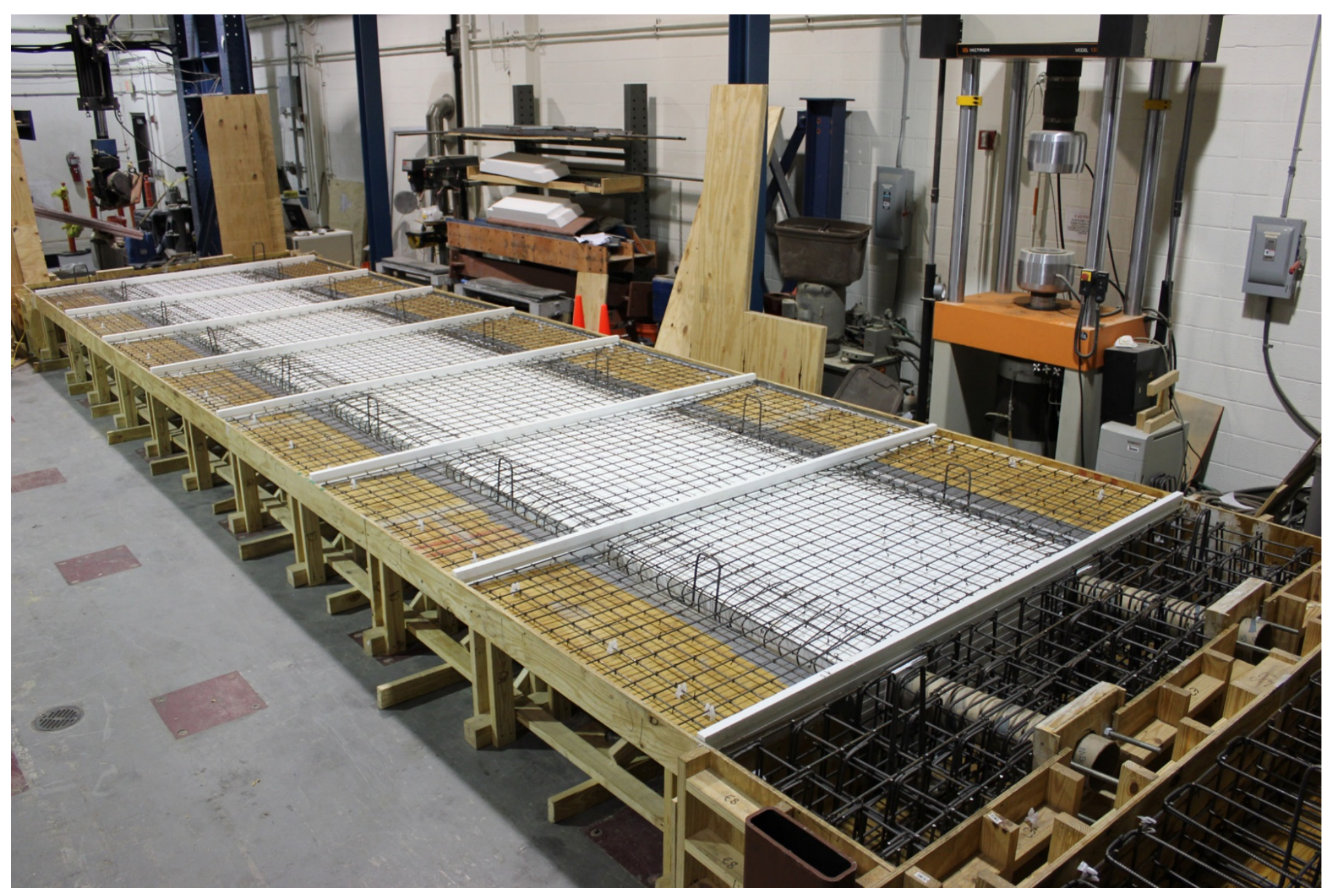

Figure 3.4 Formwork 


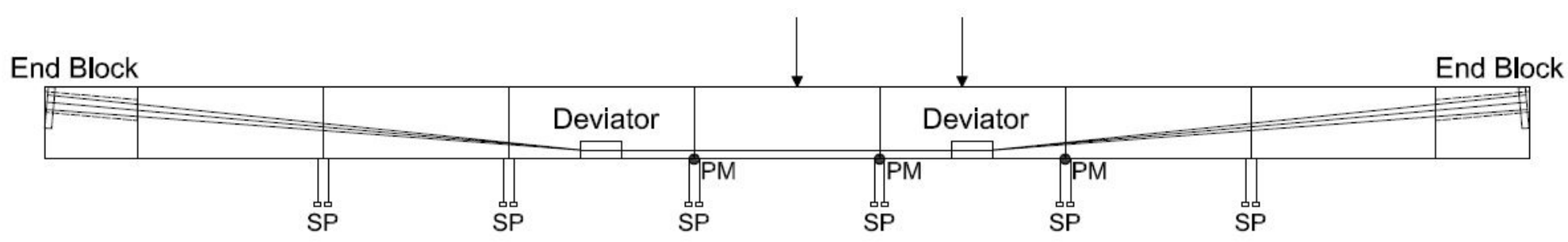

Service Load Position 1 \& Ultimate Load Position

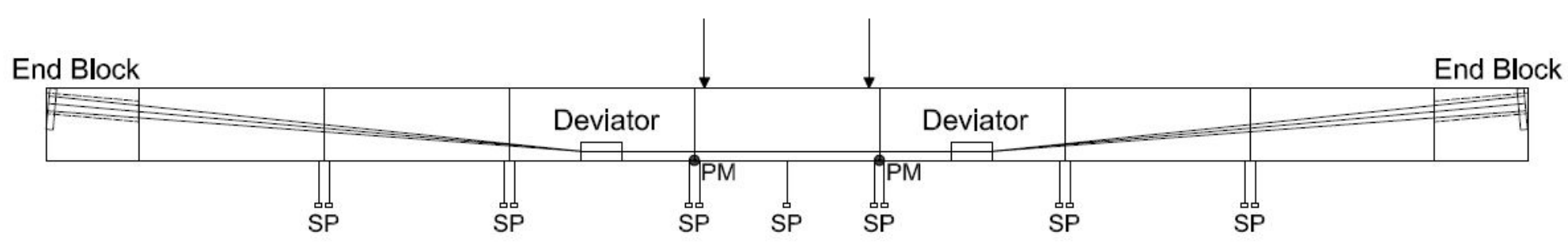

Service Load Position 2

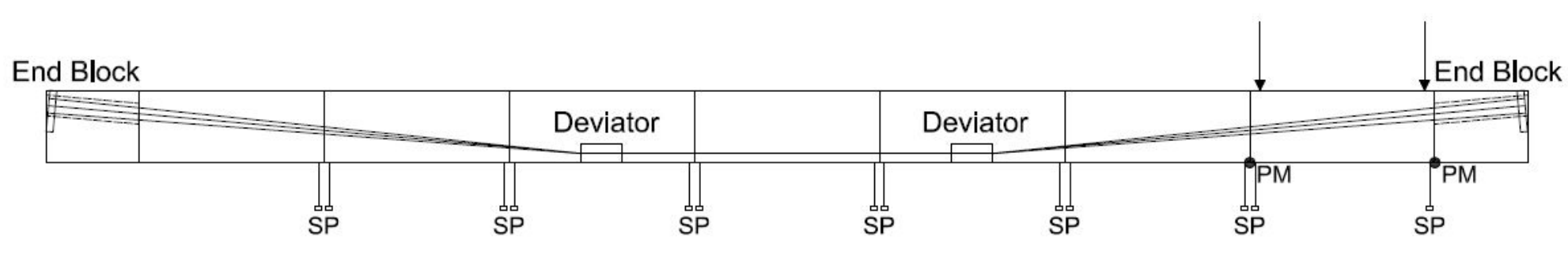

Service Load Position 3

PM - Potentiometer, SP - String Pot

Figure 3.5 Loading Positions 


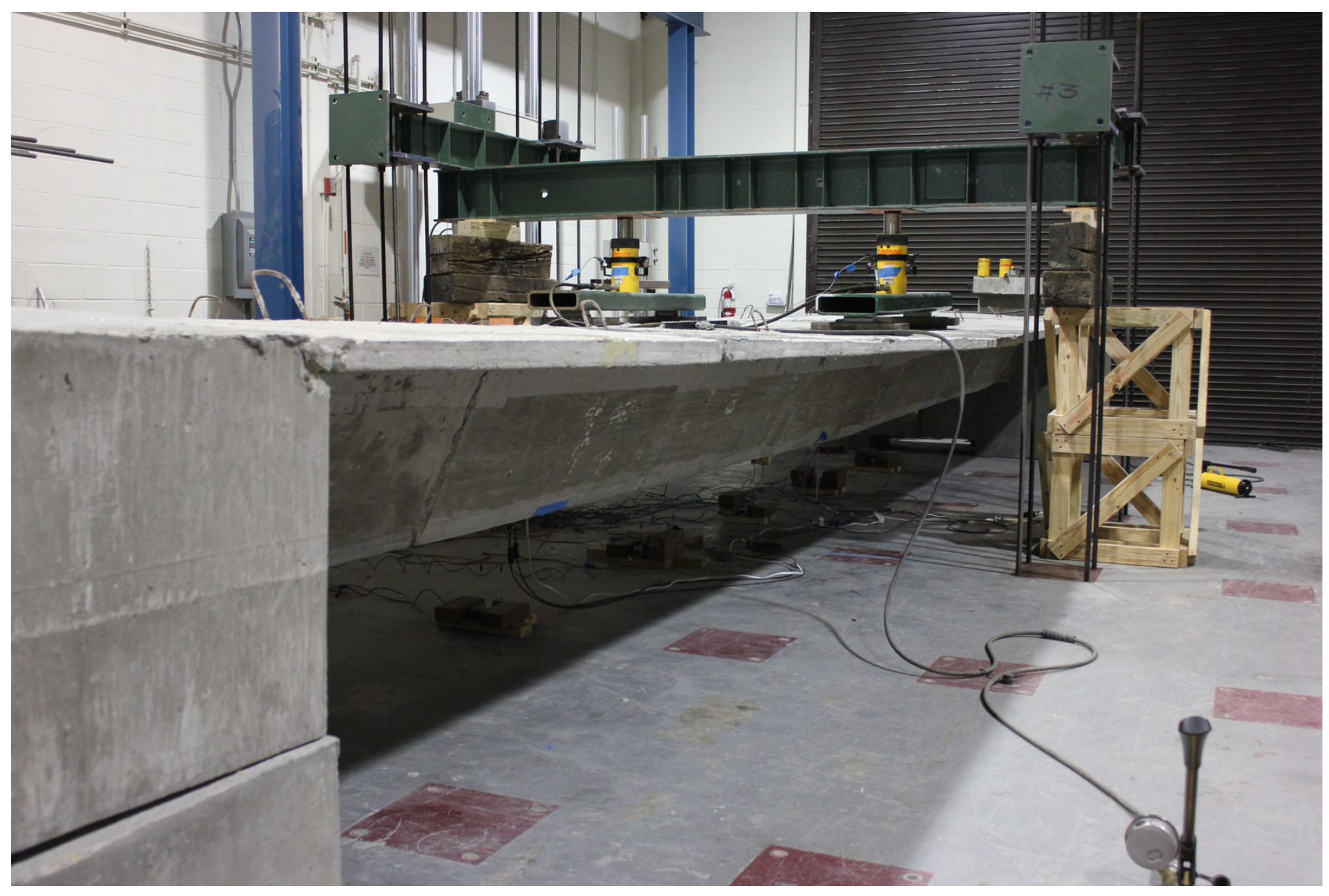

Figure 3.6 Test Setup 


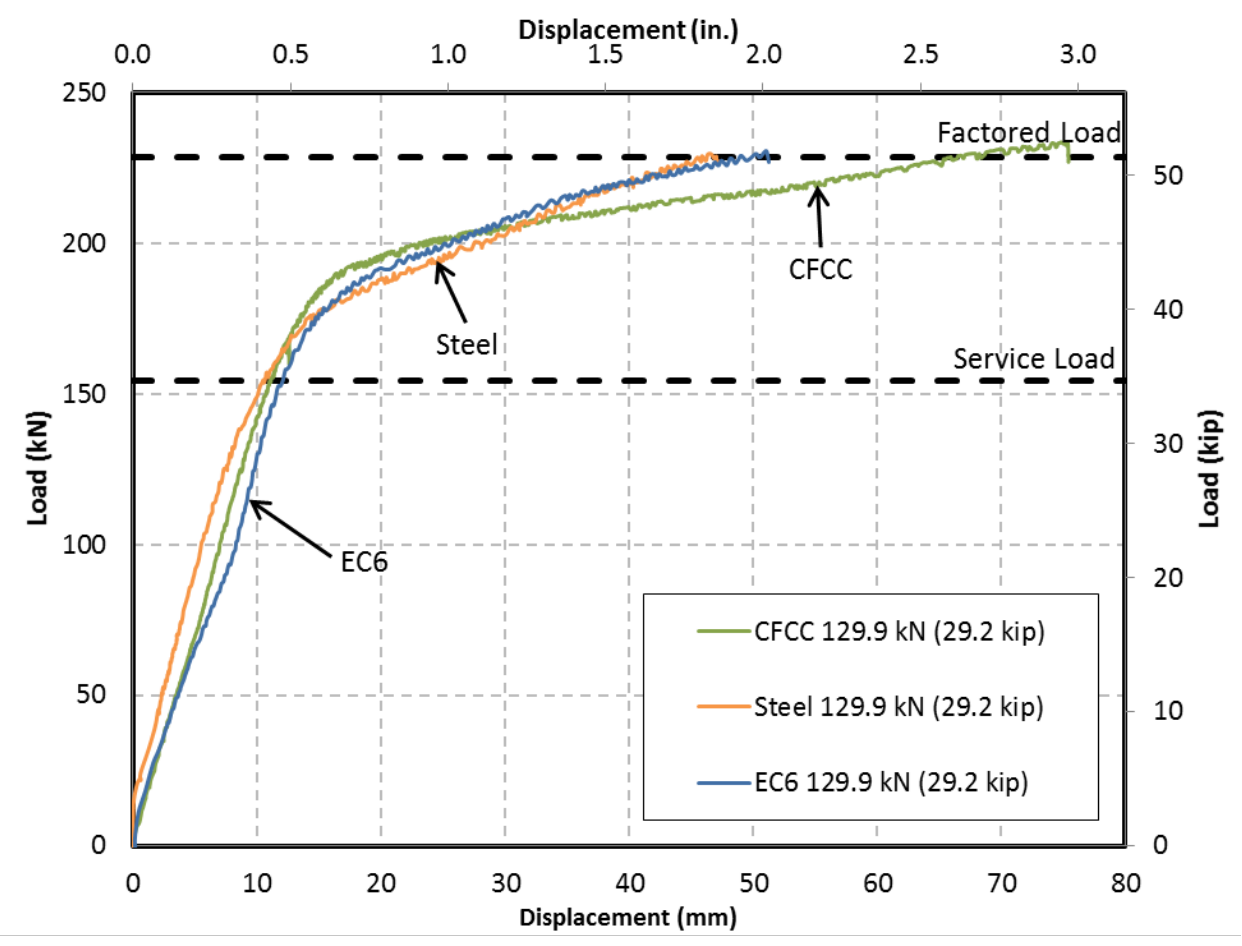

(a)

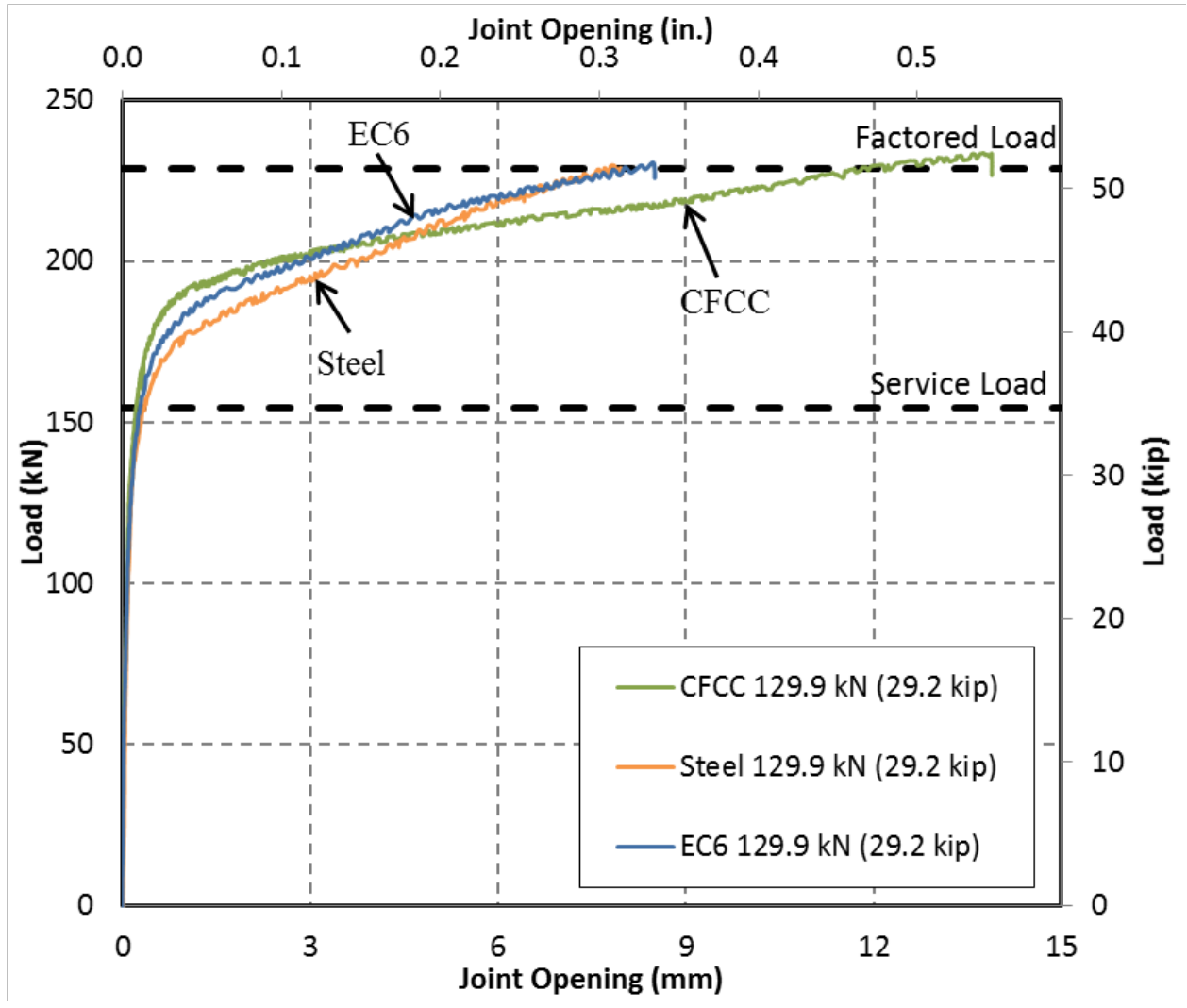

(b) 


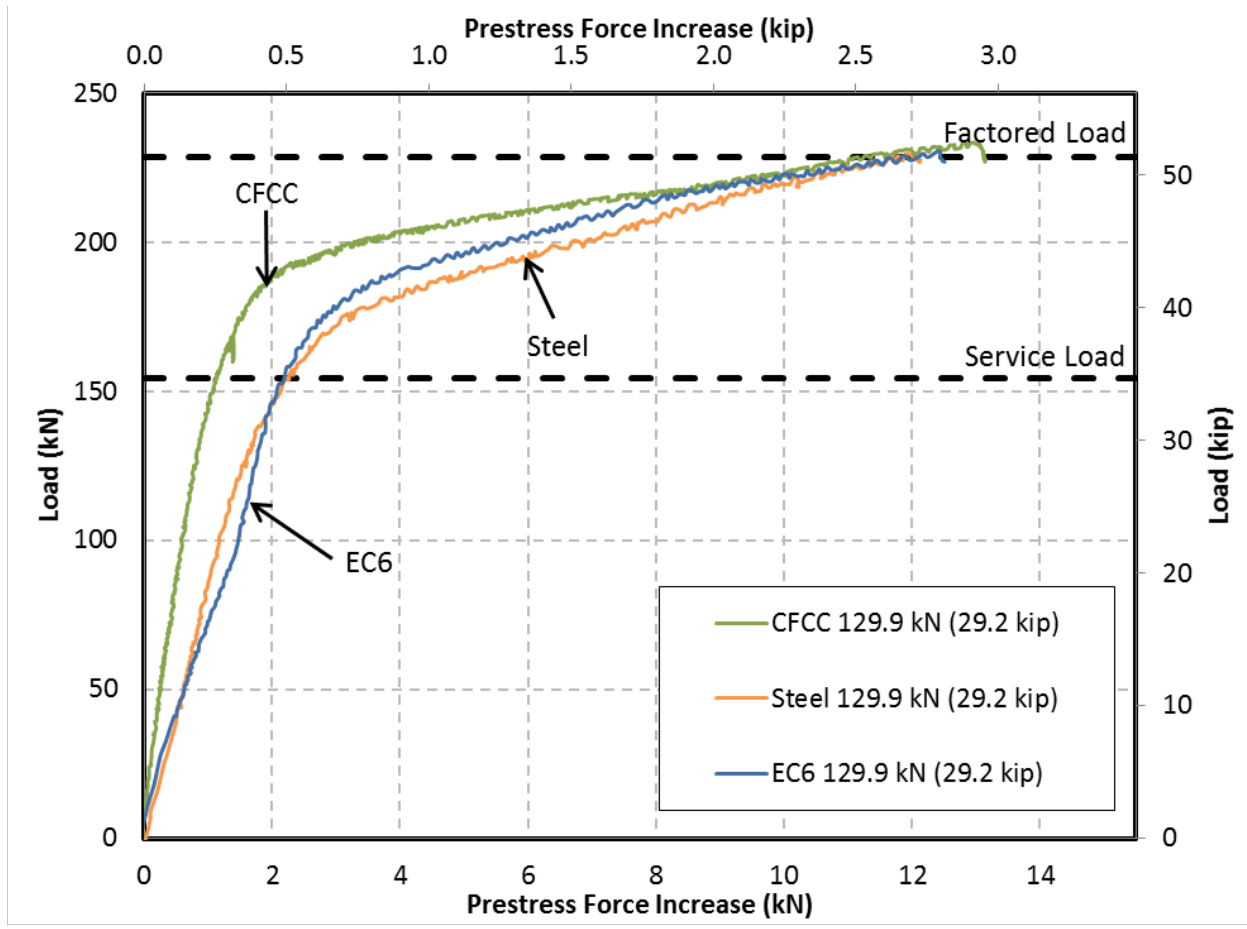

(c)

Figure 3.7 Performance Comparisons between Three Types of Strands at 129.9 kN (29.2 kip): (a) Load - Displacement, (b) Load - Joint Opening, and (c) Load - Prestress Force Increase 


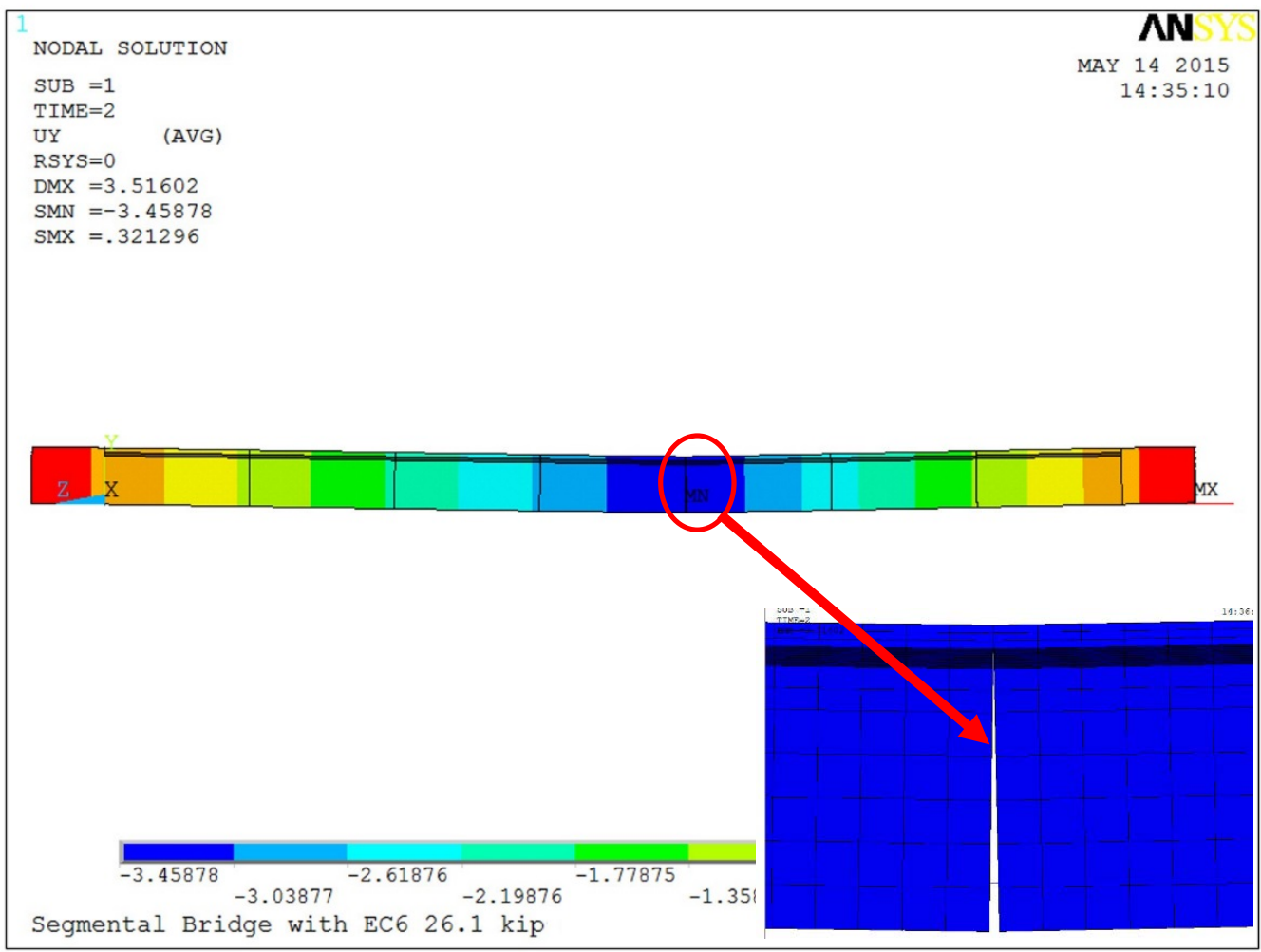

Figure 3.8 Deformed Shape with Joint Opening of the Finite Element Model 


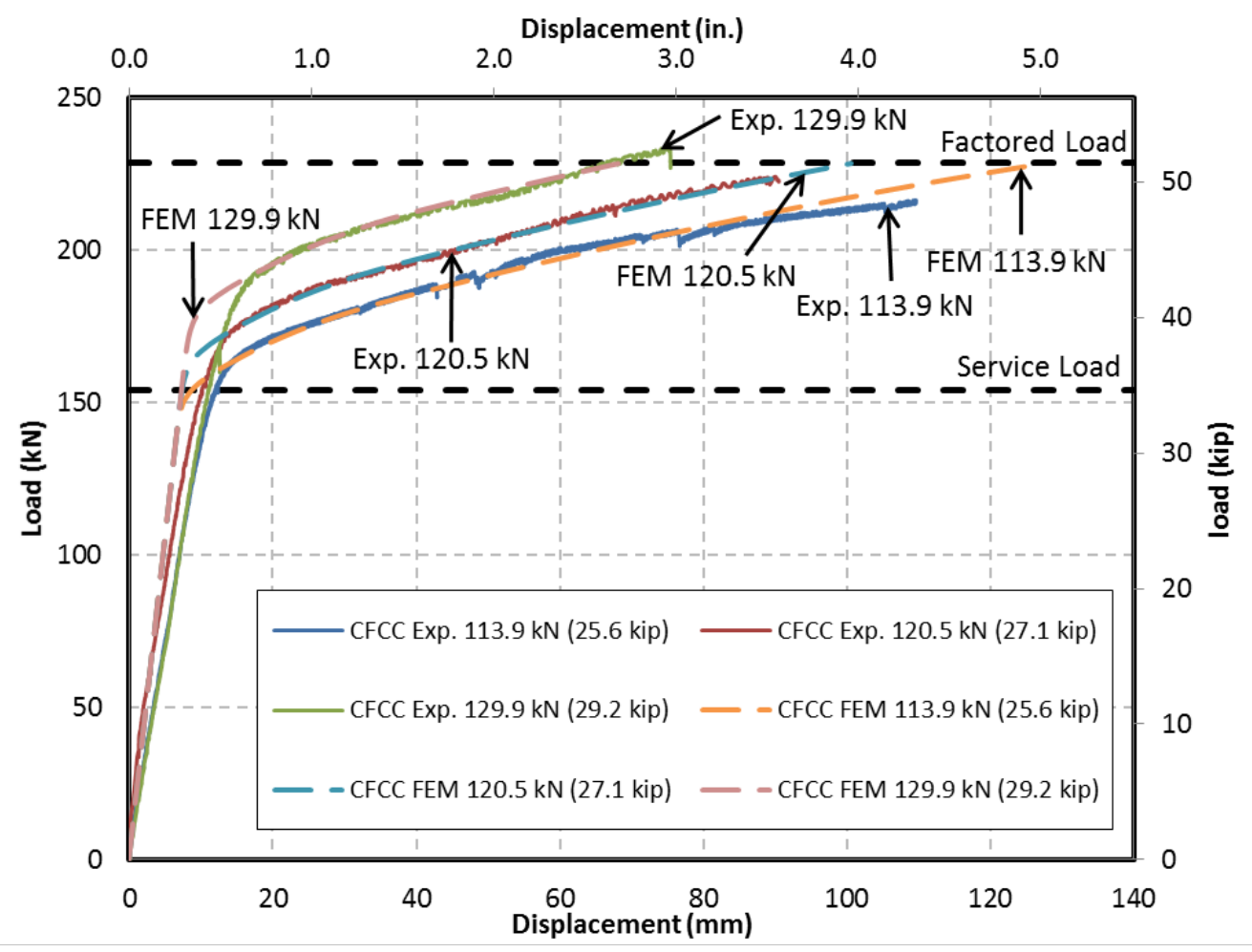

(a)

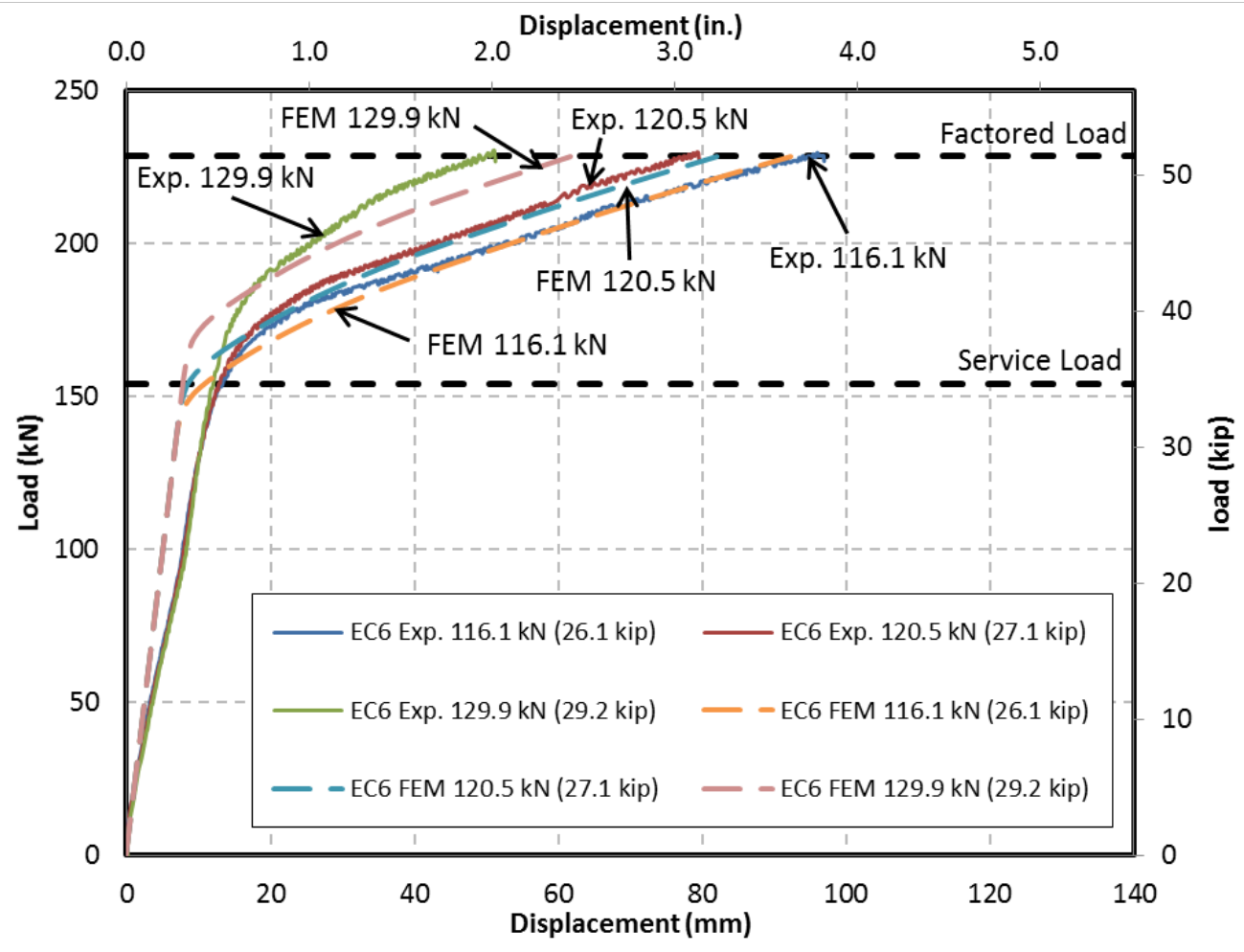

(b)

Figure 3.9 Load - Displacement Comparisons between Finite Element Model and Experimental Data: (a) CFCC, and (b) EC6 


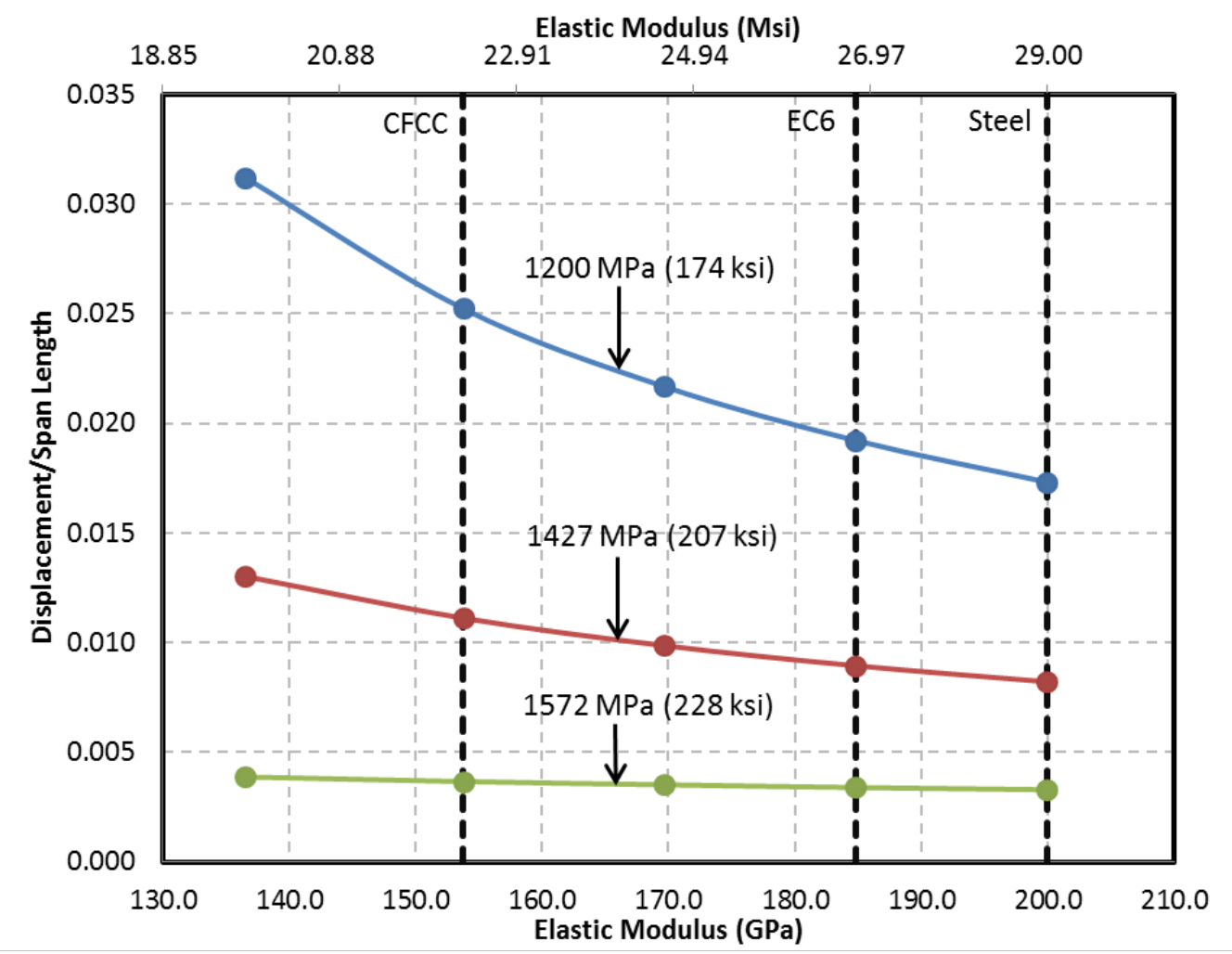

Figure 3.10 Displacement at Factored Load/Span Length - Elastic Modulus for Three Stress Levels 


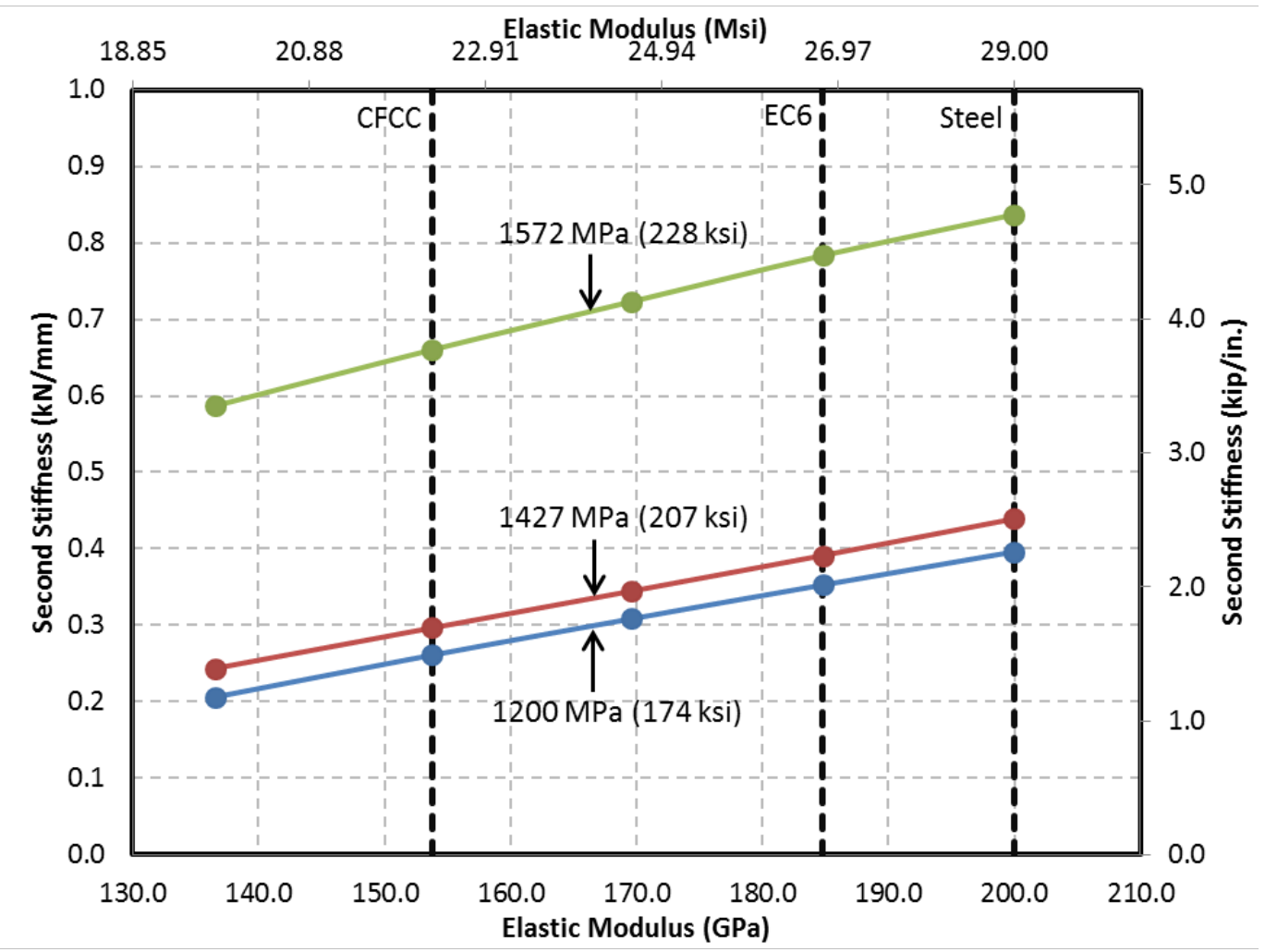

Figure 3.11 Stiffness after joint Opening - Elastic Modulus for Three Stress Levels 


\title{
4. A COMPARATIVE STUDY OF UN-BONDED CARBON FIBER AND STEEL STRANDS IN POST-TENSIONED PIER CAPS
}

\begin{abstract}
Carbon fiber strands offer a viable alternative to corrosion-prone steel strands in post-tensioning applications. This study focused on a side by side comparison of two types of carbon fiber strands with different elastic moduli against steel strands in a 51/2:1 scaled model of a typical interior hammerhead pier of San Antonio downtown "Y" project with two identical cantilever overhangs. Two different strand arrangements were used for post-tensioning, with eight and six strands, respectively representing an overdesign and a slight under-design relative to the factored demand. The model was tested under service and factored flexure and shear loads. The study confirmed the feasibility of using carbon fiber strands in un-bonded post-tensioning of pier caps. Given the strengthbased design of the pier cap, the elastic moduli of different carbon fiber strands did not seem to have affected the serviceability performance with respect to either cracking or deflection. Considering both serviceability and overload conditions, the general performance of the pier cap model under both flexure and shear loading was deemed acceptable using either type of carbon fiber strands, and quite comparable to that of steel strands.
\end{abstract}

\section{Keywords:}

Bridges; Carbon fiber strands; Hammerhead piers; Pier cap; Prestressed concrete; and Unbonded posttensioning. 


\subsection{Introduction}

Post tensioning (PT) is an effective technique for accelerated bridge construction, reducing on-site construction time and labor. Despite detailed specifications on protection of steel strands, their susceptibility to corrosion remains a major concern for PT applications. Therefore, while research continues to find better means to protect steel strands against corrosion, a parallel effort is underway to develop suitable non-corrosive alternatives. One such alternative is non-metallic strands made of fiber reinforced polymers (FRP). In addition to their superior durability, FRP strands may result in lower relaxation losses as compared to steel (Dolan et al. 2001). FRP strands may be made with different types of fibers, e.g., carbon, glass, aramid, or basalt. Carbon FRP (CFRP) offers the most practical option, given its higher strength and elastic modulus as well as its excellent durability and fatigue strength. Carbon fibers are either PAN-based, made of poly-acrylonitrile materials; or pitch-based, a by-product of petroleum refining or coal coking.

There are a number of commercially available CFRP strands, including carbon fiber composite cables (CFCC) made by Tokyo Rope and CFRP Leadline made by Mitsubishi Kaesei Corp., both of Japan, Jitec by Cousin Composite of France, Bri-Ten by British Ropes of the United Kingdom, and more recently, EC6 by Composite Rigging Southern Spars of North Kingstown, Rhode Island.

CFCC is made using PAN-based carbon fibers supplied by Toray, through a roving prepreg process for individual wires that are then twisted and wrapped with a synthetic protective yarn, before bundling them into one (i.e., a single rod), seven, 19, or

37 twisted wires. Figure 4.1 shows the CFCC strand and its anchorage sleeve. CFCC is 
available in diameters from 5 to $40 \mathrm{~mm}$ ( 0.2 to 1.6 in.) and can be shipped in coils for any length up to $1,170 \mathrm{~m}$ (1,280 yd). Recently, Roddenberry et al. (2014) investigated the bonded pre-tensioned application of CFCC in prestressed concrete piles in Florida. Other studies have assessed the structural behavior of concrete beams post-tensioned with unbonded CFCC (Grace et al. 2003, 2008, and 2011). Field applications of un-bonded CFCC strands have also been effectively demonstrated (Grace et al. 2002 and 2014).

EC6 cable has been used in rigging systems of yachts, and is now made available for bridge construction. It is fabricated from a bundle of small diameter pultruded rods made from Toray's T800 intermediate modulus fibers. Figure 4.2 shows the EC6 strand and its anchorage sleeve. EC6 is available in diameters from 4 to $82 \mathrm{~mm}$ (0.2 to $3.2 \mathrm{in}$.) and can also be shipped in coils, similar to CFCC. Table 4.1 compares the material properties of a $12.7 \mathrm{~mm}(1 / 2 \mathrm{in}$.) diameter steel strand with CFCC and EC6 strands of comparable sizes. While the strength of CFCC strand is about $30 \%$ higher than that of steel, its elastic modulus is about $23 \%$ lower as compared to steel. On the other hand, properties of EC6 strand are much closer to those of steel strand.

The regular chuck anchoring devices for steel strands cannot be applied directly to carbon fiber strands, because of the brittleness of carbon under transverse gripping pressure. Therefore, both CFCC and EC6 strands are shipped with pre-fabricated special end anchorages, which is essentially a metallic sleeve filled with either a resin or an expansive grout. The sleeve has inside threads to facilitate the post-tensioning process using a threaded steel rod, and outside threads to help lock the prestressing force using a circular nut. The length of sleeve for EC6 is about one third of that of CFCC and very close to the length of multiuse chucks for steel strands. 
In the last few years, Florida Department of Transportation has commissioned several studies into the potential use of CFRP as a viable alternative to steel strands for prestressing applications. It has also developed a set of guidelines for FRP applications (FDOT 2015). ElSafty et al. (2014) studied degradation of internal FRP reinforcement, including CFCC strands; Roddenberry et al. (2014) focused on bonded pre-tensioning applications; whereas the writers were tasked with un-bonded post-tensioning applications, including segmental bridges and pier caps. The objective of this study was to develop a realistic pier cap test bed for assessing its constructability and structural behavior, when post-tensioned with different types of carbon fiber strands in a side by side comparison with steel strands.

To date, several studies have focused on pier caps with bonded or unbonded PT strands. The University of Texas at Austin carried out a series of experiments in the mid1990s to investigate the structural behavior, constructability and economics of combining prestressed and non-prestressed reinforcement with different design philosophies based on AASHTO (1989 and 1992). Armstrong (1994) and Pereira (1994) tested seven cantilever hammerhead pier cap specimens with the same dimensions but with different reinforcing patterns including one specimen designed as a reinforced concrete pier cap and six specimens designed as prestressed concrete specimens with different design philosophies and details. Each specimen had two overhangs, providing repeatability for the experiments. The study led to an improved design method as well as means to predict crack widths for post-tensioned pier caps. These studies were followed, and their models were confirmed, by Billington (1994) who tested four two-span continuous pier caps to 
failure, one of which was reinforced concrete, while the other three were designed as prestressed concrete.

Despite a number of studies on prestressing applications of CFCC or Leadline strands, there are still some gaps in our knowledge of their effectiveness as a sole PT mechanism in a bridge element, particularly a pier cap. Moreover, the effects of higher modulus carbon fiber strands such as EC6 have not been investigated. The present study aimed at addressing these issues. It modeled as its prototype a typical interior hammerhead cantilever pier cap of the "Y" project of downtown San Antonio, TX, similar to that tested by Armstrong (1994), except for the fact that the present study used unbonded PT strands as sole flexural reinforcement.

\subsection{Experimental Work}

\subsubsection{Specimen Preparation}

A pier cap model was built for this study, similar to Armstrong (1994), with a scale factor of 51/2:1, as a T-shaped overhang with symmetric loading to avoid both a premature failure and a complex detailing for anchoring of an L-shaped specimen to the strong floor. The specimen was designed with un-bonded PT strands as its sole primary flexural reinforcement, and based on an ultimate strength design philosophy. Scaling down the rebar sizes from the prototype pier cap, different sizes of steel wires were used as shear and skin reinforcement. Figure 4.3 shows the schematics of the pier cap specimen. Figure 4.4(a and $\mathbf{b})$ show the layout for reinforcement and post-tensioning strands.

A wooden formwork, as shown in Figure 4.5, was built for casting the pier cap on its side. Eight polycarbonate tubes were used as post-tensioning ducts. The tubes had 51 
mm (2 in.) outside diameter and $47.6 \mathrm{~mm}$ (1-7/8 in.) inside diameter to allow the anchorage sleeves for the carbon fiber strands to pass through. Since the length of each tube was less than that of the specimen, a $0.6 \mathrm{~m}(2 \mathrm{ft})$ long PVC tube was used as a coupler to connect each two polycarbonate tubes together. All PVC couplers were positioned right in the middle of the specimen within the column area, and affixed to the reinforcement cage using a zip tie to prevent excessive deformation during casting (see the lower left inset in Figure 4.5). A special formwork was designed for the two anchorage zones to fix the ducts at both ends (see the upper right inset in Figure 5).

The pier cap model was cast with self-consolidating concrete (SCC) of $9.5 \mathrm{~mm}$ (3/8 in.) maximum aggregate size, with a compressive strength of $75.8 \mathrm{MPa}$ (11 ksi) (as measured from companion cylinders at the time of testing) using a hydraulic pump with a 51-mm (2-in.) diameter hose. The specimen was covered with plastic sheets after casting, and was kept moist for a week. The specimen was de-molded after two weeks. Upon demolding, the surface of the anchorage zone was found not to be completely plumb. Therefore, the surface was re-formed and re-cast using Sikadur 32 Hi-Mod epoxy.

\subsubsection{Posttensioning Application}

The ultimate capacity of the model was calculated based on AASHTO LRFD (2012) using un-bonded regular low-relaxation steel strands. The specimen was designed as fully prestressed concrete section to carry out the ultimate load. Following Armstrong (1994), an effective prestress level of 1,103 MPa (160 ksi) was chosen for each $12.7 \mathrm{~mm}$

$(1 / 2$ in.) diameter steel strand, leading to an average prestressing force of $109 \mathrm{kN}$ (24.5 kip) in steel strands. For a side by side comparison, the same prestressing force was used in both CFCC and EC6 strands. This resulted in a jacking stress level of 59\% of 
guaranteed strength in CFCC and 62\% in EC6, both satisfying the 65\% limit according to the ACI Committee 440 (2004).

The post-tensioned specimen was over-designed with eight strands to make sure no premature failure would occur since the same pier cap model was to be used as test bed for the three types of strands. After concluding all experiments with eight strands, the number of post-tensioning strands was reduced to six, making the section slightly underdesigned to further assess the performance of the same strands in a more flexible specimen [see Figure 4.4(b)].

The dead and live ends for post-tensioning with the three types of strands for the eight-strand arrangement are shown in Figures 4.6(a-f). Two $51 \mathrm{~mm}$ (2 in.) steel plates were placed at the anchorage zone on both the dead and live ends. A $267 \mathrm{kN}$ (60 kip) hollow core hydraulic jack and a steel chair with a central hole were used for posttensioning of each strand. Different sizes of threaded rods, used for tensioning purpose, were connected to the anchor sleeves of CFCC and EC6. A nut was used to lock the posttensioning in each strand. The same approach was applied to steel strands, except for using a chuck in place of a nut. Although the strands were stressed one at a time, it is quite feasible to develop a larger chair to accommodate simultaneous stressing of multiple strands in a field application.

A stressing sequence was developed to avoid exceeding the allowable tensile stresses at the bottom of the overhang while tensioning. First, the specimen, without any post-tensioning, was loaded with an equivalent dead load compensating for the scale factor. Then, partial post-tensioning was applied with four of the strands. The next step involved applying half of the total superstructure dead load before tensioning the 
remaining strands. The initial stressing stage included the four bottom strands for the eight-strand arrangement, and the four corner strands for the six-strand arrangement.

\subsubsection{Test Setup and Instrumentation}

Figures 4.7(a and b) show the test set up for the pier cap model. The test frame included 24 high-strength threaded rods tied down to the strong floor, three W-section beams supported by the threaded rods in the transverse direction to the specimen, and one long W-section along the specimen as the reacting beam. For safety reasons, two HSS sections were affixed onto the specimen in the middle over the column section, securely fastened with high-strength threaded rods and nuts to prevent any movement due to unbalanced loading. There were two loading points on each cantilever, one on the inside and one on the outside. At each loading point, two 25.4-mm (1-in.) thick 102 x 203 mm (4 x 8 in.) neoprene pads were placed as bearing pads on top of the concrete surface to simulate the two adjacent spans supported on the pier cap. Steel plates were placed on top of the neoprene pads to uniformly transfer the loads of the hydraulic jacks.

A comprehensive instrumentation plan was developed for the pier cap model. Four pressure transducers were connected to the four hydraulic jacks to monitor their loading. One load cell was placed on the dead end of each strand to continuously monitor its prestress levels during tensioning and loading. As shown in Figure 4.7, three linear potentiometers were mounted on the top surface of each cantilever span to monitor the deflections of each overhang at its tip and mid-span, as well as at the face of the column. A high-speed data acquisition system was used to record the data. The specimen was painted in white, and marked with a 102 x 102 mm (4 x 4 in.) grid to help identify cracks during testing. A crack detection microscope was used to measure the crack widths. 


\subsubsection{Loading Protocol}

The pier cap model was designed following AASHTO LRFD (2012), with its prototype as an interior pier of a four-span continuous bridge with span lengths of $33.5 \mathrm{~m}$ (110 ft) on either side. The superstructure was designed for four lanes of traffic. Due to the position of the superstructure and the arrangement of the bearings, the outside three lanes of traffic would lead to the maximum moment at the face of the column, whereas the four lanes of traffic would maximize the shear at the face of the column. Two design trucks were placed in adjacent spans, with $15.2 \mathrm{~m}$ (50 ft) of spacing between the rear axle of one truck and the front axle of the other one. A total of $90 \%$ of the effect of the two design trucks and $90 \%$ of the effect caused by the lane loading were used to calculate the reaction at the interior pier. Since the specimen was a scaled model of the prototype, the scale factor was taken into account for live load calculations as well as self-weight dead load compensation. The dead load compensation was simulated by $6.54 \mathrm{kN}$ (1.47 kip) at the outside loading points and $19.9 \mathrm{kN}$ (4.47 kip) at the inside loading points. Table 4.2 summarizes target loads and moments at different stages of loading.

The pier cap model was tested with two different strand arrangements, as explained before; and for each arrangement, the sequence of testing included CFCC, EC6,

and steel strands. The model with the eight-strand arrangement underwent four loading steps; service flexure load, service shear load, factored flexure load, and factored shear load. On the other hand, since the model with the six-strand arrangement was underdesigned, it was subjected to service flexure load, service shear load, and only 93\% of the factored flexure load. The reason for terminating the tests at $93 \%$ of the target factored flexure load was because a huge crack was observed at that load level during the first set 
of tests with six strands. Therefore, the test was stopped at that level to avoid catastrophic damages which might render the specimen unusable for the remaining experiments. All subsequent tests with the six-strand arrangement were stopped at the same load level to compare the behaviors.

Loading was applied by two pairs of hydraulic jacks, $534 \mathrm{kN}$ (120 kip) at the outside loading points and $445 \mathrm{kN}$ (100 kip) at the inside loading points. Each pair of jacks was inter-connected to a single hydraulic pump to ensure symmetric loading of the two overhangs. For each target load, loads in the outside jacks were increased in increments of $18 \mathrm{kN}$ (4 kip), while loads in the inside jacks were increased linearly and proportionally. After reaching each target level, the model was unloaded back to the dead load, before reloading it to the next target load.

\subsection{Test Results and Discussions}

The factored moment for the pier cap model was calculated as $482 \mathrm{kN} \cdot \mathrm{m}(4,270$ kip·in), based on the AASHTO LRFD (2012). The first set of loading tests was conducted with the full eight-strand arrangement, for which the ultimate moment capacity of the pier cap model was estimated as $614 \mathrm{kN} \cdot \mathrm{m}(5,433 \mathrm{kip} \cdot \mathrm{in})$, or $27 \%$ above the demand. After finishing the experiments with the over-designed section, the second set of loading tests was conducted with the six-strand arrangement, for which the ultimate moment capacity of the pier cap model was estimated as $476 \mathrm{kN} \cdot \mathrm{m}(4,210 \mathrm{kip} \cdot \mathrm{in})$, or $1.5 \%$ below the demand.

Figures 4.8(a-c) show the relationships between the moment at the face of the column and the average tip deflections of the two overhangs, for CFCC, EC6, and steel strands. Each figure shows two response curves for the eight-strand and six-strand 
arrangements. The figures show the initial fluctuations of the tip deflection for all three types of strands, caused by the stressing sequence, as described earlier. The figures also demonstrate that the camber for the six-strand arrangement was more than that for the eight-strand arrangement for all three types of strands. This may be attributed to the geometric arrangement of the strands. There were two rows of four strands for the overdesigned section, whereas the under-designed section had two center strands missing on the bottom row. As described earlier, to avoid exceeding allowable tensile stresses at the bottom of the overhang, a two-stage stressing sequence was devised. The initial stressing stage included the four bottom strands for the eight-strand arrangement, and the four corner strands for the six-strand arrangement. Therefore, a larger moment and a larger corresponding camber were developed for the underdesigned specimen at the initial tensioning stage.

The moment-deflection figures also show a generally linear response for all three types of strands under the eight-strand arrangement, and a slight softening in the sixstrand arrangement while approaching the $93 \%$ of the demand load. Figures $9(\mathbf{a}$ and $\mathbf{b}$ ) show the moment-tip deflection responses for different types of strands under the same strand arrangement. It is clear that no significant difference exists among the three types of strands in either strand arrangement.

Table 4.3 summarizes tip deflections at every target load level, for each of the three types of strands, and each of the two strand arrangements. AASHTO LRFD (2012) specifies the maximum permissible deflection for cantilever arms as L/300, which corresponds to $3.9 \mathrm{~mm}$ ( $0.15 \mathrm{in}$.) for the 1,168 $\mathrm{mm}$ (46 in.) long span of the overhangs of the pier cap model. It is clear that at service flexure loads, tip deflections for all types of 
strands are well below the maximum permissible amount. It should however be noted that long-term effects are not considered in this study. Moreover, given the high stiffness of the specimen and its strength-based design, the difference in the deflections of the three types of strands was not of any consequence, despite their different elastic moduli. The six-strand arrangement generally leads to larger deflections, as expected. However, even for the under-designed model with the six-strand arrangement, the deflections do not exceed the allowable limits for any of the strand types. It is also noteworthy that deflections at factored loads (or 93\% of factored loads for the case of six-strand arrangement) were almost twice those at service loads.

Table 4.4 summarizes the average prestressing force at different target load levels for each of the three types of strands, and each of the two strand arrangements. The prestressing forces are shown separately for the top and bottom rows of strands. In each case, the increase in prestressing force is shown between the level of dead load and that of factored flexure (or 93\% of factored flexure for the case of six-strand arrangement). The table clearly shows that the increase in prestressing force is generally higher for the six-strand arrangement, as compared to the eight-strand arrangement. Moreover, the increase in prestressing force is proportional to the elastic modulus of the strand, and therefore, is least for CFCC and highest for steel strands.

Figures 4.10(a and b) show the crack pattern after concluding all experiments. For the eight-strand arrangement, only one major crack marked as No. 1 was detected in the first test with CFCC strands. The same crack on each side of overhangs continued to grow as the experiments progressed with different types of strands. The second crack, marked as No. 2, appeared on the south side of the east overhang, at the onset of testing 
with the six-strand arrangement, again with CFCC strands, and continued to grow with subsequent experiments.

Table 4.5 summarizes the maximum crack width measured for major crack No. 1 at each target load level for each strand type and arrangement. The crack width in all cases was measured at or near the top reference line A, as depicted in Figure 4.10. The maximum crack width shown in the table is the largest of the four major cracks measured on the two overhangs. It should be noted that the first loading test was carried out on the pier cap model with eight CFCC strands, and because the cracking moment of the section was well above service loads, it showed no sign of cracking. It is also noteworthy that the pier cap model acted as a pre-cracked section for all subsequent tests, and therefore, crack width grew as the tests progressed. The maximum crack widths under service flexural load with the eight-strand arrangement are well below the acceptable service load crack width of $0.076 \mathrm{~mm}$ (0.003 in.). However, the corresponding values for the six-strand arrangement appear to be higher than the acceptable crack width. Also note that crack widths for all three types of strands of the under-designed section were generally the same at the $93 \%$ of the factored load, or about twice as much as crack widths of the overdesigned section at the factored load. That indicates no major difference in the performance of the three types of strands.

\subsection{Conclusions}

A 51/2:1 scaled model of a typical interior hammerhead pier of San Antonio downtown "Y" project was made with two identical cantilever overhangs as a test bed for a side by side comparison of the performance of three different types of strands; namely, CFCC, EC6, and steel in an un-bonded post-tensioning as primary and sole flexural 
reinforcement. Two different strand arrangements were used for the post-tensioning of the model, one with eight strands that represented 27\% excess capacity over demand, and another with six strands representing $1.5 \%$ under-design. The pier cap model was tested under service and factored flexure and shear loads (and 93\% of factored flexure for the case of six-strand arrangement). The following conclusions may be drawn from this experimental study:

- The strength of CFCC strand is about $30 \%$ higher than steel, while its elastic modulus is about 23\% lower than steel. Properties of EC6 strand, on the other hand, are much closer to those of steel. The length of sleeve for EC6 is about one third of that of CFCC and very close to the length of multi-use chucks for steel strands.

- Application of un-bonded CFCC and EC6 strands for post-tensioning of pier caps is quite feasible and similar in nature to the process for steel strands.

- Design of un-bonded post-tensioned pier cap may follow AASHTO LRFD (2012), selecting CFCC or EC6 strands (number and size) with the same capacity as that of steel strands. The design should limit the stress level in carbon fiber strands to $65 \%$ of their guaranteed strength, according to the ACI Committee 440 (2004).

- Given the strength-based design of the pier cap, the elastic moduli of different carbon fiber strands did not seem to have affected the serviceability performance of the pier cap model with respect to either cracking or deflection. Therefore, allowable stressing level of ACI Committee 440 (2004) for carbon fiber strands can be followed safely. 
- Considering both serviceability and overload conditions, the general performance of the pier cap model under both flexure and shear loading was quite acceptable using either CFCC or EC6 strands, and comparable to that of steel strands. No major difference in the performance was noted between the three types of strands.

Future research is needed to investigate the fatigue and long-time performance of pier cap using un-bonded post-tensioned with CFCC or EC6 strands.

\section{Acknowledgements}

This study was sponsored by the Florida Department of Transportation under the supervision of Mr. William Potter as Project Manager. The support of Titan America for providing the concrete, C\&C Concrete Pumping for providing the concrete pumping, Mo Steel Fabricator \& Erector for the steel frame fabrication, Mr. Emilio R. Vega, the President and CEO of Structural Prestressed Industries Inc. for providing steel strands and steel chucks, and Composite Rigging Southern Spars for providing the EC6 strands are gratefully acknowledged. All experiments were conducted at the Titan America Structures and Construction Testing Laboratory of the Florida International University. The views and findings reported here are those of the writers alone, and not necessarily the views of sponsoring agency. 


\section{References}

ACI (American Concrete Institute). (2004). "Prestressing concrete structures with FRP tendons.” 440.4R-04, Farmington Hills, MI.

AASHTO (1989). Standard specifications for highway bridge. $14^{\text {th }}$ Ed., Washington, DC.

AASHTO (1992). Standard specifications for highway bridge. $15^{\text {th }}$ Ed., Washington, DC.

AASHTO LRFD (2012). AASHTO LRFD bridge design specifications, $6^{\text {th }}$ Ed., Washington, D.C.

Armstrong, S.D. (1994). "Design and behavior of large concrete cantilever overhang with combination of prestressed and non-prestressed reinforcement.” M.S. thesis, Univ. of Texas, Austin, TX.

Billington, S.L. (1994). "Behavior of two-span continuous pier caps with varying levels of prestress.” M.S. Thesis, Univ. of Texas, Austin, TX.

Dolan, C.W., Bakis, C.E., and Nanni, A. (2001). "Design recommendations for concrete structures prestressed with FRP tendons.” Report No. DTFH61-96-C-00019, Federal Highway Association.

ElSafty, A., Benmokrane, I., Rizkalla, S., Mohamed, H., and Hassan, M. (2014). "Degradation assessment of internal continuous fiber reinforcement in concrete environment.” Final Rep., Florida Dept. of Transportation, Tallahassee, FL.

FDOT (Florida Department of Transportation). (2015). "Fiber reinforced polymer guidelines.” FDOT structures manual Vol. 4, Florida Dept. of Transportation, Tallahassee, FL.

Grace, N.F., Bebawy, M., and Ushijima, K. (2014). "Field application of composite posttensioning system.” ACI Concr. Int., 36(11), 39-42.

Grace, N., Enomoto, T., Abel-Mohti, A., Tokal, Y., and Puravankara, S., (2008). "Flexural behavior of concrete box beams post-tensioned with un-bonded carbonfiber-composite cables.” PCI J., 53(4), 62-82.

Grace, N., Enomoto, T., Abdel-Sayed, G., Yagi, K., and Collavino, L. (2003). "Experimental study and analysis of a full-scale CFRP/CFCC double-tee bridge beam.” PCI J., 48(4), 120-139.

Grace, N.F., Navarre, F.C, Nacey, R.B., Bonus, W., and Collavino, L. (2002). "Designconstruction of Bridge Street Bridge-First CFRP bridge in the United States.” PCI J., 47(5), 20-35. 
Grace, N., Patki, K., Soliman, E., and Hanson, J. (2011). "Flexural behavior of dide-byside box-beam bridges: A comparative dtudy.” PCI J., 56(3), 94-112.

Pereira, R. (1994). "Behavior of structural concrete cantilever piers using T-headed reinforcing bars and varied prestressing design criteria” M.S. Thesis, Univ. of Texas, Austin, TX.

Roddenberry, M., Mtenga, P., and Joshi, K. (2014). "Investigation of carbon fiber composite cables (CFCC) in prestressed concrete piles.” Final Rep., Florida Dept. of Transportation, Tallahassee, FL. 
Table 4.1 Comparison of Material Properties and Anchorage of CFCC, EC6, and Steel Strands

\begin{tabular}{lccccccc}
\hline Tendon Type & $\begin{array}{c}\text { Nominal } \\
\text { Diameter, } \\
\mathrm{mm}(\mathrm{in} .)\end{array}$ & $\begin{array}{c}\text { Effective } \\
\text { Area, } \\
\mathrm{mm}^{2}\left(\mathrm{in}{ }^{2}\right)\end{array}$ & $\begin{array}{c}\text { Guaranteed } \\
\text { Strength, } \\
\text { MPa (ksi) }\end{array}$ & $\begin{array}{c}\text { Guaranteed } \\
\text { Capacity, } \\
\mathrm{kN}(\mathrm{kip})\end{array}$ & $\begin{array}{c}\text { Elastic } \\
\text { Modulus, } \\
\mathrm{GPa}(\mathrm{msi})\end{array}$ & $\begin{array}{c}\text { Mass } \\
\text { Density, }(\mathrm{lb} / \mathrm{ft})\end{array}$ & $\begin{array}{c}\text { Anchorage } \\
\text { Device Length, } \\
\mathrm{mm}(\mathrm{in.})\end{array}$ \\
\hline CFCC & $12.5(0.492)$ & $76(0.118)$ & $2,420(351)$ & $184(41.4)$ & $154(22.3)$ & $145(0.10)$ & $330(13)$ \\
\hline EC6 & $12.3(0.484)$ & $96(0.149)$ & $1,850(268)$ & $177(39.7)$ & $185(26.8)$ & $553(0.37)$ & $108(4.3)$ \\
\hline Steel $^{*}$ & $12.7(0.5)$ & $99(0.153)$ & $1,860(270)$ & $184(41.3)$ & $200(29.0)$ & $781(0.53)$ & $92(3.6)$ \\
\hline
\end{tabular}

* Steel strands were seven-wire low-relaxation. 
Table 4.2 AASHTO LRFD Design Loads

\begin{tabular}{lccc}
\hline Load Level & $\begin{array}{c}\text { Outside Point Load } \\
\mathrm{kN}(\mathrm{kip})\end{array}$ & $\begin{array}{c}\text { Inside Point Load } \\
\mathrm{kN}(\mathrm{kip})\end{array}$ & $\begin{array}{c}\text { Moment at Face of Column* } \\
\text { kN.m (kip.in) }\end{array}$ \\
\hline Self-Weight Compensation & $6.54(1.47)$ & $19.9(4.47)$ & $15.9(141)$ \\
\hline Superstructure Dead Load & $180(40.5)$ & $193(43.5)$ & $245(2,170)$ \\
\hline Service Load for Flexure & $295(66.4)$ & $159(35.8)$ & $348(3,080)$ \\
\hline Service Load for Shear & $221(49.8)$ & $235(52.8)$ & $483(4,270)$ \\
\hline Factored Load for Flexure & $425(95.6)$ & $177(39.7)$ & $398(3,520)$ \\
\hline Factored Load for Shear & $296(66.5)$ & $309(69.5)$ &
\end{tabular}

${ }^{*}$ Moment at face of column includes self-weight of the specimen 
Table 4.3 Tip Deflection Summary

\begin{tabular}{|c|c|c|c|c|c|c|}
\hline \multirow{2}{*}{ Load Level } & \multicolumn{3}{|c|}{ Eight-Strand Arrangement } & \multicolumn{3}{|c|}{ Six-Strand Arrangement } \\
\hline & CFCC & EC6 & Steel & CFCC & EC6 & Steel \\
\hline Dead Load & $0.26(0.010)$ & $-0.01(0.000)$ & $0.09(0.003)$ & $0.21(0.008)$ & $0.13(0.005)$ & $0.22(0.009)$ \\
\hline Service Flexure & $0.72(0.028)$ & $0.47(0.018)$ & $0.69(0.027)$ & $0.89(0.035)$ & $0.90(0.035)$ & $1.00(0.039)$ \\
\hline Service Shear & $0.52(0.020)$ & $0.26(0.010)$ & $0.36(0.014)$ & $0.48(0.019)$ & $0.48(0.019)$ & $0.57(0.022)$ \\
\hline $\begin{array}{l}93 \% \text { of Factored } \\
\text { Flexure }\end{array}$ & $1.20(0.047)$ & $1.06(0.042)$ & $1.16(0.046)$ & $2.09(0.082)$ & $2.00(0.079)$ & $2.12(0.083)$ \\
\hline Factored Flexure & $1.50(0.059)$ & $1.35(0.053)$ & $1.53(0.060)$ & - & - & - \\
\hline Factored Shear & $1.08(0.043)$ & $0.75(0.029)$ & $0.89(0.035)$ & - & - & - \\
\hline
\end{tabular}

${ }^{*}$ Units are in mm (in.). Downward deflection is positive. 
Table 4.4 Average Prestressing Force in Strands

\begin{tabular}{|c|c|c|c|c|c|c|c|}
\hline \multirow{2}{*}{$\begin{array}{l}\text { Load } \\
\text { Level }\end{array}$} & \multirow{2}{*}{ Strand Location } & \multicolumn{3}{|c|}{ Eight-Strand Arrangement } & \multicolumn{3}{|c|}{ Six-Strand Arrangement } \\
\hline & & CFCC & EC6 & Steel & CFCC & EC6 & Steel \\
\hline \multirow{2}{*}{ Dead Load } & Top Row & $111(24.9)$ & $111(24.9)$ & $111(24.9)$ & $111(24.9)$ & $111(25.0)$ & $112(25.1)$ \\
\hline & Bottom Row & $110(24.7)$ & $111(25.0)$ & $110(24.7)$ & $111(24.9)$ & $111(25.0)$ & $111(25.0)$ \\
\hline \multirow{2}{*}{$\begin{array}{l}93 \% \text { of } \\
\text { Factored } \\
\text { Flexure }\end{array}$} & Top Row & - & - & - & $117(26.2)$ & $118(26.5)$ & $119(26.7)$ \\
\hline & Bottom Row & - & - & - & $115(25.8)$ & $117(26.2)$ & $117(26.2)$ \\
\hline \multirow{2}{*}{$\begin{array}{l}\text { Factored } \\
\text { Flexure }\end{array}$} & Top Row & $113(25.5)$ & $115(25.8)$ & $115(25.8)$ & - & - & - \\
\hline & Bottom Row & $112(25.1)$ & $114(25.6)$ & $113(25.4)$ & - & - & - \\
\hline \multirow{2}{*}{$\begin{array}{l}\text { Increase in } \\
\text { Prestressing } \\
\text { Force }\end{array}$} & Top Row & $2.6(0.6)$ & $4.0(0.9)$ & $4.0(0.9)$ & $5.7(1.3)$ & $6.7(1.5)$ & $7.1(1.6)$ \\
\hline & Bottom Row & $1.8(0.4)$ & $2.7(0.6)$ & $3.1(0.7)$ & $4.0(0.9)$ & $5.3(1.2)$ & $5.3(1.2)$ \\
\hline
\end{tabular}

${ }^{*}$ Units are in $\mathrm{kN}$ (kip). 
Table 4.5 Maximum Crack Width Summary for the Major Crack

\begin{tabular}{lcccccc}
\hline \multirow{2}{*}{ Load Level } & \multicolumn{2}{c}{ Eight-Strand Arrangement } & \multicolumn{2}{c}{ Six-Strand Arrangement } \\
\cline { 2 - 7 } & CFCC & EC6 & Steel & CFCC & EC6 & Steel \\
\hline Dead Load & - & 0.02 & 0.04 & 0.06 & 0.06 & 0.06 \\
\hline Service Flexure & - & 0.06 & 0.04 & 0.14 & 0.22 & 0.27 \\
\hline Service Shear & - & 0.06 & 0.18 & 0.10 & 0.14 & 0.10 \\
\hline $\begin{array}{l}\text { 93\% of Factored } \\
\text { Flexure }\end{array}$ & - & - & - & 0.62 & 0.66 & 0.62 \\
\hline $\begin{array}{l}\text { Factored Flexure } \\
\text { Factored Shear }\end{array}$ & 0.10 & 0.30 & 0.32 & - & - & - \\
\hline * Units are in mm & 0.03 & 0.06 & 0.06 & - & - & - \\
\hline
\end{tabular}

* Units are in $\mathrm{mm}$. 


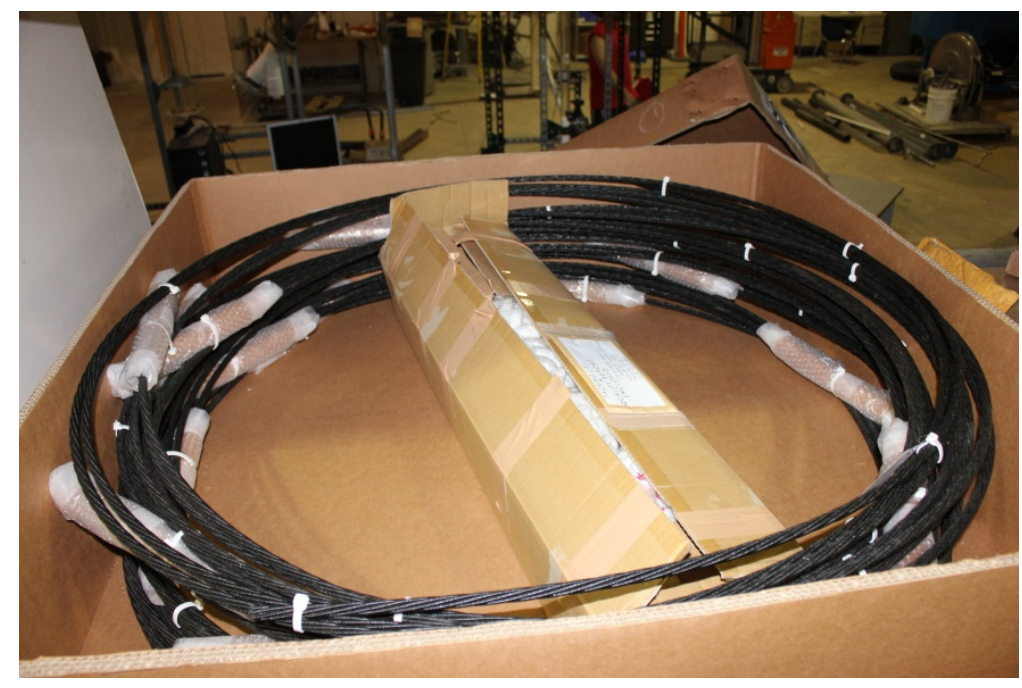

(a)

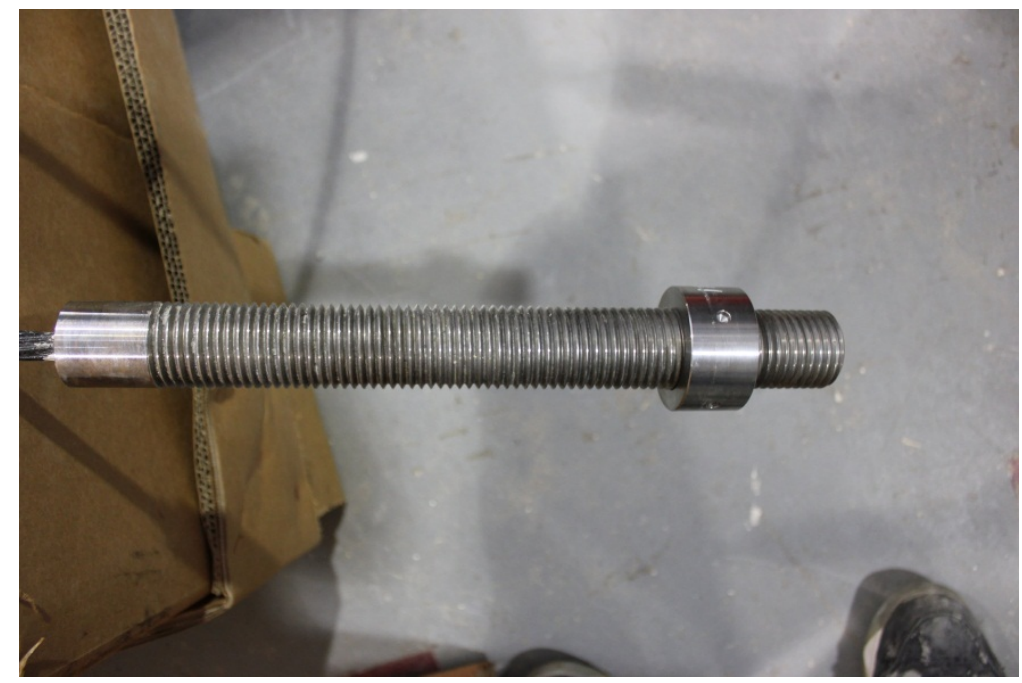

(b)

Figure 4.1 Carbon Fiber Composite Cable: (a) CFCC Strand, and (b) CFCC Anchorage Sleeve 


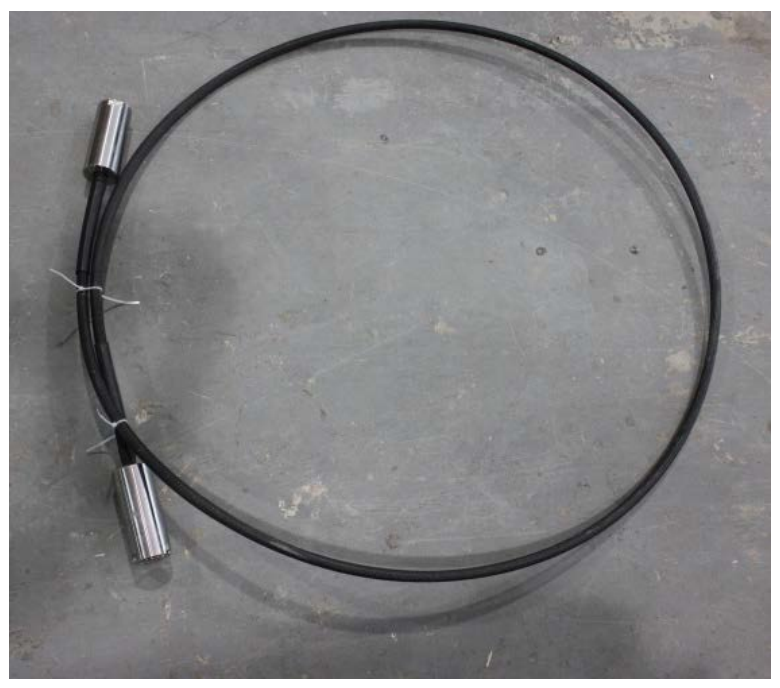

(a)

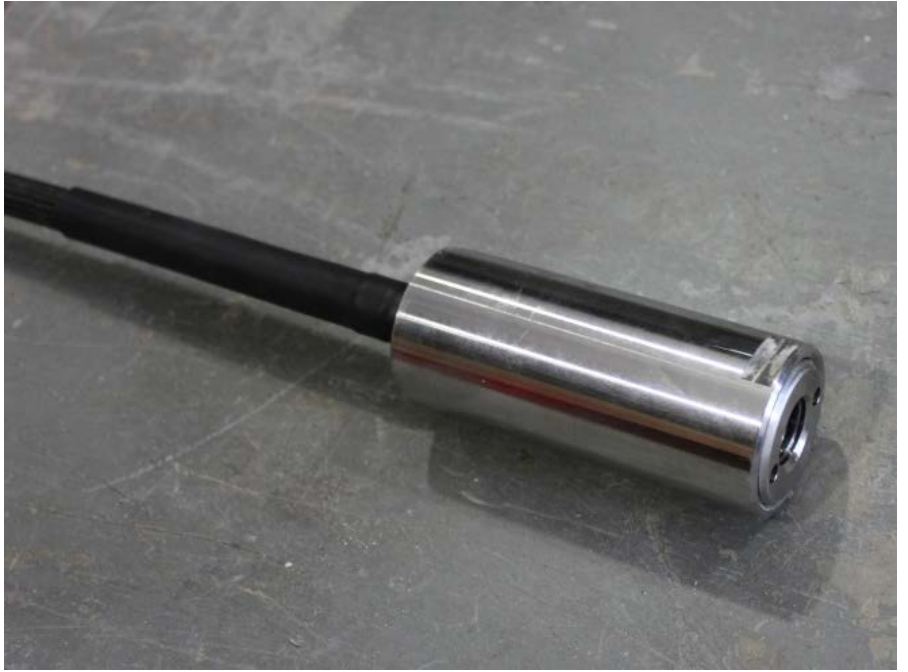

(b)

Figure 4.2 EC6 Composite Cable: (a) EC6 Strand, and (b) EC6 Anchorage 


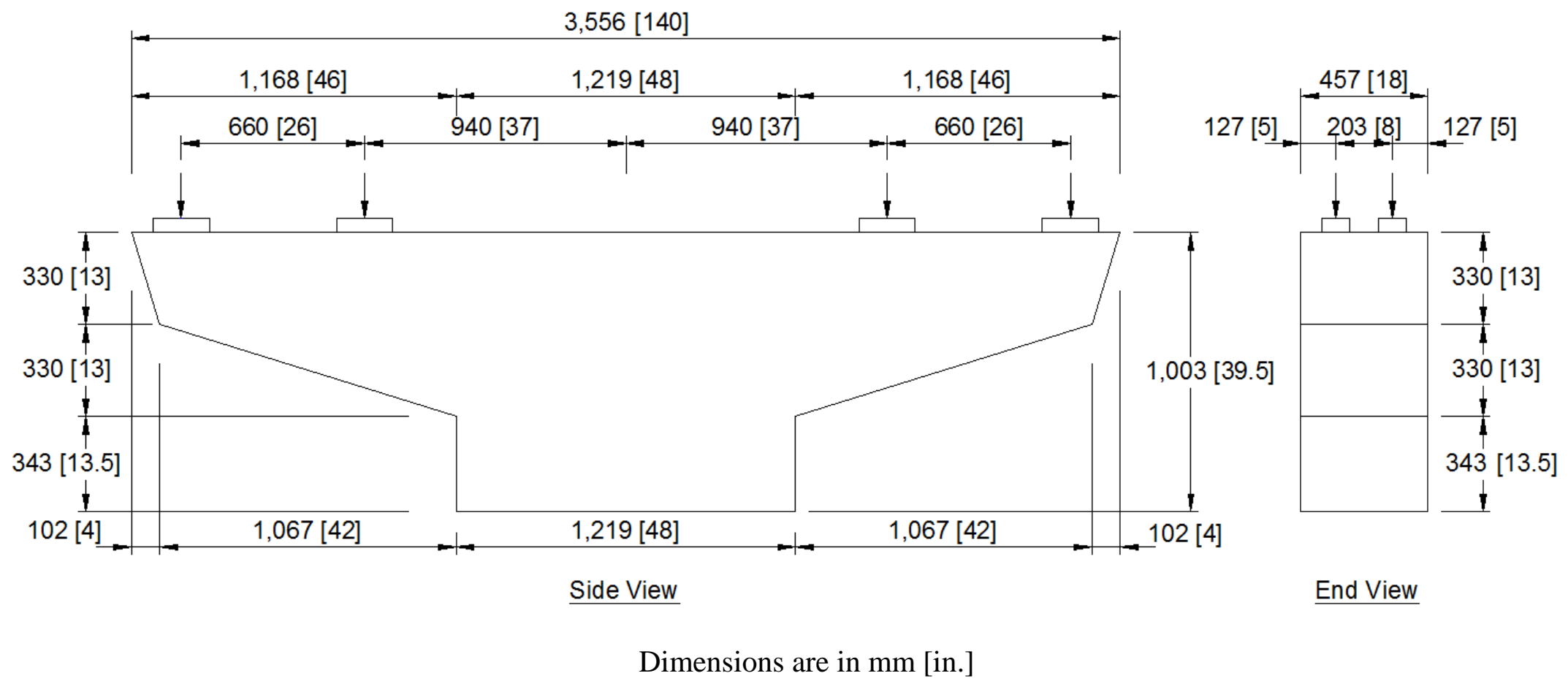

Figure 4.3 Pier Cap Test Model and Loading Pattern 

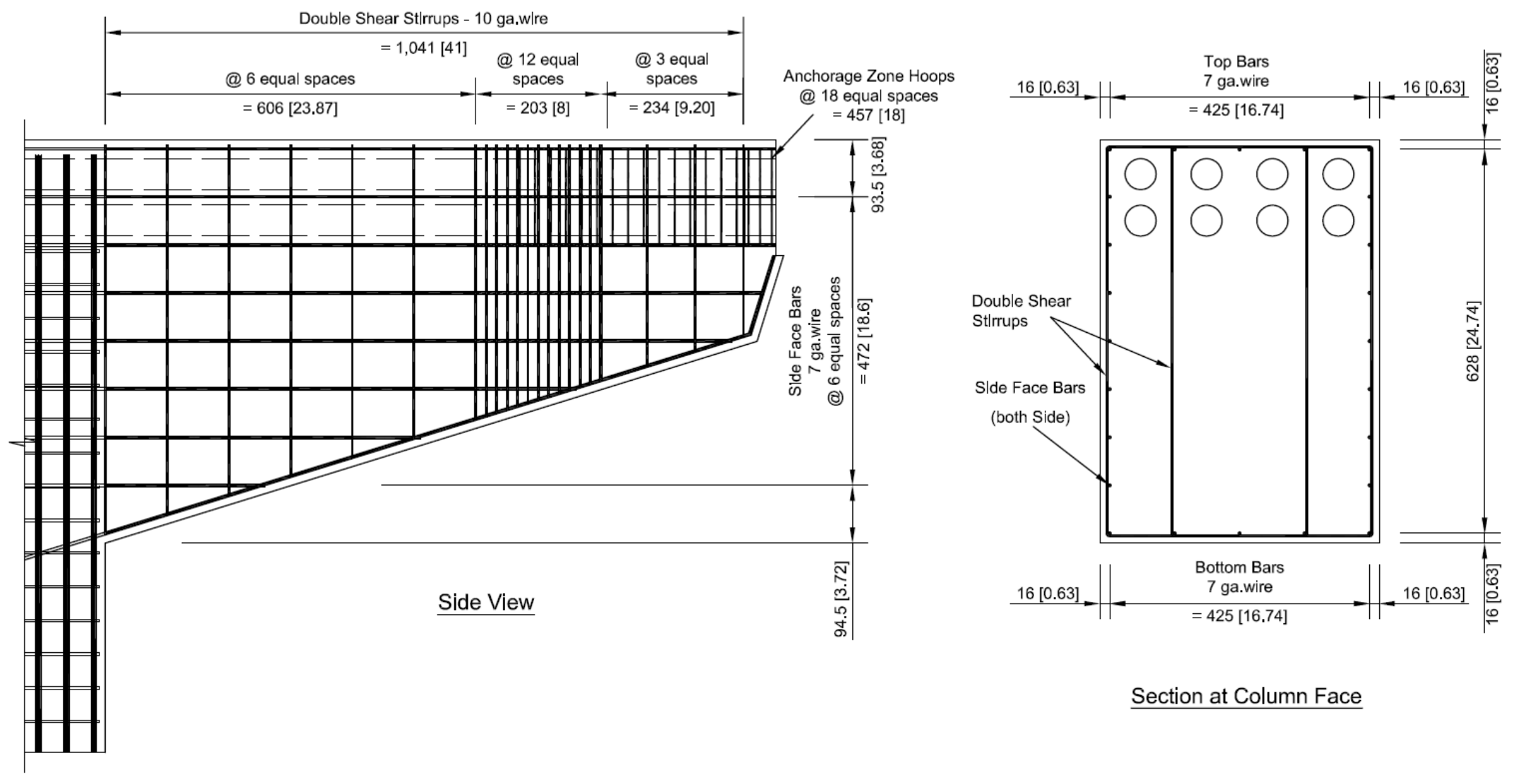

(a) 


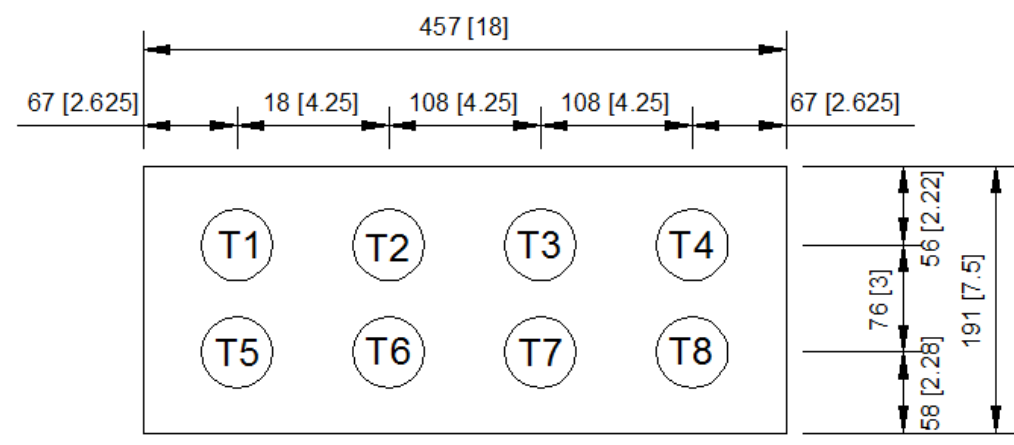

Layout for 8 strands

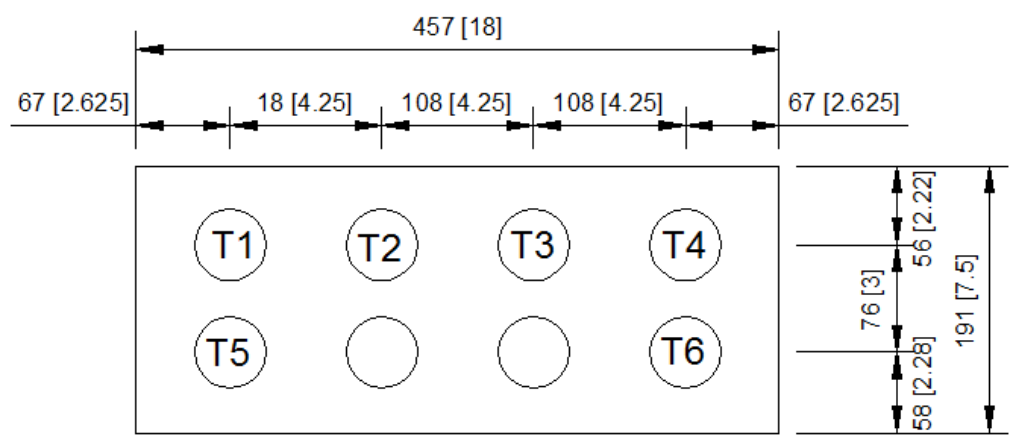

Layout for 6 strands

(b)

Dimensions are in mm [in.]

Figure 4.4 Layout for Reinforcement and Post-Tensioning Strands: (a) Reinforcement Layout, and (b) Strands Layout 


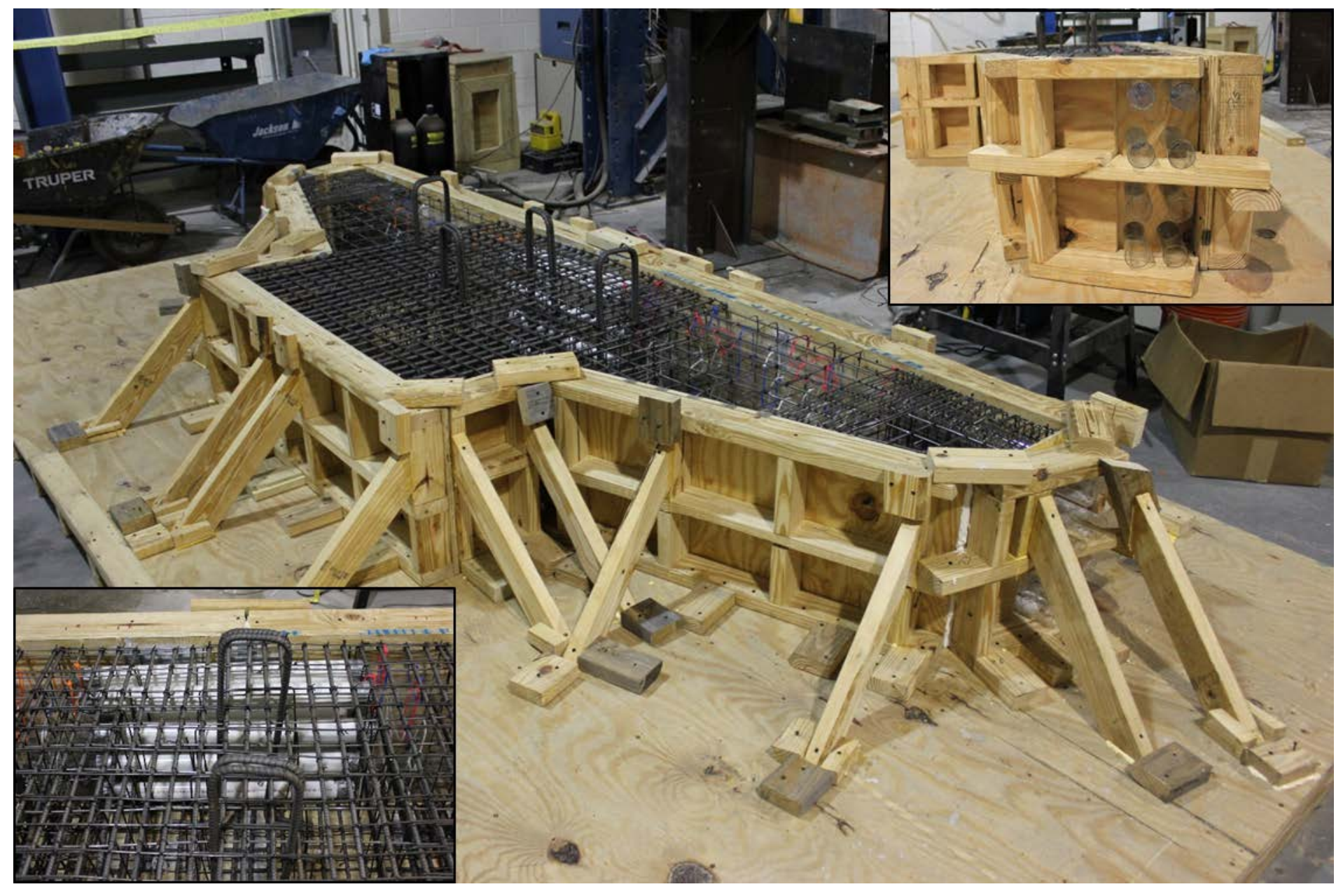

Figure 4.5 Pier Cap Formwork 


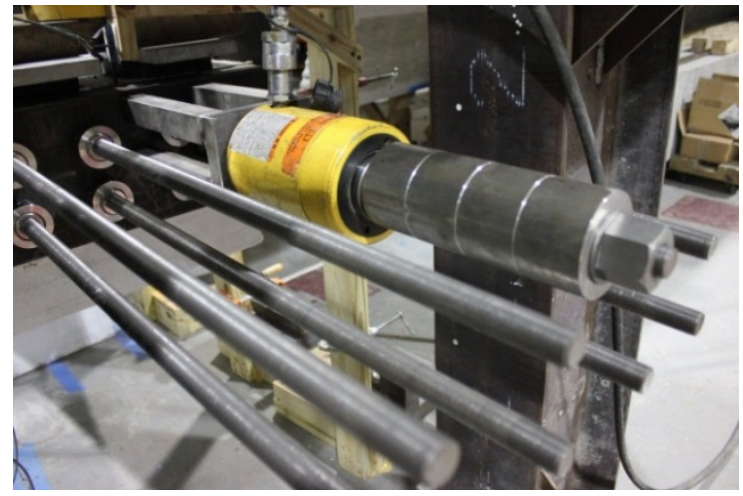

(a)

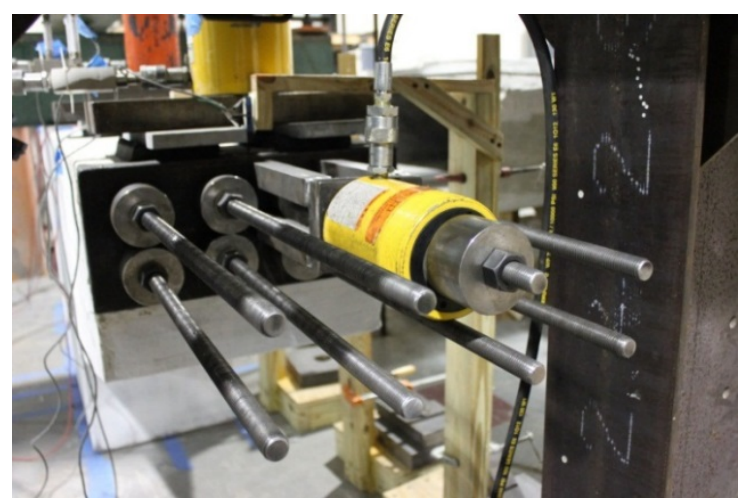

(c)

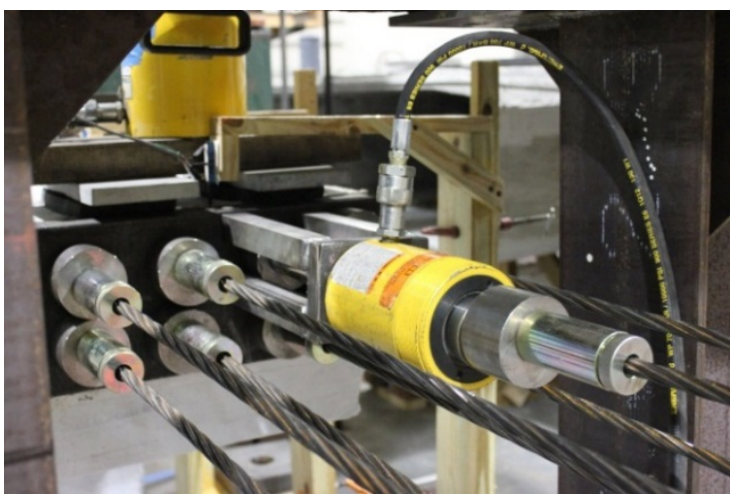

(e)

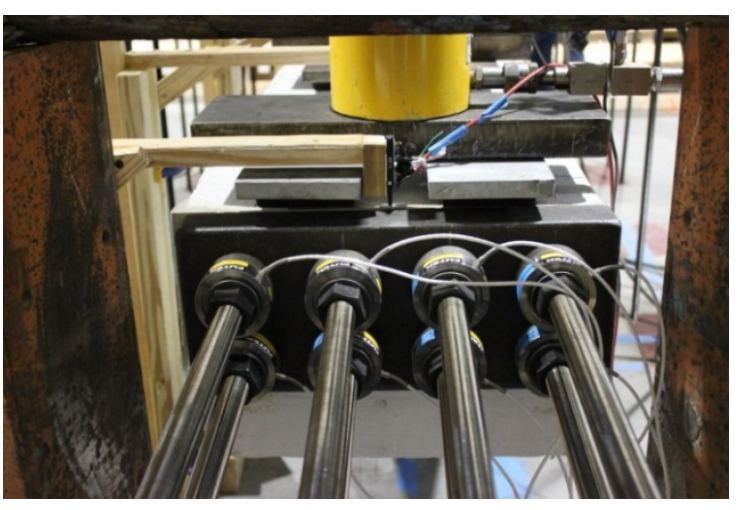

(b)

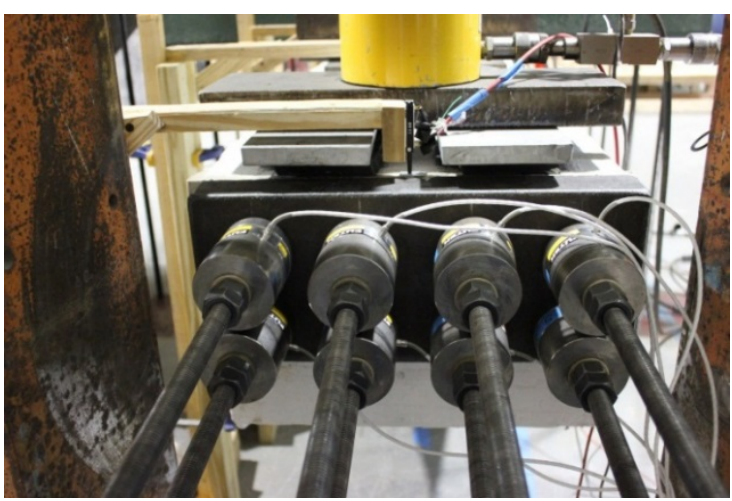

(d)

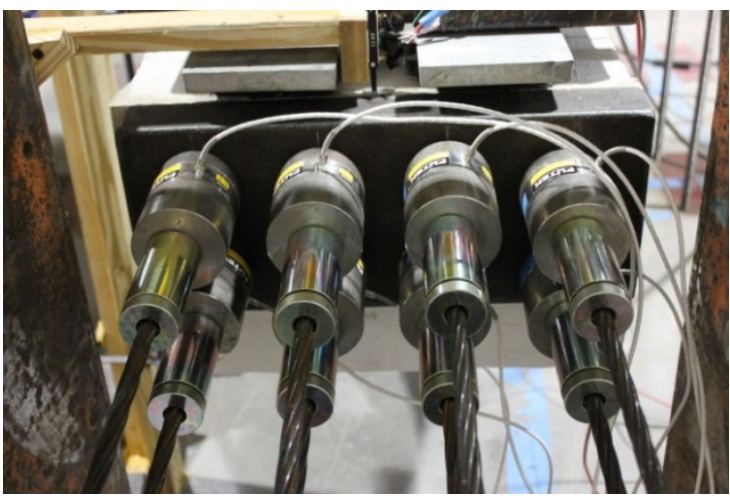

(f)

Figure 4.6 Post-tensioning System: (a) Live End for CFCC, (b) Dead End for CFCC, (c) Live End for EC6, (d) Dead End for EC6, (e) Live End for Steel, and (f) Dead End for Steel Strands 


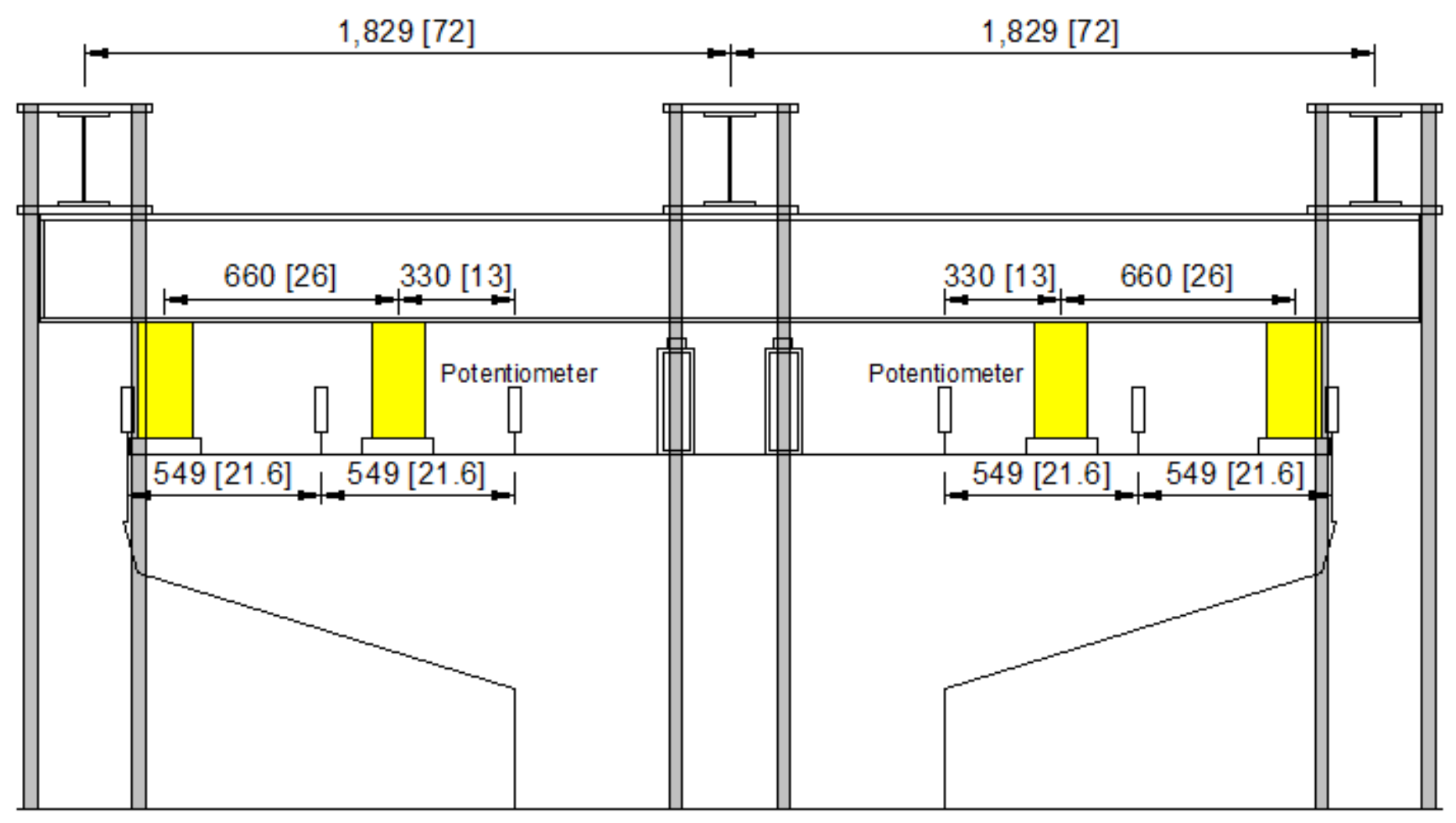

(a) 


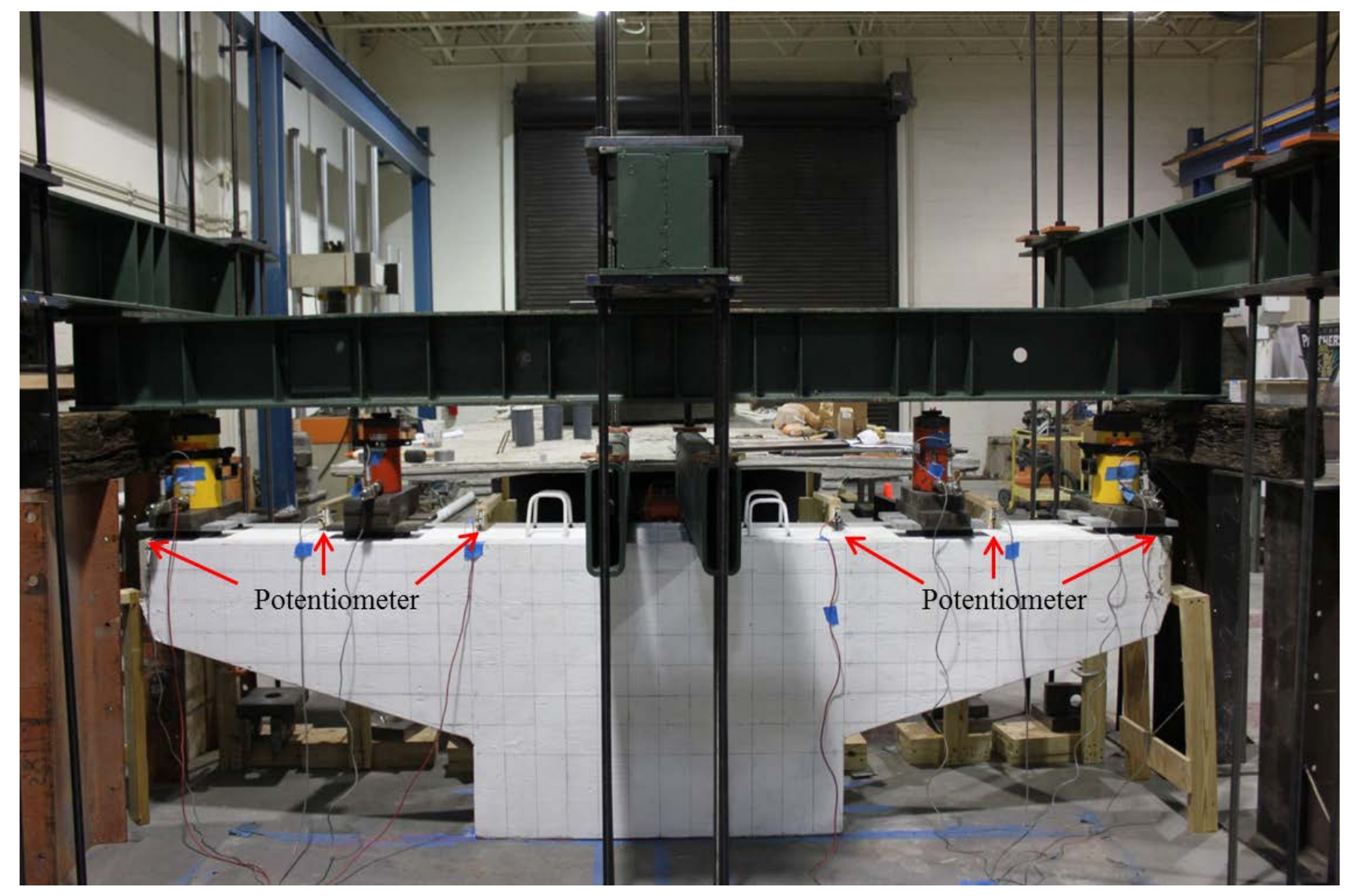

(b)

Dimensions are in $\mathrm{mm}$ [in.]

Figure 4.7 Test Setup and Instrumentation: (a) Sketch for Test Setup, and (b) Experimental Test Setup 


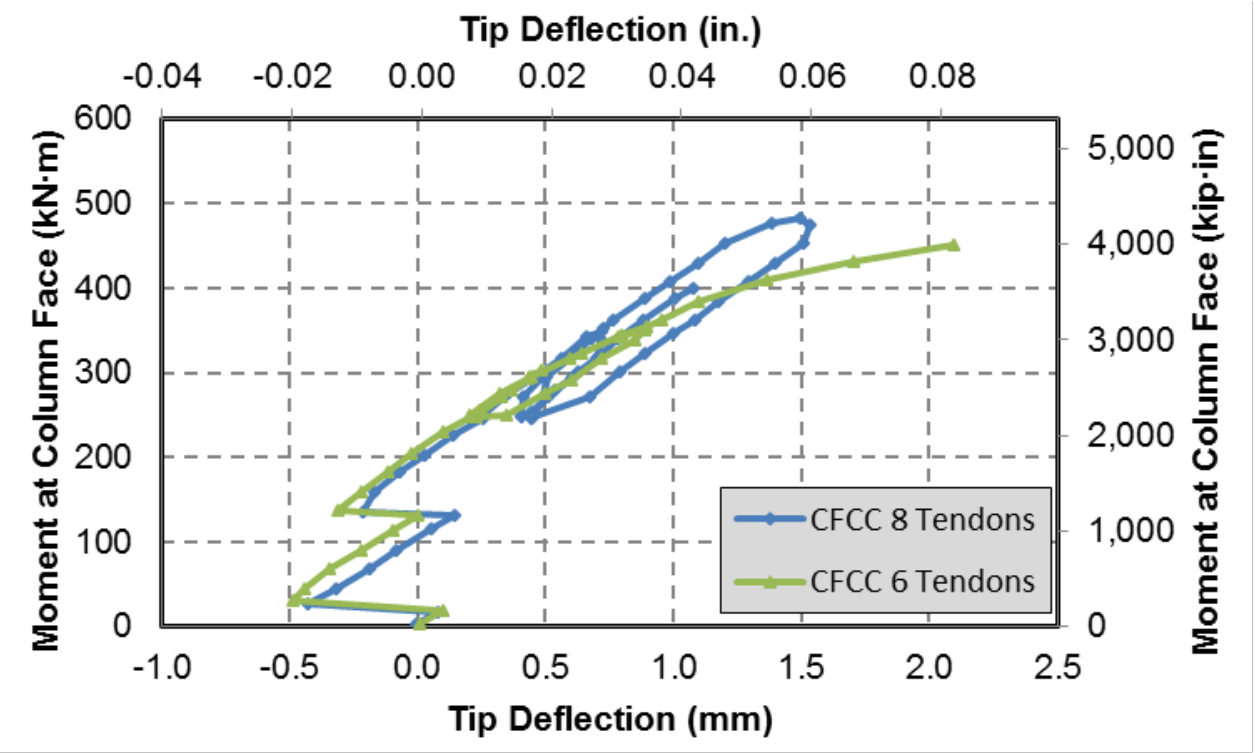

(a)

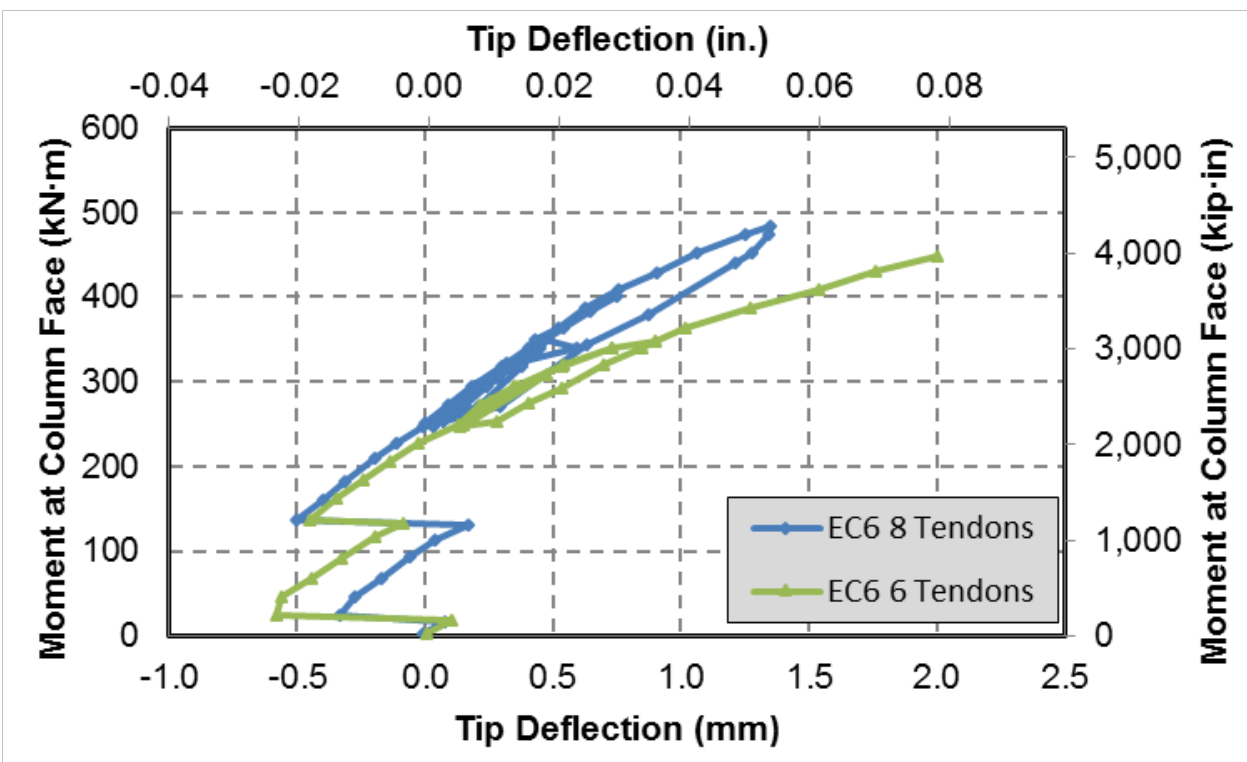

(b) 


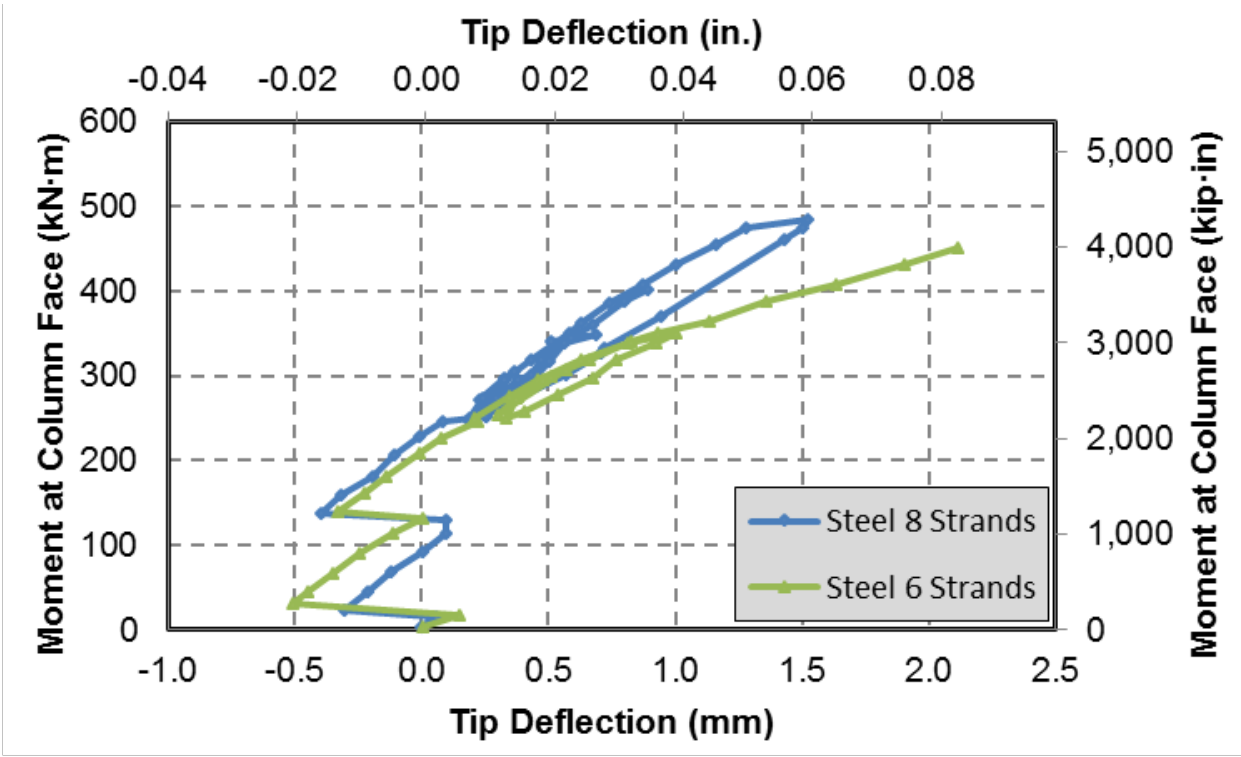

(c)

Figure 4.8 Moment-Tip Deflection Comparison of Pier Cap Model: (a) CFCC Tendons,

(b) EC6 Tendons, and (c) Steel strands 


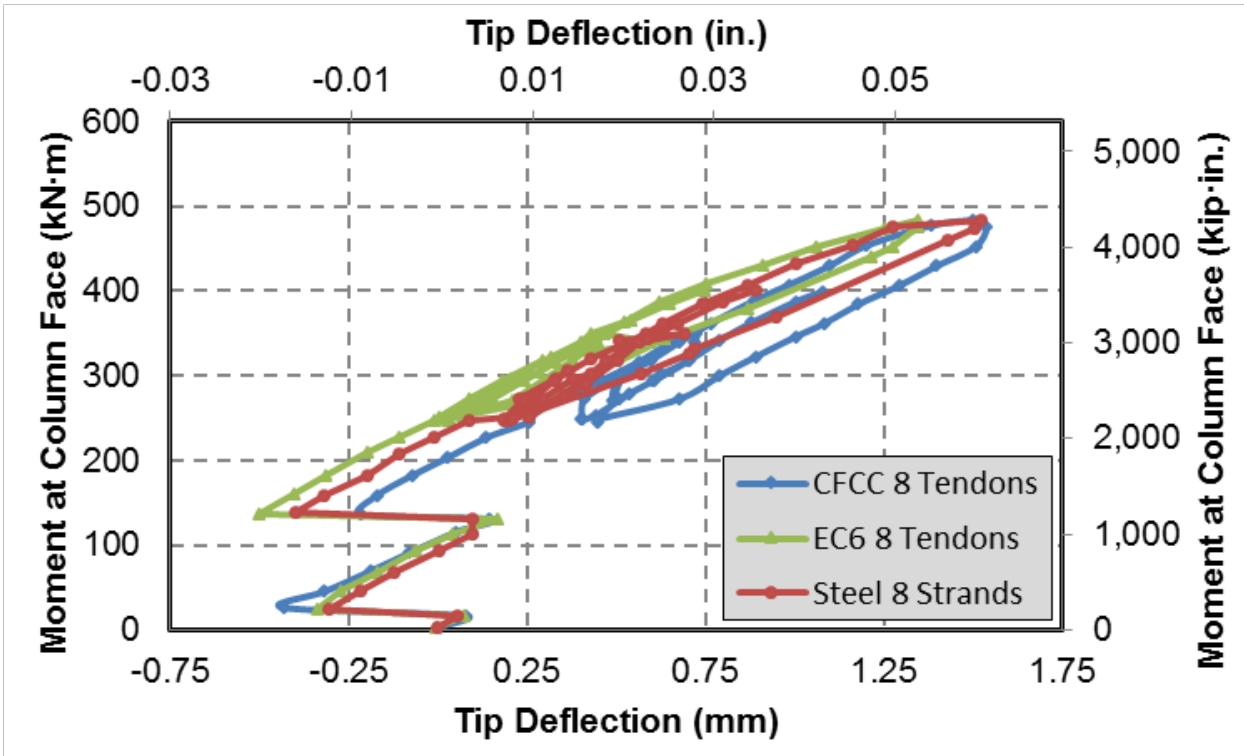

(a)

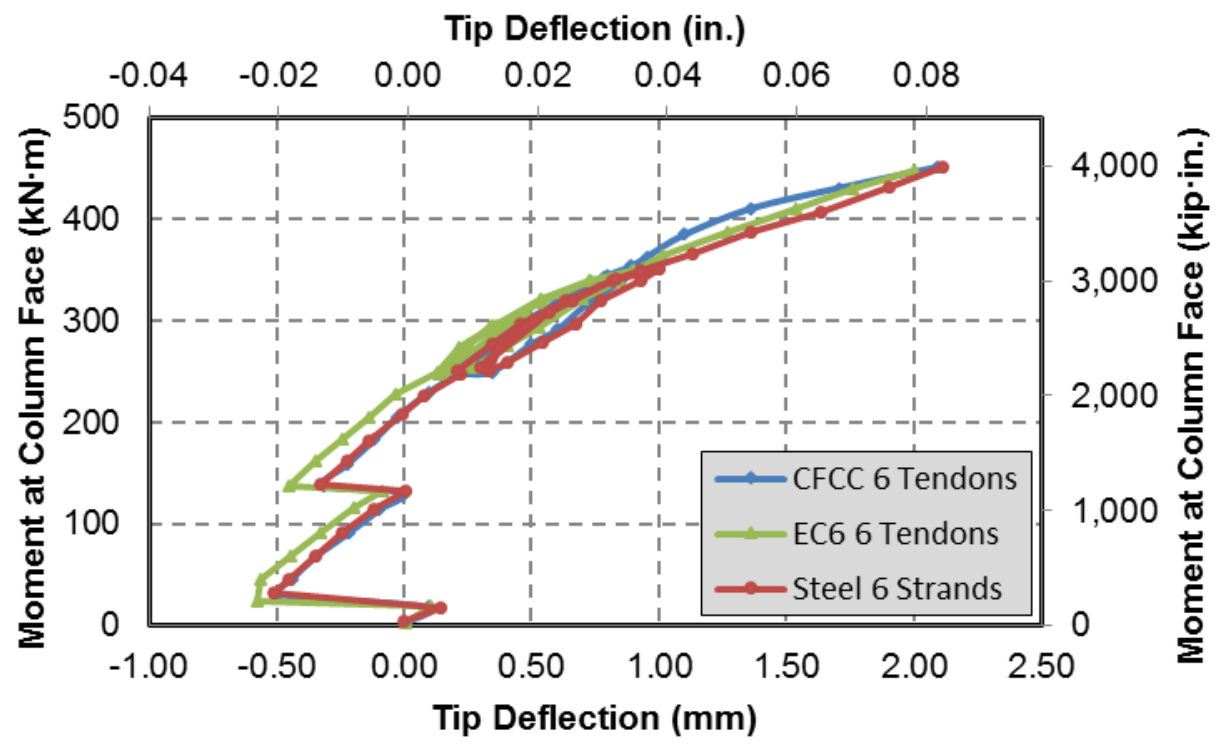

(b)

Figure 4.9 Moment-Tip Deflection Comparison of Pier Cap Model: (a) 8 Tendons, and (b) 6 Tendons 


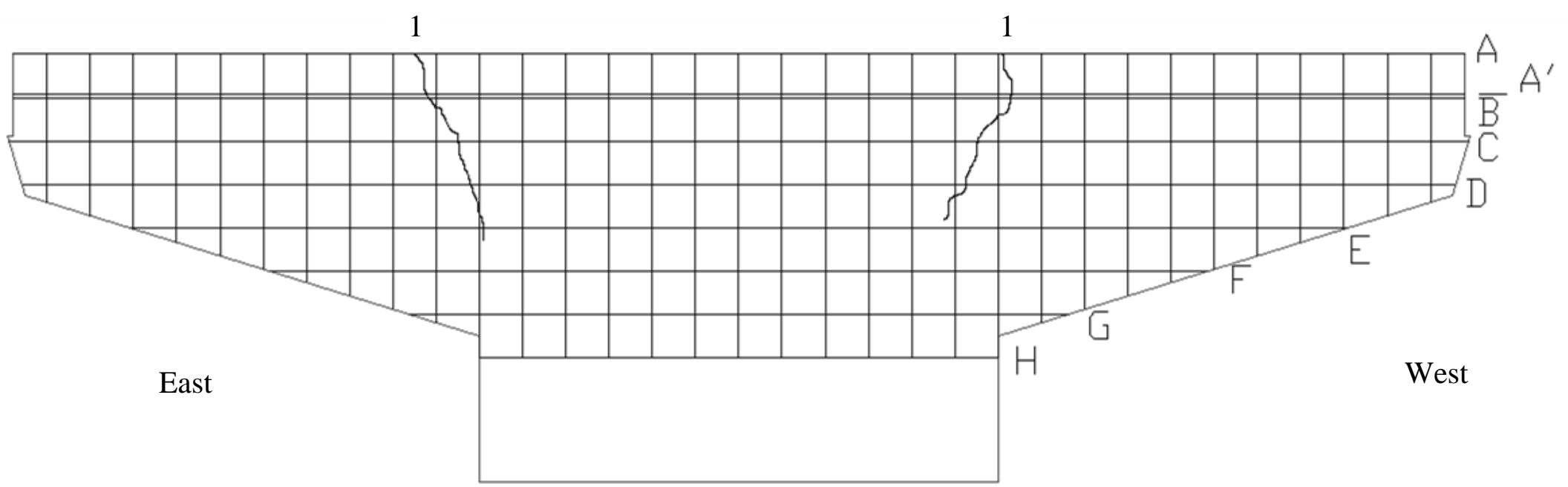

(a)

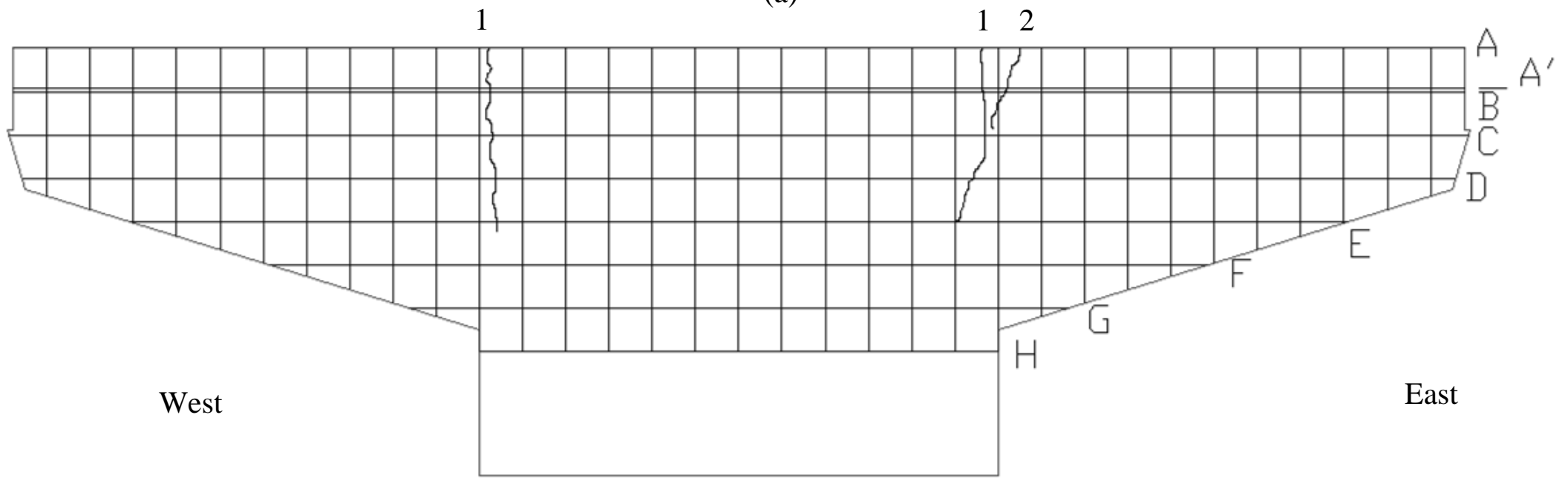

(b)

Figure 4.10 Crack Pattern: (a) North Side, and (b) South Side 


\title{
5. CREEP STRESS TEST OF CARBON FIBER COMPOSITE CABLE (CFCC) WITH FIELD-MADE ANCHORAGES AT HIGH STRESS LEVEL
}

\begin{abstract}
Carbon fiber reinforced polymer (CFRP) tendons can serve as a viable alternative to steel strands in prestressed concrete, which has suffered a serious problems related to the corrosion of the prestressing strands. This study conducted the creep stress tests using one of the commercial product carbon fiber composite cable (CFCC). The anchorages for all the specimens were prepared using a commercially available expansive grout by the research team. Specimens withstood 95\% of the guaranteed capacity provided by the manufacturer for a period of five months at room temperature $75^{\circ} \mathrm{F}\left(23.9^{\circ} \mathrm{C}\right)$, without any sign of rupture. The long-term performance of the anchorage was acceptable. All specimens were tested to failure to determine the residual strength after the creep stress test and the failure load for all tendons are beyond the manufacturer's guaranteed capacity.
\end{abstract}

\section{Keywords:}

Carbon fiber Composite Cable (CFCC); Fiber reinforced polymers (FRP); Creep; Residual Strength; Anchorage.

\subsection{Introduction}

Fiber reinforced polymer (FRP) is a composite material made of fibers, such as glass, carbon, or aramid, combined with a polymer matrix, which usually is epoxy or vinlyester resin. This type of new material has been widely used in different structural components over the past decades. The FRP rods and FRP tendons are used as an alternative to regular steel reinforcement and prestressing steel strands respectively to 
eliminate the corrosion issue of steel. For the application of prestressed concrete, carbon fiber reinforced polymer (CFRP) is more practical and popular, among different types of fibers, given the higher strength, higher elastic modulus, excellent durability, and higher fatigue strength.

Carbon fiber composite cable (CFCC) is one of the available commercial products, which is made by Tokyo Rope, Japan. CFCC tendons are made as the same way as steel strands by twisting several individual wires, and are available up to $40 \mathrm{~mm}$ (1.57 in.) in diameters and 1,070 KN (241 kip) in guaranteed strength. In this study, the 7-wire CFCC tendon with $12.5 \mathrm{~mm}$ (0.492 in.) in diameter, 2,421 MPa (351 ksi) in guaranteed strength, and $184 \mathrm{KN}$ (41.4 kip) in guaranteed capacity was chosen.

To date, numbers of studies have conducted to assess the feasibility, both in the aspects of design and construction, for using CFCC in prestressed concrete structures especially in the posttensioning application (Grace et al. 2003, 2008, 2011, and Yang et al. 2015 a \& b). And CFCC has already been used in the construction of several bridges in states (Grace et al. 2014, and Rohleder et al. 2008).

The investigation of the long-term behavior of CFCC is critical for the field applications. The relaxation, creep, and fatigue behavior of CFCC tendons was investigated by Saadatmanesh and Tannous (1999). CFCC tendons were tested in air and in chemical solution, which simulating aggressive condition, at different temperatures for a period of 3,000 hours. The loss of tensile stress at stress ratios 0.4 and 0.6 was less than $10 \%$. It was found that the initial stress level, and the type and temperature of the environment can affect the amount of stress loss. 
Elsafty et al. (2014) studied the effects on the material characteristics of CFCC under severe conditions. The un-stressed CFCC specimens were immersed in the alkaline solution with $\mathrm{PH}$ of 12.8 at four different temperatures over different time periods up 7,000 hours and then tested to failure. The results indicated that CFCC performed excellent durability with $7 \%$ degradation in the average tensile strength, which is still beyond the guaranteed strength provided by the manufacturer, and $2.6 \%$ reduction of the elastic modulus for the worst scenario.

Even though several studies have been conducted to investigate the long-term material characteristics of CFCC tendons, additional research is still required to help fully understand the long-term durability of this products. This study focused on the creep behavior of CFCC tendons at 95\% stress level of the guaranteed capacity provided by the manufacturer and the residual strength of the unbroken tendons. It must be noted that the regular grip system for steel strands cannot be used since the CFCC tendon is so brittle. Steel sleeves filled with a proprietary epoxy or grout should be used as the anchorage system for CFCC tendons. Therefore the research team casted all the anchorages for CFCC tendons specimens using a commercially available expansive grout Bustar. The long-term performance of the anchorage material was also another factor need to be considered and investigated in this study.

\subsection{Experimental Work}

\subsubsection{Specimen Preparation}

The CFCC tendons used in this study are shown in Figure 5.1. It was received as one coil and then was cut into pieces for the purpose of specimen preparation. Two types of grout were chosen initially, Sikadur 32 Hi-Mod epoxy and Bustar expansive grout. 
However, Sikadur 32 Hi-Mod epoxy was found out later in the CFCC rupture tests that it cannot provide enough bond to grip the tendons and slippage happened between the CFCC tendons and the epoxy. Therefore the preparation for the CFCC tendons with the anchorage filled with Sikadur 32 Hi-Mod epoxy is not included in the paper.

Two CFCC specimens were made for testing the performance of the Bustar expansive grout. Two pairs of steel tubes with a length of $381 \mathrm{~mm}(15 \mathrm{in}$.$) and 508 \mathrm{~mm}$ (20 in.) respectively were used. The outside diameter of both steel tube is $38.1 \mathrm{~mm}$ (1.5 in.) with a wall thickness of $6.35 \mathrm{~mm}(0.25 \mathrm{in}$.). The mechanical properties of the steel sleeve correspond to A531-MT1020 steel drawn over a mandrel (DOM) tube are: yield strength of $414 \mathrm{MPa}$ (60 ksi) and ultimate strength of $483 \mathrm{MPa}(70 \mathrm{ksi})$. The tubes were manually machines with a 6 threads count per inch on the exterior surface over the entire length to match an industry standard hardened steel hexagonal threshed nut.

A wooden frame, shown in Figure 5.2, was fabricated to align the CFCC tendons to be concentric with the Bustar expansive grout filling which was poured within the steel sleeves. The wooden frame consists of four parts of vertical timbers. Several platforms consisted of two pieces of plywood with two $38.1 \mathrm{~mm}$ (1.5 in.) diameter pre-drilled holes were connected and aligned by the timbers. The top sleeve and bottom sleeve are aligned between the top, middle, and bottom main compartments of the frame. Steel washers were used and sealed on the bottom and top end of the steel sleeves to secure the CFCC tendons to be concentric within the sleeves during the casting of Bustar.

Bustar is a non-explosive demolition agent. It has been used in construction projects ranging from concrete removal and concrete demolition of structures ranging 
from small equipment pads to massive bridge piers, heavily reinforced turbine foundation. Bustar expands more with longer duration of the set time. It will continue to work up to 7-day time frame to reach an expansive pressure of 7,000 $\mathrm{T} / \mathrm{m}^{2}$ (9,956 psi). There are three types of Bustar and the "Blue” Bustar was the one utilized in this study because of the higher allowable working temperature. The interaction between the increase in volume of Bustar and the steel tube radial restraint is what creates the necessary frictional force to anchor the CFCC tendon inside the steel sleeve.

A pilot test, the CFCC rupture test, was conducted to test the performance of the anchorage filled with Bustar. After the CFCC rupture test, the fabrication of the anchorage for CFCC tendons was modified. The material properties and general sleeve dimensions were the same as the ones described in the previous paragraph. The steel sleeve was machined with the interior thread at the top and bottom end inside the tube and without any outside thread on the exterior surface. The CFCC tendons was positioned concentrically aligned inside the steel sleeve with two $12.7 \mathrm{~mm}\left(1 \frac{1}{2} \mathrm{in}\right.$.) thick threaded washers, which were fabricated using a $28.58 \mathrm{~mm}(1-1 / 8 \mathrm{in}$.) diameter threaded rod as shown in Figure 5.3(a). The top washer allows the tendon to pass through concentrically within the steel sleeve, whereas the bottom washer has internal thread that allows the use of a head cap screw which is for preventing the leakage of the Bustar during casting. The head cap screw was removed in 24 hours after casting. The objective was to retain Bustar grout inside the sleeves and be able to fully engage the steel threaded rod, shown in Figure 5.3(b), which will be attached to either the testing frame or the hydraulic jack for the creep stress tests. 


\subsubsection{CFCC Rupture Test}

Both CFCC tendons with anchorages filled with Sikadur 32 Hi-Mod epoxy and Bustar expansive grout were tested. However, slippage occurred between the CFCC tendons and Sikadur $32 \mathrm{Hi}-$ Mod epoxy. Therefore only the test details for the specimen with the anchorage using Bustar expansive grout are discussed in this section.

Figure 5.4(a) shows the test setup. Four A513 steel tubes were cut into a length of $457.2 \mathrm{~mm}$ (18 in.) and used along with three $25.4 \mathrm{~mm}$ (1 in.) thick steel plates to create a self-reacting frame for applying the tensile load. The plates were aligned using four threaded rods and the test frame was designed to ensure a concentric alignment for the CFCC tendons. During the loading process, the frame was enclosed with a Plexiglas box for safety precautions to contain flying debris from ruptures CFCC tendons. A pair of low profile hydraulic jacks was used to tension the tendons up to the failure. The load was read through a data acquisition system by using a pressure transducer which was connected to the hand pump.

Figure 5.4(b) shows the fragments of the CFCC tendons after rupture. The failure load was $249 \mathrm{KN}$ (56 kip) and $258 \mathrm{KN}$ (58 kip) for the specimen with $381 \mathrm{~mm}$ (15 in.) and $208 \mathrm{~mm}$ (20 in.) sleeve length respectively. No slippage was observed between the tendons and the Bustar grout. The Bustar expansive grout under confinement within the steel sleeves develops sufficient pressure on the CFCC tendons to prevent any possible slippage.

\subsubsection{Creep Stress Test Setup and Instrumentation}

The test frame for the creep stress test is shown in Figure 5.5. The structural elements, plates, HSS, and W sections were attached using fillet welds. A custom-made 
transparent protective screen enclosure was made to cover the specimens all around during the experiment. This test frame is designed for four CFCC tendons stressed at the same time.

Special mechanism was adopted for this creep stress test to compensate the stress loss and stabilize the load on the specimens due to relaxation, since the relaxation of CFCC tendon is at the same level as low relaxation steel strands which range from $1.25 \%$ to $4.5 \%$ based on different initial stress level.

The Belleville washers were chosen initially to serve as the special mechanism to compensate the stress losses. Two Belleville washers were placed in parallel at the bottom of the frame followed by a $12.7 \mathrm{~mm}(1 / 2 \mathrm{in}$.) think steel bearing plate with a center hole, one load cell, a second bearing plate, and finally the nuts that fit the thread rod, as shown in Figure 5.6. On top of the frame, a bearing plate was placed, followed by a nut, the loading chair, a hydraulic jack, a second bearing plate, and another nut to complete the loading system for the tensioning of the specimens. The loading chair rested on two $12.7 \mathrm{~mm}(1 / 2 \mathrm{in}$.$) thick steel plates. The two extra plates were adopted to avoid direct$ contact between the chair legs and fillet weld of the frame.

The Belleville washer is a convex disc supported at the outer periphery by one force and an opposing force on the center of the disc. Belleville disc are made from High Carbon (C1075) steel with an elastic modulus of 206.8 GPa (30,000 ksi) and a Poisson’s ratio of 0.30 . The washers was supposed to spring back when the relaxation loss occurs therefore to compensate the loss and maintain a constant load on the specimens. However, the decrease of the stress level on the specimens cannot be controlled by the Belleville washers after several trials at different initial stress levels and different time periods. No 
difference was found between the specimen with washer and without washer. Careful visual inspection of the CFCC specimens and the marking of on the tendons indicated slippage of the tendons with respect to the Bustar grout filled within the steel sleeve. The Belleville washers had a very high stiffness with limited deformation capability and thus did not contribute to maintain the tendons in the CFCC tendons since the slippage occurred, even though it was just a small amount of slip.

Therefore the research team explored an alternate method to maintain the constant tension force in the tendons, the helical steel springs. The outside diameter of the helical spring is $304.8 \mathrm{~mm}$ (12 in.) with a stiffness of $1664 \mathrm{KN} / \mathrm{m}$ (9.5 kip/in.). Accounting for the slippage of the tendons, the coil spring has sufficient reserve capacity with a total deflection of $203.2 \mathrm{~mm}$ (8 in.), which will ensure the application of compressive force all the time during the tests.

The test frame was modified to accommodate the mounting of four helical steel coil springs. The loading chair was redesigned, and four additional steel plates were used to act as a bearing surface for the load cell and the locking nuts. Moreover, considering the height and the weight of the spring, which is around $90.7 \mathrm{~kg}$ (200 lb), the steel frame was placed horizontally during the test for safety reason. Figure 5.7 shows an overview of the test frame with coil springs. Four new CFCC specimens were made and tensioned approximately to $95 \%$ of the guaranteed capacity provided by the manufacturer. The load on each specimen was measured by one calibrated load cell which was connected to the data acquisition system. The specimens were tensioned on by one through a sequential loading sequence. 


\subsubsection{Creep Stress Test Results and Discussions}

The data was recorded once a day every weekday, totally for 151 days (3,624 hours) as the test period. A summary of the tension force on each specimen is shown in Table 5.1. The average initial stress ratio for four specimens was 0.952 and average $1.3 \%$ load loss occurred during the period of test which turned the final average stress level into 0.939 of the guaranteed breaking load.

The plot of load ratio versus the testing time in hour is shown in Figure 5.8. The major load losses were happened at the begin stage of the entire test period and the load was approximately maintained constantly after 1,000 hours. Figure 5.9 shows load ratio versus log time of stress time in hour.

\subsubsection{Residual Strength of CFCC Tendons}

After the creep stress test, all specimens were completely de-tensioned and removed from the test frame. The residual strength test, one tendon at a time, was conducted on the same test frame.

Table 5.2 summarized the breaking load for each specimen. Strengths for all four specimens exceed the manufacturer's guaranteed breaking load of $184 \mathrm{KN}$ (41.1 kip). In addition, the residual strengths are compared with the failure loads recorded in the CFCC rupture test, average $254 \mathrm{KN}$ (57 kip). The graphical comparison of the cited ratios is shown in Figure 5.10. The ratio of the residual strength of CFCC tendons to the guaranteed breaking load is expected to be much greater than one. However, specimen No. 2 (SP-2), which failed at $188 \mathrm{KN}$ (42.3 kip), showed underperformed. The average of the two ratios for the rest three specimens are shown by the dash line in the figure. The actual average failure load of CFCC tendons, after 151 days stressed at 95\% initial stress 
level, is still $24.4 \%$ more than the guaranteed breaking load provided by the manufacturer. However, the failure strength of the specimens has been decreased by about $10 \%$ compared to the CFCC tendons tested in the CFCC rupture test.

The failed specimens were visually inspected after the tests, shown in Figure 5.11(a). The failure patterns of all the specimens were similar exhibiting sudden and complete rupture accompanied by loud noise. The only one that shows a different failure mode is specimen No. 4 (SP-4). The tendons were completed gone for SP-4. This might be attributed to the fact that this specimen held the highest load. Therefore the blast was stronger as a result of a higher energy release. Furthermore, it was detected that specimens lost between $19 \mathrm{~mm}$ (0.75 in.) to $35 \mathrm{~mm}$ (1.38 in.) depth of Bustar confinement at the interior end of each steel tube, as shown in Figure 5.11(b). The loss the Bustar could lead to the decrease of the anchorage force, which may affected the failure test results.

\subsection{Conclusions}

The creep behavior for the CFCC tendons at a high stress ratio, $95 \%$ of the manufacturer's guaranteed capacity, was investigated for a period of 3,624 hours. Two types of material, Sikaduar 32 Hi-Mod epoxy and expansive grout Bustar were used for the anchorage of all CFCC specimens. The residual strength test for the specimens was also conducted. The following conclusions may be drawn from this study:

- Sikadur $32 \mathrm{Hi-Mod}$ did not perform as expected in providing the ideal bond with CFRP tendons. Slippage was observed between tendon and grout. Hence, breaking load could not be achieved with CFRP tendons. This epoxy is not recommended for anchoring systems of CFCC tendons. 
- It is feasible to make a generic anchorage device for CFCC tendons in the field with adequate strength, using expansive grout Bustar. Long-term performance of the grout will require further in-depth studies.

- Creep stress test of four CFCC tendons at 95\% of manufacturer guaranteed strength for a period of over 3,624 hours shown that the stress level can be maintained and that no sign of rupture exists in the tendons.

- Average residual strength ranged from 122 to $127 \%$ compared to guaranteed manufacturer's breaking load. The strength loss after 3,624 hours at an average load ratio of 0.94 ranged from -7.7 to $-11.4 \%$ compared with the average experimental breaking load of $254 \mathrm{KN}$ (57 kip) as reference.

- Further study is suggested for determining the effects of loss in anchoring force when testing for residual strength.

\section{Acknowledgements}

This study was sponsored by the Florida Department of Transportation under the supervision of Mr. William Potter as Project Manager. All experiments were conducted at the Titan America Structures and Construction Testing Laboratory of the Florida International University. The views and findings reported here are those of the writers alone, and not necessarily the views of sponsoring agencies.

\section{Notation}

The following symbols are used in this paper:

$P_{i}=$ initial tension force;

$P_{s}=$ the tension force at the end of creep stress test

$P_{u 1}=$ residual strength of CFCC tendon 
$P_{u 2}=$ manufacturer's guaranteed breaking load

$P_{u 3}=$ average experiment breaking load 


\section{References}

Grace, N.F., Bebawy, M., and Ushijima, K. (2014). "Field Application of Composite Post-Tensioning System.” Concrete International, ACI, 36(11), 39-42.

Grace, N., Enomoto, T., Abel-Mohti, A., Tokal, Y., and Puravankara, S., (2008). "Flexural Behavior of Concrete Box Beams Post-tensioned with Un-bonded Carbon-Fiber-Composite Cables.” PCI Journal, 53(4), 62-82.

Grace, N., Enomoto, T., Abdel-Sayed, G., Yagi, K., and Collavino, L. (2003). "Experimental Study and Analysis of a Full-Scale CFRP/CFCC Double-Tee Bridge Beam.” PCI Journal, 48(4), 120-139.

Grace, N., Patki, K., Soliman, E., and Hanson, J. (2011). "Flexural Behavior of Side-byside Box-beam Bridges: A Comparative Study.” PCI Journal, 56(3), 94-112.

Rohleder, W.J., Tang, B., Doe, T.A., Grace, N.F., and Burgess, C.J. (2008). "Carbon Fiber-Reinforced Polymer Strand Application on Cable-Stayed Bridge, Penobscot Narrows, Maine.” Journal of Transportation Research Board, 2050, 169-176.

Yang, X., Zohrevand, P., Mirmiran, A., Arockiasamy, M., and William, P. (2015a). "Post Tensioning of Segmental Bridges using Carbon Fiber Composite Cables.” PCI Journal, 60(3), 50-62.

Yang, X., Zohrevand, P., Mirmiran, A., Arockiasamy, M., and William, P. (2015b). “A Comparative Study of Unbonded Carbon Fiber and Steel Strands in Posttensioned Pier Caps.” Journal of Composites for Construction, hard copy in press. DOI: 10.1061/ (ASCE) CC.1943-5614.0000596.

ElSafty, A., Benmokrane, I., Rizkalla, S., Mohamed, H., and Hassan, M. (2014). "Degradation Assessment of Internal Continuous Fiber Reinforcement in Concrete Environment.” Final Report, Florida Department of Transportation, Tallahassee, FL, 297 p.

Saadatmanesh, H., and Tannous, F. E. (1999). "Relaxation, Creep, and Fatigue Behavior of Carbon Fiber Reinforced Plastic Tendons.” ACI Materials Journal, 96(2), 143153. 
Table 5.1 Test Results Summary for the Creep Stress Test

\begin{tabular}{|c|c|c|c|c|c|c|}
\hline Specimen & $\mathrm{P}_{\mathrm{i}}, \mathrm{KN}$ (lb) & $\begin{array}{l}\text { Initial } \\
\text { Load } \\
\text { Ratio }\end{array}$ & $\begin{array}{l}\text { Sustained } \\
\text { Load } \\
\text { Duration } \\
\text { (hr) }\end{array}$ & $\mathrm{P}_{\mathrm{s}}, \mathrm{KN}$ (lb) & $\begin{array}{l}\text { Final } \\
\text { Load } \\
\text { Ratio }\end{array}$ & $\begin{array}{l}\text { \% Load } \\
\text { Loss }\end{array}$ \\
\hline SP-1 & $177(39,730)$ & 0.960 & 3,624 & $176(39,462)$ & 0.954 & $-0.67 \%$ \\
\hline SP-2 & $174(39,190)$ & 0.947 & 3,624 & $172(38,638)$ & 0.934 & $-1.41 \%$ \\
\hline SP-3 & $175(39,280)$ & 0.950 & 3,624 & $173(38,979)$ & 0.942 & $-0.77 \%$ \\
\hline SP-4 & $175(39,315)$ & 0.950 & 3,624 & $170(38,269)$ & 0.925 & $-2.66 \%$ \\
\hline
\end{tabular}

Table 5.2 Breaking Load Summary and Comparison

\begin{tabular}{cccc}
\hline Specimen & $\mathrm{P}_{\mathrm{u} 1}, \mathrm{KN}(\mathrm{lb})$ & $\mathrm{P}_{\mathrm{u} 1} / \mathrm{P}_{\mathrm{u} 2}$ & $\mathrm{P}_{\mathrm{u} 1} / \mathrm{P}_{\mathrm{u} 3}$ \\
\hline SP-1 & $229(51,414)$ & 1.242 & 0.902 \\
SP-2 & $188(42,271)$ & 1.021 & 0.742 \\
SP-3 & $225(50,494)$ & 1.220 & 0.886 \\
SP-4 & $233(52,586)$ & 1.270 & 0.923 \\
\hline
\end{tabular}

Note:

- Pu1: Residual Strength of CFCC Tendon

- Pu2: Manufacturer's Guaranteed Breaking Load, 184 KN (41.4 kip)

- Puз: Average Experimental Breaking Load, 254 KN (57 kip 


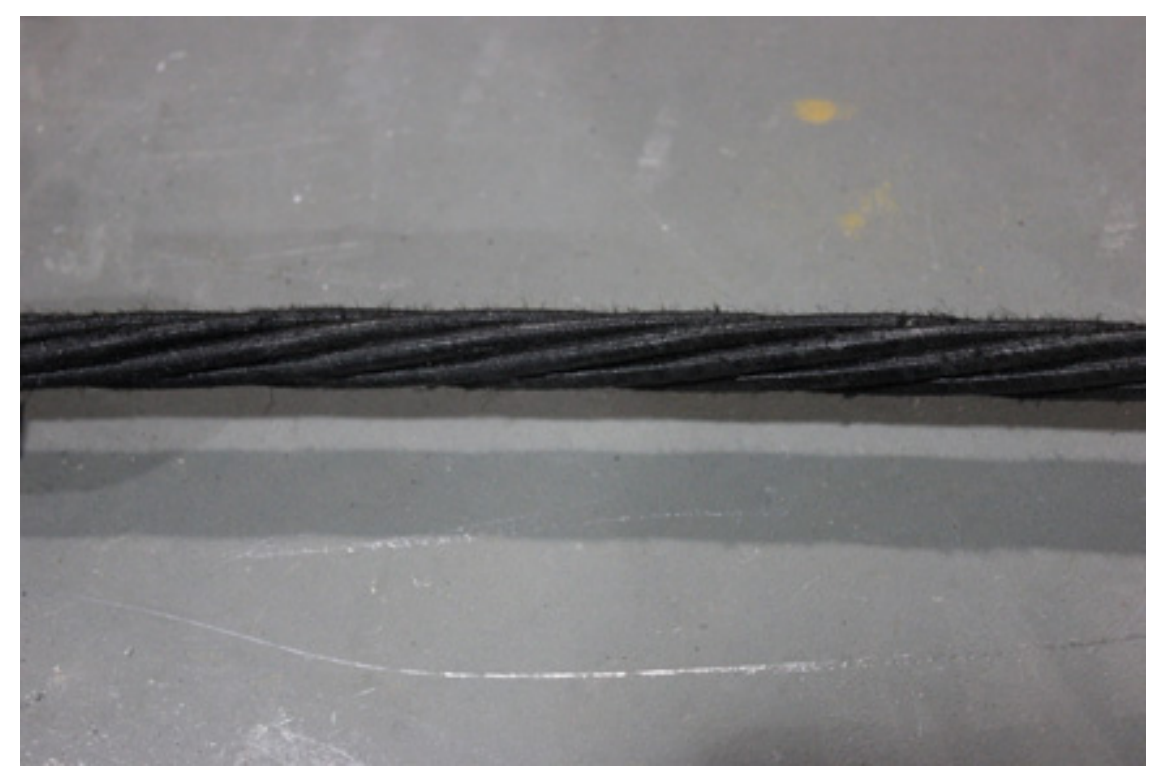

Figure 5.1 CFCC Tendons

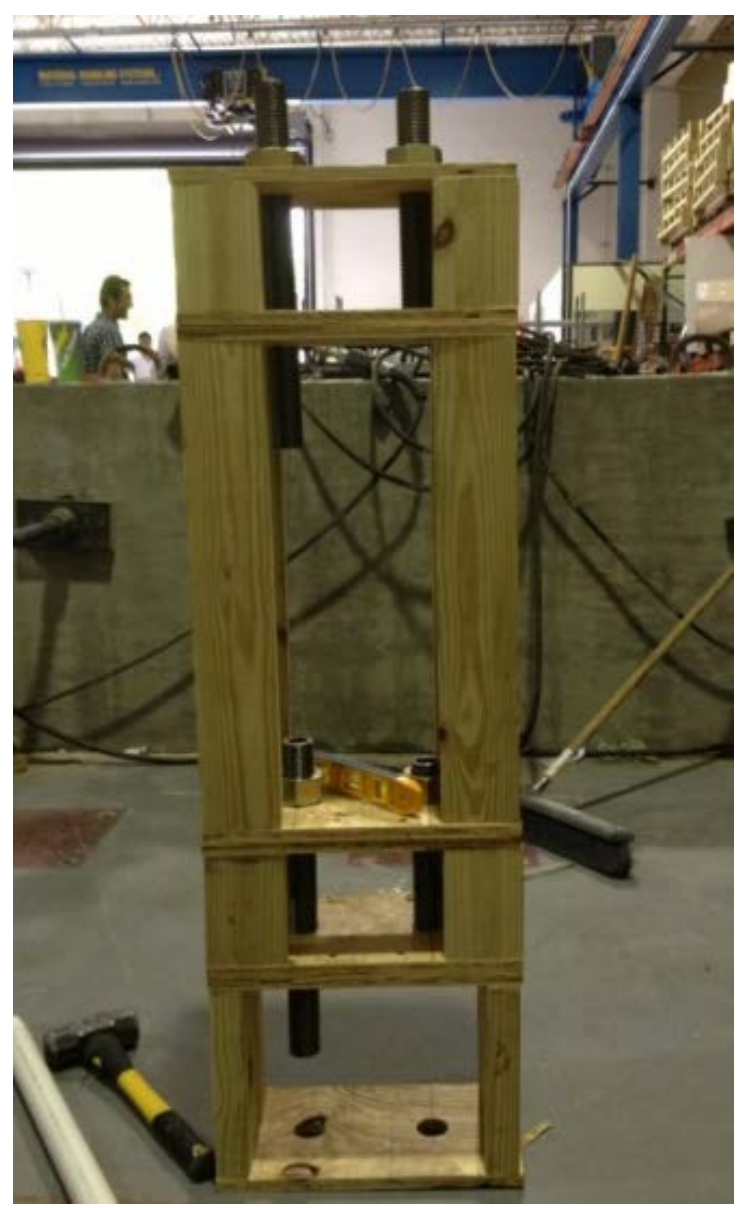

Figure 5.2 Wooden Frame for Casting 


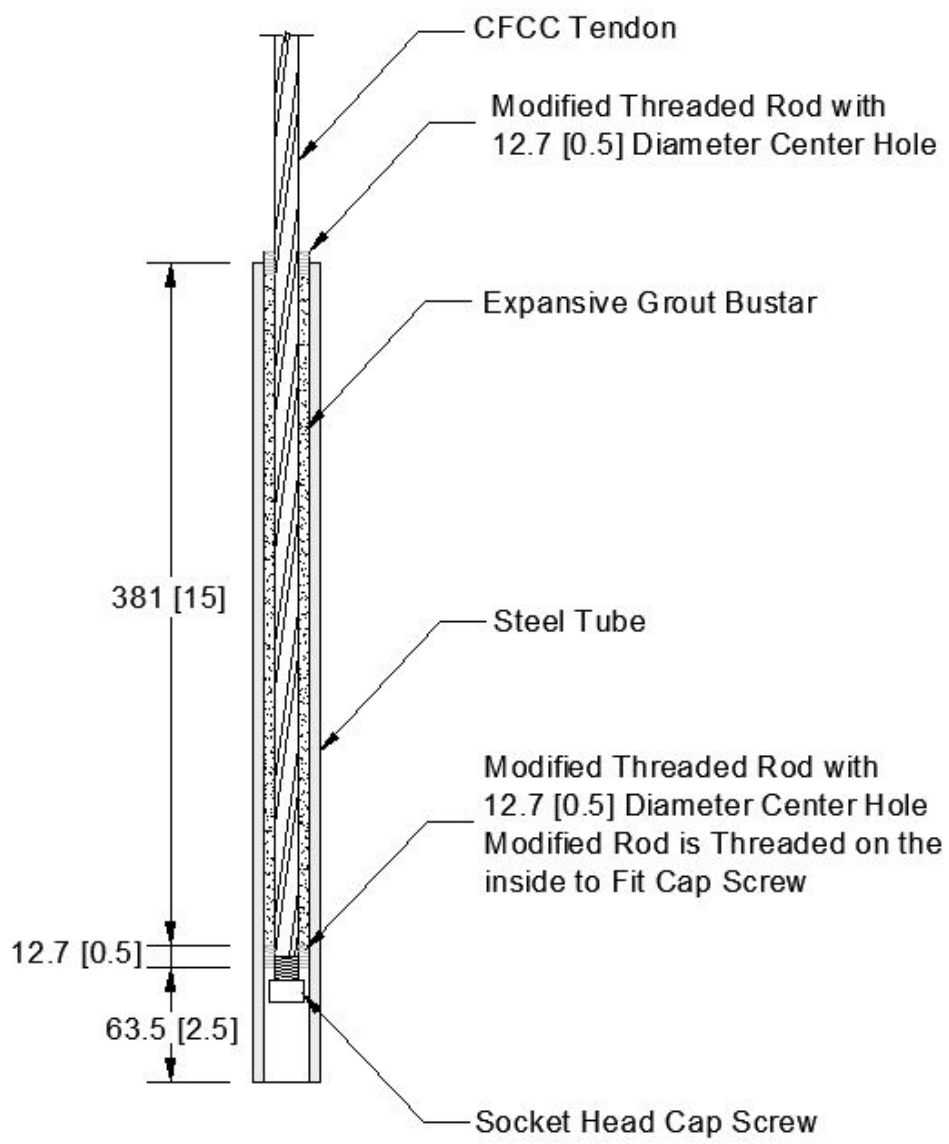

(a)

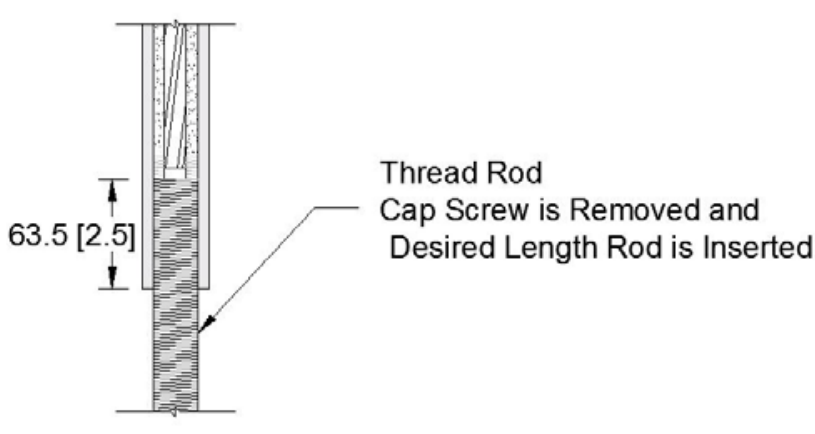

(b)

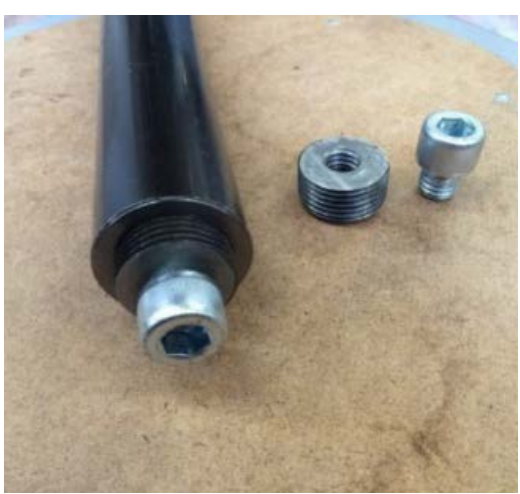

(c)

Dimensions are in mm [in.]

Figure 5.3 CFCC Tendon Anchorage: (a) Anchorage Sleeve Details for Bustar Expansive Cement Grout, (b) Threaded Rod for Tensioning, and (c) Screws used for Anchorage Casting 


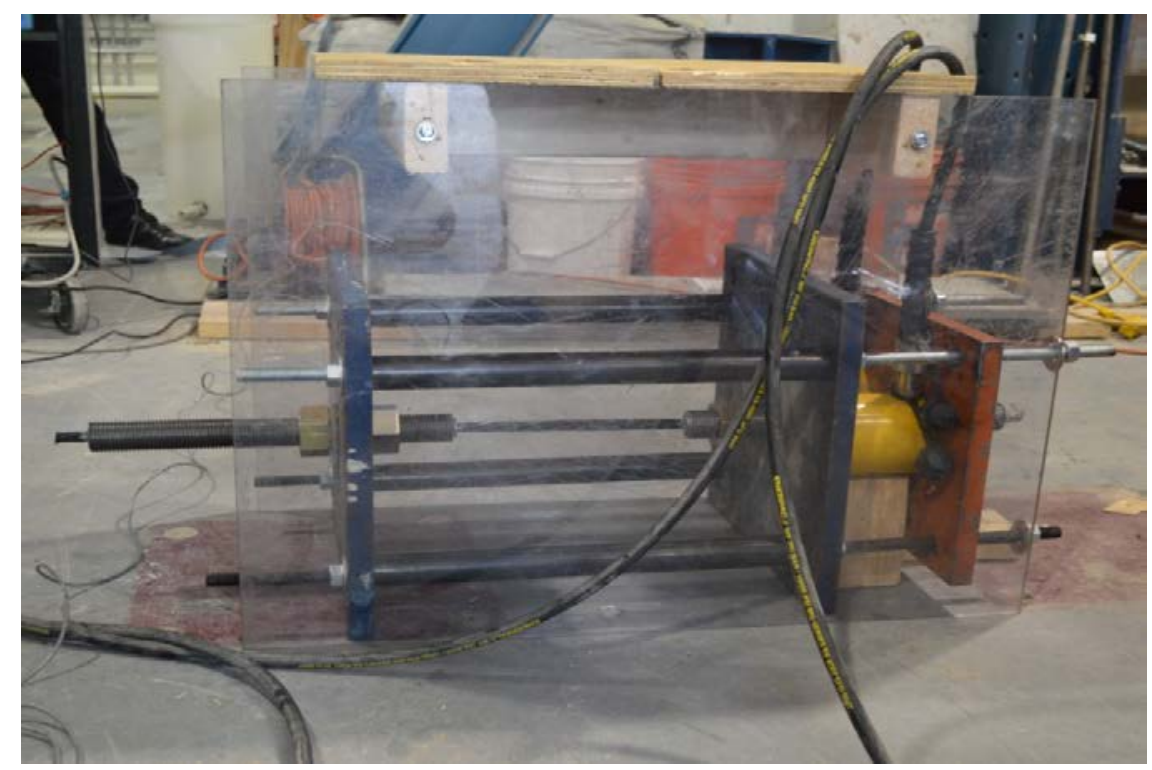

(a)

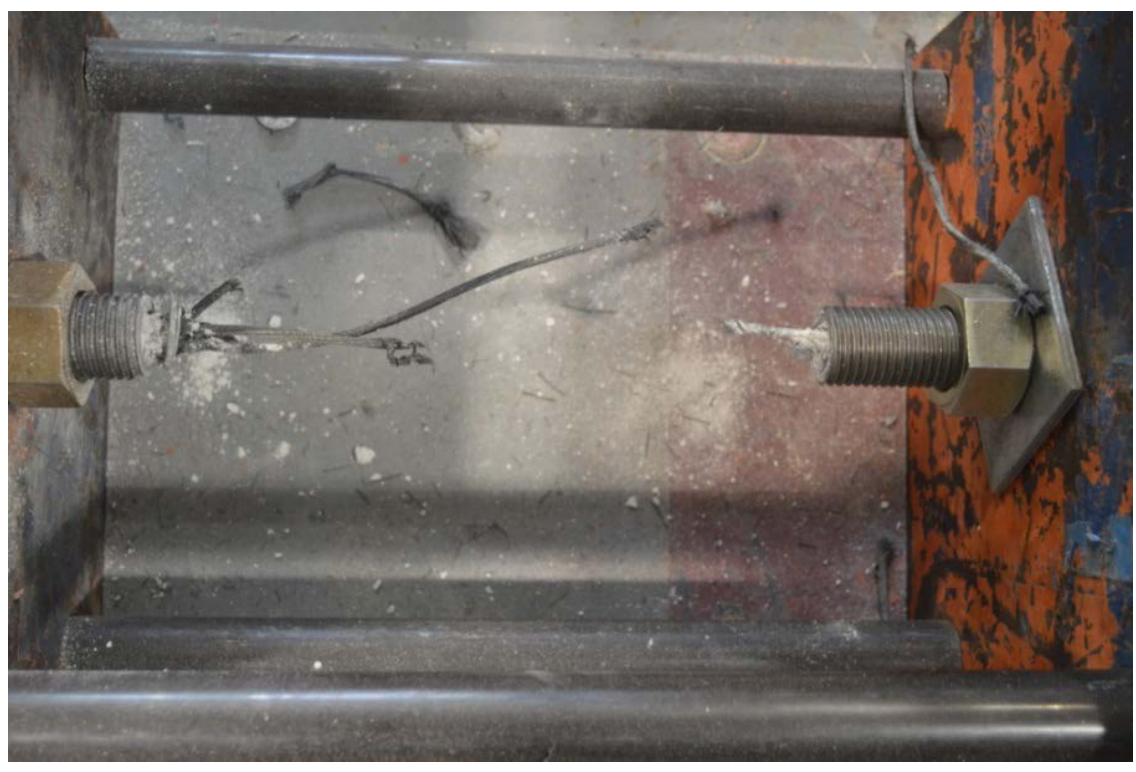

(b)

Figure 5.4 CFCC Rupture Test: (a) Test Setup, (b) Ruptured CFCC Tendon 


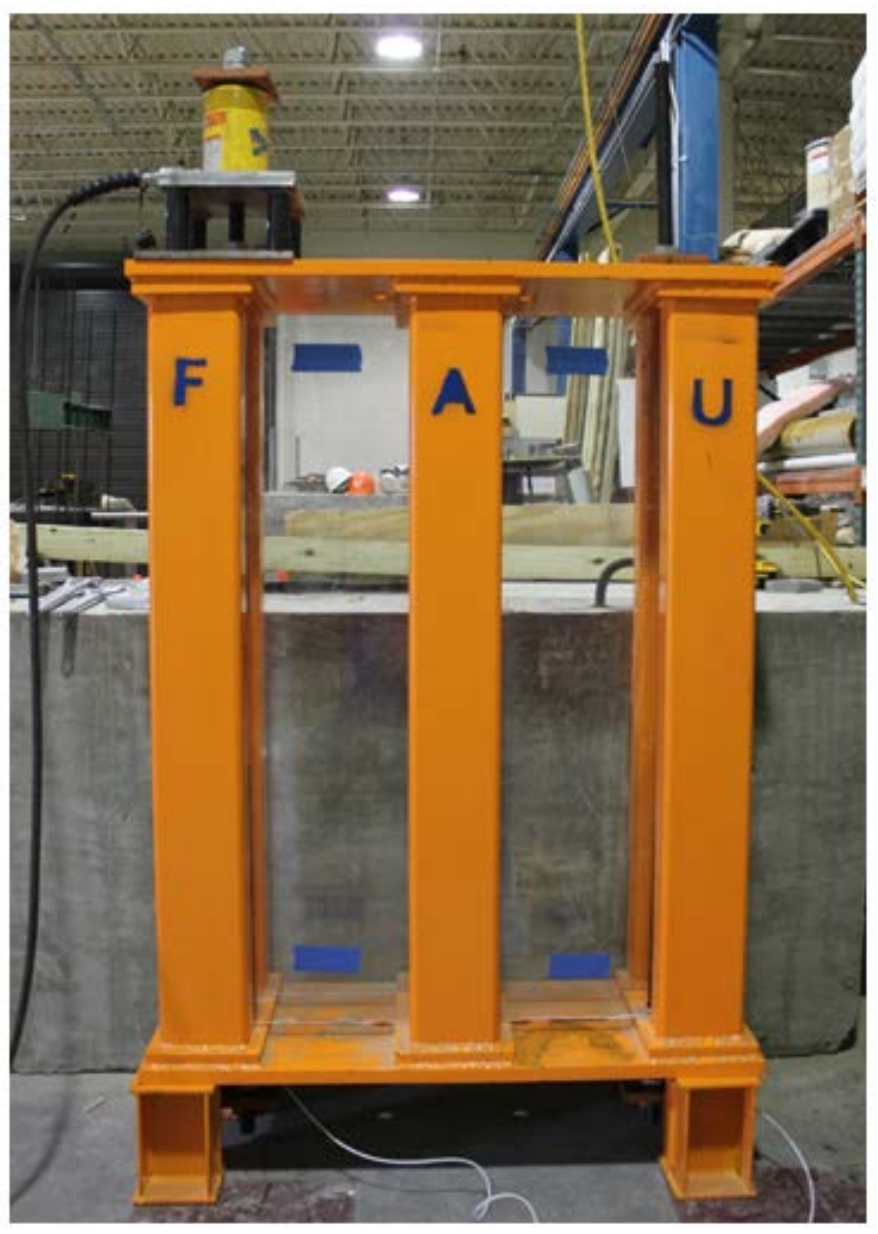

Figure 5.5 Test Frame for Creep Stress Test 


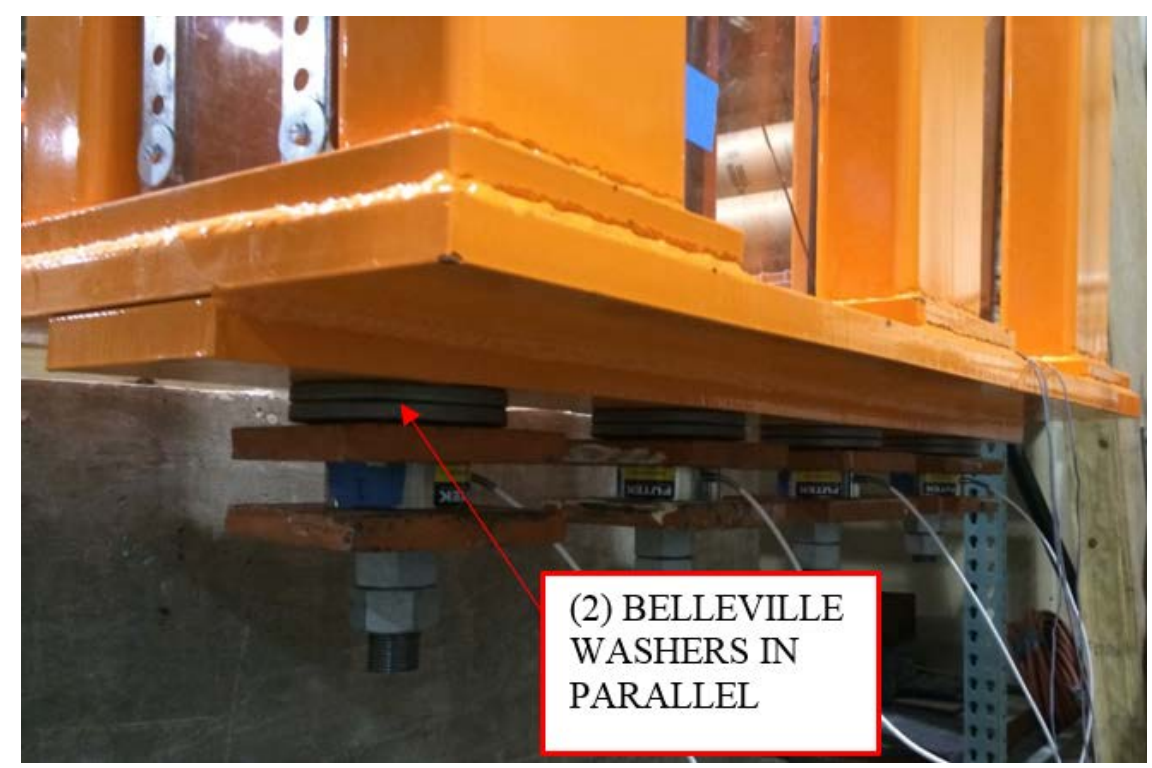

Figure 5.6 Creep Stress Test with Belleville Washers

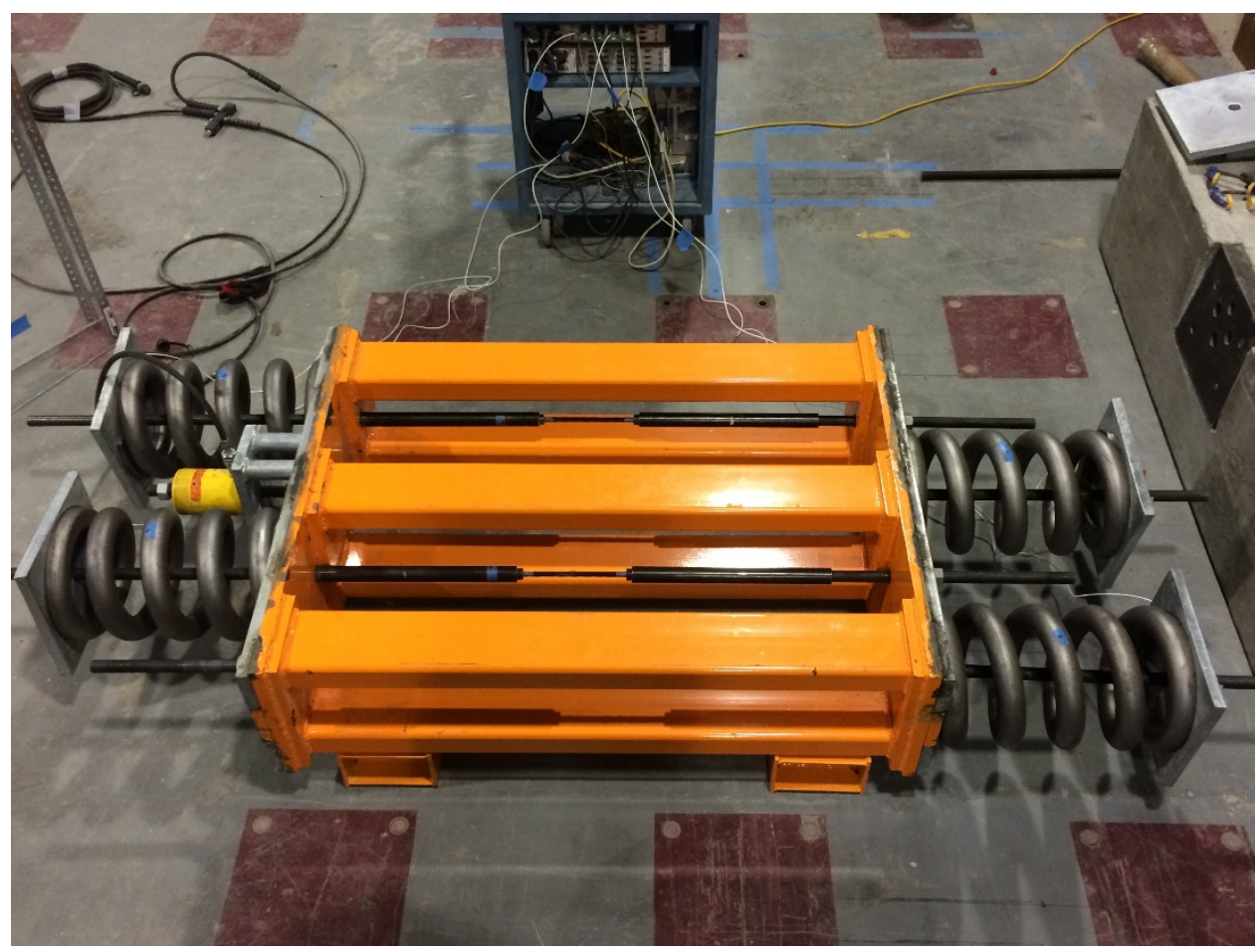

Figure 5.7 Creep Stress Test with Coil Springs 


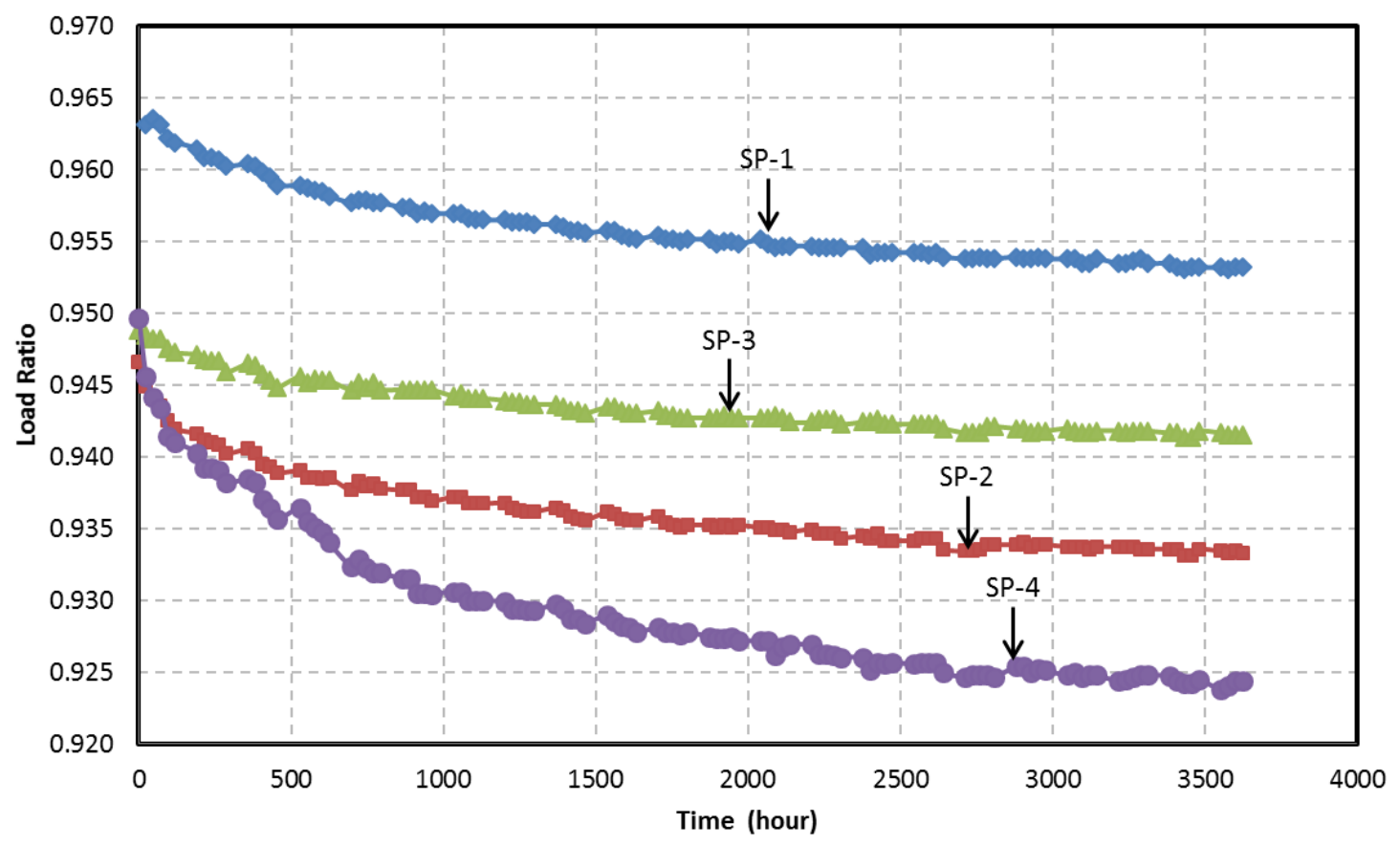

Figure 5.8 Load Ratio vs. Time (hour)

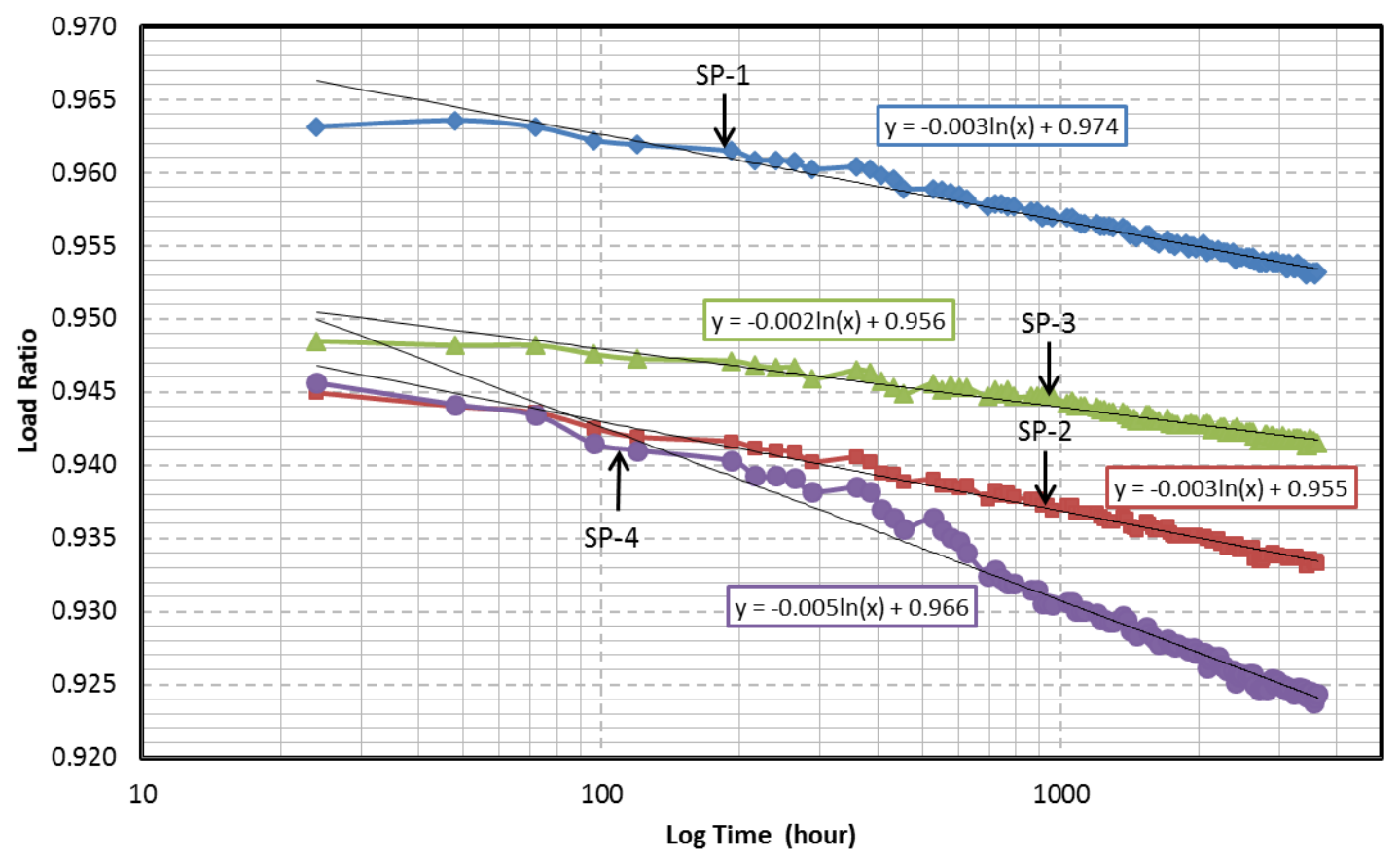

Figure 5.9 Load Ratio vs. Log Time (hour) 


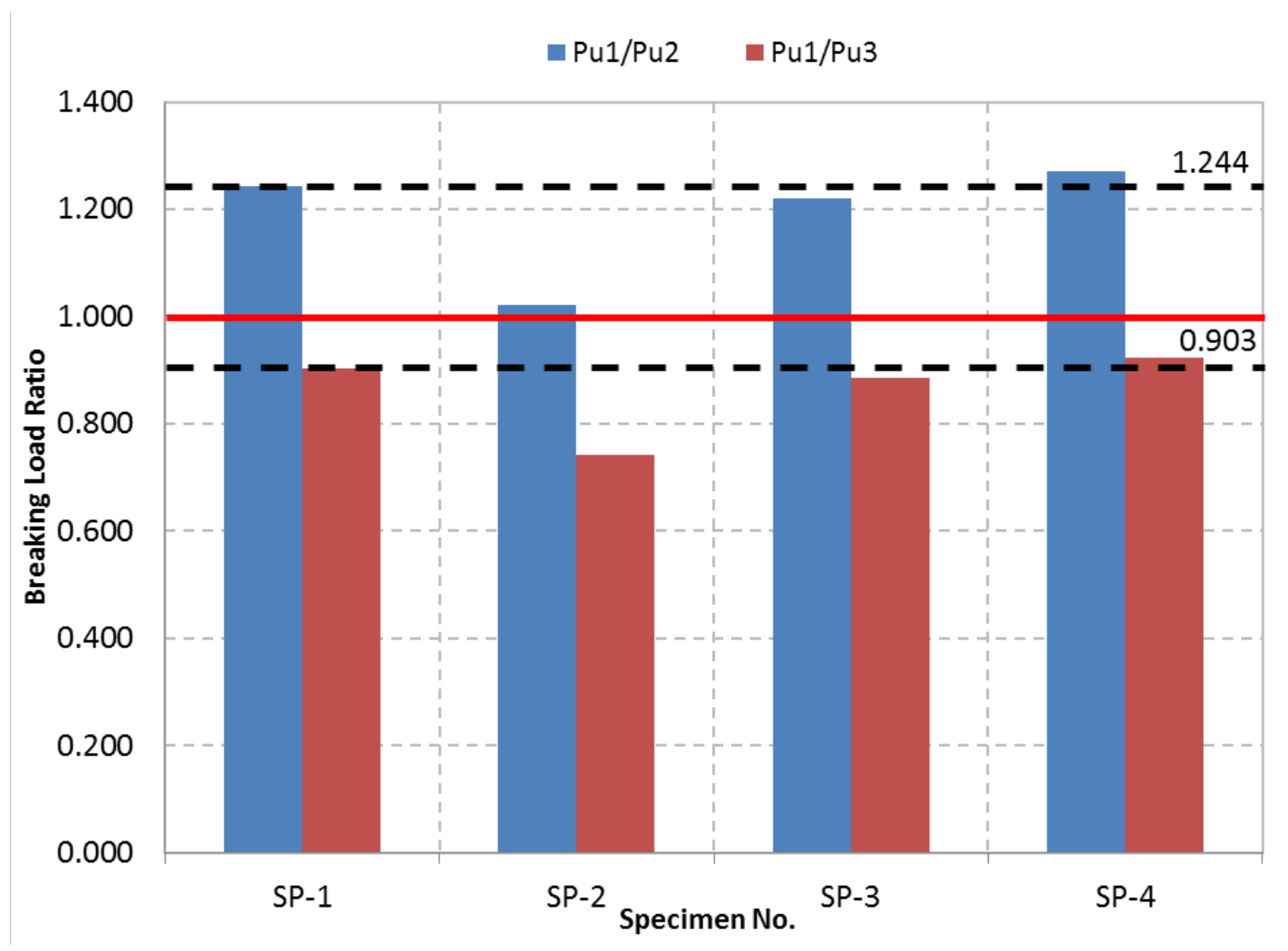

Figure 5.10 Residual Strength Test Results Comparison 


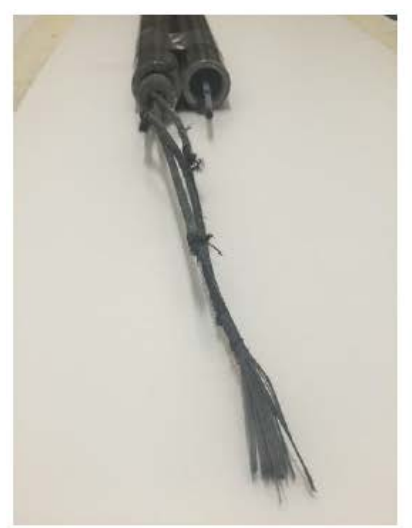

SP-1

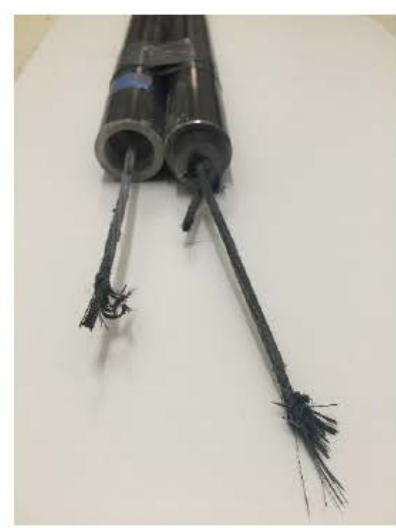

SP-3

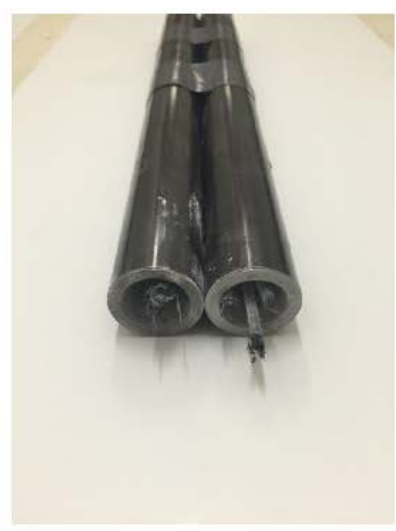

SP-4

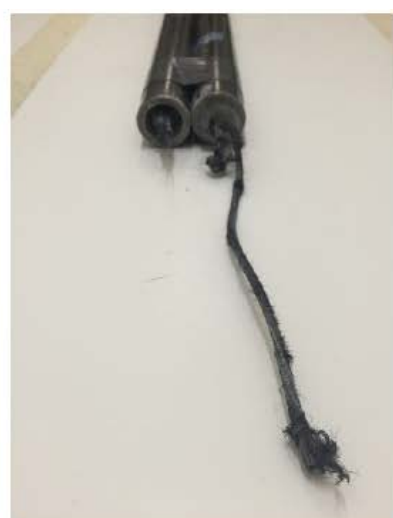

SP-2

(a)
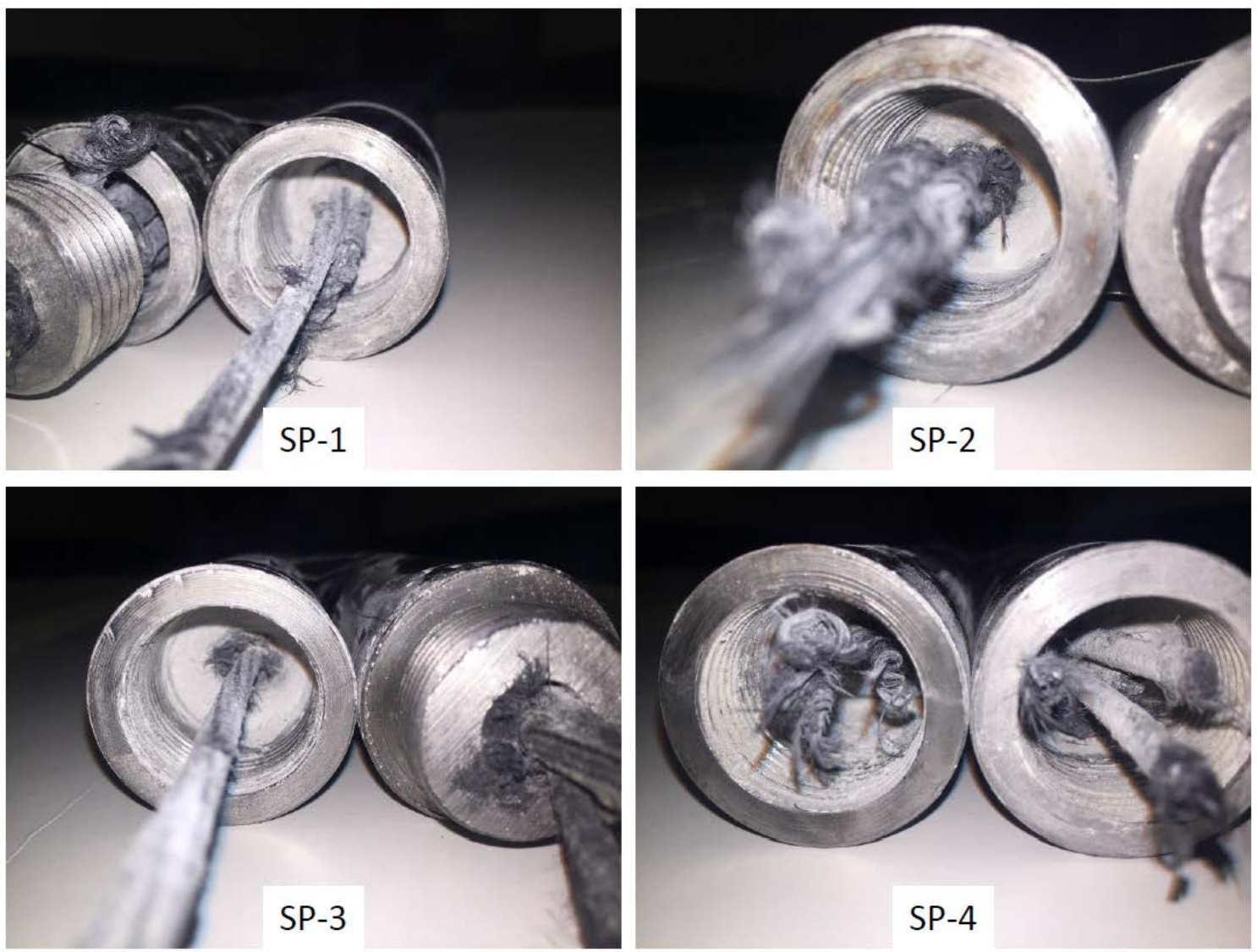

(b)

Figure 5.11 Specimen Failures after Residual Strength Test: (a) Ruptured CFCC Tendons, (b) Bustar Expansive Cement Grout Losses 


\section{RECOMMENDATIONS FOR DESIGN, CONSTRUCTION, INSPECTION, AND REPAIR SPECIFICATIONS}

\subsection{Review of Currently Available Specifications on CFRP Post-Tensioning System}

ACI 440.4R-04 provides guidelines for the design of concrete prestressed with FRP tendons. It covers the characteristics of different FRP tendons and anchorages, flexural design, shear design, serviceability, bonded development length, and unbonded external tendon systems.

ISIS Canada Design manual No. 5 provides comprehensive information regarding the design of prestressed concrete members using FRP, covering almost the same topics as ACI 440.4R-04.

Japan Society of Civil Engineers (JSCE) had published some general recommendations for design and construction of concrete structures using continuous fiber reinforcing materials, back to the 1990s. They also published the quality assurance specifications and test methods for continuous fiber reinforcing materials.

Even though the ACI, ISIS, and JSCE provide the general recommendation, more specific design guidelines and construction specifications may be required due to different behaviors of different structural elements and different material properties of various FRP tendons.

Florida DOT has recently published the Fiber Reinforced Polymer Guidelines. One chapter covers the carbon fiber reinforced polymer (CFRP) Strands. However, only the application for piles is available at this stage and it mainly specifies the same recommendations as ACI. Guidelines and specifications for other structural elements, especially for unbonded post-tensioned system, are still required to be developed. 
Florida State University investigated the application of carbon fiber composite cables (CFCC) in prestressed concrete piles which included the installation of CFCC and stressing couplers, CFCC bond characteristics, and flexural capacity of CFCC prestressed pile.

Lawrence Technological University conducted several studies to investigate CFRP leadline tendons and CFCC in prestressed concrete applications. Experimental tests and analytical studies have been performed to assess the flexural behavior of decked bulb T-beams, AASHTO type I beams, box beams using CFRP materials, the transverse CFCC post-tensioning system for box beams and the unbonded external CFCC posttensioning system which was applied to the Bridge Street Bridge.

CFRP material has shown great potential to be used on bridge construction projects especially for prestressed concrete structures. However, no comprehensive specification and guideline has yet been developed for CFRP material.

Michigan and Maine DOTs have both provided some special provisions for CFCC transverse post-tensioning using CFCC strands. Methods and steps were provided to check the CFCC material properties including length, diameter, linear density, breaking load, tensile modulus, and elongation at break. The post-tensioning accessories, such as polyethylene sheathing, sheathing wrap, gasket, stress transfer plate, protective cover, connection rod, and stressing chair have all been standardized in these provisions. General storage, handling, and installation instruction has also been listed in the provisions. Information and standards for CFCC anchorage device and instrumentation for monitoring the tendons has also been summarized in Michigan DOT provisions. 
The objectives of this study were to develop recommendations for the design guidelines, construction specifications, inspection and repair specifications of CFRP posttensioning system for FDOT.

\subsection{Issues for Design Guidelines}

- Unbonded segmental bridges behave in a bilinear pattern. The initial stiffness of segmental bridge is mainly decided by the geometry of the concrete cross section. After decompression and joint opening of the segmental bridge, the stiffness of the cable itself would greatly affect the stiffness of the entire structure. Therefore, the cable with lower modulus of elasticity than steel may cause much more deflection beyond service limit. Given the higher flexibility of segmental bridges post-tensioned with CFCC and EC6, a stiffness-based equivalency approach could be appropriate, which will further reduce the maximum allowable stress level of 65\% specified in ACI 440.4R-04. However, the behavior beyond service limit is typically not a concern as long as the ultimate capacity are similar or meet the load demand at this stage of philosophy for design. Additionally, epoxy joints are required for the segmental bridges nowadays, which could provide some slight differences in behavior compared to the segmental bridge with dry joints.

- The general performances of pier cap using CFCC and EC6 were quite comparable with steel. For these types of short-span structures, as well as those members that require transverse post-tensioning, strength-based design philosophy, similar to steel strands, seems to be adequate, given the expected small deflections. 


\subsection{Issues for Construction Specifications}

- Both CFCC and EC6 are available in large diameters, which can reduce the number of tendons used in the structure to achieve the same amount of posttensioning load. It can also address the congestion problems at the anchorage and simplify the tensioning device.

- CFCC and EC6 have high strength in the longitudinal direction but in the lateral direction they are brittle and weak. Some damages were detected on CFCC at the corners of the deviators after finishing all experiments. Therefore, further protection is required for the cable in the lateral direction.

- A more efficient tensioning-anchoring system, which should allow a close spacing of tendons to optimize the system or allow for multiple strands to be tensioned simultaneously, is need for field applications. The new system should be able to pull the cable and cast the anchor on site. Additionally, curing of the grout used inside the sleeve should be within hours.

\subsection{Issues for Inspection and Repair Specifications}

- For the structures such as segmental bridge, which allow the access to the cables, the condition of the tendons can be detected visually much the same as what did in this study by mounting four web cameras inside the segmental bridge model to monitor the tendons during tensioning and testing. However, sometimes the visual detection maybe limited since some sort of covering (HDPE Pipe, etc.) should be provided for general protection due to potential construction activities or vandalism as the CFRP is very weak in shear. Therefore, it is important to include load cells for continuous monitoring of all carbon fiber strands. 
- For the structures, such as pier cap, which the condition of the cable cannot be detected visually, load cells are certainly needed.

- Since the unbonded CFRP post-tensioning system is not grouted, rehabilitation for the damaged cable will be much easier than the bonded system. Additionally, means should be provided to pull through and anchor additional strands if necessary. 
References

ACI Committee 440. (2011). "Prestressing Concrete Structures with FRP Tendons”, ACI 440.4R-04.

FDOT. (2015). “Fiber Reinforced Polymer Guidelines (FRPG).” FDOT Structural Manual V.4.

Grace, N. F., and Singh, S. B. (2003). "Design Approach for CFRP Prestressed Concrete Bridge Beams.” ACI Structural Journal, V. 100, No. 3, pp. 365-376.

Grace, N., Enomoto, T., Abel-Mohti, A., Tokal, Y., and Puravankara, S., (2008). "Flexural Behavior of Concrete Box Beams Post-tensioned with Unbonded Carbon-Fiber-Composite Cables.” PCI Journal, V. 53, No. 4, pp. 62-82.

Grace, N., Patki, K., Soliman, E., and Hanson, J., (2011) "Flexural Behavior of Side-byside Box-beam Bridges: A comparative Study.” PCI Journal, V. 56, No. 3, pp. 94-112.

Grace, N.; Enomoto, T.; Baah, P. and Bebawy, M., (2012). "Flexural Behavior of CFRP Precast Prestressed Decked Bulb T Beams.” ASCE Journal of Composites for Construction, V. 16, No. 3, pp. 225-234.

Grace, N.; Jensen, E.; Matsagar, V.; and Penjendra, P., (2013). "Performance of AASHTO Beam Bridge Prestressed with CFRP Tendons." Journal of Bridge Engineering, V. 18, No. 2, pp. 110-121.

Grace, N.F. (2000). "Response of Continuous CFRP Prestressed Concrete Bridges Under Static and Repeated Loadings.” PCI Journal, V. 45, No. 6, 84-102.

Grace, N.F., Navarre, F.C, Nacey, R.B., Bonus, W., and Collavino, L., (2002). “DesignConstruction of Bridge Street Bridge-First CFRP Bridge in the United States." PCI Journal, V. 47, No. 5, pp. 20-35.

Intelligent Sensing for Innovative Structures Canada Corporation (ISIS). (2008). “Prestressing Concrete Structures with FRPs.” Design Manual No.5.

JSCE Research Subcommittee on Continuous Fiber Reinforcing Materials. (1997). "Recommendation for Design and Construction of Concrete Structures using Continuous Fiber Reinforcing Materials.” Concrete Engineering Series 23.

MaineDOT Transportation Research Division. (2013). "Post-Tensioned Carbon Fiber Composite Cable (CFCC), Little Pond Bridge, Route 302, Fryeburgm Maine.” MaineDOT Technical Report 13-02.

MDOT. (2011). “Carbon Fiber Composite Cables Anchoring Device - 12DS800(D195).” MDOT Special Provision. 
MDOT. (2011). “Carbon Fiber Composite Cables Transverse Post-Tensioning - 12DS708 (A255).” MDOT Special Provision.

MDOT. (2011). “Carbon Fiber Reinforced Polymer (CFRP) Element - 12DS819 (A260).” MDOT Special Provision.

MDOT. (2013). “Carbon Fiber Composite Cable Element Instrumentation and Data Collection - 12DS800 (D480).” MDOT Special Provision.

MDOT. (2013). “Carbon Fiber Composite Cables Transverse Post-Tensioning - 12DS708 (E430).” MDOT Special Provision.

MDOT. (2013). “Carbon Fiber Reinforced Polymer Post Tensioning - 12DS708 (E265).” MDOT Special Provision.

MDOT. (2013). "Field Installation of Carbon Fiber Composite Cable Reinforcement 12DS800 (D475).” MDOT Special Provision.

Roddenberry, M., Mtenga, P., and Joshi, K. (2014). "Investigation of Carbon Fiber Composite Cable (CFCC) in Prestressed Concrete Pile.” FDOT Final Report. 


\section{SUMMARY AND CONCLUSIONS}

The primary objective of this study was to assess the feasibility of the use of innovative Carbon Fiber Reinforced Polymer (CFRP) tendons and to develop guidelines for CFRP in post-tensioned bridge applications, including segmental bridges and pier caps. The main motivation for the use of advanced composites is that they are not susceptible to corrosion unlike prestressing steel.

This study consisted of a three-part investigation. The first part is the $1: 31 / 2$ scaled model of the Long Key segmental box girder bridge post-tensioned using three different types of strands; namely, CFCC, EC6, and steel. The bridge model was tested at three different prestress levels and at three different loading configurations. The most important distinction between the two types of carbon fiber strands is their elastic moduli, which for EC6 is about 93\% of that of steel, while for CFCC is only $77 \%$ of that of steel. A finite element model of the same scaled segmental bridge model was developed and calibrated against the experimental data. A parametric study was also carried out to investigate the effect of the elastic modulus of carbon fiber strands on the performance of the post-tensioned segmental bridge.

The second part is the 1:51/2 scaled model of a typical interior hammerhead pier of San Antonio downtown "Y" project. The pier cap model was made with two identical cantilever overhangs as a test bed for a side by side comparison of the performance of the same three types of strands used for the segmental bridge model with unbonded posttensioning as the primary and sole flexural reinforcement. Two different strand arrangements were used for the post-tensioning of the model, one with eight strands that represented $27 \%$ excess capacity over demand, and another with six strands representing 
1.5\% under-design. The pier cap model was tested under service and factored flexure and shear loads, and 93\% of factored flexure for the case of six-strand arrangement.

The last part of the study is the CFCC anchorage and creep rupture test. Four CFCC tendons were stressed at $95 \%$ of the guaranteed capacity provided by the manufacturer for 5 months with the anchors made by the Research Team.

These experimental and analytical studies led to the following conclusions and recommendations.

\subsection{CFRP Post-Tensioned Segmental Bridge}

- CFCC and EC6 have the potentials for use in post-tensioned segmental bridges, from the perspectives of both constructability and design even though some of the construction details for CFCC and EC6 post-tensioning mechanisms and strand arrangements are quite different than those used for the steel post-tensioning system.

- The main constructability concern for CFCC and EC6 tendons is that their end anchorages are factory-made together with the strands, and therefore, strands must be ordered at predetermined lengths, considering the increased elongation of the stressed tendons. The system does not easily accommodate deviations from the pre-ordered length and may require abandoning the entire cable or potentially developing a build-up at the jacking end to make up for the difference. To date, field application of the anchorage are not well proven and require a substantial amount of time.

- The segmental bridge model shows a bilinear response irrespective of the type of strand, whether carbon or steel. While the initial stiffness is generally the same for 
all three types of strands, the secondary stiffness is higher for EC6 and steel strands, in comparison with CFCC strands, after decompression and joint opening.

- Higher prestress levels can delay joint openings and reduce overall deflections in the segmental bridge model after joint opening.

- Given the higher flexibility of the segmental bridge model post-tensioned with CFCC, a stiffness-based equivalency approach may provide a more comparable performance to the same bridge model post-tensioned with steel beyond service load. Such an approach, however, may lower the stress in CFCC commensurate with its lower elastic modulus. However, the behavior beyond service limit is typically not a concern as long as the ultimate capacity are similar or meet the load demand at this stage of philosophy for design. Additionally, epoxy joints are required for the segmental bridges nowadays, which could provide some slight differences in behavior compared to the segmental bridge with dry joints.

\subsection{CFRP Post-Tensioned Pier Cap}

- For Application of un-bonded CFCC and EC6 strands for post-tensioning of pier caps, similar constructability problems exist as that for the application in segmental bridges. However, this may not be as large of an obstacle.

- Design of un-bonded post-tensioned pier caps may follow AASHTO (2012), selecting CFCC or EC6 strands (number and size) with the same capacity as that of steel strands. The design should limit the stress level in carbon fiber strands to $65 \%$ of their guaranteed strength, according to the ACI Committee 440 (2004).

- Given the strength-based design of the pier cap, the elastic moduli of different carbon fiber strands did not seem to have affected the serviceability performance 
of the pier cap model with respect to either cracking or deflection. Therefore, allowable stress levels of ACI Committee 440 (2004) for carbon fiber strands can be followed quite safely.

- Considering both serviceability and overload conditions, the general performance of the pier cap model under both flexure and shear loading was quite acceptable using either CFCC or EC6 strands, and comparable to that of steel strands. No major difference in the performance was noted between the three types of strands.

- Future research is needed to investigate the fatigue and long-time performance of pier caps using unbonded post-tensioning CFCC or EC6 strands.

\subsection{CFCC Creep Rupture Test}

- It is feasible to make a generic anchorage device for CFCC tendons in the field with adequate strength, using expansive cement grout. Long-term performance of the grout will require further in-depth studies.

- Creep stress test of four CFCC tendons at 95\% of manufacturer guaranteed strength for a period of over 3,624 hours shown that the stress level can be maintained and that no sign of rupture exists in the tendons.

- Average residual strength ranged from 122 to $127 \%$ compared to guaranteed manufacturer's breaking load. The strength loss after 3,624 hours at an average load ratio of 0.94 ranged from -7.7 to $-11.4 \%$ compared with the average experimental breaking load of 57 kips as reference.

- Further study is suggested for determining the effects of loss in anchoring force when testing for residual strength 


\subsection{Recommendations for Design, Construction, Inspection, and Repair \\ Specifications}

- Segmental bridges behave in a bilinear pattern. The initial stiffness of a segmental bridge is mainly determined by the geometry of the concrete cross-section. After decompression and joint opening of the segmental bridge, the stiffness of the cable itself greatly affect the stiffness of the entire structure. Therefore, the cable with lower modulus of elasticity than steel may cause much more deflection. Given the higher flexibility of segmental bridges post-tensioned with CFCC and EC6, a stiffness-based equivalency approach could be appropriate, which will further reduce the maximum allowable stress level of $65 \%$ specified in ACI 440.4R-04. However, the behavior beyond service limit is typically not a concern as long as the ultimate capacity are similar or meet the load demand at this stage of philosophy for design.

- The general performances of pier caps using CFCC and EC6 were quite comparable with steel. For these types of short-span structures, as well as those members that require transverse post-tensioning, strength-based design philosophy, similar to steel strands, shows to be adequate, given the expected small deflections.

- Both CFCC and EC6 are available in large diameters, which can reduce the number of tendons used in the structure to achieve the same amount of posttensioning load. It can also address the congestion problems at the anchorage and simplify the tensioning device. 
- CFCC and EC6 have high strength in the longitudinal direction, but in the lateral direction, they are brittle and weak. Some damages were detected on CFCC at the corners of the deviators after finishing all experiments. Therefore, further protection is required for the cable in the lateral direction.

- A more efficient tensioning-anchoring system, which should allow a close spacing of tendons to optimize the system or allow for multiple strands to be tensioned simultaneously, is need for field applications. The new system should be able to pull the cable and cast the anchor on site. Additionally, curing of the grout used inside the sleeve should within hours.

- For the structures, such as segmental bridge, which allow the access to the cables, the condition of the tendons can be detected visually much the same as the what did in this study by mounting four web cameras inside the segmental bridge model to monitor the tendons during tensioning and testing. However, sometimes the visual detection maybe limited since some sort of covering (HDPE Pipe, etc.) should be provided for general protection due to potential construction activities or vandalism as the CFRP is very weak in shear. Therefore, it is important to include load cells for continuous monitoring of all carbon fiber strands.

- For the structures, such as pier cap, which the condition of the cable cannot be detected visually, load cells are certainly needed.

- Since the unbonded CFRP post-tensioning system is not grouted, rehabilitation for the damaged cable will be much easier than the bonded system. Additionally, means should be provided to pull through and anchor additional strands if necessary. 
- Although not studied in this study, it is understood that the cost for CFRP tendons and the anchorage is much higher than prestressing system using steel strands. However, long term costs of repair and maintenance for corrosion will be significantly reduced due to the fact that carbon fibers are not corrosive. 
APPENDICES 
APPENDIX A. CFRP POST-TENSIONED SEGMENTAL BRIDGE MODEL

\section{PREPARATION}

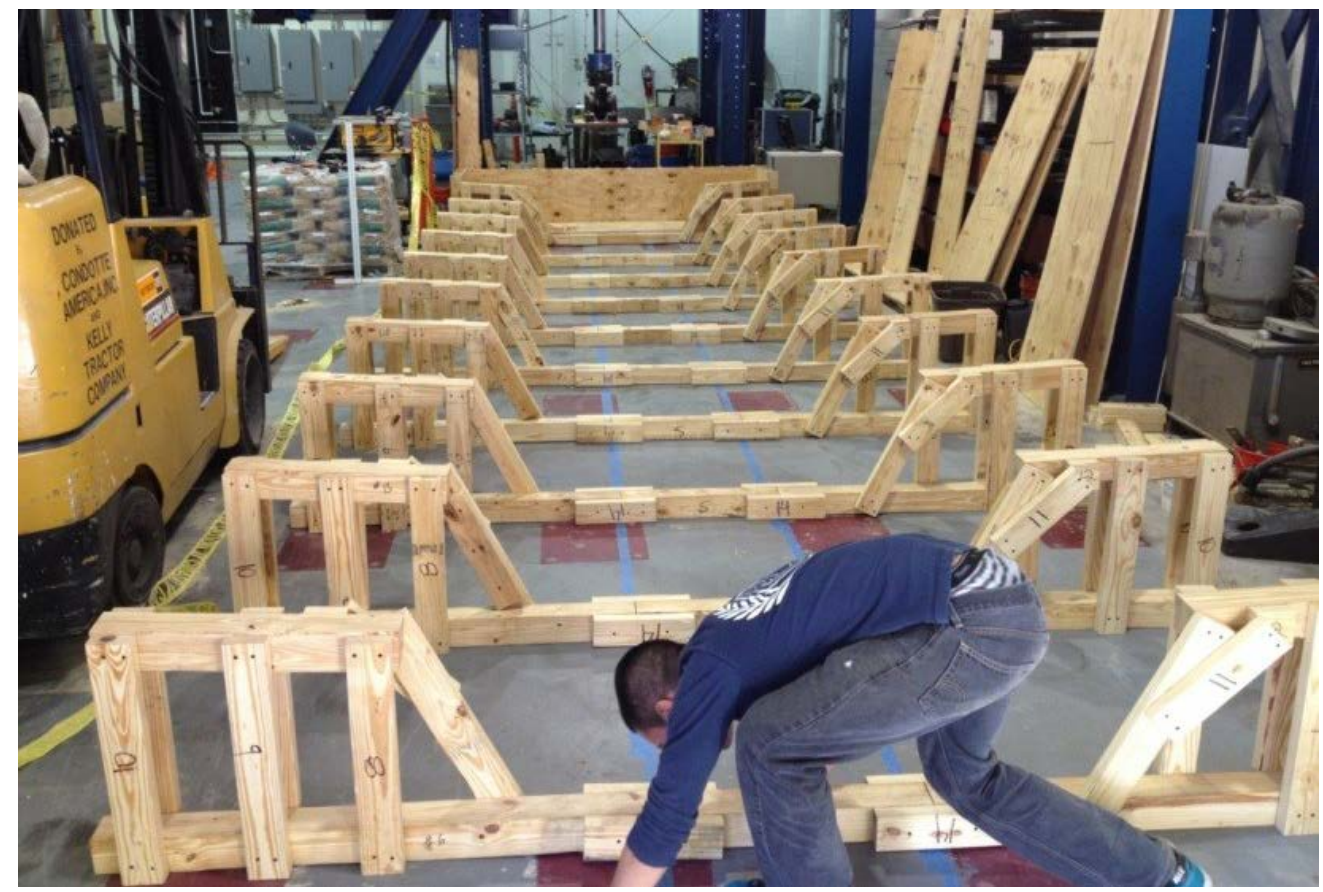

Figure A1. Formwork Framing

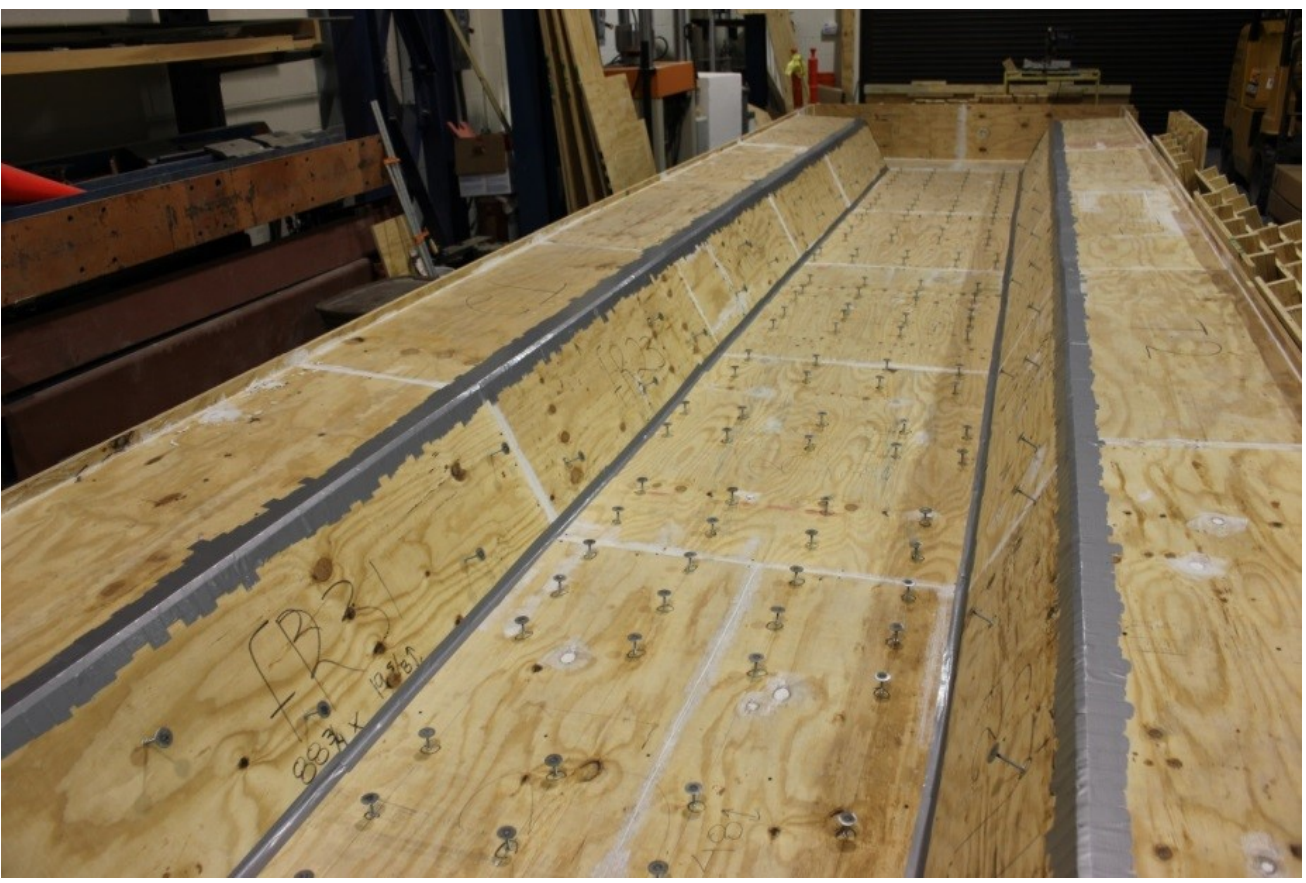

Figure A2. Formwork Base 


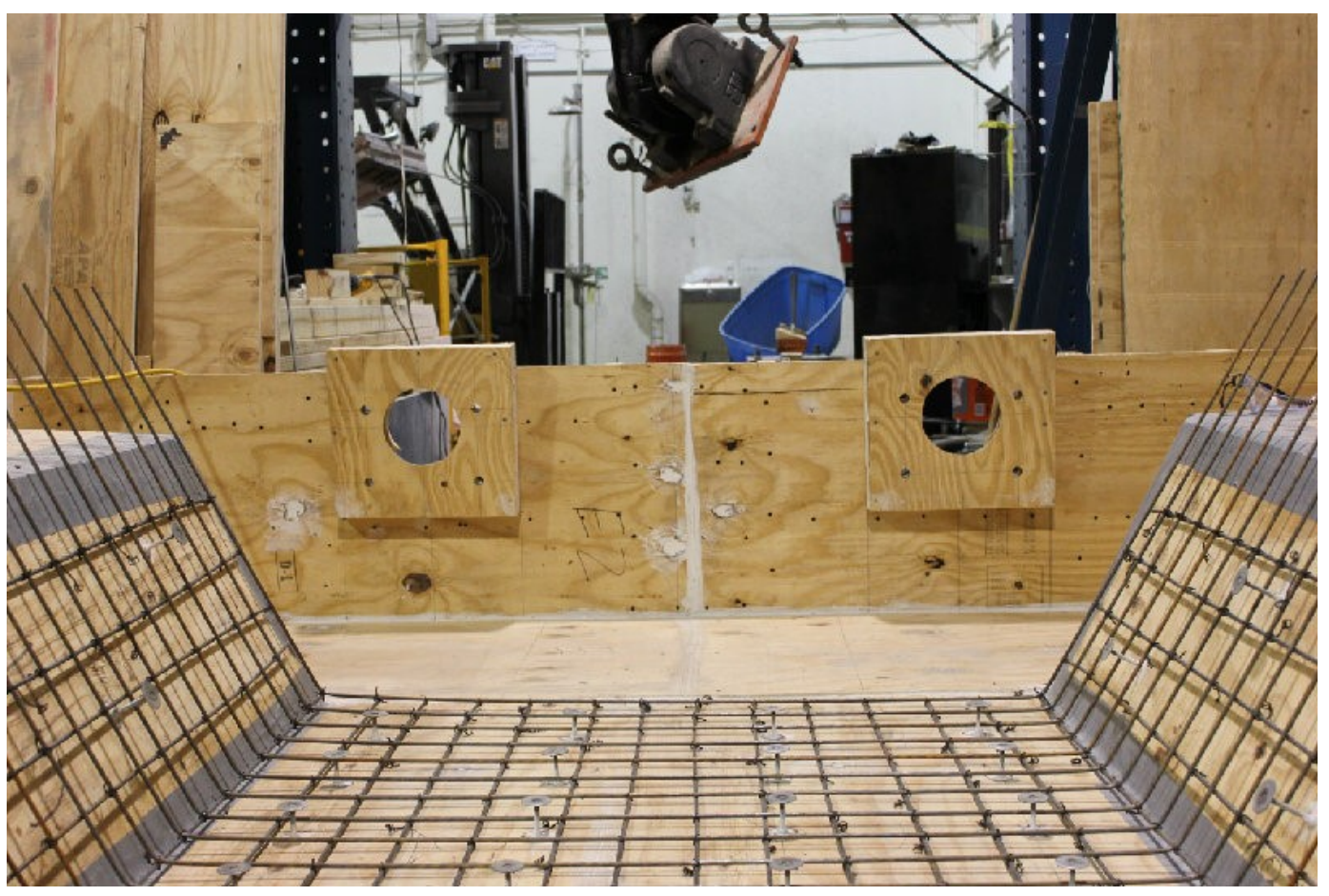

Figure A3. Formwork for End Blocks

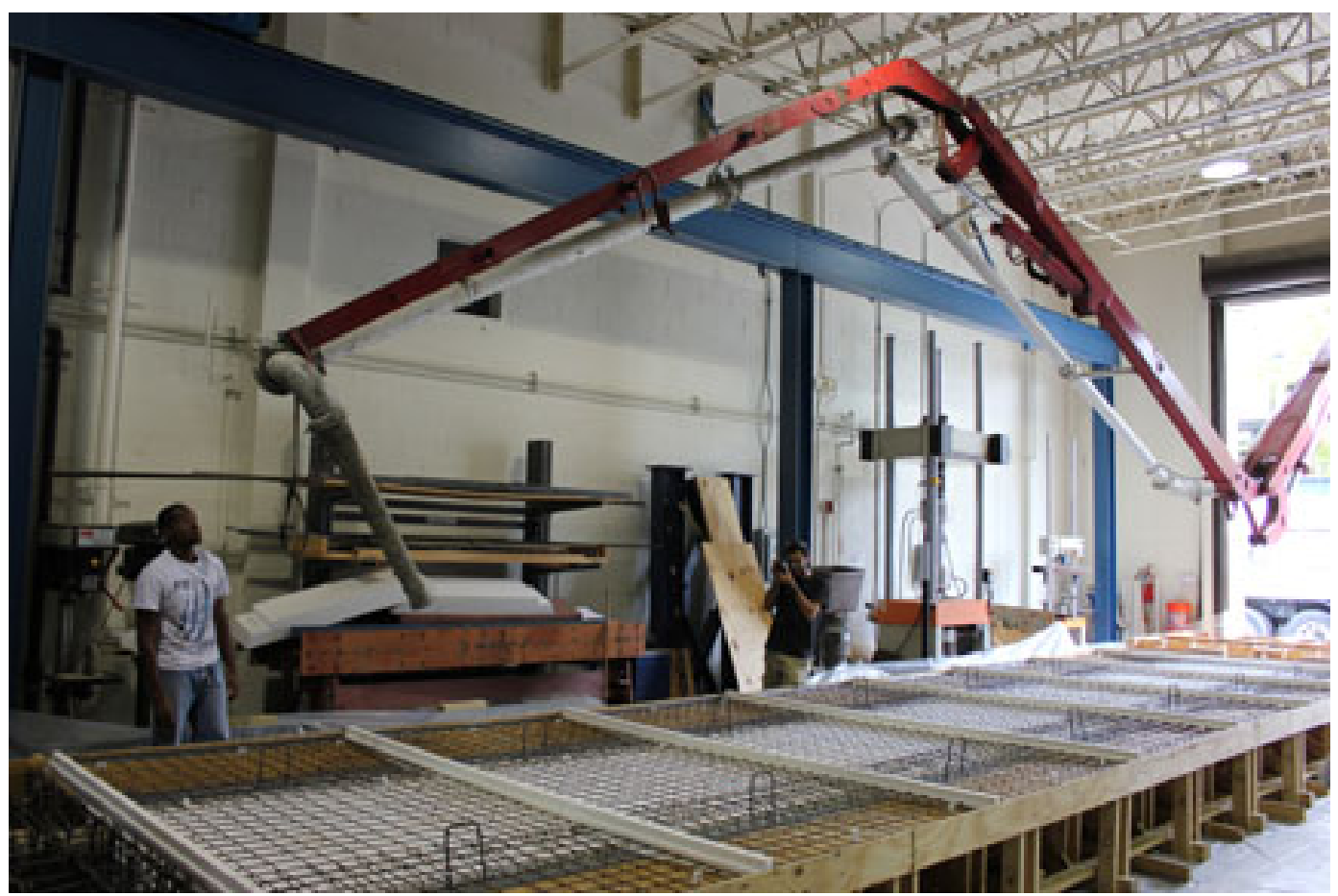

Figure A4. Casting 


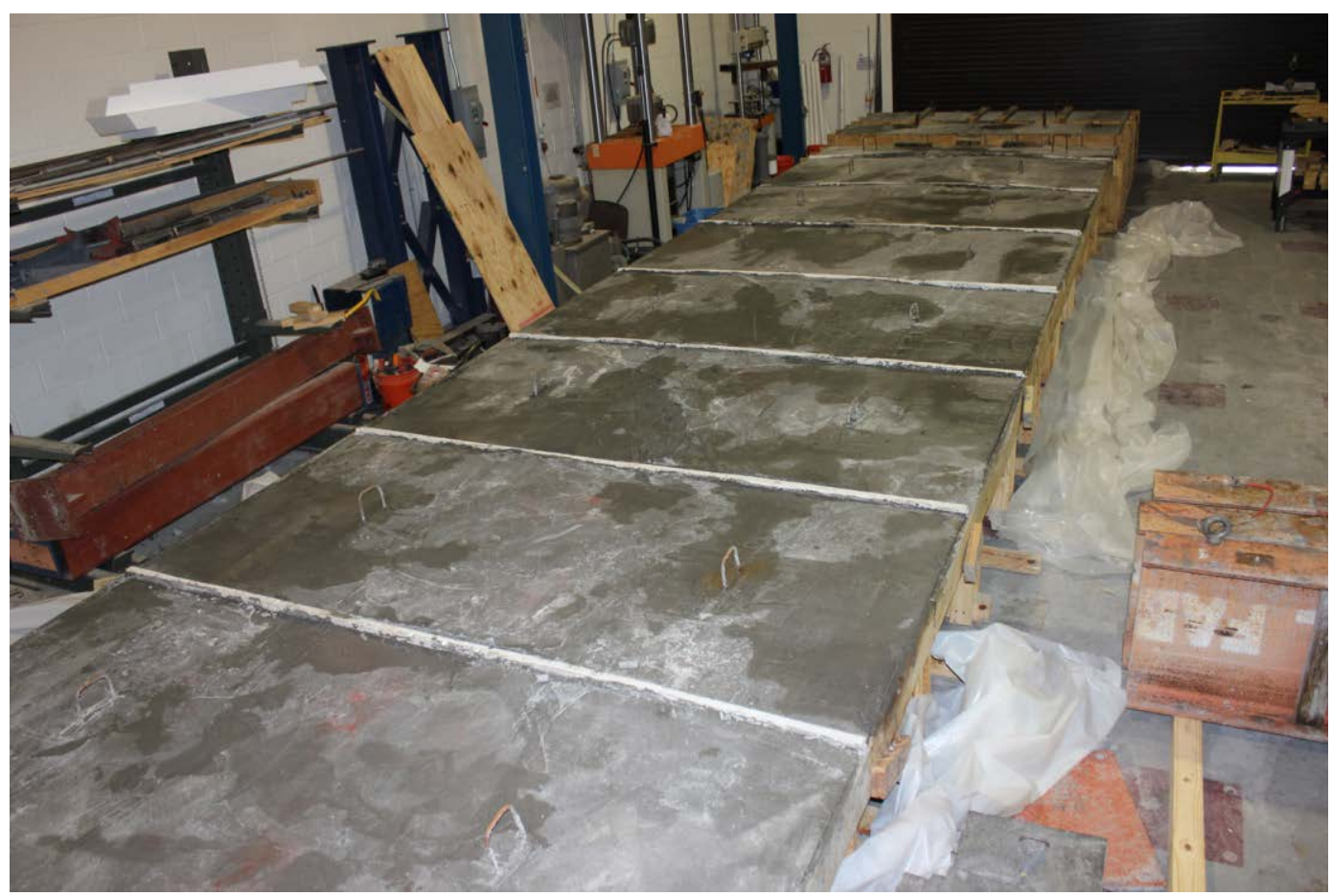

Figure A5. Specimen after Casting

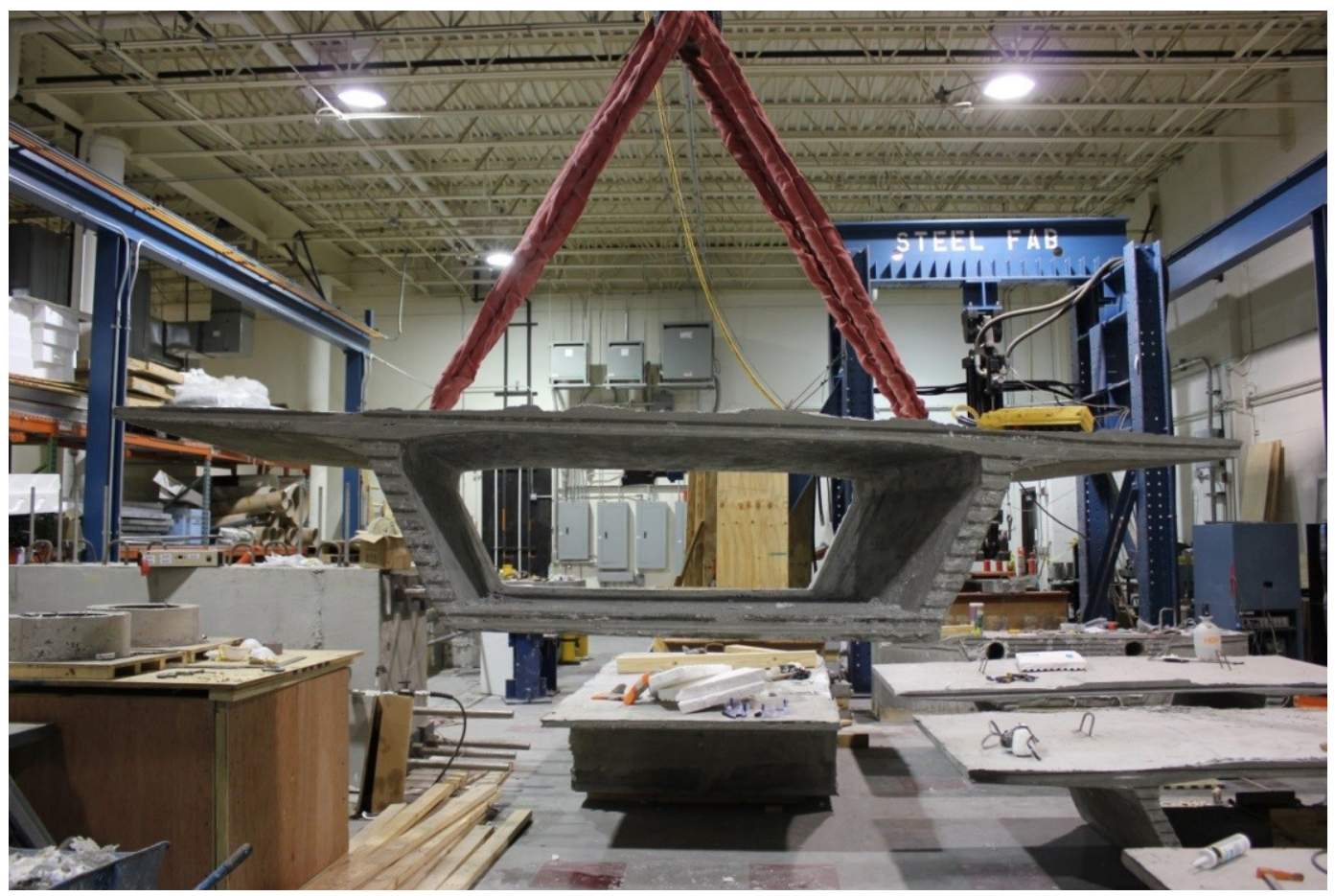

Figure A6. Specimen Demolding 


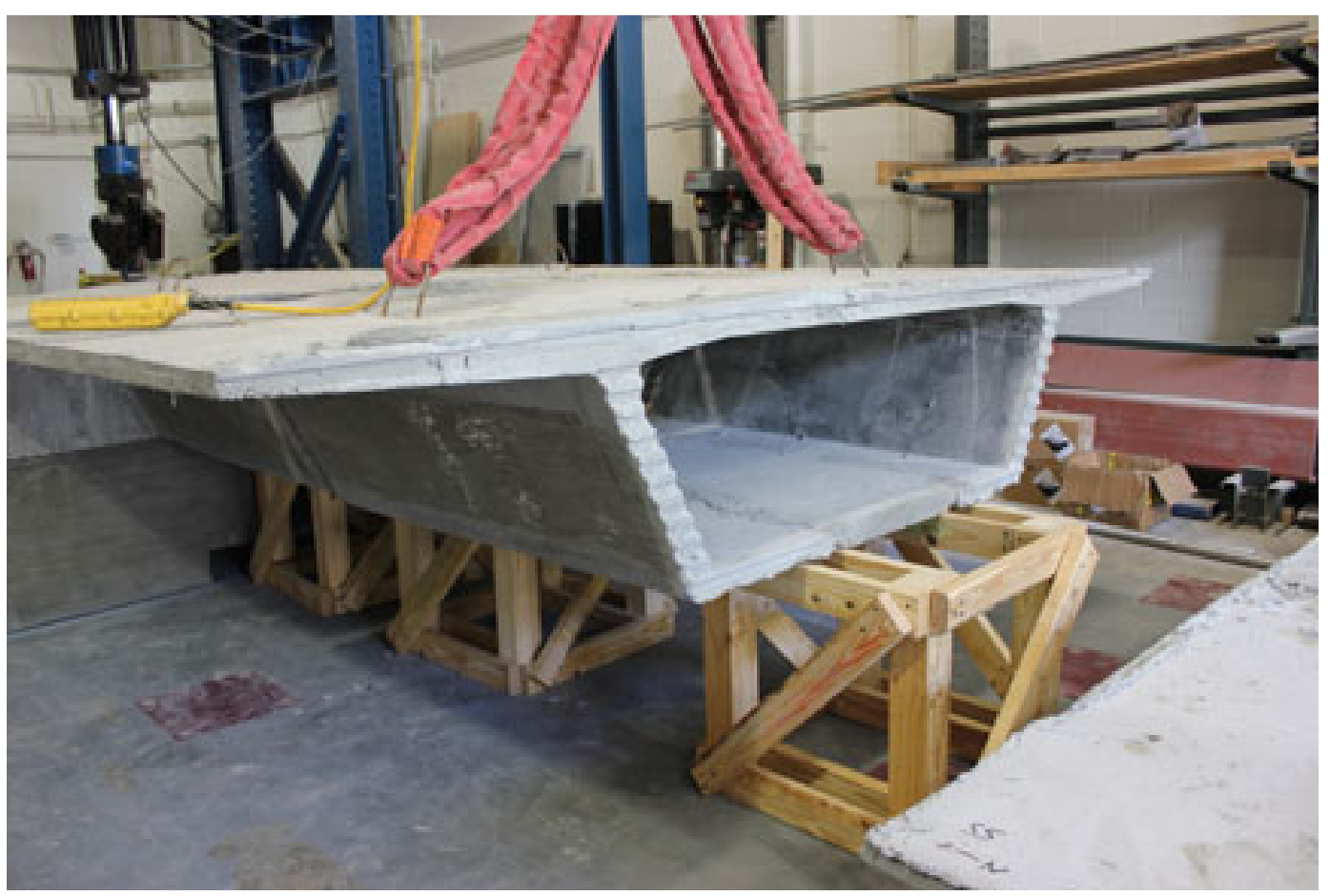

Figure A7. Specimen Erection (1)

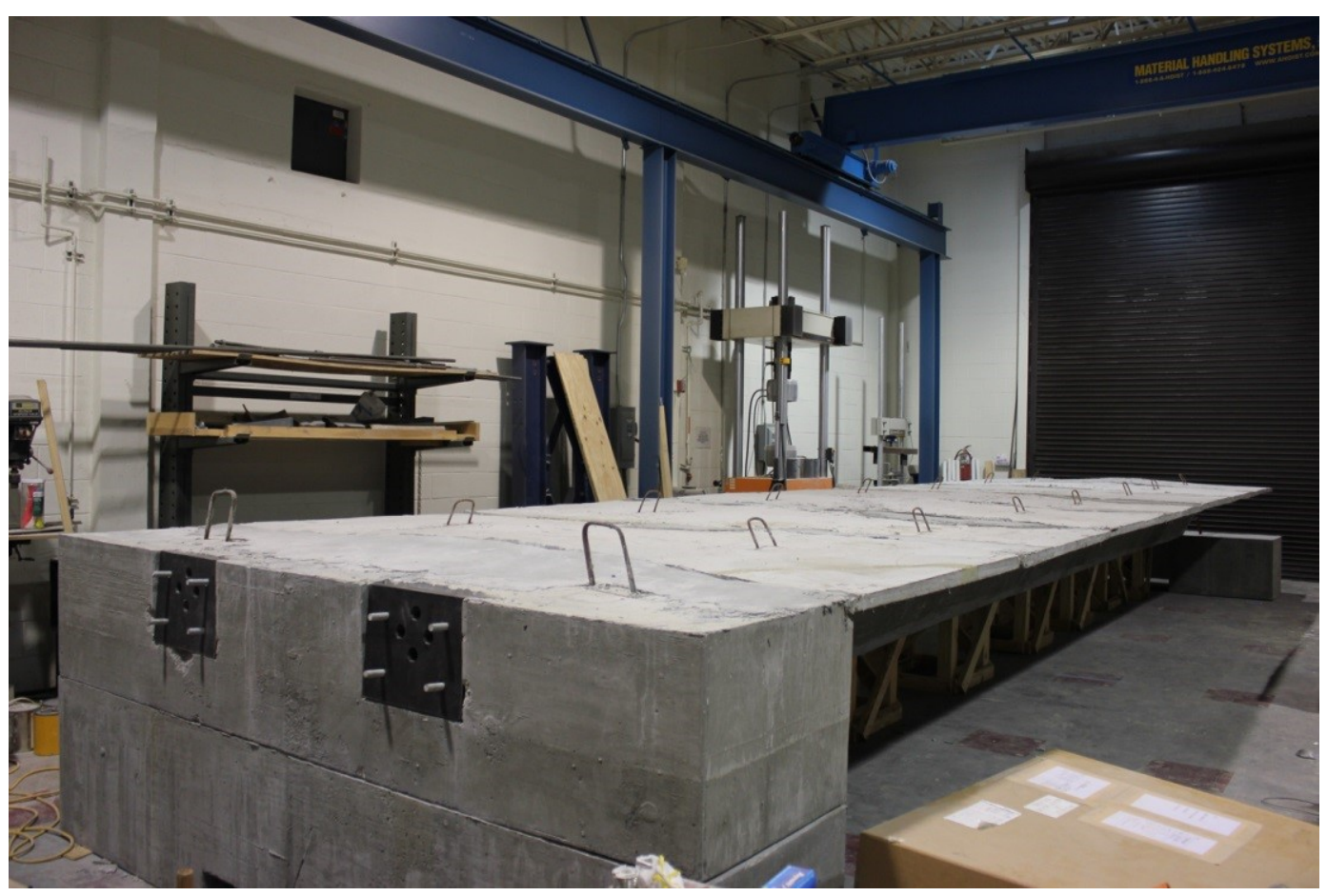

Figure A8. Specimen Erection (2) 

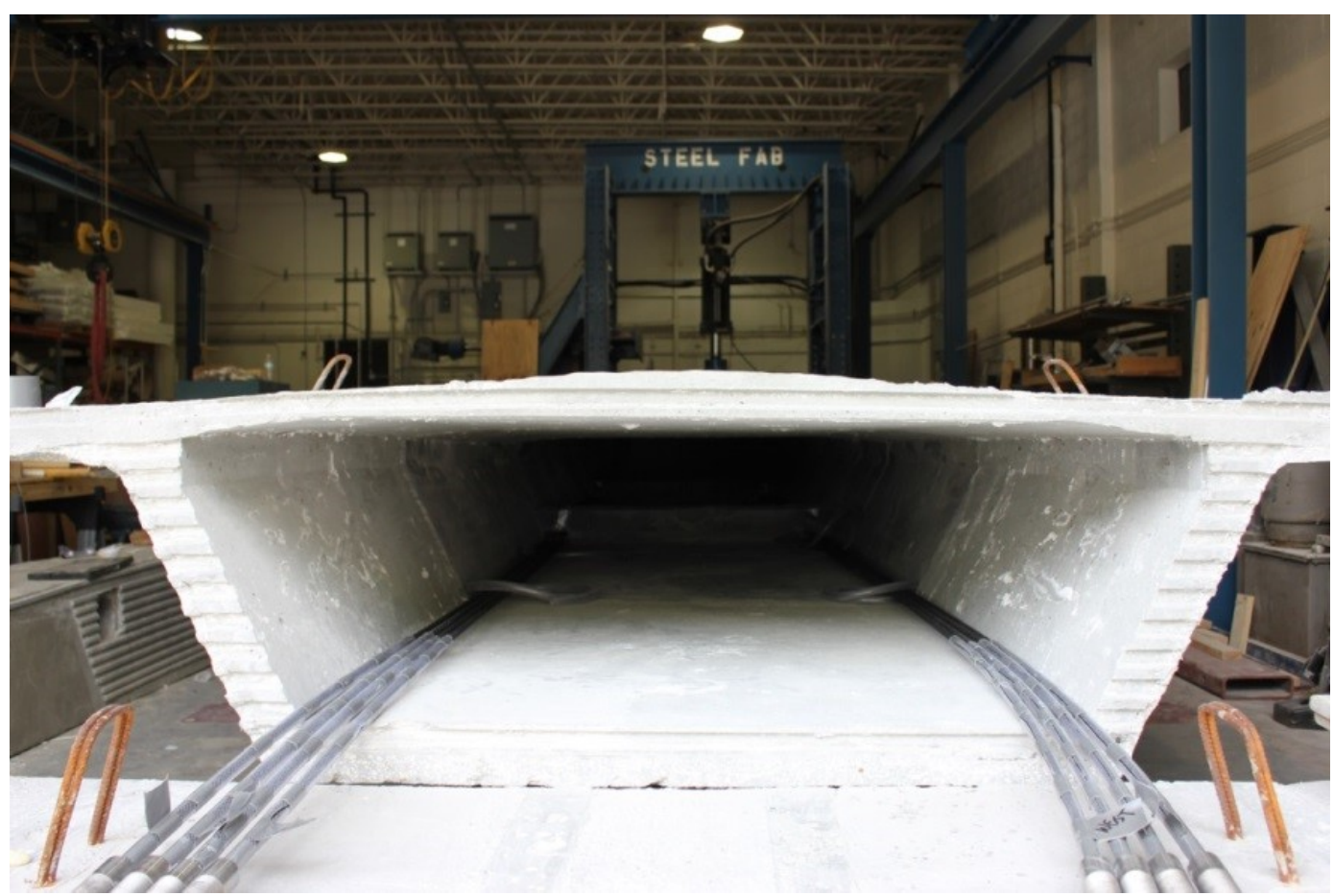

Figure A9. Post-Tensioning Cables through the Segments

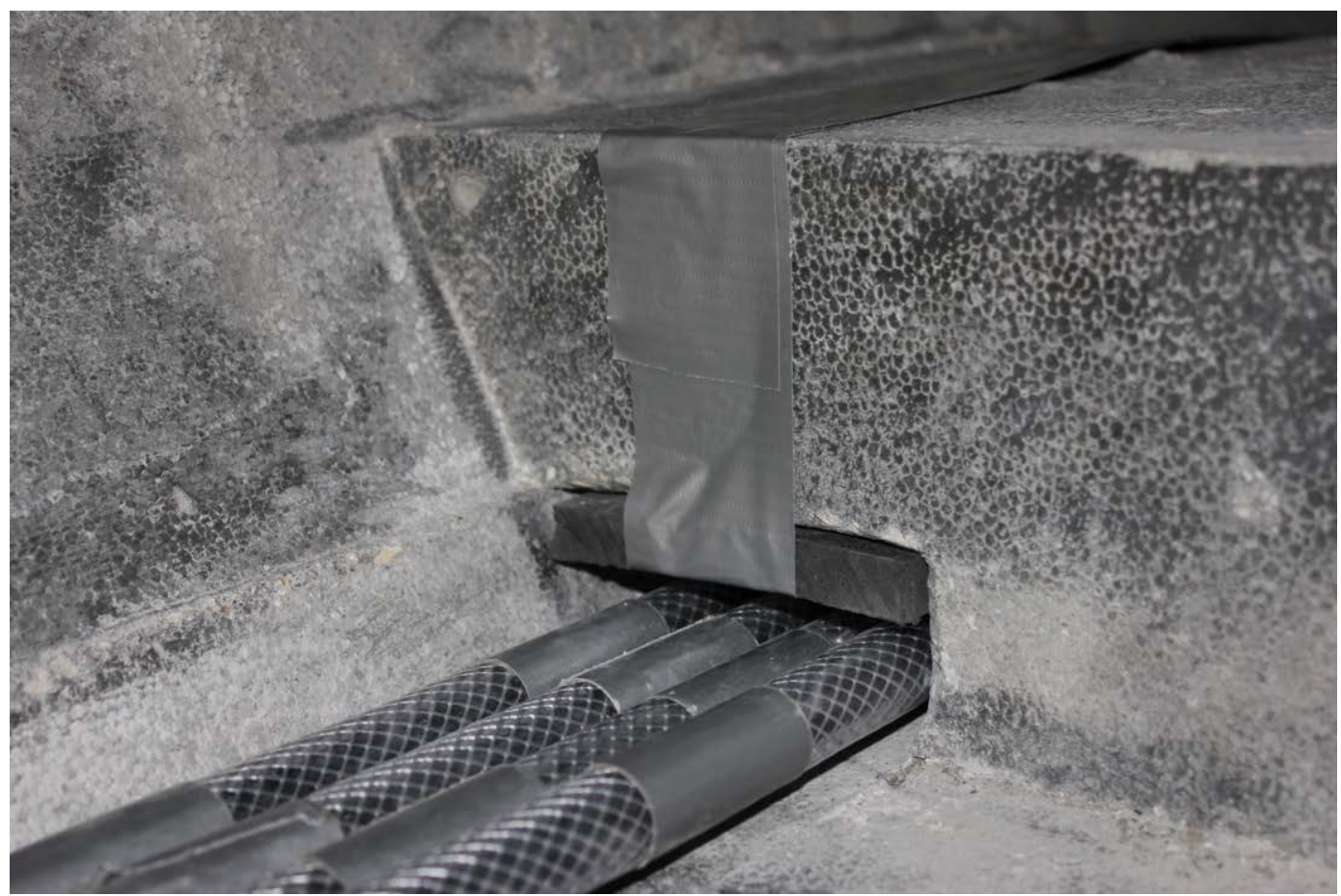

Figure A10. Protecting the Post-Tensioning Cables at Deviator Block 
APPENDIX B. TEST SETUP FOR ALL SEGMENTAL BRIDGE MODEL

\section{LOADING POSITIONS}

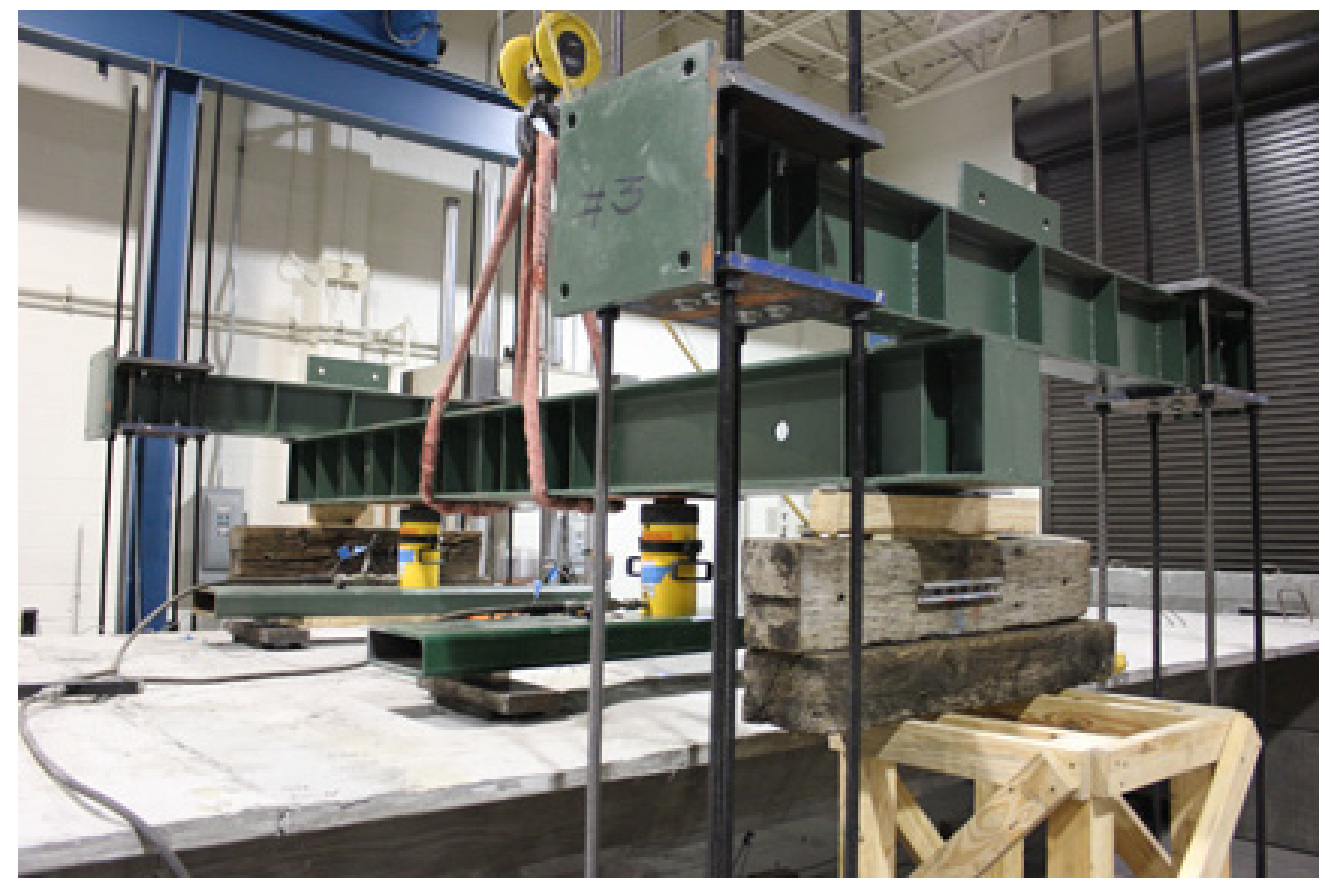

Figure B1. Test Setup for Service Load Position 1 and Ultimate Load Test

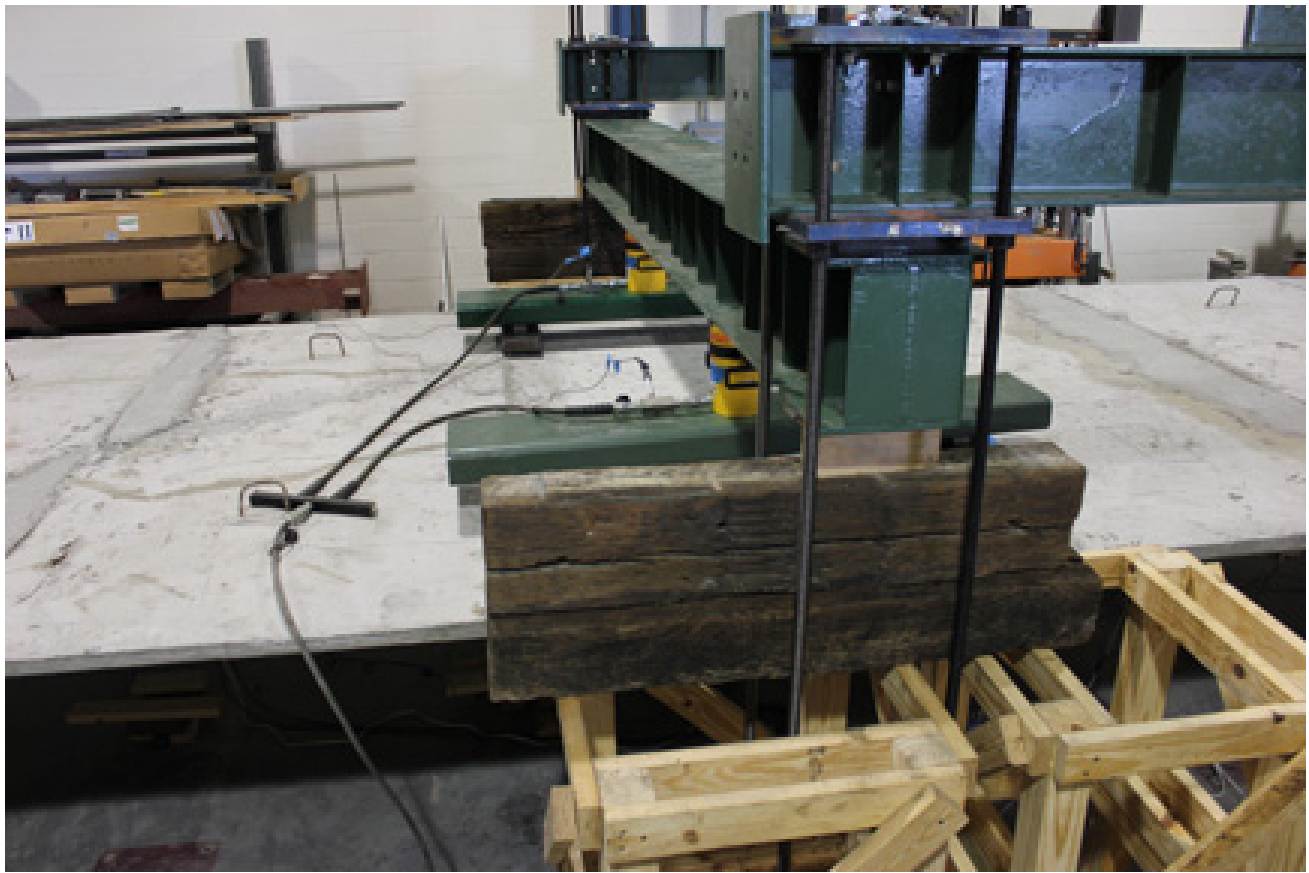

Figure B2. Test Setup for Service Load Position 2 


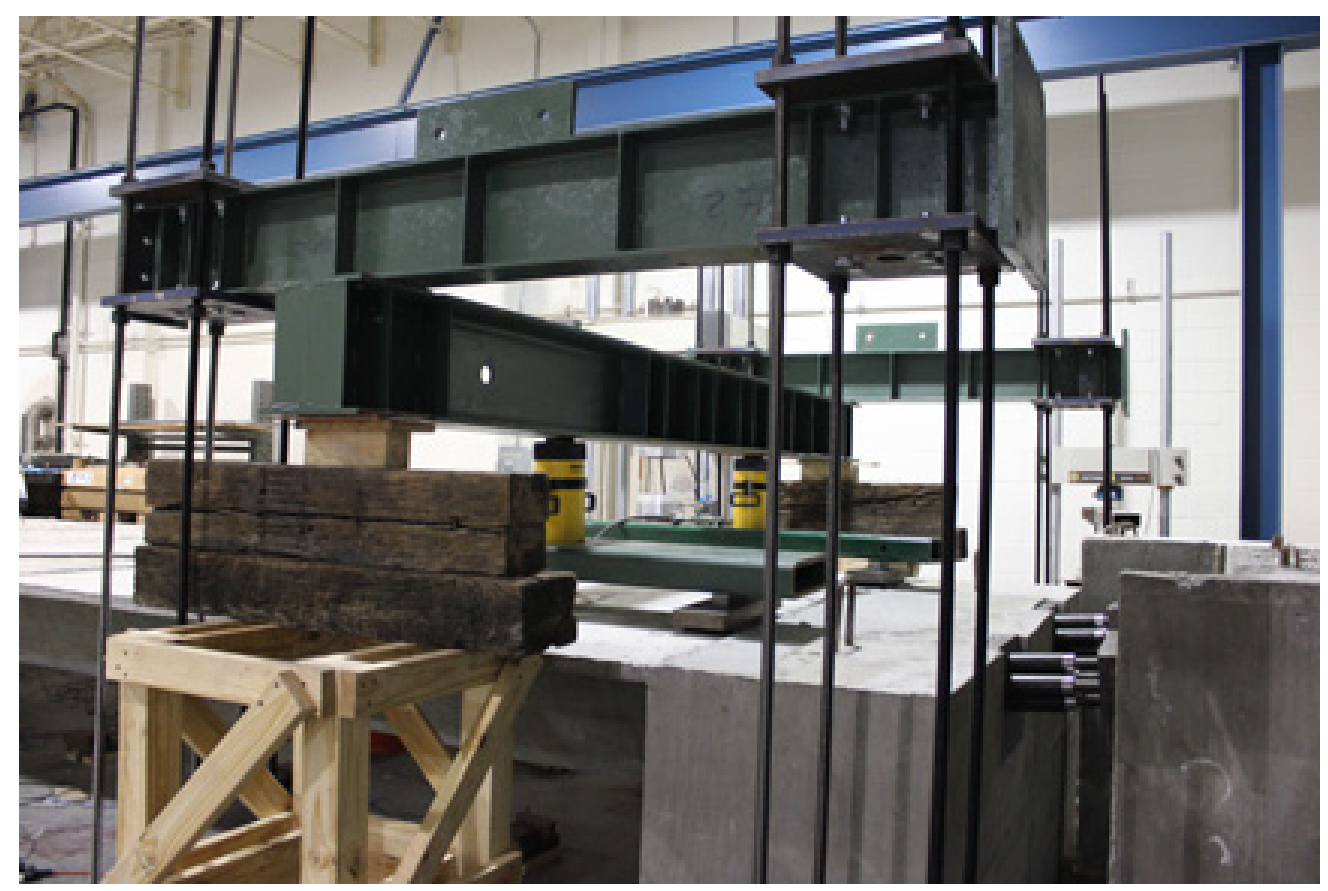

Figure B3. Test Setup for Service Load Position 3 


\section{APPENDIX C. TEST RESULTS FOR CFRP POST-TENSIONED SEGMENTAL \\ BRIDGE MODEL}

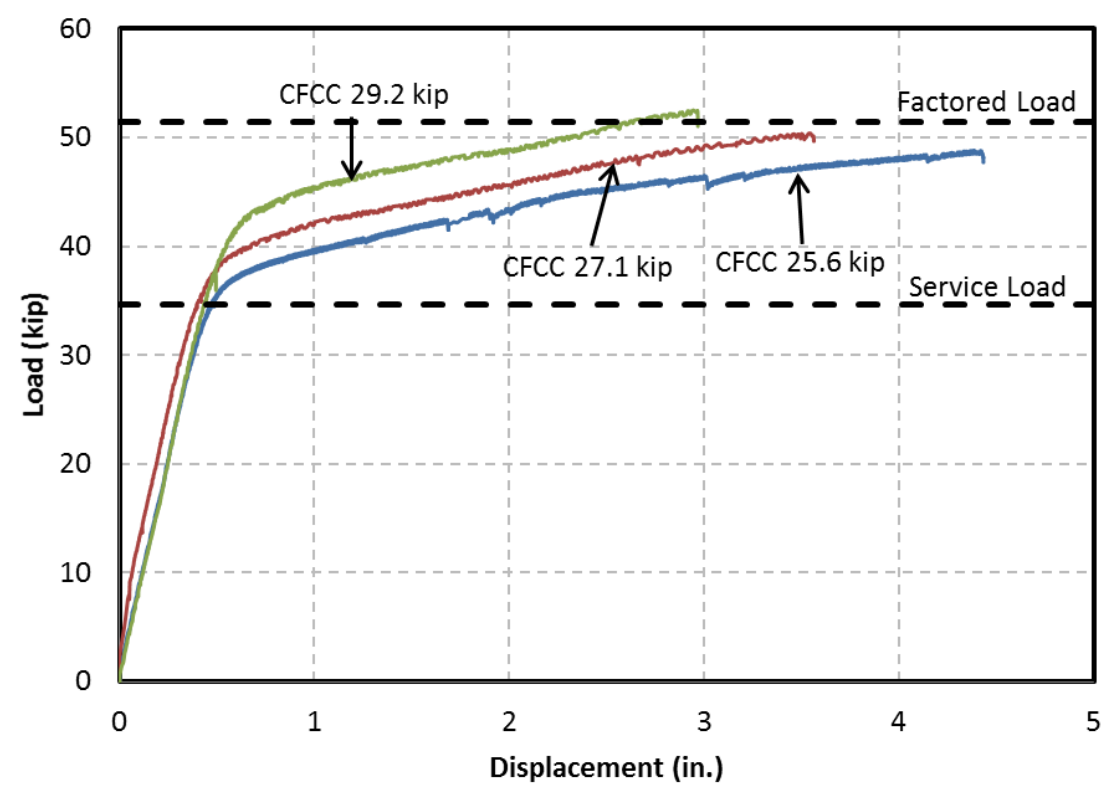

Figure C1. CFCC Load - Displacement for Service Load Position1 and Ultimate Load

Test

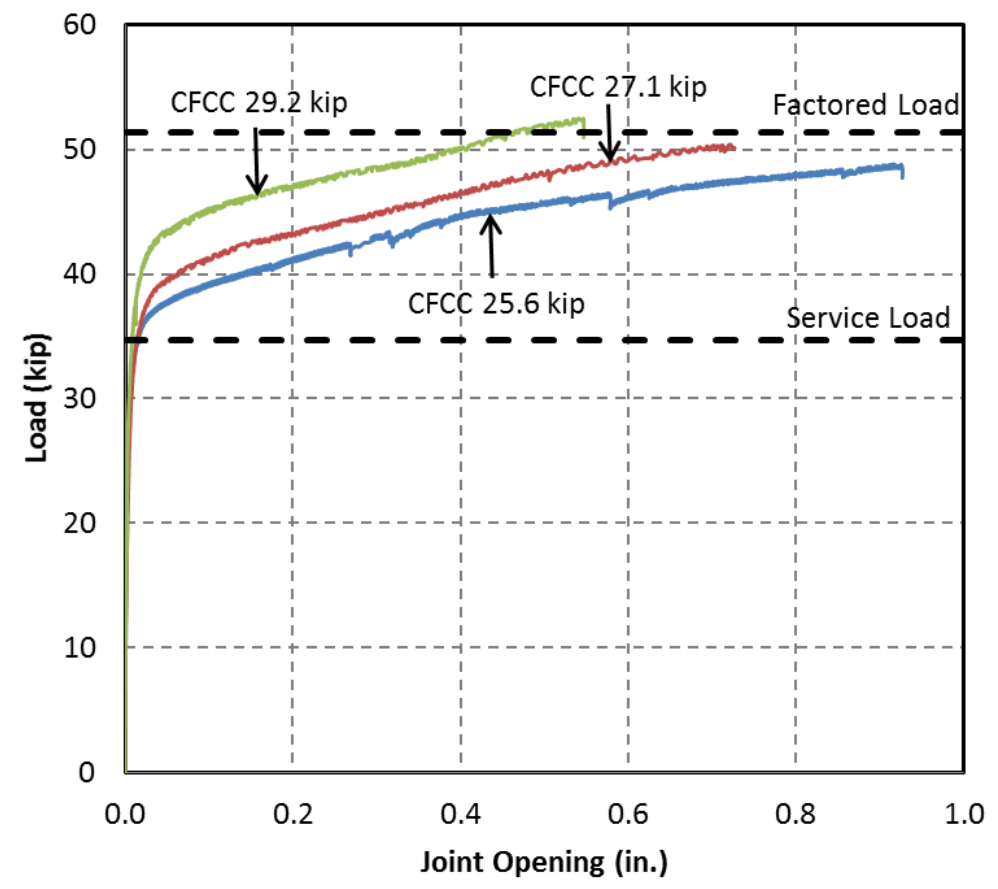

Figure C2. CFCC Load - Joint Opening for Service Load Position1 and Ultimate Load

Test 


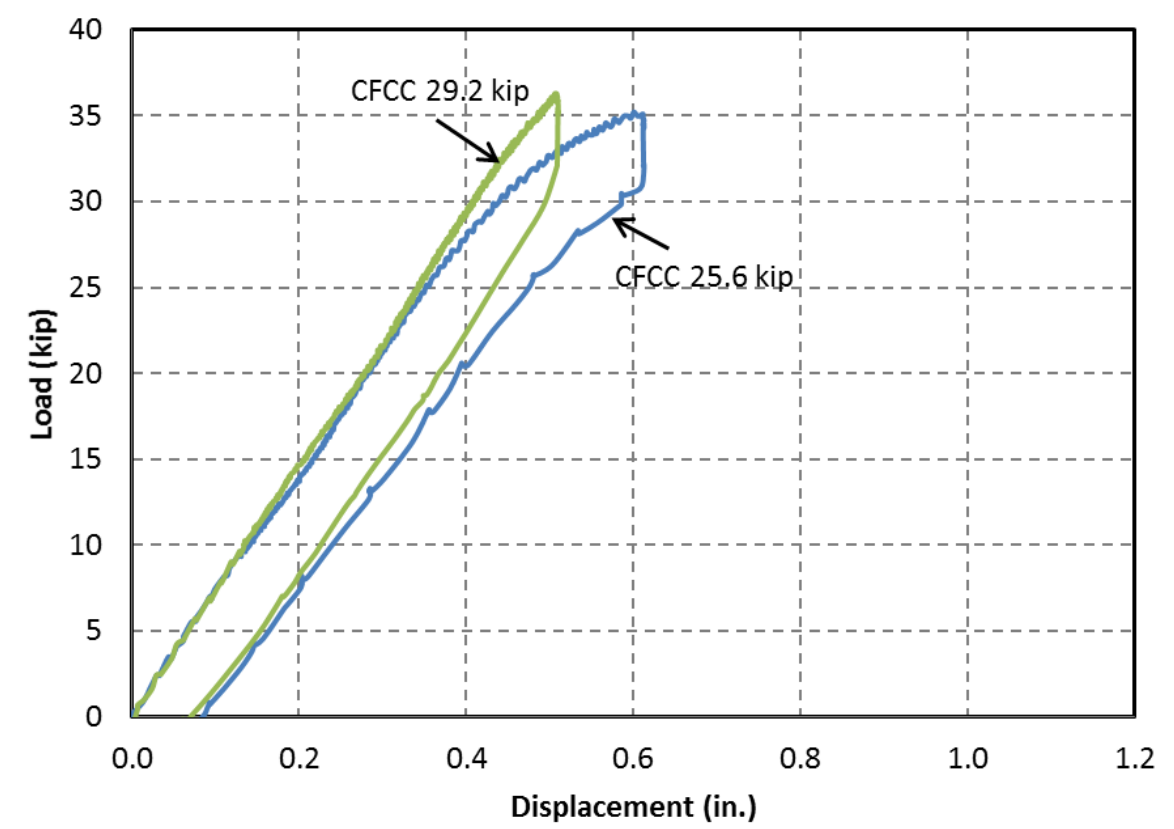

Figure C3. CFCC Load - Displacement Opening for Service Load Position 2

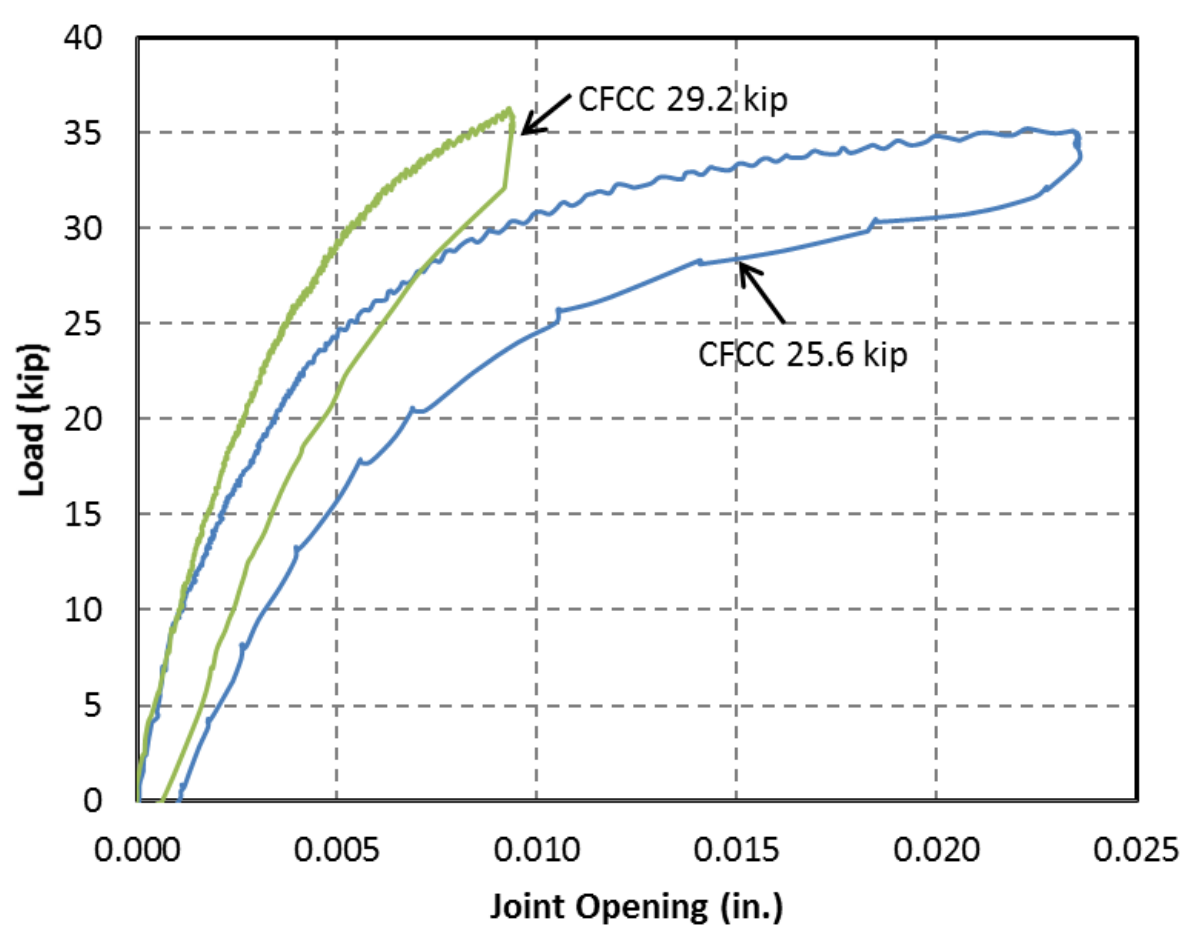

Figure C4. CFCC Load - Joint Opening for Service Load Position 2 


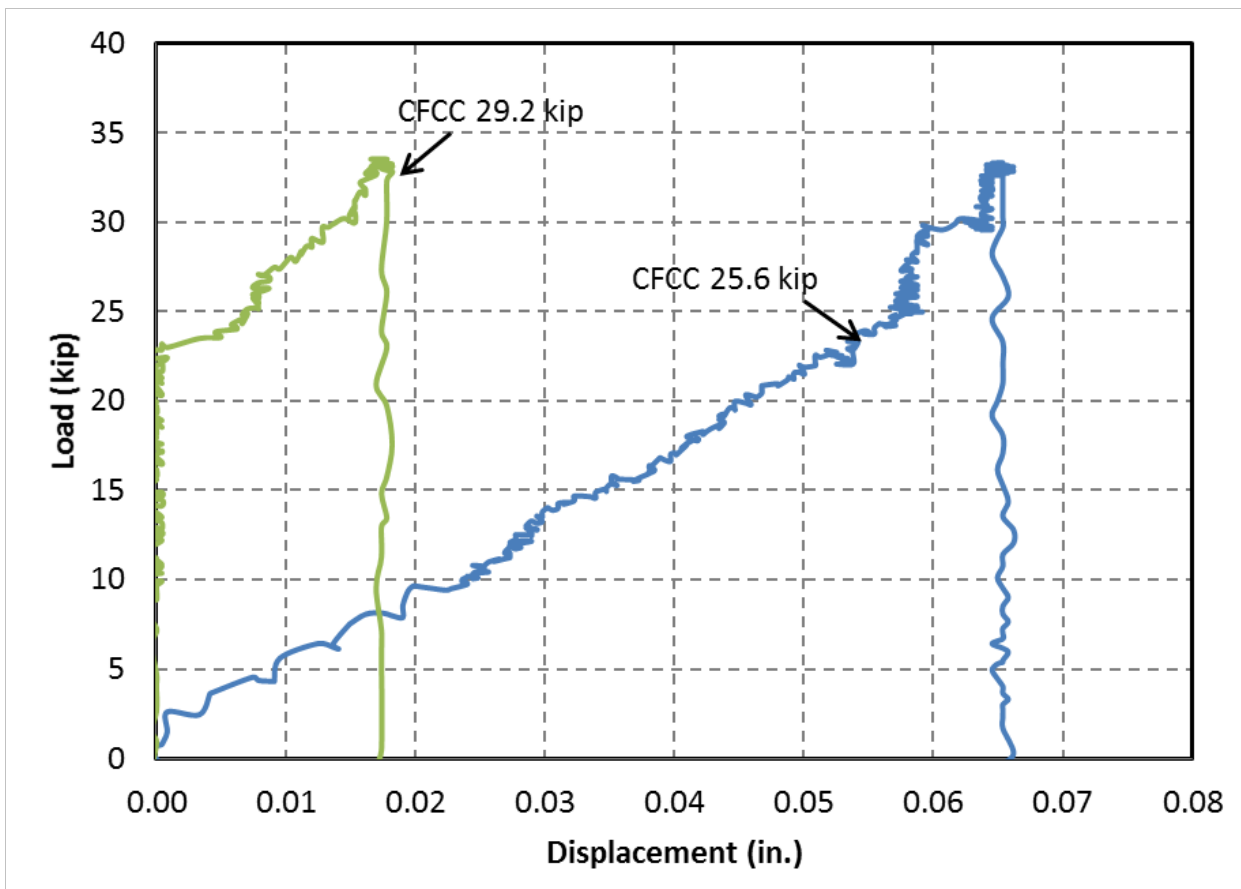

Figure C5. CFCC Load - Displacement Opening for Service Load Position 3

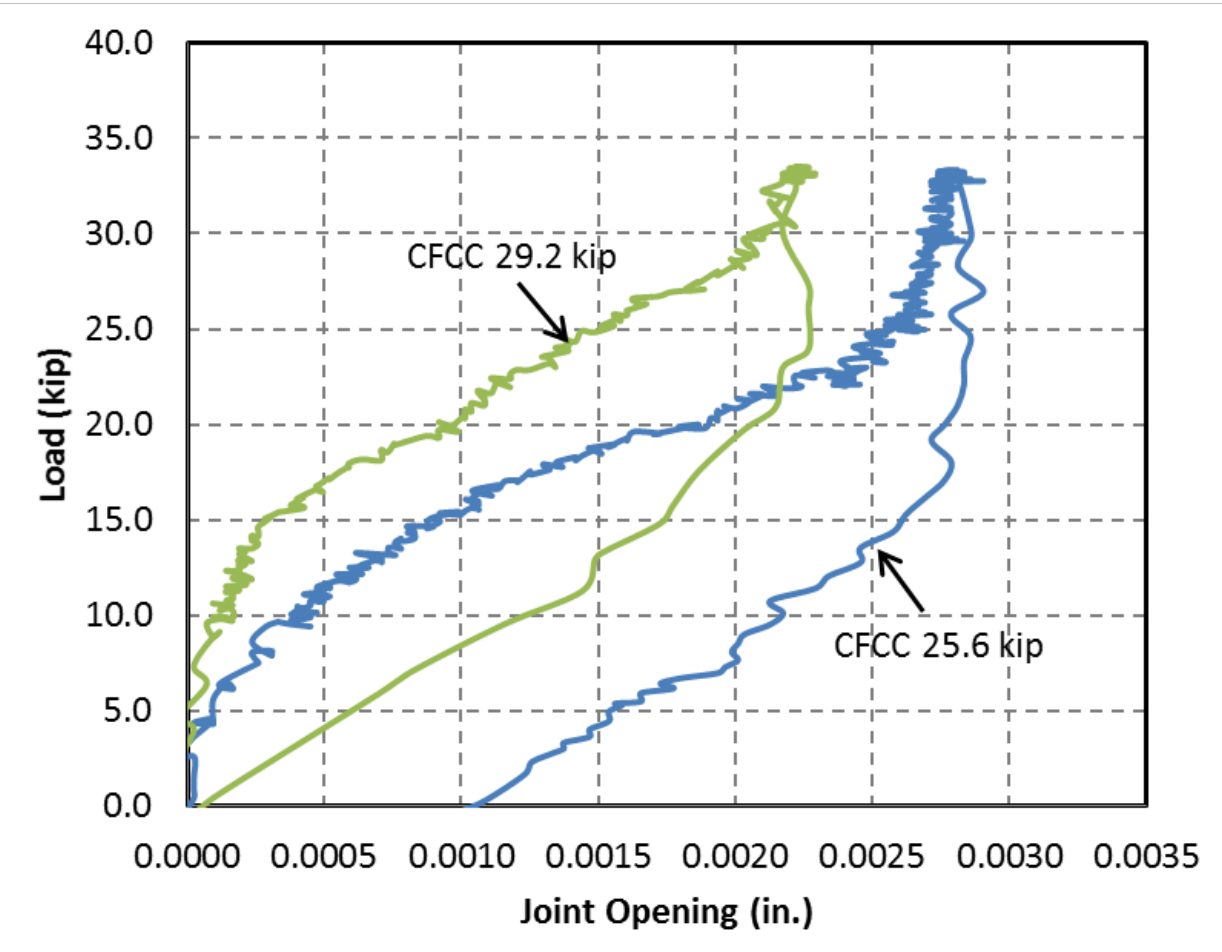

Figure C6. CFCC Load - Joint Opening for Service Load Position 3 


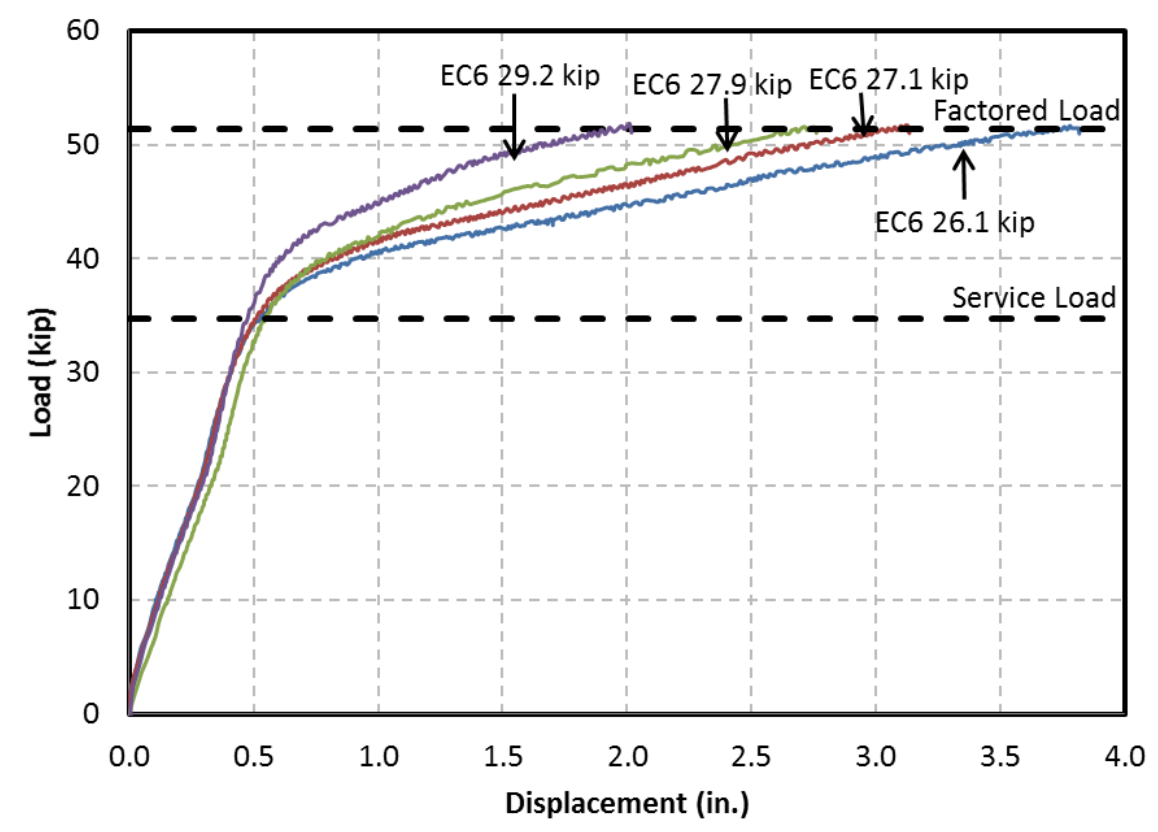

Figure C7. EC6 Load - Displacement for Service Load Position1 and Ultimate Load Test

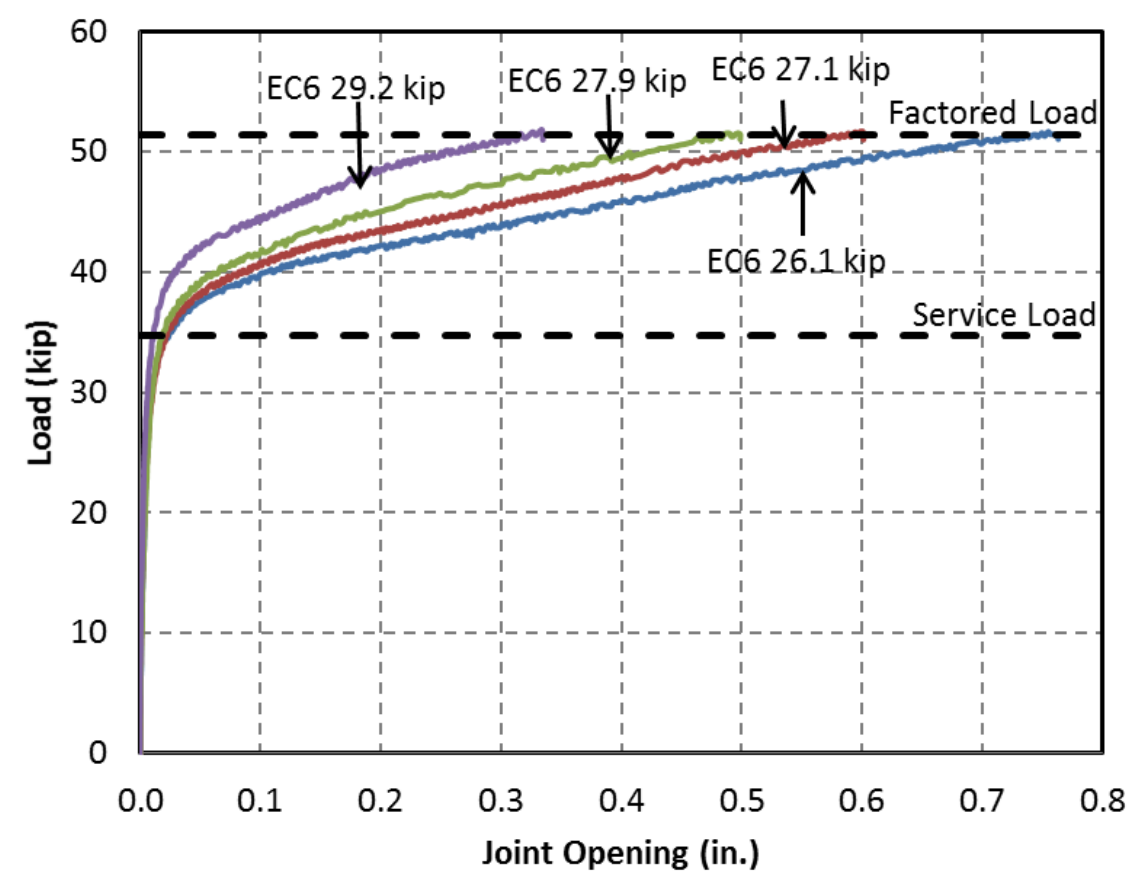

Figure C8. EC6 Load - Joint Opening for Service Load Position1 and Ultimate Load Test 


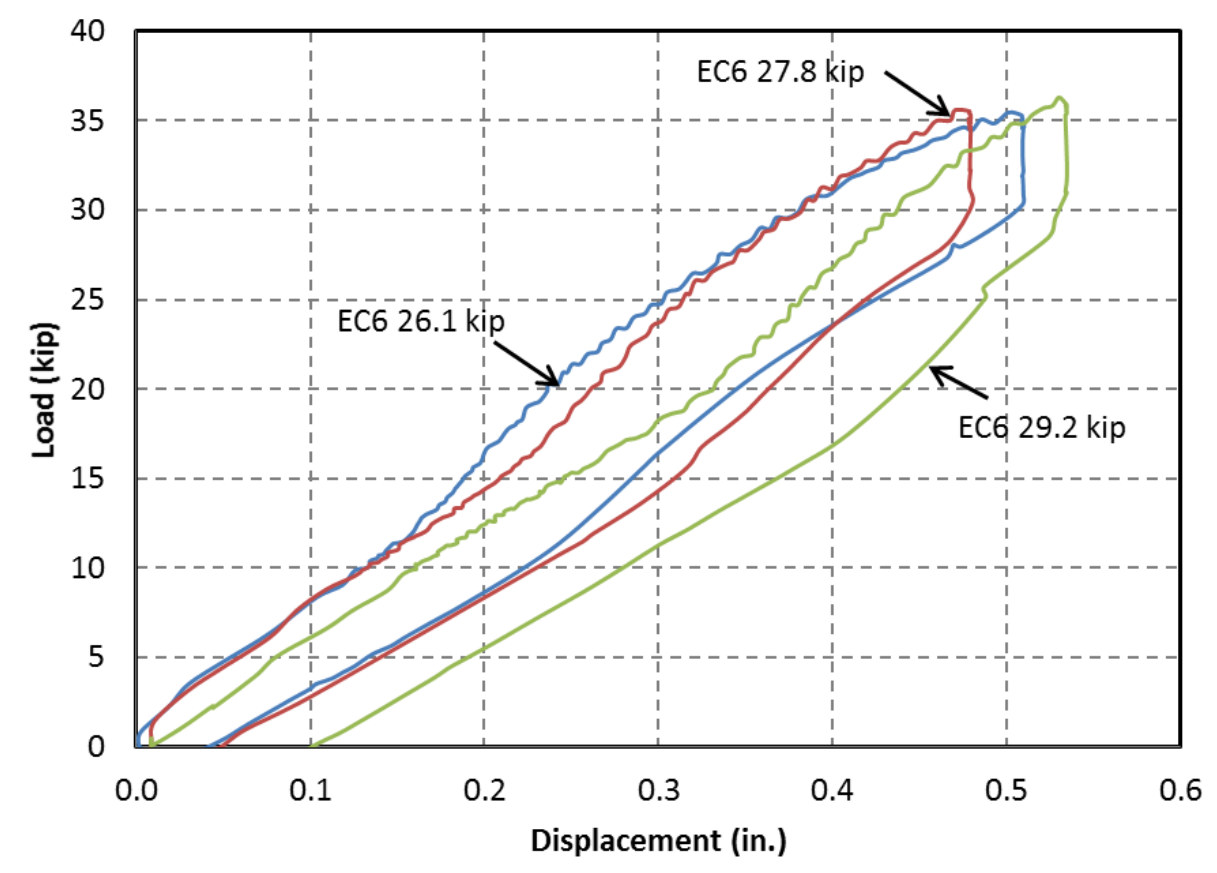

Figure C9. EC6 Load - Displacement for Service Load Position 2

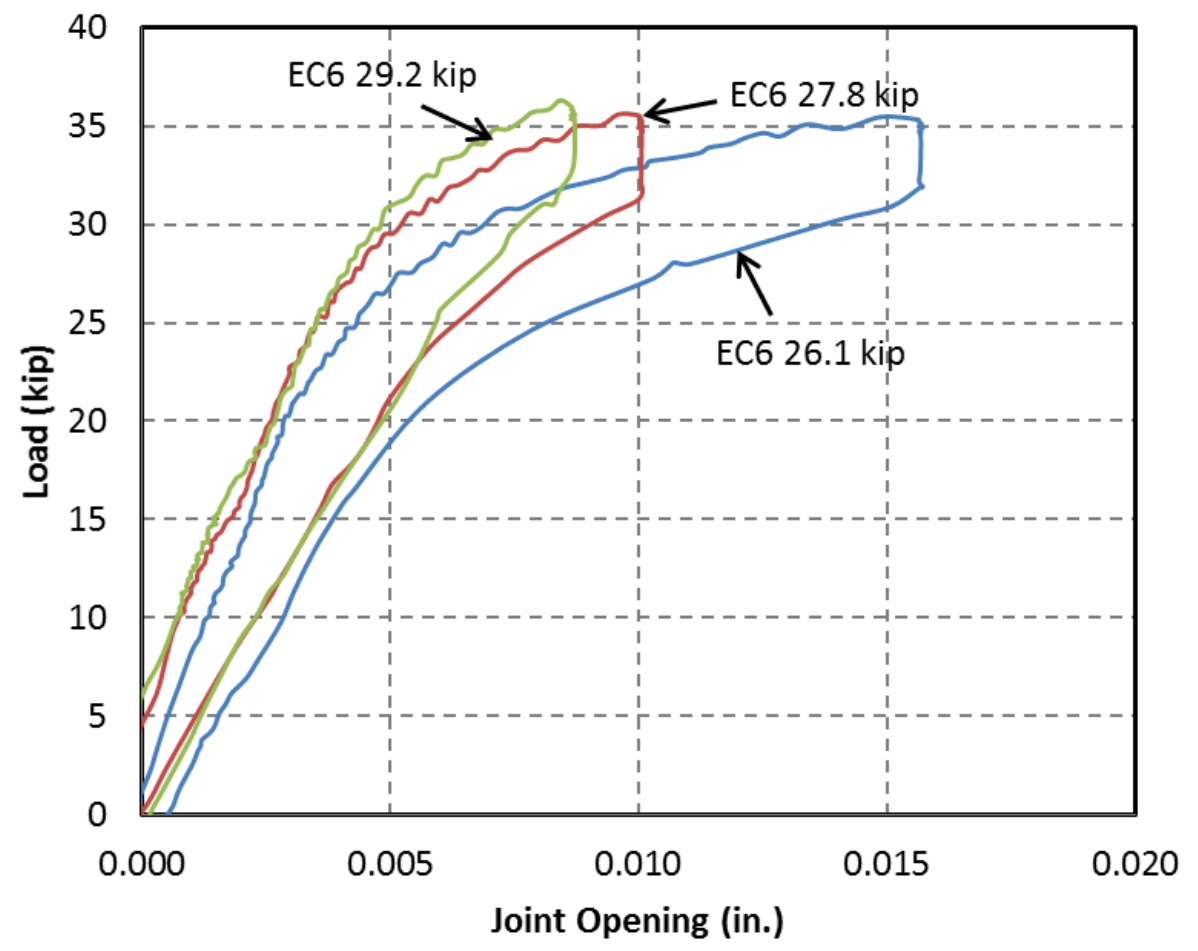

Figure C10. EC6 Load - Joint Opening for Service Load Position 2 


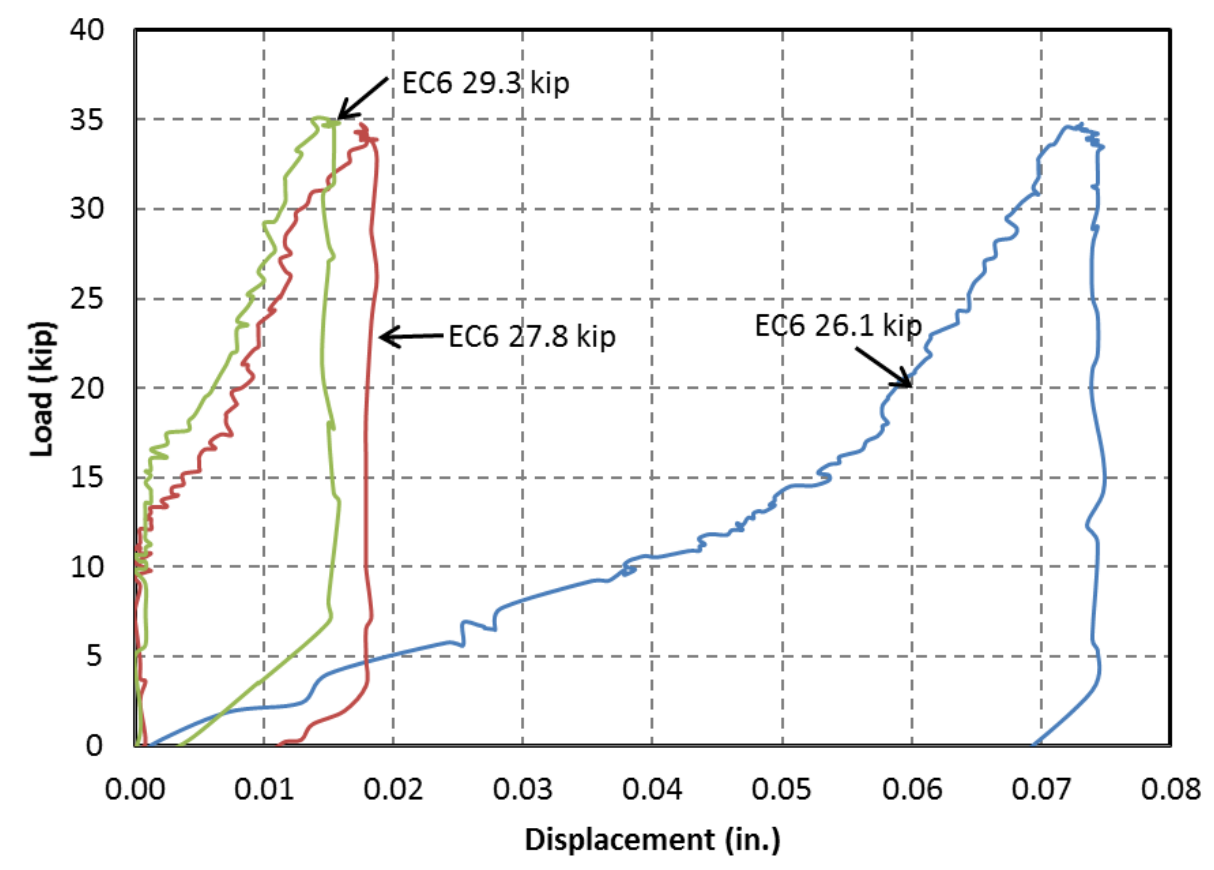

Figure C11. EC6 Load - Displacement for Service Load Position 3

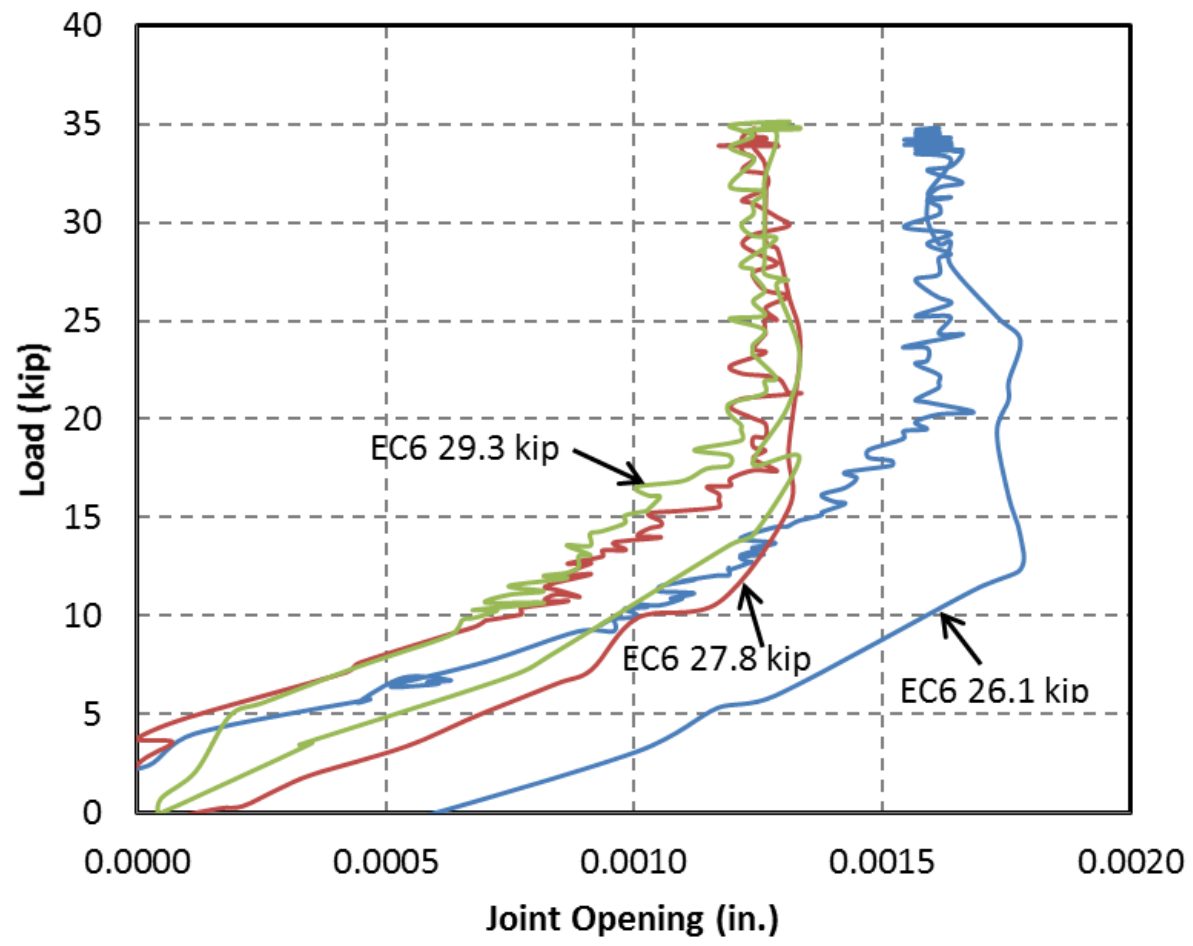

Figure C12. EC6 Load - Joint Opening for Service Load Position 3 


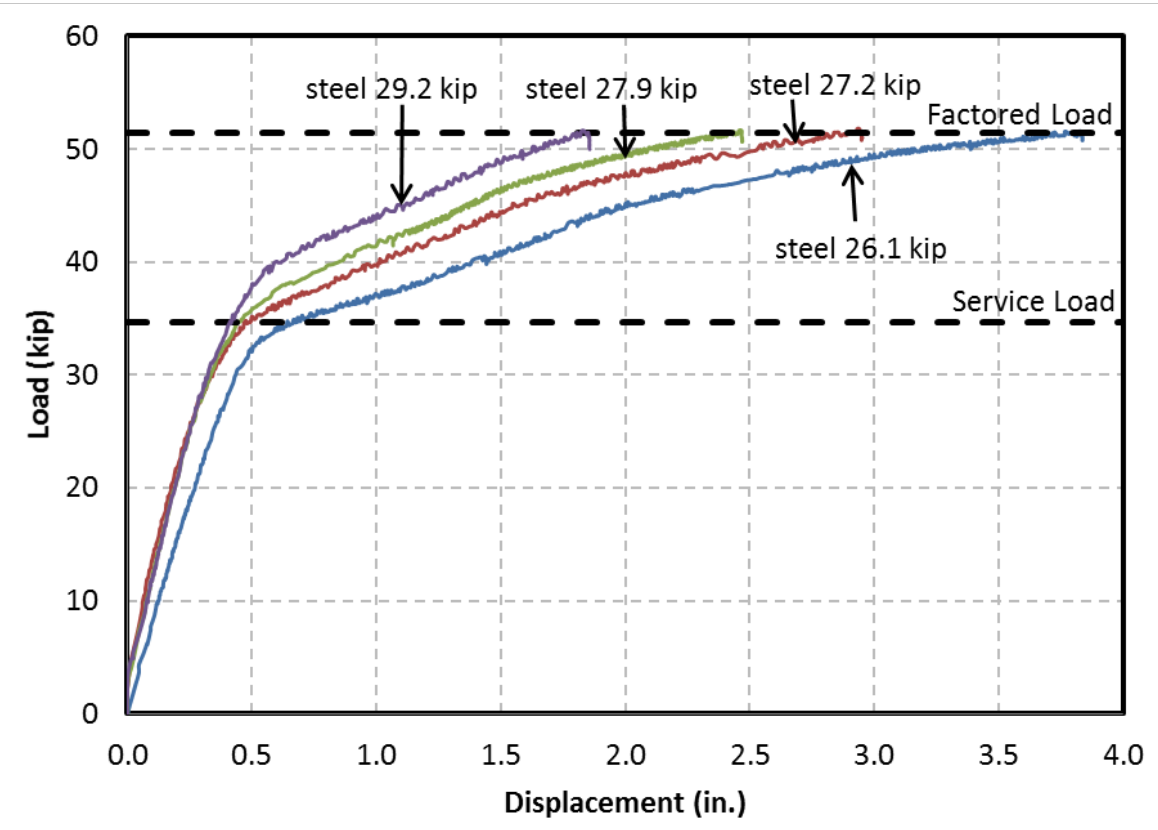

Figure C13. Steel Load - Displacement for Service Load Position1 and Ultimate Load Test

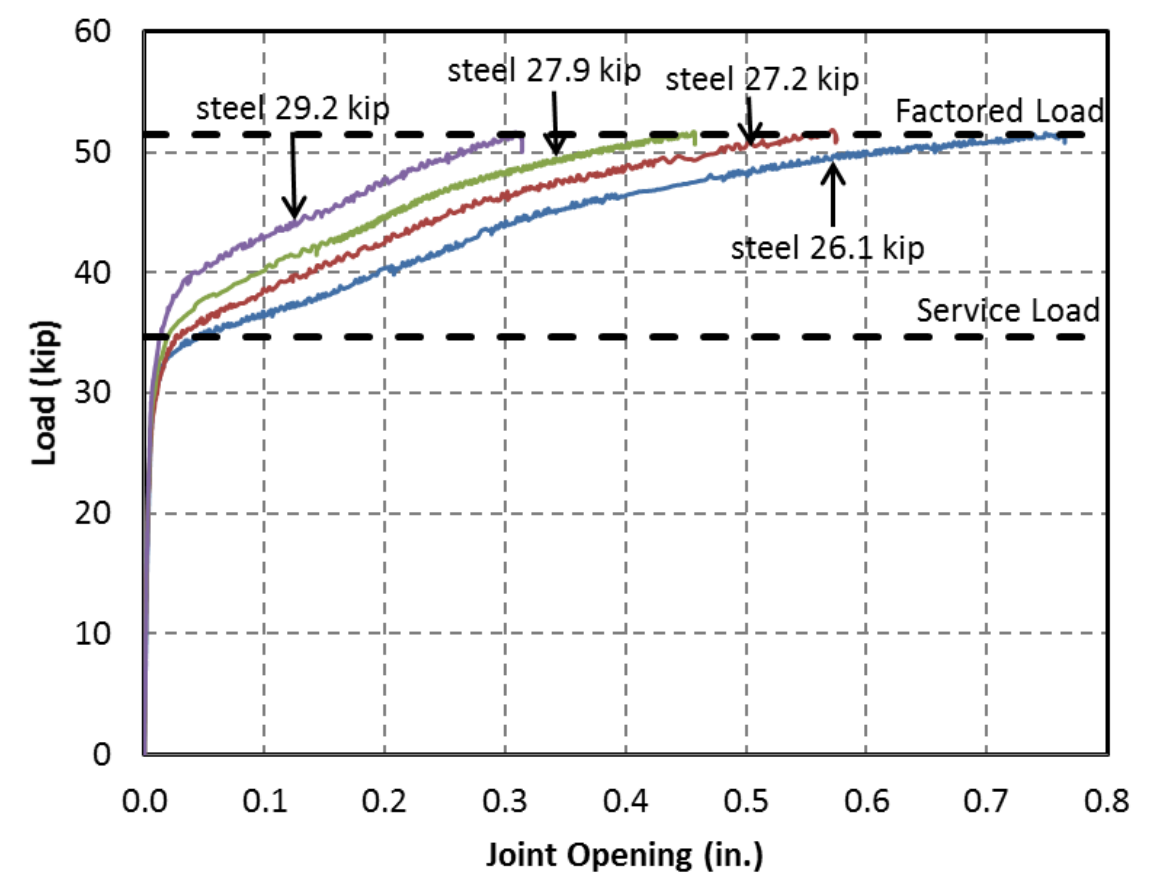

Figure C14. Steel Load - Joint Opening for Service Load Position1 and Ultimate Load Test 


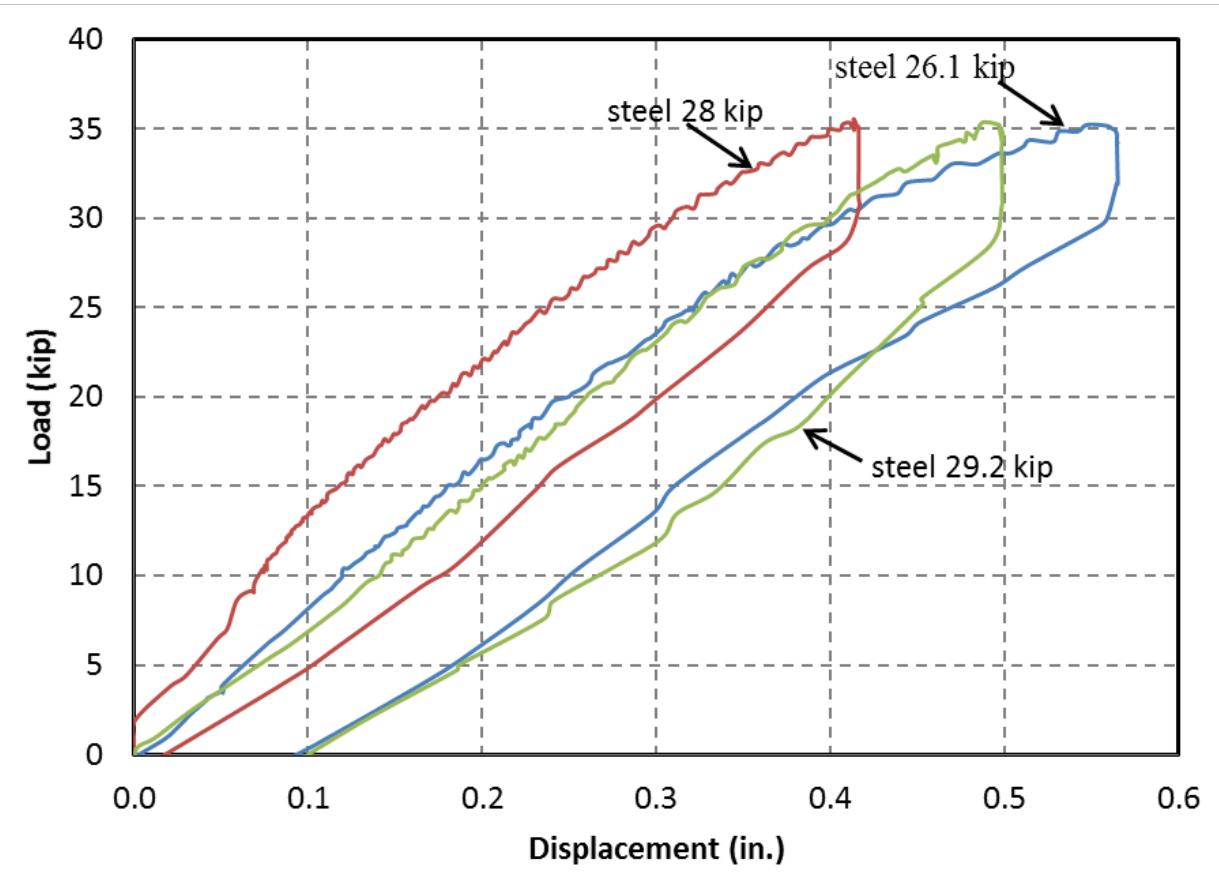

Figure C15. Steel Load - Displacement for Service Load Position 2

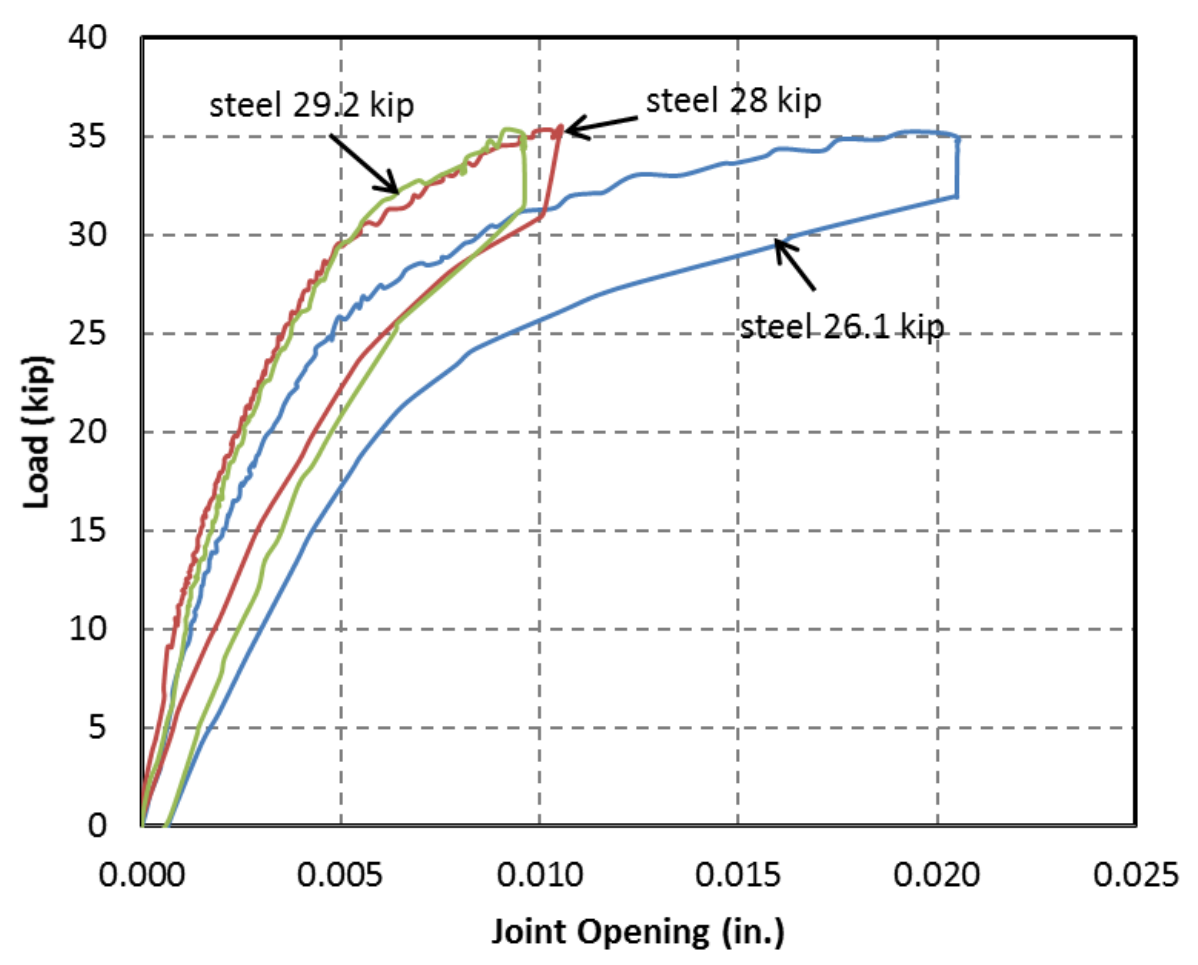

Figure C16. Steel Load - Joint Opening for Service Load Position 2 


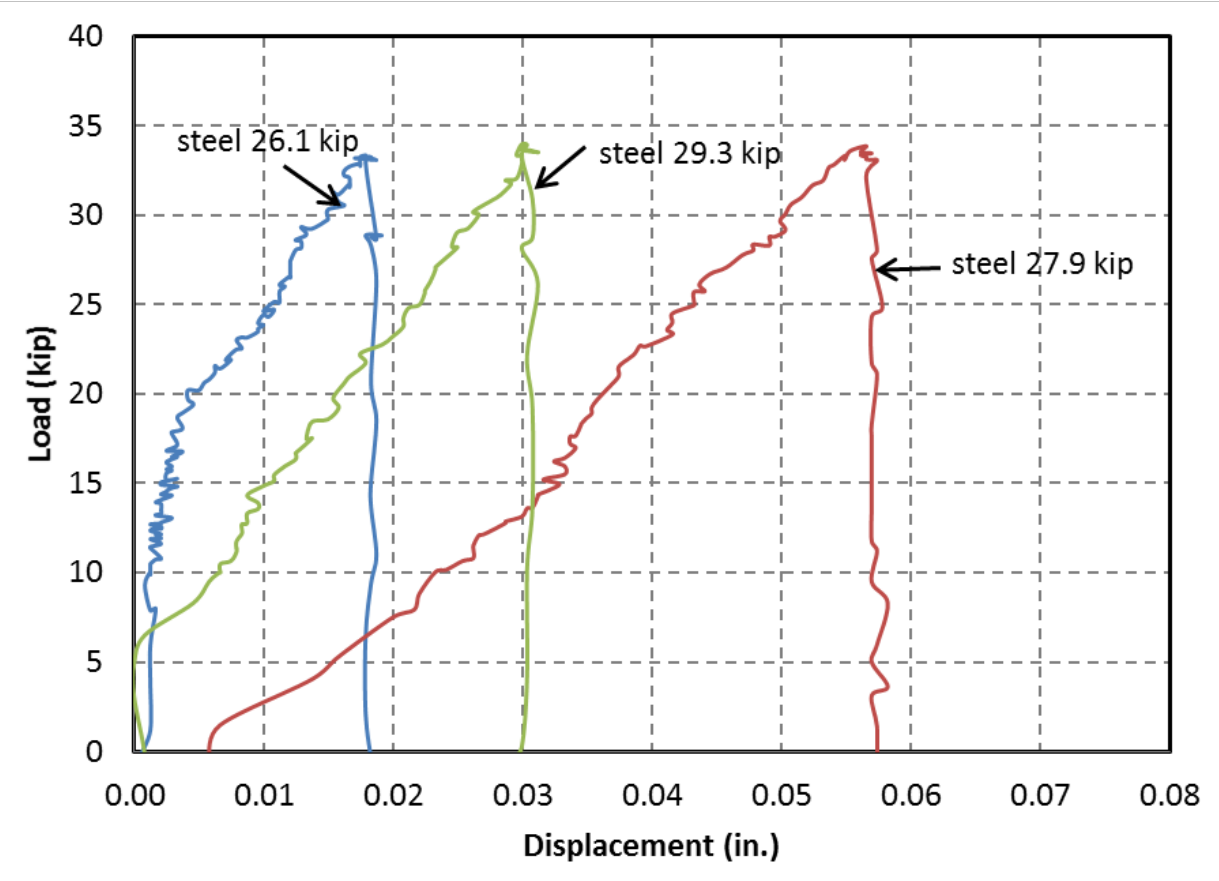

Figure C17. Steel Load - Displacement for Service Load Position 3

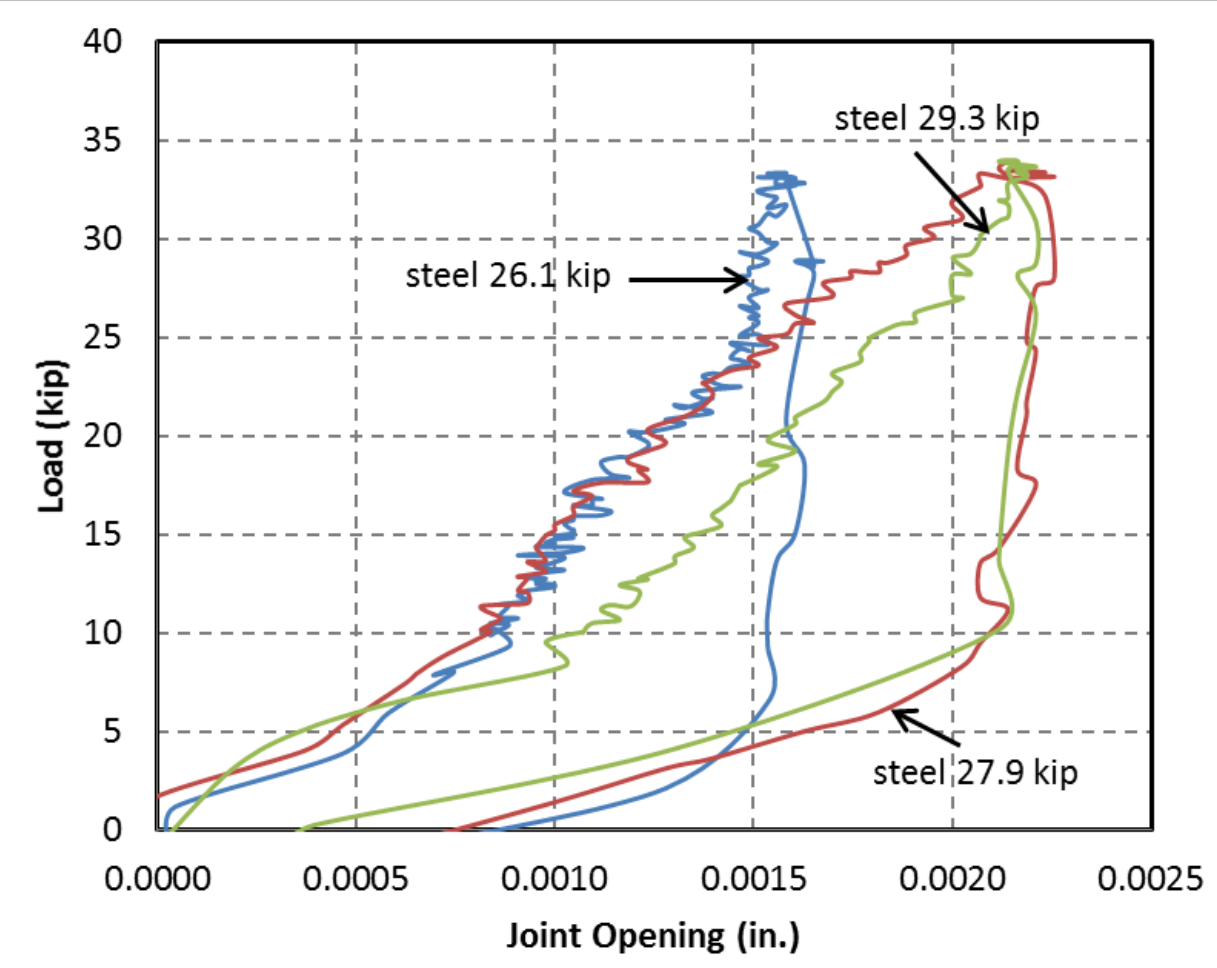

Figure C18. Steel Load - Joint Opening for Service Load Position 3 
APPENDIX D. CFRP POST-TENSIONED PIER CAP MODEL PREPARATION

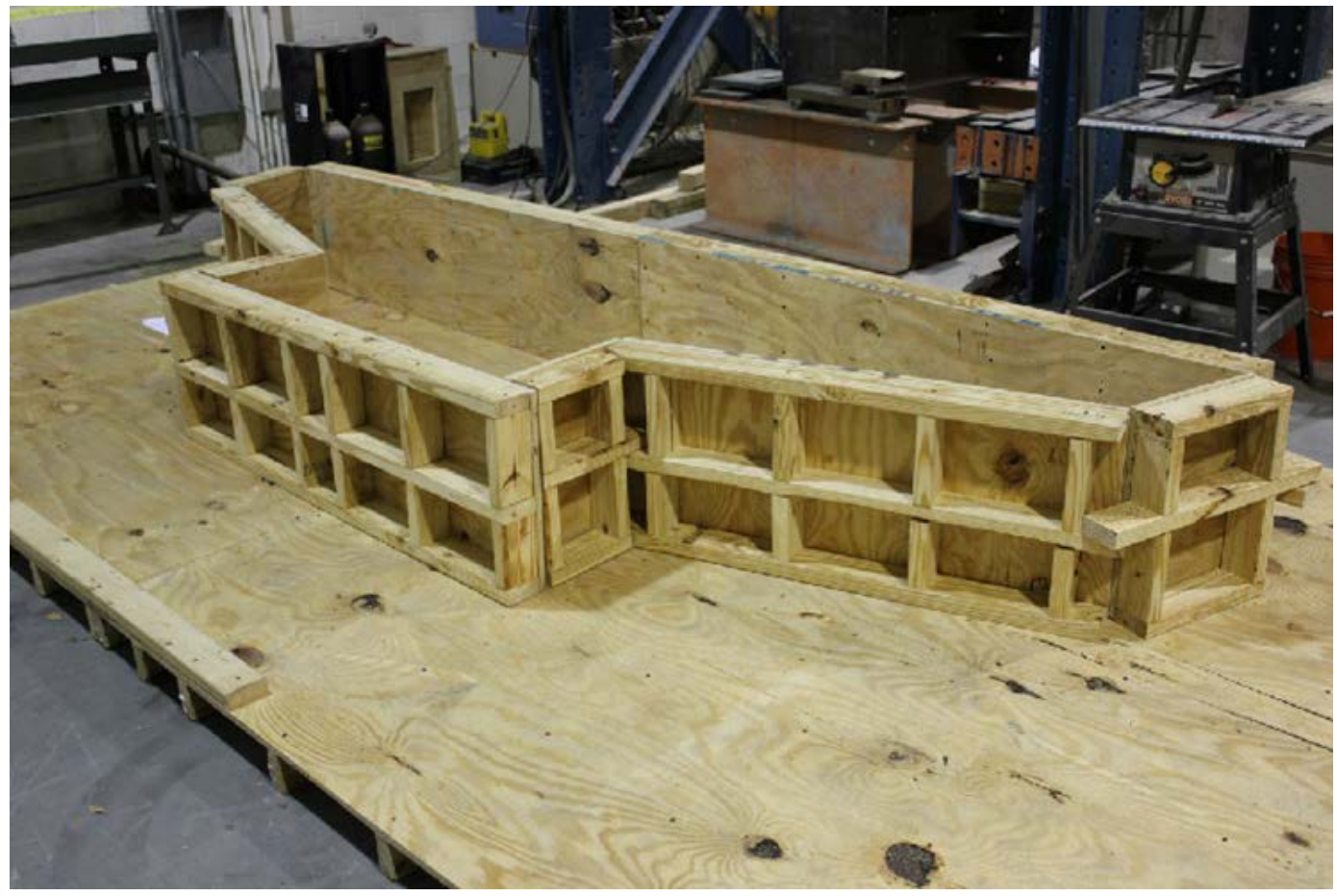

Figure D1. Formwork

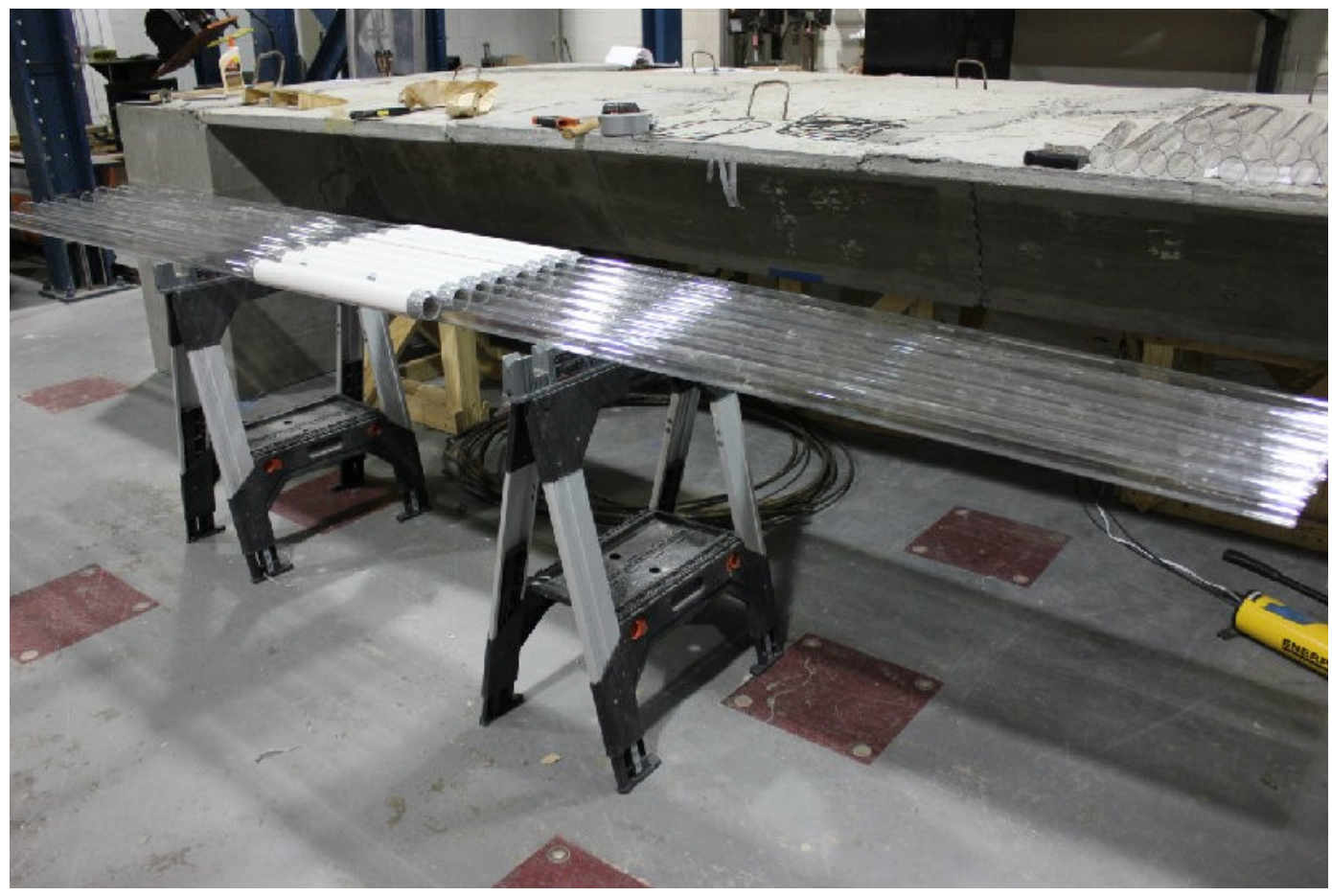

Figure D2. Ducts for Post-tensioning 


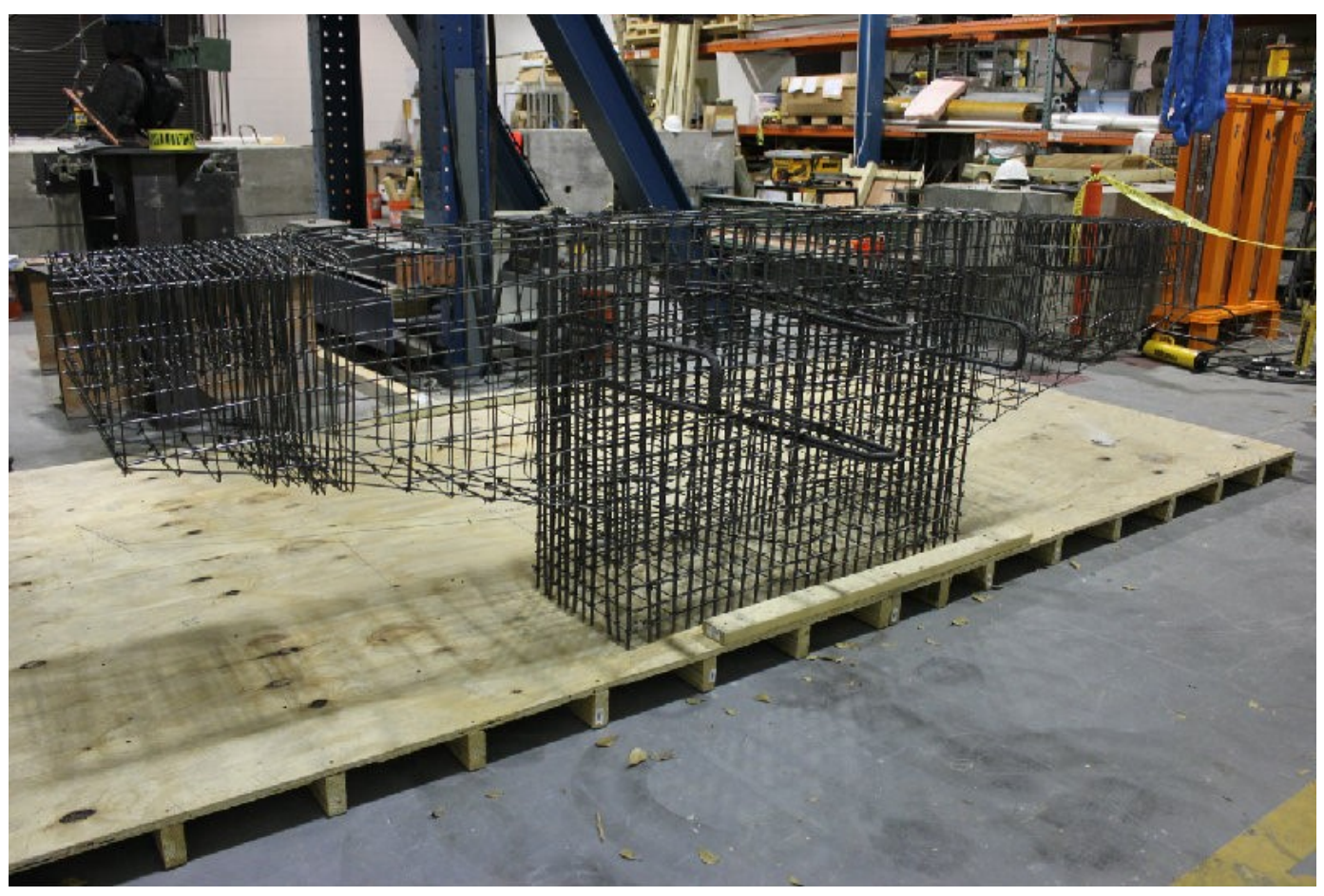

Figure D3. Reinforcement Cage

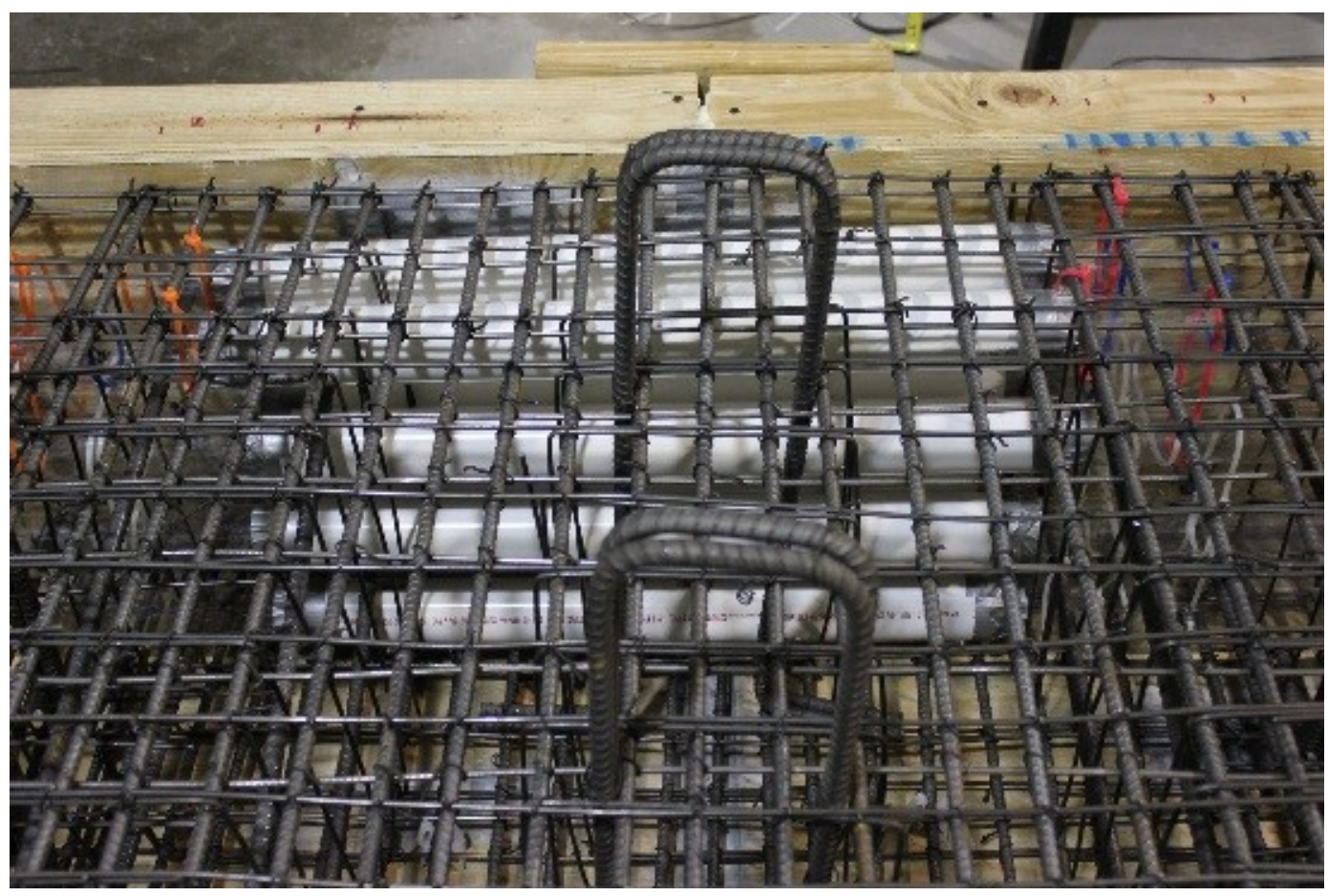

Figure D4. PVC Tube Connection for Post-Tensioning Ducts 


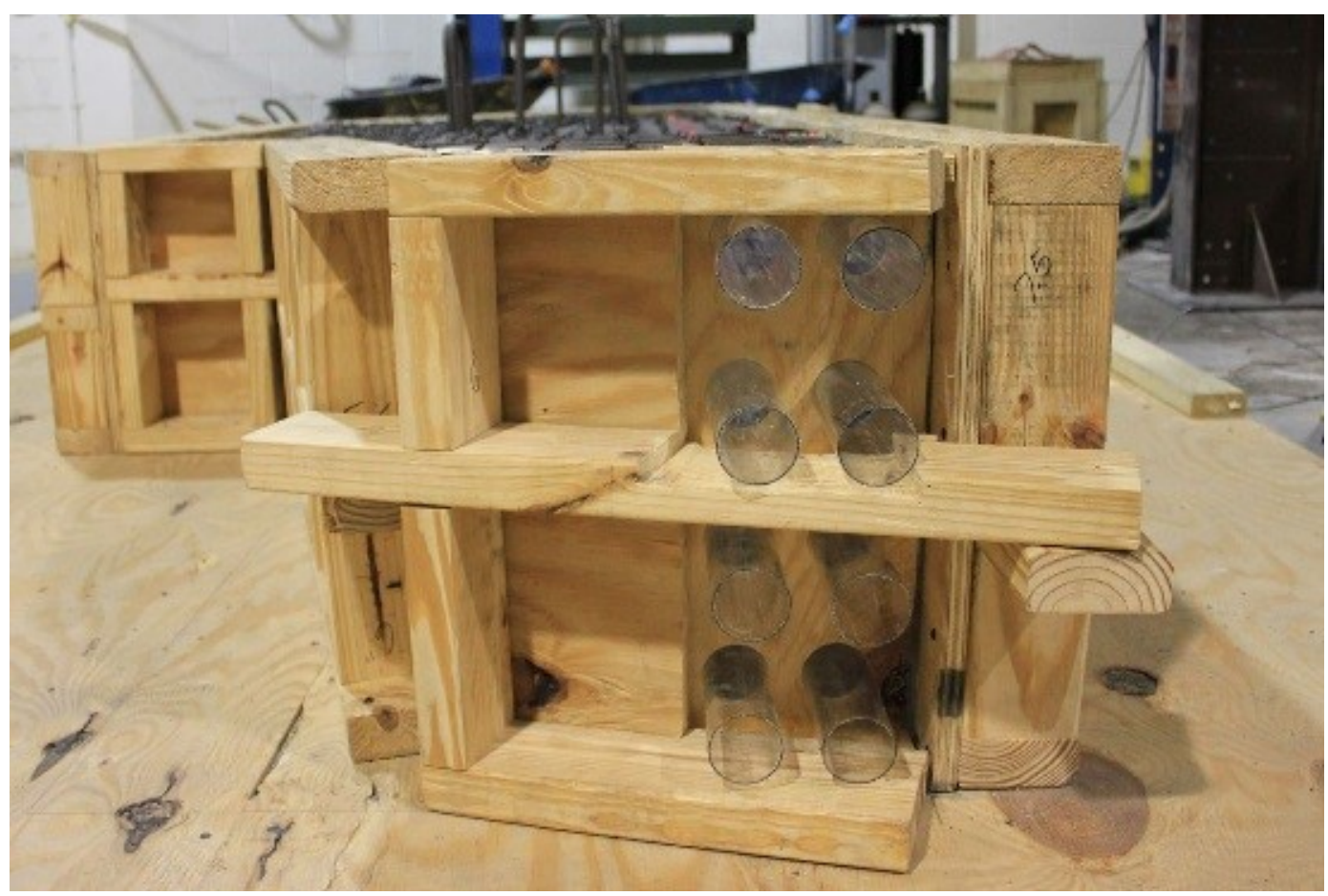

Figure D5. Anchorage Detail (1)

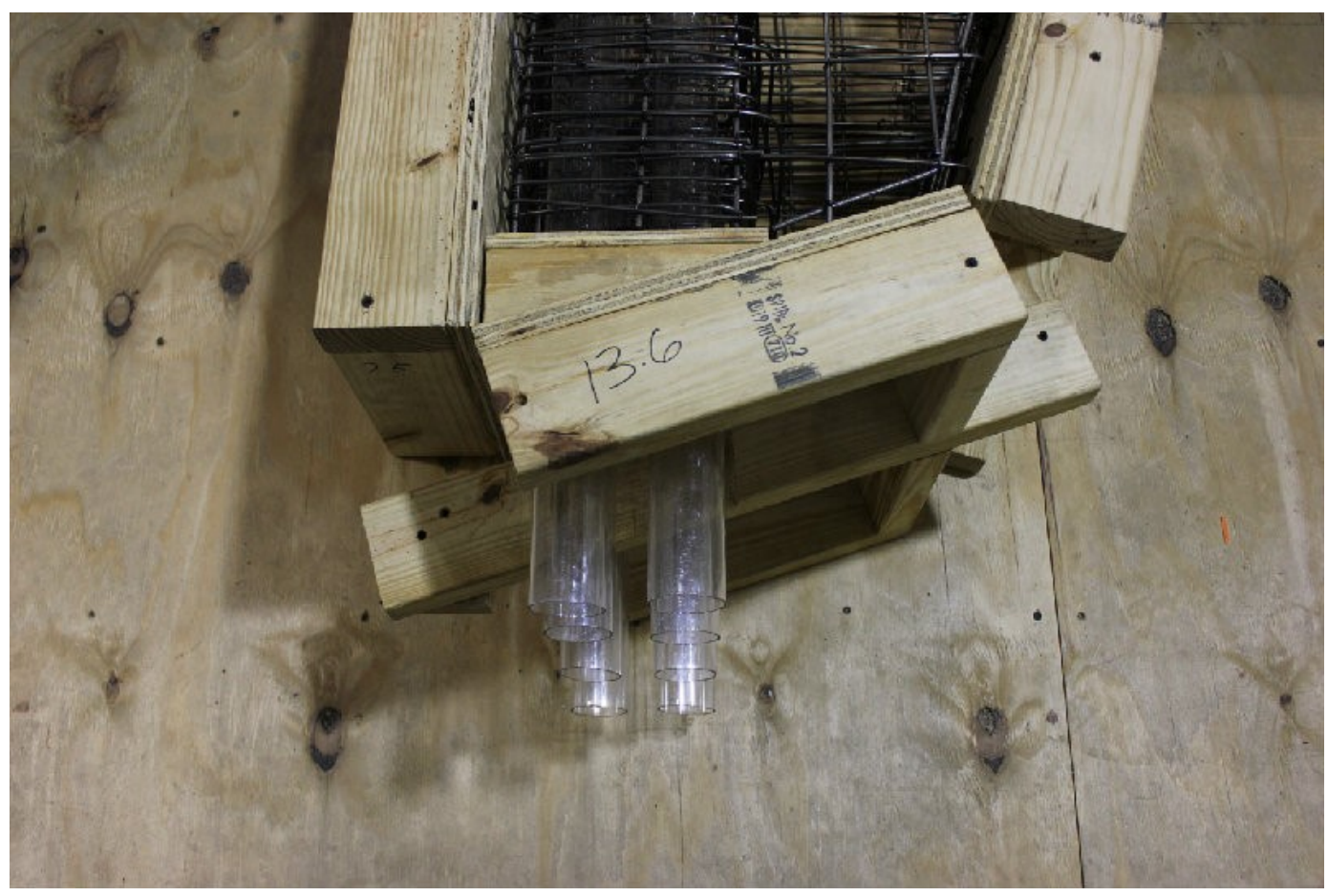

Figure D6. Anchorage Detail (2) 


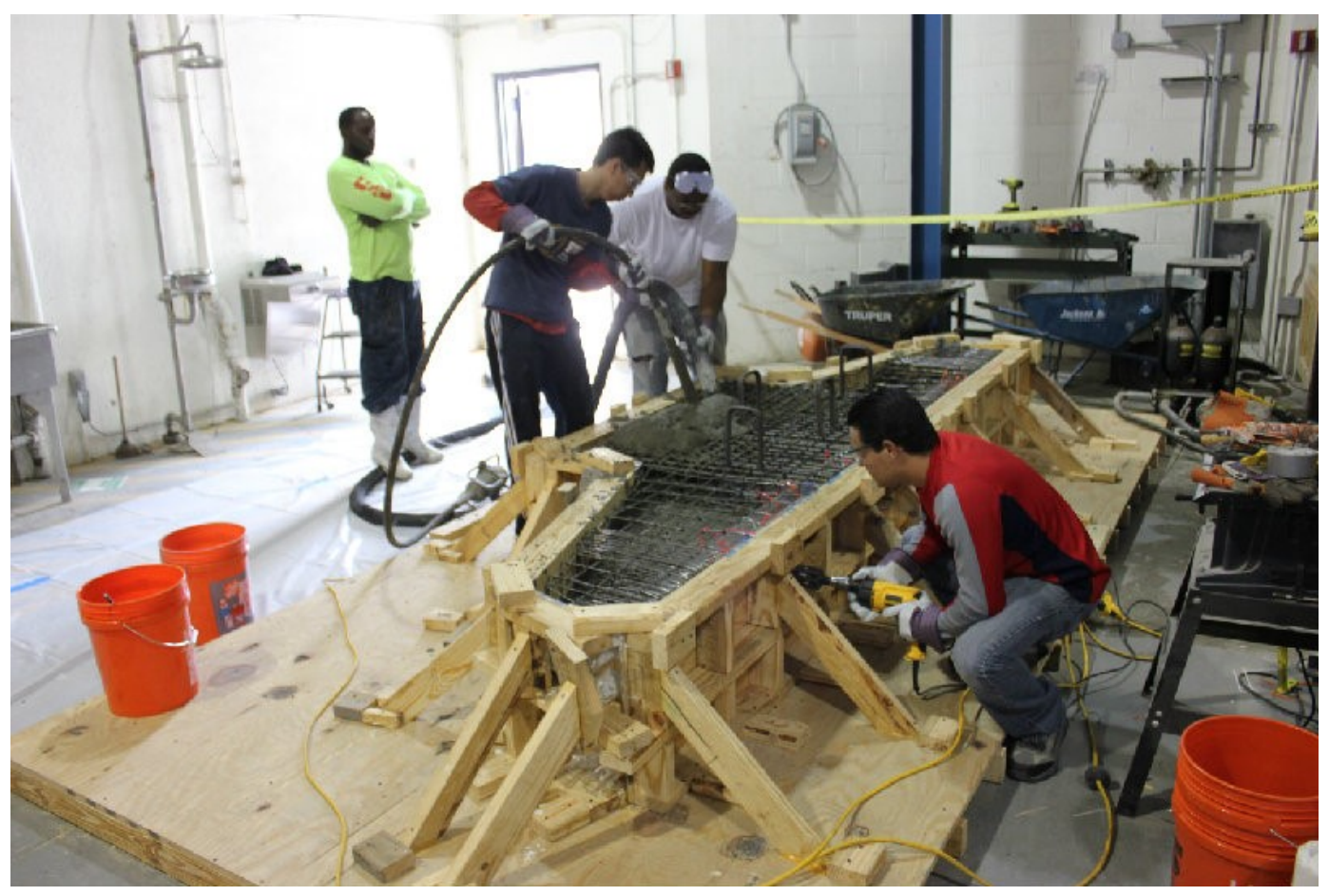

Figure D7. Casting

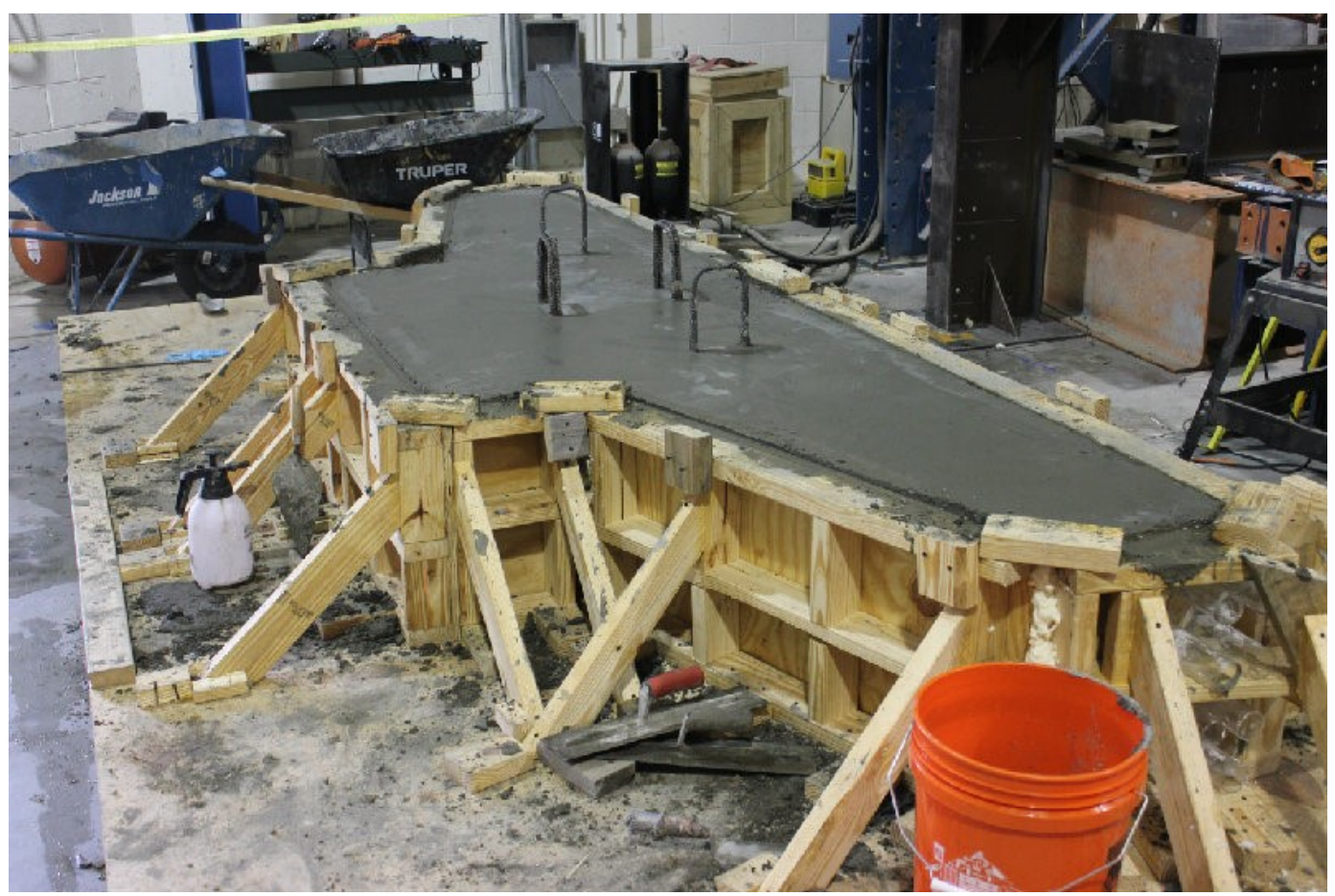

Figure D8. Specimen after Casting 


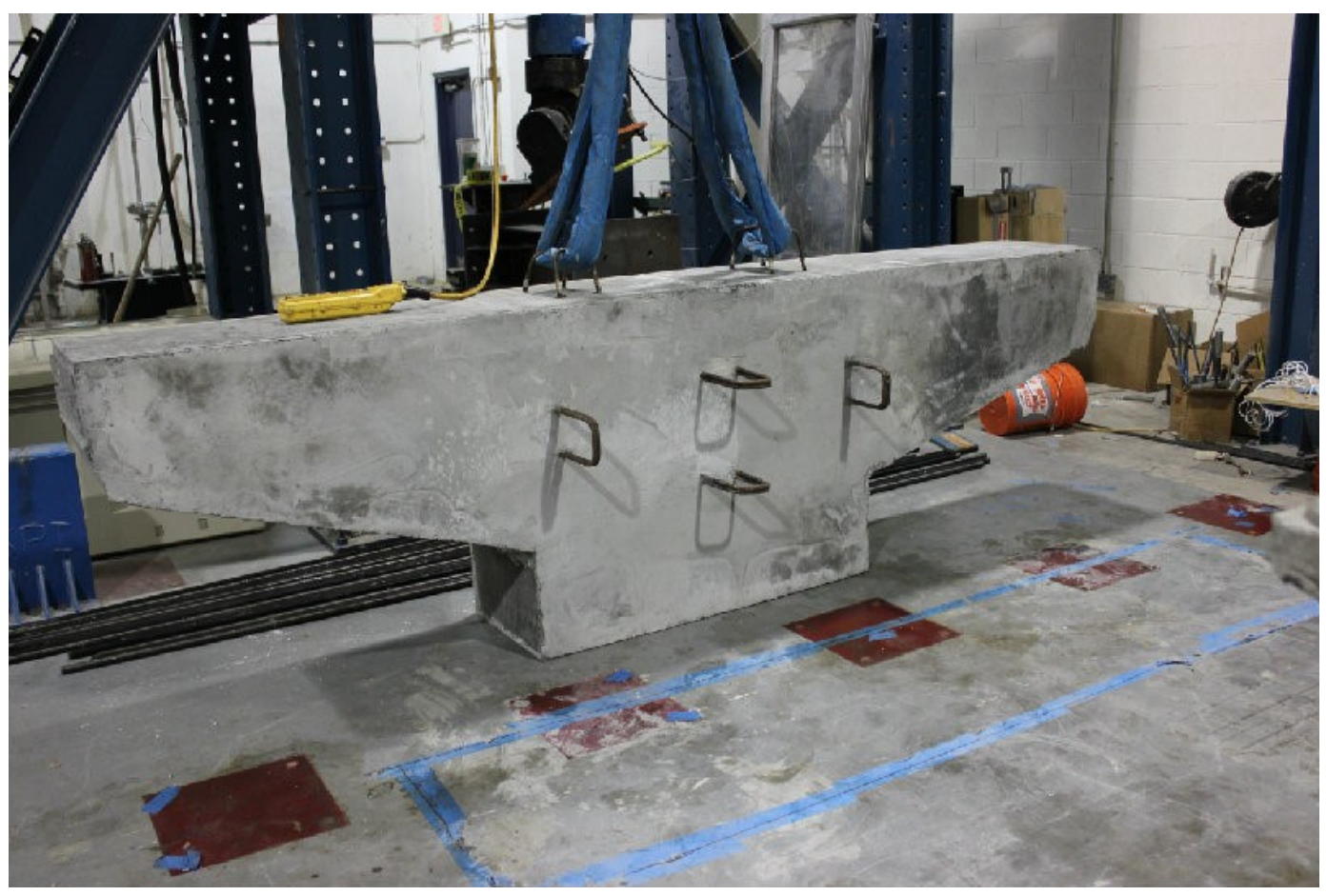

Figure D9. Specimen after Demolding

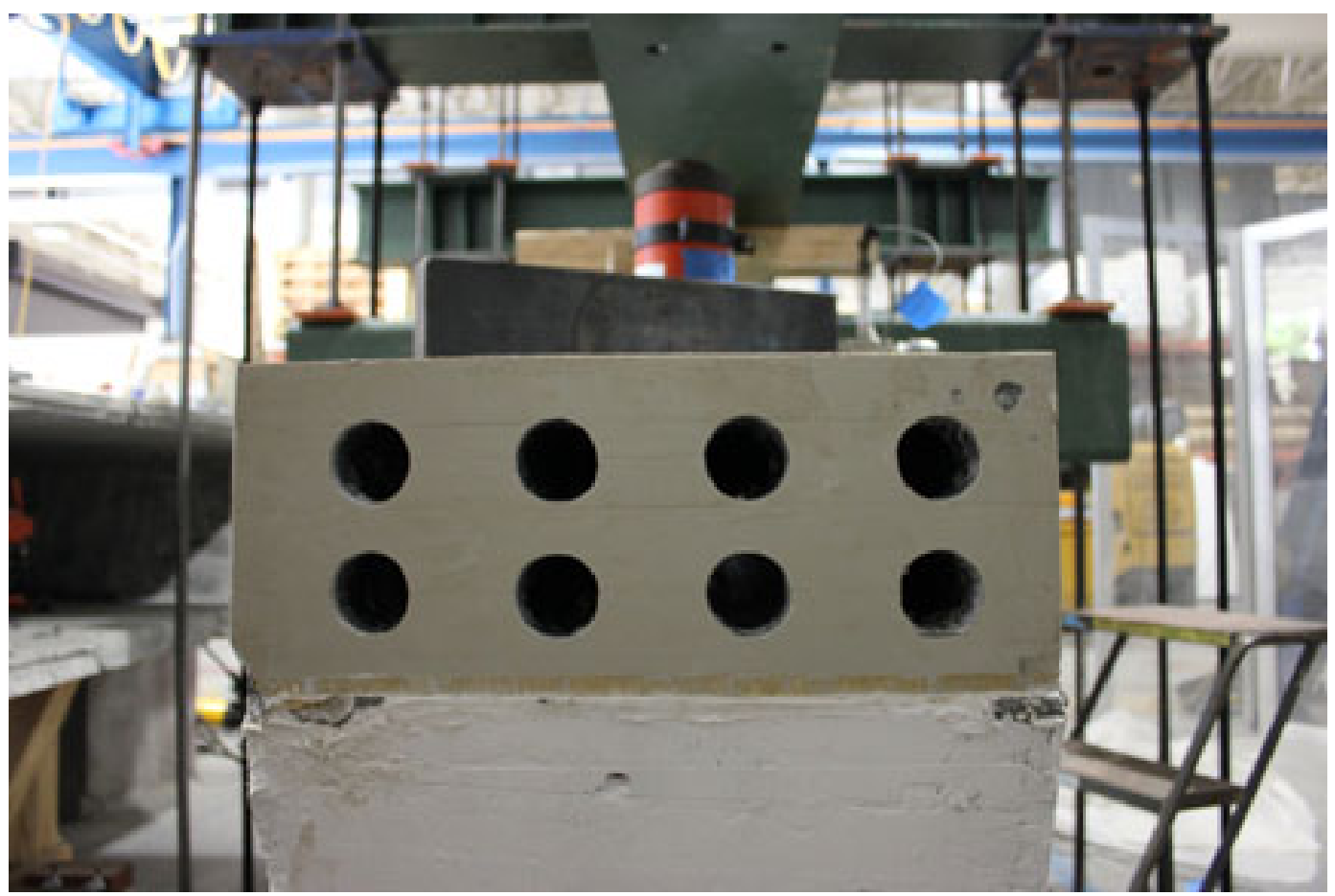

Figure D10. Anchorage Zone Recasting Using Sikadur 32 Hi-Mod Epoxy 


\title{
APPENDIX E. TECHNICAL DATA FOR THE COIL SPRING
}

\author{
Duer/Carolina Coll, Inc. \\ P.O. Box 730 Reidville, SC 29375-0730 \\ (864) $989-4141$ \\ SPRING DESIGN
}

Designed by: Jay Weaver ID\# : JW

DATE: 7/29/2014 Time: $2: 58: 56 \mathrm{PM}$

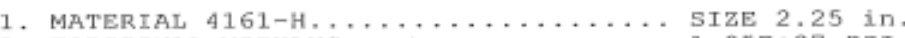

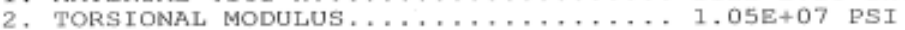

3. INSIDE DIAMETER............... $7.5 \mathrm{i} n$.

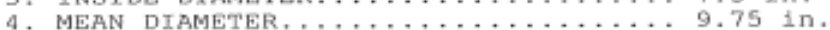

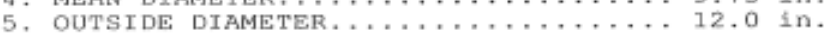

6. RATE. . . . . . . . . . . . . . . . 9499.683 LBS/INCH

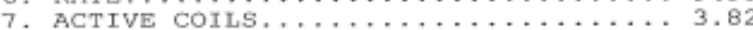

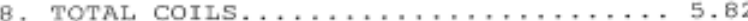

9. SOLID HEIGHT,................ 11.971 in., METHOD OF CALCULATION: C

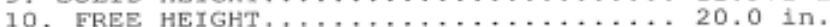

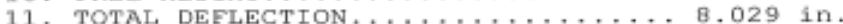

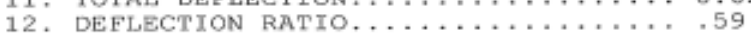

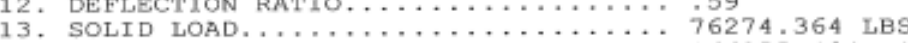

14. UNCORRECTED STRESS E SOLID...... 166255.404 PSI

15. UNCORRECTED STRESS E MWD.......... 98086.602 PSI

16. TAPERED LENGTH OF MATERIAL....... 178.281 in.

17. WEIGHT OF MATERIAL..........................

18. TYPE OE ENDS. . . . . . . . . . . . . SQD \& GRD

19. LOAD 9 HEIGHT $41 \ldots \ldots \ldots \ldots \ldots \ldots$ LBS

20. HEIGHT $1 \ldots \ldots \ldots \ldots \ldots \ldots \ldots \ldots \ldots . \ldots \ldots$ in.

21. LOAD \& HEIGHT $\# 2 \ldots \ldots \ldots \ldots . . .45000 .0$ LBS

22. HEIGHT $\# 2 \ldots \ldots \ldots \ldots \ldots \ldots \ldots . \ldots \ldots$ in.

23. SMI OR ASTM TOLERANCE ON DIAMETER, . 25 in.

24,38 HGT $209 \& 608$ OF TOTAL DEFL $18,394 \& 15,183$ in.

25. SPRING INDEX (D/d) ........... 4.333

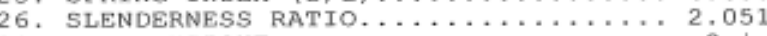

27. BUILT HEIGHT.................. 0 in.

28 , SMI OR ASTM TOLERANCE OE FH.........438 in.

29,37 . FH PITCH, BUILT HGT PITCH...... $4.352, .0$ in.

30. MAX WORKING DEFLECTION .......4.4.737 in.

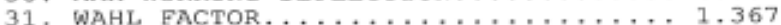

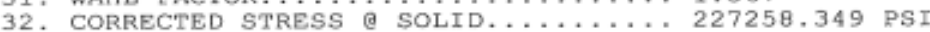

33. CORRECTED STRESS @ MWD......................

34,39 . BLUNT LENGTH OF MATERIAL....... $169.281 \mathrm{in.,} \mathrm{LGTH} \mathrm{OF} \mathrm{TAPER} 17.0$ in.

36. SMI OR ASTM TOL, ON SQUARENESS..... 1.5 DEG

Customer Approval

Customer

Customer Part

comnents ararstersede solid-we vould set remore to $14.5^{\prime \prime}$ height. 


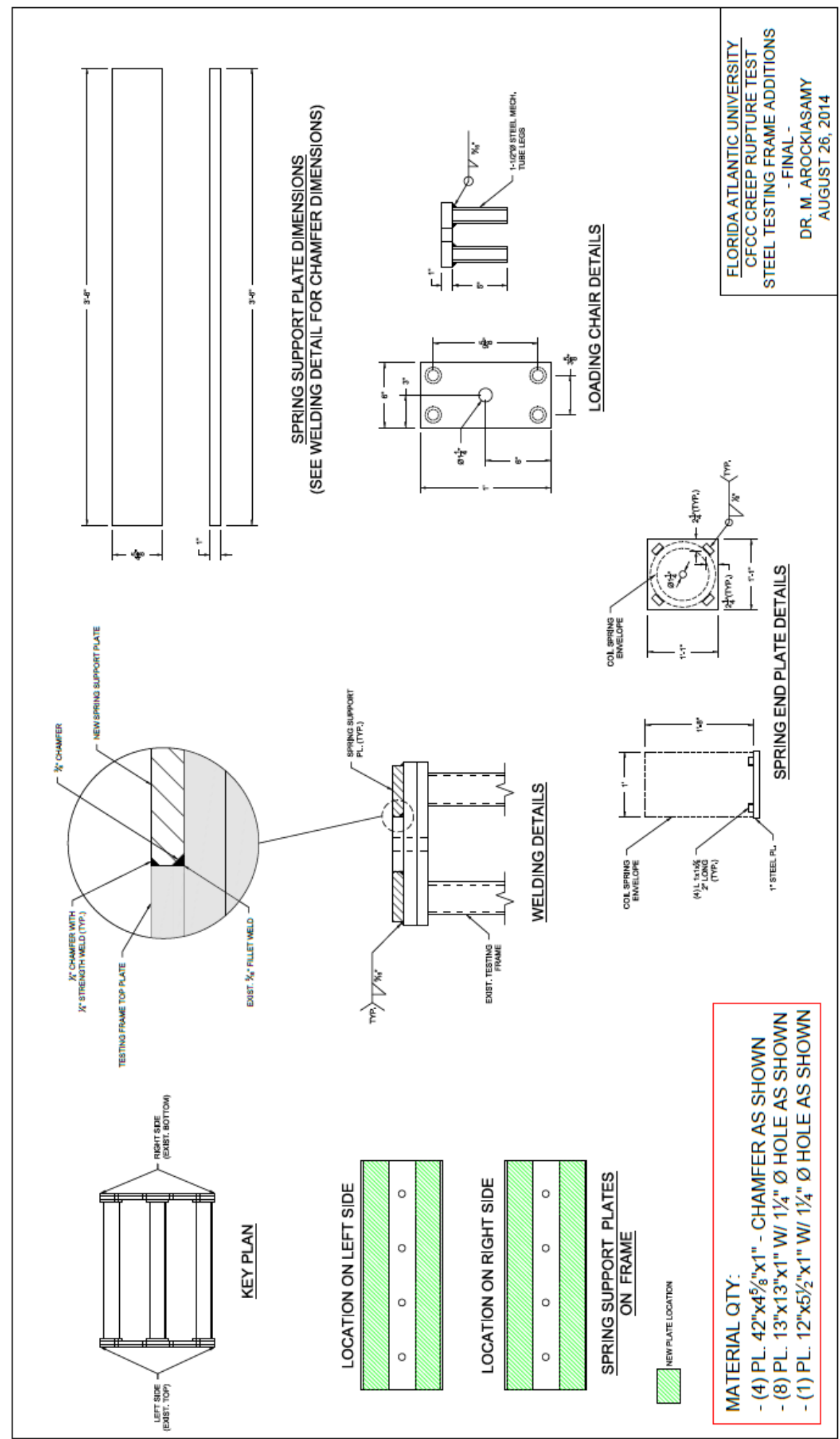


VITA

XIONG YANG

Oct. 12, 1988

2007-2011

2011-2012

2011-2015

20111-2015
Born, Beijing, China

B.Sc. Civil Engineering

Beijing University of Civil

Engineering and Architecture

Beijing, China

M.Sc. Civil Engineering Florida International University

Miami, Florida, US

Research/Teaching Assistant

Florida International University

Miami, Florida, US

Ph.D. Candidate, Civil

Engineering

Florida International University

Miami, Florida, US

\section{PUBLICATIONS}

Yang, X., Zohrevand, P., Mirmiran, A., Arockiasamy, M., and William, P. (2015). "Post Tensioning of Segmental Bridges using Carbon Fiber Composite Cables.” PCI Journal, 60(3), 50-62.

Yang, X., Zohrevand, P., Mirmiran, A., Arockiasamy, M., and William, P. (2015). “A Comparative Study of Unbonded Carbon Fiber and Steel Strands in Posttensioned Pier Caps.” ASCE Journal of Composites for Construction, hard copy in press. DOI: 10.1061/ (ASCE) CC.1943-5614.0000596.

Zohrevand, P., Yang, X., Jiao, X., and Mirmiran, A. (2014). "Punching Shear Enhancement of Flat Slabs with Partial Use of Ultrahigh-Performance Concrete.” ASCE Journal of Materials in Civil Engineering, hard copy in press. DOI: 10.1061/ (ASCE) MT.1943-5533.0001219.

Yang, X., Zohrevand, P., Mirmiran, A., Arockiasamy, M., and William, P. (2015). "Effect of Elastic Modulus of Carbon Fiber Reinforced Polymer Strands on the Behavior of Post-tensioned Segmental Bridges.” ASCE Journal of Composites for Construction, under review. 
Yang, X., Zohrevand, P., and Mirmiran, A. (2015). "Behavior of Ultrahigh-Performance Concrete Confined by Steel Spiral Reinforcement.” ASCE Journal of Materials in Civil Engineering, under review. 